UNIVERSIDAD NACIONAL DE LA PLATA

FACULTAD DE HUMANIDADES Y CIENCIAS DE LA

EDUCACIÓN

SECRETARÍA DE POSGRADO

\title{
Políticas académicas y estrategias de legitimación disciplinar de la Educación Física en la Universidad Nacional de La Plata (1992-2004)
}

\author{
Prof. Celeste Felipe
}

Tesis para optar por el grado de Magíster en Educación

Directora: Dra. Luciana Garatte

Codirectora: Mg. María Cecilia Carrera

La Plata, 01 de agosto de 2018 


\section{DEDICATORIA}

A la memoria de Ricardo Nassif, Julia Silber y Eduardo Remedi. 


\section{AGRADECIMIENTOS}

La hechura de una tesis es un proceso largo y complejo, en el que intervienen múltiples personas y condiciones. Es un trayecto atravesado por emociones a veces encontradas, en donde el apoyo de los/as colegas, los/as compañeros y la familia resulta fundamental. Pero, sobre todo, la persistencia. El camino fue largo para mí, y estuvo surcado por elecciones, abandonos, desencantos y vueltas a confiar.

En primer lugar, mi gratitud y reconocimiento a la educación pública en general, y a la universidad pública en particular. Desde el jardín de infantes hasta la formación de posgrado, pude formarme en sus aulas y trabajar en ella, y desde allí forjar una esperanza de futuro para mí, y aportar a la construcción de un mundo más justo para todos/as. Que sigamos encontrándonos cada vez muchos más de este lado "de la mecha".

A la Maestría en Educación de la FaHCE-UNLP, su directora y secretaria, por la predisposición y el estímulo constante. A la UNLP, por otorgarme una beca de investigación que permitió finalizar el trabajo de campo de esta investigación e iniciar las primeras escrituras. Al Instituto de Investigaciones en Humanidades y Ciencias Sociales (IdlHCS) por su acogida e interés por mi trabajo. Al Consejo Nacional de Investigaciones Científicas y Técnicas (CONICET), por otorgarme recientemente una beca doctoral y al pueblo argentino que con sus impuestos contribuye a financiar la línea de investigación iniciada en esta tesis.

Un agradecimiento especial y cariñoso a mi directora y compañera, Luciana Garatte. Sin su insistencia, orientación, generosidad intelectual y su confianza constante en este trabajo, esta tesis nunca hubiera sido posible. Sin contar que gran parte de la misma fue realizada en medio de la licencia por parto gemelar de Luciana y los primeros pasos y contactos lingüísticos de las niñas con el mundo circundante.

Un reconocimiento y gratitud a mi codirectora, Cecilia Carrera, quien me acompañó y orientó muchísimo. Le agradezco sobre todo la honestidad en cada comentario, que me ayudó a afinar el problema, y sus orientaciones precisas con respecto a la escritura, también, y sobre todo, porque creyó desde el primer momento en este trabajo.

A Ricardo Crisorio y Marcelo Prati, mis directores de beca y tesis doctoral, por la fe y confianza en mí y en este trabajo desde el primer día, y por los aportes valiosos que me brindan y que enriquecen mi formación académica. Un agradecimiento destacado a Ricardo, quien me permitió acceder a personas y fuentes fundamentales para esta tesis. 
A los/as profesores/as que se abrieron y me brindaron su testimonio sobre aquella Facultad "a la vuelta de la esquina", pero a la que yo todavía ni conocía.

A Laura G. por el apoyo técnico con las fuentes, también indispensable para poder terminar de escribir en medio de días interminables de trabajo fuera de casa.

A los/as trabajadores/as de los Departamentos de Mesa de Entradas, Personal, Enseñanza y del Archivo del Consejo Académico de la FaHCE. En especial a Martín, Alejandro, Joana, Mariela y Candelaria, por permitirme acceder a buena parte de los datos de esta tesis.

A mis compañeras de la cátedra de Pedagogía para Educación Física: Mónica Paso, Luciana Garatte, Cecilia Carrera, Jésica Montenegro, Noelia Orienti, Julieta Alcoba, Agostina Lapuente. Todas ellas desde algún lugar aportaron a esta tesis. A todas ellas, gracias. A los y las estudiantes de Educación Física, simplemente por pasarla bien y por constituir un estímulo permanente a este trabajo. Sus inquietudes y nuestras interacciones en la cursada son buena parte de los intereses de esta tesis.

A mis compañeros y compañeras de los equipos de investigación en los que he participado y participo actualmente en la Facultad de Ciencias Agrarias y Forestales y en la Facultad de Humanidades y Ciencias de la Educación.

Al espacio del "PIA": Mónica Paso, Jesica Montenegro, Rocío Levato. Por el aprendizaje, la calidez, las risas y "los pescados".

A mi familia por el apoyo constante y la profunda creencia y confianza en mí como persona y profesional. Esa valoración positiva y orgullo de ser "la primera hija universitaria" por momentos me pesó, pero en otros supo darme mucha fuerza. A mi mamá Lidia, una de esas creyentes incansables, a mis hermanas, a mi abuela Tata, jtodo un matriarcado!... y a mi abuelo Bebe, a quien imploré para finalizar esta tesis y no dejar el sueño en ello. A donde estés, todo el amor de siempre, todo tu amor en mí siempre.

A todos/as los/as que se alegran por mis logros. $\mathrm{Y}$ a todo lo bueno que quiera venir, que venga...

A Martín, porque estemos donde estemos, hagamos lo que hagamos, "nosotros salvamos al amor, y el amor nos salva a nosotros".

La Plata, invierno de 2018. 


\section{LISTA DE ABREVIATURAS}

EF: Educación Física

UNT: Universidad Nacional de Tucumán

UNLP: Universidad Nacional de La Plata

UA: Unidades académicas

FaHCE: Facultad de Humanidades y Ciencias de la Educación

DEF: Departamento de Educación Física

DCE: Departamento de Ciencias de la Educación

CA: Consejo Académico

INEF: Instituto Nacional Superior de Educación Física

INSF: Instituto Nacional de Educación Física "General Manuel Belgrano"

UCR: Unión Cívica Radical

PJ: Partido Justicialista

FM: Franja Morada

FAG: Frente Amplio de Graduados

ES: Educación Superior

SES: Sistema de Educación Superior

LES: Ley de Educación Superior

MCE: Ministerio de Cultura y Educación

CBC: Contenidos Básicos Comunes

SPU: Secretaría de Políticas Universitarias

CONEAU: Comisión Nacional de Evaluación y Acreditación Universitaria

BM: Banco Mundial

BIRF: Banco Internacional de Reconstrucción y Fomento

FOMEC: Fondo para el Mejoramiento de la Calidad Universitaria

PI: Programa de Incentivos a la Investigación 


\section{RESUMEN}

Esta investigación tuvo como objeto analizar y comprender el proceso de legitimación de la Educación Física (EF) en la UNLP entre los años 1992 y 2004, a partir del estudio de políticas y estrategias desplegadas por académicos/as de la disciplina homónima y sus perspectivas sobre ese proceso y las de académicos/as de otras disciplinas que comparten el espacio social de la FaHCE. A partir de un diseño metodológico cualitativo, descriptivo y analítico, se optó por una estrategia de estudio de caso instrumental único, que buscó captar su singularidad y complejidad en sus distintas dimensiones institucionales. Se realizaron entrevistas semi-estructuradas a informantes clave y análisis documental. Como resultado, pudimos advertir que ciertos problemas como el reconocimiento social y la legitimación fueron fundacionales en la carrera, y se reactualizaron con otros contenidos en el período en estudio. Asimismo, fue posible caracterizar las políticas y estrategias académicas desarrolladas por esta comunidad en los años '90 que tendieron, entre otros aspectos, a legitimar la disciplina en la FaHCE así como a reorientar su perfil de formación. Desde un enfoque teórico-metodológico microsocial identificamos las prácticas académicas, trayectorias, redes y formas de sociabilidad de un grupo de académicos que tuvieron un protagonismo central en el procesamiento y diseño de esas políticas. Esta reconstrucción permitió observar que, si bien parte de esas políticas se originaron desde fuerzas exógenas -Estado Nacional-, para nuestro caso, el proceso de legitimación académica de la EF ya se había iniciado previamente, con la realización del primer Congreso en 1993. Los resultados son consistentes con la perspectiva teórico-metodológica asumida, dado que se evidenció el nivel de autonomía de los universitarios en este ámbito de la acción humana. No obstante, y también en línea con los enfoques seleccionados, dimos cuenta que en esas políticas intervienen tanto factores internos como externos. Es decir que identificamos, tanto un buen aprovechamiento (según intereses propios y estilos y tácticas locales) de esas políticas, como también la generación propia de políticas -aunque enmarcadas en una tendencia del momento y en una "exigencia" de la academia local para legitimarse-. Advertimos, tanto el influjo del nuevo modelo de relación entre el Estado y la Universidad en los '90, caracterizado como "Estado evaluador" por la literatura de referencia, así como la proactividad de los agentes de EF por obtener un lugar de prestigio en la institución.

Palabras clave: políticas académicas- estrategias- legitimación disciplinar- Educación Física-Universidad Nacional de La Plata. 


\begin{abstract}
The purpose of this research was to analyze and understand the process of legitimization of Physical Education (PE) in the UNLP between 1992 and 2004, based on the study of policies and strategies deployed by academics of the homonymous discipline and their perspectives on that process and those of academics from other disciplines that share the social space of the FaHCE. Based on a qualitative, descriptive and analytical methodological design, we opted for a unique instrumental case study strategy, which sought to capture its uniqueness and complexity in its different institutional dimensions. Semi-structured interviews with key informants and documentary analysis were conducted. As a result, we could notice that certain problems such as social recognition and legitimation were foundational in the career, and were updated with other contents in the study period. Likewise, it was possible to characterize the academic policies and strategies developed by this community in the 1990s that tended, among other aspects, to legitimize discipline in the FaHCE as well as to reorient their training profile. From a microsocial theoretical-methodological approach we identified the academic practices, trajectories, networks and forms of sociability of a group of academics who played a central role in the processing and design of these policies. This reconstruction allowed us to observe that, although part of these policies originated from exogenous forces National State - for our case, the process of academic legitimization of the EF had already been initiated previously, with the realization of the first Congress in 1993. The results are consistent with the assumed theoretical-methodological perspective, given that the level of autonomy of university students in this area of human action was evident. However, and also in line with the selected approaches, we realized that both internal and external factors intervene in these policies. That is to say, we identify both a good use (according to own interests and local styles and tactics) of those policies, as well as the generation of policies, although framed by a trend of the moment and a "demand" of the local academy to legitimize itself -. We note, both the influence of the new model of relationship between the State and the University in the '90s, characterized as "Evaluating State" by the reference literature, as well as the proactivity of the PE agents to obtain a prestigious place in the institution.
\end{abstract}

Key words: academic policies - strategies - disciplinary legitimation - Physical Education National University of La Plata. 


\section{RESUMO}

Esta pesquisa foi analisar e compreender o processo de legitimação de Educação Física (EF) na UNLP entre 1992 e 2004, a partir do estudo de políticas e estratégias implementadas pelos acadêmicos / as da disciplina homônima e suas perspectivas sobre esse processo e os de acadêmicos de outras disciplinas que compartilham o espaço social da FaHCE. A partir de um desenho de estudo qualitativo, descritivo e analítico, optamos por uma estratégia de estudo de caso apenas instrumental, que procurou captar a sua singularidade e complexidade em suas diferentes dimensões institucionais. Entrevistas semi-estruturadas com informantes-chave e análise documental foram realizadas. Como resultado, pudemos perceber que certos problemas como reconhecimento social e legitimação foram fundamentais na carreira, e foram atualizados com outros conteúdos no período do estudo. Também foi possível caracterizar as estratégias políticas e acadêmicas desenvolvidas por esta comunidade nos anos 90 que tendiam, entre outras coisas, para legitimar FaHCE disciplina e reorientar seu perfil de treino. A partir de uma abordagem teórica e metodológica micro-sociais para identificar práticas acadêmicas, trajetórias, redes e formas de sociabilidade de um grupo de acadêmicos que desempenhou um papel central no processamento e design dessas políticas. Esta reconstrução permitiu observar que, embora parte dessas políticas originado de forças exógenas -Estado Nacional-, no nosso caso, o processo de legitimação acadêmica e EF anteriormente iniciados com a realização do primeiro Congresso em 1993. O Os resultados são consistentes com a perspectiva teóricometodológica assumida, uma vez que o nível de autonomia dos estudantes universitários nessa área da ação humana era evidente. No entanto, e também de acordo com as abordagens selecionadas, percebemos que fatores internos e externos intervêm nessas políticas. Ou seja, identificamos tanto bom uso (de acordo com interesses próprios e estilos locais e táticas) destas políticas, bem como políticas de auto-geração embora enquadrado em uma tendência do momento e uma "exigência" da academia local para legitimada -. Nós alertou tanto a influência da nova relação entre o Estado ea Universidade nos anos 90, caracterizados como 'estado avaliativo' por agentes da literatura de referência e EF proatividade para obter uma localização privilegiada no instituição

Palavras-chave: políticas acadêmicas - estratégias - legitimação disciplinar - Educação Física - Universidade Nacional de La Plata. 


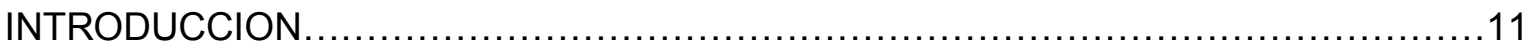

1. El problema y objeto de estudio de esta investigación...........................11

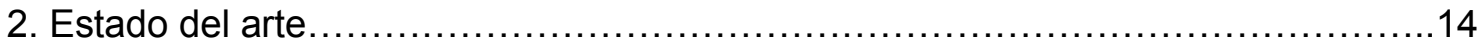

3. Propósito general de la investigación y objetivos específicos......................25

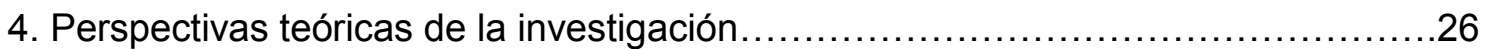

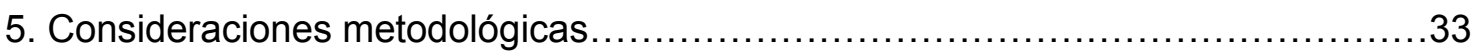

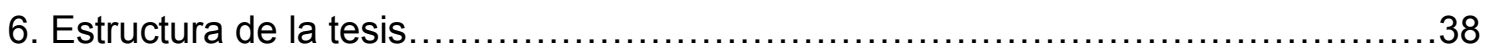

CAPITULO 1. La institucionalización y legitimación de los estudios universitarios en

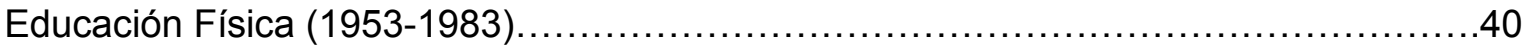

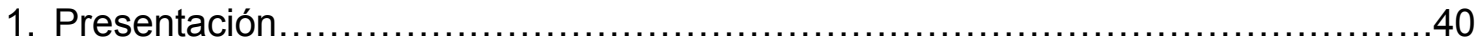

2. La formación profesional en Educación Física a partir de su configuración como disciplina escolar a comienzos del siglo XX.......................................4 41

3. La Educación Física ingresa a la Universidad: itinerarios y marcas de origen en La Plata y Tucumán...................................................................

4. El problema del reconocimiento y la legitimidad en la creación de la carrera: Educación Física en la Facultad de Humanidades y Ciencias de la Educación en los años 1950

5. ¿Quién fue Alejandro Amavet? Trayectoria profesional y académica del "fundador" de la carrera de EF en Humanidades.

5. 1. La consolidación de una EF de corte humanista e integral

6. El procesamiento de la pertinencia y legitimidad de la carrera de EF en los años posteriores al fallecimiento de Amavet.

7. Conclusiones

CAPITULO 2. Redes de relaciones, estrategias y trayectorias de académicos de

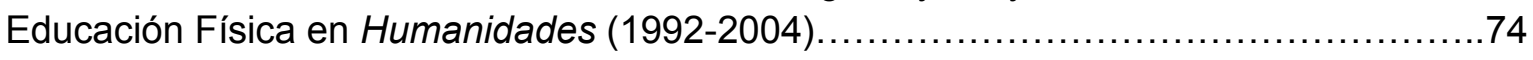

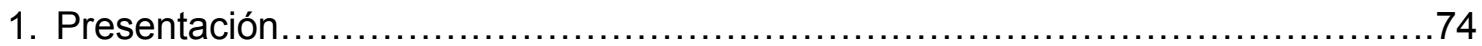

2. La configuración social de los académicos de EF y su participación en el gobierno institucional de la FaHCE y de la carrera entre los años 1983 y $1992 \ldots \ldots \ldots \ldots \ldots . . . .76$

3. El Frente Amplio de Graduados y la participación de actores de EF en un nuevo proyecto institucional.............................................................

4. Política universitaria, redes de relaciones y gestión académica en el Departamento de Educación Física en los años '90

4. 1. La reconstrucción de una "gesta épica" en el Departamento de EF desde el relato oficial a partir del año 1984: sentidos, tendencias y contradicciones. .90 
5. La conformación de un grupo de profesores en EF y sus trayectorias académicas en Humanidades en los años '90.

5.1. "Ellos remaron": la construcción del grupo de profesores protagonista de la "gesta épica"..

5.2. Trayectorias profesionales, políticas y académicas de los protagonistas de la "gesta épica".....

6. El viaje a Chile: una experiencia colectiva de formación y el armado de una nueva concepción disciplinar.

7. Conclusiones.

CAPITULO 3. Políticas de producción científica y de revisión curricular en Educación Física. 124

1. Presentación 124

2. "La prepotencia de trabajo": el proceso de legitimación de EF en Humanidades en los años '90.

2.1. El escenario del proceso de legitimación: Política nacional y universitaria en los años '90.

3. "Una bisagra": El armado del Primer Congreso de Educación Física y Ciencias...131

4. El "hermano menor" ya tiene quien le escriba: la Revista Educación Física y Ciencia. 138

4.1. El germen de la Revista: El Congreso Educación Física y Ciencias. 138

5. "Nosotros tenemos que aprender de ellos": el comienzo de un camino en la investigación en Educación Física.

6. "Nosotros somos los que estamos innovando": Propuesta de renovación curricular en EF a mediados de los años '90. 148

6.1. Las reformas curriculares a mediados de los años 1990: nuevas normativas y políticas de financiamiento

6.2. Las discusiones sobre el proyecto de la carrera de Licenciatura en Educación Física en el año 1998.

7. Conclusiones. 163

Conclusiones finales. 169

Referencias bibliográficas..... 183

Anexos. 193 


\section{INTRODUCCIÓN}

\section{El problema y objeto de estudio de esta investigación}

Esta investigación tuvo como objeto analizar y comprender el proceso de legitimación disciplinar de la Educación Física (EF) en la Facultad de Humanidades y Ciencias de la Educación (FaHCE) -en adelante "Humanidades"1- de la Universidad Nacional de La Plata (UNLP) a partir del estudio de las políticas académicas, estrategias, prácticas y formas de sociabilidad que esta comunidad desarrolló entre los años 1992 y 2004. La investigación se focalizó en la perspectiva de los actores que intervinieron con la intencionalidad de legitimar su campo disciplinar y su carrera en la FaHCE, en un período histórico particularmente intenso en cuanto al diseño y desarrollo de políticas académicas ligadas a la revisión curricular, la formación académica y la producción científica. El trabajo analizó las formas de apropiación y resignificación actual de esas políticas, estrategias, prácticas y formas de sociabilidad con relación a la configuración identitaria de la disciplina académica.

La EF como disciplina académica tiene un desarrollo relativamente reciente en comparación a otros campos de conocimiento científico con los que comparte el espacio institucional de la FaHCE, como por ejemplo Historia, Filosofía o Letras. La creación de la carrera $^{2}$ de Profesorado en EF data de 1953 y es, junto con la Universidad Nacional de Tucumán, pionera en el desarrollo de carreras universitarias en este campo del saber. Para la reconstrucción de las políticas, estrategias, prácticas y formas de sociabilidad de un grupo acotado de actores de esta comunidad académica en el espacio universitario local, y las perspectivas que construyen sobre las mismas con relación al reconocimiento social de su campo disciplinar y carrera en el presente, retomamos algunas tensiones y tradiciones históricas que han configurado el campo disciplinar de la EF y su devenir en la UNLP.

El período que abarcó esta investigación (1992-2004) respondió a variables de tipo micro y macropolíticas. En el primer caso, recortó tres gestiones departamentales, de dos directores distintos, en un período caracterizado por el desarrollo de políticas

\footnotetext{
1 "Humanidades" es una categoría de uso nativo en la comunidad académica de la FaHCE. También es habitual escuchar la apócope "Huma" para referirse a la institución, fundamentalmente entre los/as estudiantes. Tanto Humanidades como FaHCE, serán utilizadas en forma indistinta en este escrito.

${ }^{2}$ En lo que sigue, cuando se utiliza la expresión "la carrera" nos referimos a ambas carreras, el Profesorado en Educación Física y la Licenciatura en Educación Física.
} 
académicas de profunda incidencia en EF, tanto a nivel del grado como del posgrado: la reforma curricular y consecuente creación de la Licenciatura en Educación Física, dando lugar a un nuevo Plan de Estudios que fue aprobado en 1998 e implementado por primera vez en el 2000; el desarrollo de un Ciclo de Licenciatura para carreras terciarias en EF en varias regiones del país; las primeras investigaciones en el área y conformación de grupos de investigación, y la creación de la primera maestría a nivel nacional en la disciplina y una de las primeras a nivel institucional, denominada Maestría en Educación Corporal en el año 2001 y la Maestría en Deporte, en 2004, entre otras.

Las razones de tipo macropolíticas, se vincularon con un contexto de cambios en las relaciones entre el Estado y la Universidad, y de políticas universitarias que introdujeron nuevas lógicas y mecanismos de funcionamiento en las instituciones académicas (Araujo, 2001; Chiroleu, Suasnábar y Rovelli, 2012; Krotsch, Camou y Prati, 2007; Marquina, Mazzola y Soprano, 2009; Puiggrós y Krotsch, 1994). En este sentido, el recorte temporal retomó dos políticas estatales específicas para las universidades nacionales como fueron el Fondo para el Mejoramiento de la Calidad Universitaria (FOMEC) y el Programa de Incentivos a la Investigación (PI). El FOMEC fue aprobado en 1995 y comenzó a funcionar en 1996, y formó parte de un programa más general, denominado "Programa de Reforma de la Educación Superior" (PRES), financiado por el Banco Mundial -Banco Internacional de Reconstrucción y Fomento- (BM/BIRF) y una contrapartida nacional aportada por las universidades, que se propuso revisar áreas sensibles como la enseñanza y la investigación. El PI fue creado a través del decreto presidencial 2427 del año 1993, instrumentándose en 1994, y tuvo como objetivo impulsar la investigación en las universidades nacionales, a través de mecanismos de evaluación y control de la producción científica de los docentes y el otorgamiento de un incentivo económico. Este programa tiene continuidad hasta el presente.

Las dos políticas estatales mencionadas ejercieron influencia en la FaHCE y fueron particularmente aprovechadas por la comunidad académica de EF (Atairo, 2007; Carballo, 2009; Levoratti y Macario, 2013).

Por otro lado, la elección de este período histórico, se justificó dado su exiguo abordaje en el ámbito de la UNLP y en la relación entre ésta y el Estado. Son también escasos los trabajos que abordan esta etapa particularmente en la FaHCE y en sus carreras específicas. En este sentido, este período aún permanece opaco al análisis, y abundan los documentos oficiales y una percepción negativa relativamente generalizada sobre los años '90 en el ámbito académico. Encontramos algunas tesis de grado y 
posgrado que, aunque en varios casos no coinciden en el período histórico que recortan con este trabajo, o rebasan los años '90, toman por objeto distintas políticas estatales generadas en esa etapa, y sus implicancias en la UNLP y en algunas de sus unidades académicas en particular. ${ }^{3}$

El interés por este tema de investigación surgió a partir de mi inserción académica como docente de Pedagogía en Educación Física y de la percepción que, como nativa de la FaHCE, fui construyendo de los universitarios de esa disciplina ${ }^{4}$. En la institución han circulado y circulan representaciones de la EF que la identifican con el mero hacer sin reflexión, desde una posición de descalificación: expresiones como "músculo y sonrisa", "los profesores de ejercicio", o "la prima pobre del campo" evidencian una relación asimétrica con otras disciplinas de la institución. Al respecto, los estudiantes de esa carrera son reconocidos como "diferentes" por docentes propios y de otras disciplinas. Esa diferencia refiere fundamentalmente a la comparación constante entre los estudiantes de EF y estudiantes de otras carreras. Caracterizados como "alegres", "simpáticos", renuentes al trabajo intelectual, desinteresados, en contraposición a un estudiante modélico de Humanidades, más afecto al estudio, a la discusión política y a la participación ${ }^{5}$.

En este sentido, las carreras de Educación Física son vistas como más sencillas, con menor carga teórica y exigencia que otras carreras de la FaHCE. Esta visión desprestigiada se asocia, como veremos más adelante, a debates internos en el campo respecto del valor educativo y el componente cognitivo de la EF, que se proyectan entre la cultura escolar y la cultura académica de la disciplina (Aisenstein, 1995; Bracht, 2000; Carballo, 2010; Kirk, 1990; Villa, 2003).

Algunos autores han planteado que esta representación de la EF no es construida solamente desde otros campos disciplinares, sino también internamente, en respuesta a su subordinación por más de un siglo a las prescripciones de las ciencias biológicas y

\footnotetext{
${ }^{3}$ Para el caso FOMEC y su grado de recepción en distintas facultades, ver Atairo, 2007; en cuanto a la apropiación del Programa de Incentivos y su traducción en dos carreras de la FaHCE -Historia y Educación Física-, ver Macario, 2007; para el análisis de esta misma política en distintas universidades nacionales, incluyendo la UNLP, y con foco en dos campos disciplinares, Física e Historia, ver Prati, 2011; para política de acreditación en la Facultad de Ciencias Médicas desde la perspectiva de los estudiantes, ver Trotta, 2016; sobre políticas de acceso a la UNLP en distintas unidades académicas, consultar Montenegro, 2016.

${ }^{4}$ Ingresé como estudiante de Ciencias de la Educación en la FaHCE en el año 2003, participé en distintos espacios político-académicos con estudiantes de Educación Física y de otras carreras, y egresé a mediados del 2009. A partir del año 2011 me desempeño como ayudante diplomada en la cátedra de Pedagogía para Educación Física, cursé la Maestría en Educación desde fines del año 2009 y soy estudiante del Doctorado en Ciencias de la Educación en la misma institución desde 2018.

${ }^{5}$ Notas de campo derivadas de intercambios con estudiantes, graduados y profesores de EF de la FaHCE y de entrevistas a profesores de EF desarrolladas durante los años 2015 y 2016 (Entrevista al Prof. Ricardo Crisorio el 26 de octubre de 2015, entrevista al Prof. Carlos Carballo el 13 de abril de 2016).
} 
psicológicas, así como por la escisión moderna de la que ha sido particularmente receptora entre cuerpo-intelecto (Aisenstein, 1995; Aisenstein y Scharagrodsky, 2006; Crisorio, 2009; Villa, 2003). Esa división ha contribuido en la desjerarquización de la disciplina, en la medida en que ha quedado del lado de la técnica, del hacer irreflexivo.

Asumimos que la identidad de una disciplina académica se constituye dentro de sus propios márgenes, pero también en sus relaciones con las disciplinas más próximas con las que comparte el espacio social. En razón de ello identificamos, por un lado, quiénes fueron los actores participantes de las políticas académicas ya mencionadas, qué roles de autoridad cumplieron, qué cargos ocuparon en su condición de estudiantes, graduados y docentes, qué trayectorias académicas y profesionales desplegaron y en qué redes de relaciones sociales de contenido diverso participaron, tanto dentro como fuera de su comunidad disciplinar. Por otro lado, analizamos el proceso de legitimación de su campo disciplinar y carrera, a partir de los sentidos atribuidos por esos actores y otros procedentes de disciplinas académicas próximas a la EF en el espacio social de la FaHCE, a las políticas académicas, prácticas, estrategias y formas de sociabilidad desarrolladas por esta comunidad en el período delimitado.

\section{Estado del arte}

En este apartado recopilamos investigaciones que, a nivel nacional, han tomado por objeto de estudio a la Educación Física (EF), organizadas según ejes temáticos que se vinculan a dimensiones del problema de investigación. Por el desarrollo de la agenda de investigación en EF y la definición problemática, hemos decidido recortar el abordaje a partir de la década de 1980 en Argentina y considerar algunas producciones representativas de Brasil y a un autor anglosajón que han dialogado con producciones locales. Este recorte se fundamenta en la evidencia de un campo académico -si bien más desarrollado en Brasil- incipiente a partir de esos años, y que se vincula fuertemente con una "refundación del campo" a nivel de esos países (Pich y Rodríguez, 2014). La proliferación de estudios en este área se vincula a la existencia de redes de circulación de conocimientos de alcance local, regional y mundial, como eventos y publicaciones periódicas, el desarrollo de institutos, áreas y centros de investigación en la especialidad con distintos grados de estructuración ${ }^{6}$, la apertura creciente de carreras de grado y

\footnotetext{
${ }^{6}$ Un centro de investigaciones importante en Brasil, de los más antiguos, es el Colegio Brasilero de Ciencias del Deporte (CBCE), surgido en 1978, que tiene representación estadual y organiza cada dos años desde 1979 el CONBRACE (Congreso Brasilero de Ciencias del Deporte), uno de los eventos principales del área a nivel nacional. Cada edición convoca con un eje temático distinto. El primero se denominó "Infancia y
} 
posgrado en Argentina y América Latina ${ }^{7}$, y la existencia de una masa crítica de investigadores de reconocida incidencia en el ámbito nacional, con tendencia al crecimiento y la diferenciación en sub-áreas de estudio y perspectivas teóricas ${ }^{8}$.

No serán considerados aquí aquellos estudios en EF desde una perspectiva bio-médica o vinculada al área de salud, dado que no resultan pertinentes para nuestro problema, además de ser una perspectiva que desde los autores reseñados (y aún con diferentes objetos y enfoques) es considerada tributaria de otros campos (como la Medicina, la Fisiología o la Psicología) y no de la EF. No obstante, como se desarrolla en esta tesis, se la considera como una perspectiva en discusión o antagónica a la perspectiva críticosocial en la disciplina. Por último, las producciones aquí reunidas son investigaciones finalizadas, contenidas en tesis de grado y posgrado, libros y capítulos de libro, y presentaciones a congresos más representativas de los temas seleccionados.

Actividad Física", y se desarrollaron otros vinculados a la identidad y epistemología de la disciplina tales como "¿Qué ciencia es ésta? Historia y tendencias" (1993), "Interdisciplinariedad, ciencia y pedagogía” (1995), “ Educación Física / Ciencias del Deporte: renovaciones, modas e intereses" (1997) que dan cuenta de debates similares en nuestro país, en el mismo contexto temporal. En 2017 fue convocado el XX CONBRACE que se desarrolló en Goiânia bajo el eje "Democracia y emancipación. Desafíos para la Educación Física y las Ciencias del Deporte en América Latina". Cabe señalar que, desde el 2003, se realiza además junto a éste, el Congreso Internacional de Ciencias del Deporte, y edita la Revista de Ciencias del Deporte de periodicidad anual, también desde 1979. Su actual editor es el Dr. Alexandre Fernandez Vaz, y se han destacado figuras que aún permanecen en el consejo editorial como Valter Bracht.

7 Si bien en la Universidad Nacional de La Plata se crean los primeros posgrados en EF en Argentina, estos son de reciente creación (Maestría en Educación Corporal, 2001, Maestría en Deporte, 2004). En cambio, en Brasil, el desarrollo es anterior y más vertiginoso (tener en cuenta que la primera carrera universitaria de grado data de 1930). Allí, la primera experiencia de posgrado puramente disciplinar es del año 1977 en la Universidad de Sao Paulo (USP). Esta institución hegemonizó la formación superior en el área hasta la década de 1980, cuando entra en crisis la matriz epistemológica biofisiológica, para dar lugar a una perspectiva histórico-social en la disciplina. A pesar de movimientos contrahegemónicos, la perspectiva biológica terminó predominando la concepción de ciencia e investigación en la EF brasilera, observable en la inserción de la disciplina en la política de posgrado en el área de la Salud. Para el 2012, Brasil contaba con 21 programas de maestría y 11 de doctorado en EF (Castellani Filho: 102, en González de Alvárez, 2012). En Argentina no existen programas de Doctorado en el área.

8 Para el caso argentino, y siendo asunto de investigación de esta tesis, las primeras investigaciones institucionalizadas fueron en la UNLP, a partir del Programa de Incentivos a la Investigación, de la Secretaría de Políticas Universitarias (SPU) del por entonces Ministerio de Cultura y Educación en el año 1993. A partir de allí, se desarrollaron el Congreso Argentino de Educación Física y Ciencias del Departamento de Educación Física de la FaHCE/UNLP en el mismo año, y de periodicidad bianual, y en el año 1995 se edita por primera vez la Revista Educación Física y Ciencia. Como dijéramos más arriba, en los albores de los años 2000 se crean los primeros posgrados en el área en esta institución. En el año 2009, a partir del crecimiento presupuestario que alcanzó a toda la universidad argentina entre los años 2003 y 2015, se crea el IdIHCS (Instituto de investigaciones en Humanidades y Ciencias Sociales), instituto de doble dependencia (UNLP-CONICET) en la FaHCE, conformado por 17 unidades de investigación, y que nuclea cerca de 200 investigadores y 180 becarios. Allí se radican el CICES (Centro Interdisciplinario Cuerpo, Educación y Sociedad) y el AEIEF (Área de Estudios e Investigaciones en Educación Física), centro y área de Educación Física en la Facultad. 
Los inicios y fundamentos de la Educación Física como disciplina

Un trabajo pionero en EF es el que Saraví Riviere (2012) realizó en 1985. El autor inició los estudios históricos en la disciplina, y editó una compilación de dos volúmenes, denominada Historia de la Educación Física. El primer volumen referido a la época precolombina y colonial, y el segundo, sobre la etapa independentista y de consolidación del Estado Nacional. En 1998 se editó un libro que incluye ambos volúmenes. Esta producción constituye la historia consagrada de la EF argentina, y recoge una serie de eventos y personajes clave en su definición, a través de la utilización de fuentes documentales. Podríamos decir que constituye una historia institucional, de tipo acontecimental.

Otro trabajo fundante, ya en el plano académico, es el de Aisenstein (1995), quien se propone estudiar el modelo didáctico predominante en la enseñanza de la disciplina hacia los años 1990 y 1991, analizando la formación docente en el Instituto Nacional Superior en Educación Física (INEF) y la práctica docente de sus egresados en escuelas primarias de la Ciudad de Buenos Aires y el conurbano ${ }^{9}$. Desde una perspectiva teórica socio-histórica y didáctica, y un enfoque comparativo entre los diseños curriculares, las propuestas de enseñanza y observaciones de clase en el nivel primario y de formación docente, establece que los modelos prevalecientes en ambos niveles resultan contingentes y poco significativos para el aprendizaje en EF hacia fines del siglo XX. Esos rasgos van colocando a la disciplina en un lugar subsidiario, en contraposición a un lugar destacado a comienzos del mismo siglo. De este trabajo nos interesa resaltar la caracterización que realiza de la EF escolar, siendo ésta la forma como se manifiesta inicialmente la disciplina en nuestro país. En dicha caracterización se menciona la preocupación por lo corporal en la escuela desde los inicios del sistema educativo a fines del siglo XIX y excediendo la tarea de la EF, y cómo ésta se ha construido en torno a una concepción dualista del sujeto, escindido en cuerpo-mente y sobre la que ha prevalecido una visión centrada en su contribución al mejoramiento de la salud, entendida como necesidad. Allí la autora parte de considerar a la escuela como una institución creada para la transmisión de contenidos significativos y la integración de los sujetos a la cultura de una sociedad. En este sentido, guía su trabajo la idea de que la EF ha contribuido fundamentalmente a este último objetivo, teniendo como meta el disciplinamiento social por la vía de la acción de los cuerpos (Aisenstein, 1995).

\footnotetext{
${ }^{9}$ Cabe destacar que este trabajo de Aisenstein es la primera tesis de posgrado en EF del país, realizada en FLACSO, y publicada en el año 1995.
} 
En un trabajo de Crisorio se desarrolla una concepción ya reconocida en el campo, que considera a la disciplina como "profundamente moderna" en la medida que "nace del vientre de la ciencia y de la mano del Estado" (2009: 48). Esta característica se liga directamente con el proceso de cientifización del cuerpo. Es decir, la reposición de la naturalidad del cuerpo y su construcción como dato científico, susceptible de ser conocido, medido, clasificado, eliminando toda diversidad en búsqueda de una homogeneización. Así como la Pedagogía, como disciplina moderna, encuentra en la infancia su objeto de estudio e intervención, su razón de ser, la EF hace lo propio con la formación del cuerpo. Esta EF como producto netamente moderno adquiere la denominación actual en reemplazo del término Gimnástica (utilizado en Europa), prácticamente a comienzos del siglo XX.

En otro trabajo de Aisenstein y Scharagrodsky (2006) se plantean algunas características históricas y derivaciones políticas sobre la cuestión de la Educación Física de fines del siglo $X I X^{10}$. Alli se reconstruye el proceso de inclusión de la EF como asignatura en el curriculum escolar, las discusiones y disputas en torno a los contenidos legítimos a seleccionar, y el sentido y la función de la EF en la escuela. Algunos de los fundamentos para su inclusión y posterior sostenimiento tienen que ver con aquello que Carballo (2014) definió como las misiones que adoptó la EF, formación del carácter y mejoramiento de la salud física. Es así como, al decir del mismo autor, la EF "no nace con un saber propio (previo a la constitución de la escuela moderna), sino con una misión (básicamente, normalizadora)" (2014: 129). Por otro lado, también en esa obra de Aisenstein y Scharagrodsky (2006), se destaca la contribución de la disciplina en la construcción de una sociedad generificada.

Las pesquisas que identificamos aquí ubican el origen de la EF en la escuela y ligan su fundamentación a la Medicina y la Fisiología, relacionando la legitimidad alcanzada por la primera a la vinculación con esas disciplinas científicas (Aisenstein, 1995; Aisenstein y Scharagrodsky, 2006; Carballo, 2009; 2014; Carballo y Fernandez Vaz, 2003; Crisorio, 2009; Crisorio y Bracht, 2003; Galak, 2012a; 2012b; Galak y Simoy, 2015; Paso y Garatte 2011; Scharagrodsky, 2011; Villa, 2007).

En su constitución como disciplina, la justificación del valor educativo de la EF cumplió un rol decisivo. La tensión entre la mente y el cuerpo, el intelecto y la materia, y su ligazón con la ciencia médica, fueron evidencia de ello, así como el carácter

\footnotetext{
${ }^{10}$ Se trata de, a esta altura, una referencia ineludible en el campo de la formación e investigación en EF, "Tras las huellas de la Educación Física Escolar Argentina. Cuerpo, Género y Pedagogía. 1880-1950", editado en 2006 por la Editorial Prometeo.
} 
subsidiario o complementario que adquirió en el ámbito escolar (Aisenstein y Scharagrodsky, 2006; Galak, 2012a). Otros autores como Carballo y Fernandez Vaz (2003) caracterizan a la EF como una disciplina de intervención en sus inicios y entrado el siglo XX como disciplina de conocimiento, e identifican su origen escolar como una marca indeleble, que la acompañará en su instalación como disciplina académica.

\section{El proceso de profesionalización de la Educación Física}

La formación profesional en la disciplina surgió a comienzos del siglo XX, apuntada centralmente a la formación de docentes para el sistema educativo. La formación universitaria, en cambio, se instaló recién a mediados del siglo XX. La primera institución de formación de profesores en el país es la Escuela de Gimnasia y Esgrima del Ejército, creada en 1897 (Escuela). Allí se formaron algunos de los referentes que luego se hicieron cargo de la distribución de este saber dentro y fuera de las escuelas, y que egresaban con el título de "Maestros en Gimnasia y Esgrima” (Galak, 2012b).

La segunda institución de formación de profesores en EF es del ámbito civil, el Instituto Nacional Superior de Educación Física en 1912 (INEF). Uno de los referentes principales del proceso de creación del INEF fue Enrique Romero Brest, un joven médico egresado de la UBA, que mantenía relaciones con funcionarios del Consejo Nacional de Educación de fines del siglo XIX y primeros años del XX (entre ellos, el inspector Pablo Pizzurno) y que es reputado como el fundador de la EF en nuestro país ${ }^{11}$ (Galak, 2012b; Scharagrodsky, 2006). Los antecedentes del INEF son cursos temporarios dictados a maestros normales en los primeros años del siglo $\mathrm{XX}$, y tanto estos como el propio Instituto buscaban una EF distintiva de la formación militar. Esta corriente es denominada como cívico-pedagógica, y se fundamentaba en la Fisiología en relación a la búsqueda de una EF racional, metódica, natural y placentera (Galak, 2012b).

De este modo, varios autores (Galak, 2012a, 2012b; Galak y Simoy, 2015; Scharagrodsky, 2011) identifican a la Escuela y el INEF de Romero Brest como dos concepciones distintas y en disputa que dan origen al campo de la EF en el primer cuarto del siglo $\mathrm{XX}$.

Otro grupo importante de pesquisas de los últimos años y que contribuyen decididamente en la construcción de nuestro objeto de estudio, son aquellas que comienzan a analizar la EF en su relación con los procesos sociales y políticos más

\footnotetext{
11 Para una mayor referencia sobre Enrique Romero Brest (1873-1958), consultar Galak, 2012b; Scharagrodsky, 2006.
} 
amplios (Crisorio, 2007; Franco, 2011; Galak, 2012b, 2014; Orbuch, 2016). Situados en diferentes momentos históricos e incluyendo objetos diversos, estos trabajos van a analizar a la EF en su vinculación con la política estatal. Desde el disciplinamiento social, la formación del ciudadano, la construcción de un individuo capaz de autogobernarse, pasando por la figura del trabajador, la EF, según estos autores, ha servido para la producción de un determinado sujeto en el marco de un proyecto político más amplio. Según Galak (2014) la EF ha permanecido ligada a los designios de la política, aun presentándose como una asignatura pedagógica a-política, o políticamente neutral. Es decir, ha tenido un margen de autonomía acotado en relación a las políticas estatales.

El trabajo de Orbuch (2016) indaga las políticas públicas durante el primer peronismo en materia de EF, para mostrar cómo esta ha contribuido en la formación de un nuevo ciudadano para la Nueva Argentina que se estaba construyendo. Este trabajo intenta superar miradas que asocian al peronismo con el totalitarismo, y se distancia de aquellas que entienden que las políticas diseñadas específicamente para la EF son una continuidad con las llevadas adelante en los años '30. Se constituye en un antecedente por cuanto pone de manifiesto la centralidad que adquirió la EF durante el peronismo, contexto en el cual se creó la carrera homónima en la UNLP.

\section{La identidad y legitimidad de la Educación Física como disciplina académica}

El problema de la identidad y legitimidad de la EF aparece como una cuestión central y específica en la bibliografía académica del propio campo, en la década de 1980 en Brasil y en los años 1990 en Inglaterra y Argentina (Aisenstein, 1995; Bracht, 2000; Crisorio y Bracht, 2003; Kirk, 1990; Ron, 2003). Esta diferencia temporal responde al mayor desarrollo en el campo académico brasilero que en el local. Según estos autores, la disciplina atravesó una "crisis de identidad" que se explicaría por la pérdida de eficacia de la función social de la EF, la penetración de novatos y extranjeros en el campo laboral (entrenadores y técnicos, por ejemplo), y una representación social de la EF como puro hacer, alejado del saber propio, representación a la que contribuirían los propios especialistas (Crisorio, 2003; Villa, 2003). Esta mirada es compartida por Ron (2003) quien sostiene que circulaba una creencia bastante generalizada acerca del saber de la EF como puramente práctico, y una visión de sus profesionales como "hacedores de prácticas". Según estos análisis, esta visión contribuyó a sostener una representación de los especialistas como técnicos, en afinidad con la concepción tradicional de la EF escolar como descarga, entretenimiento, compensación o mera preparación para la 
actividad considerada verdadera, la intelectual (Aisenstein, 1995; Ron, 2003). Otros autores como Paso y Garatte (2011) han advertido también sobre la voluntad de subordinación que otros campos disciplinares como la Biología, la Fisiología o la Psicología le han impreso a su relación con la EF. Estos trabajos funcionan como antecedentes para nuestra investigación, dado que describen y analizan las razones de la desvalorización de la EF, tanto a nivel nacional como de la UNLP, y de sentidos que permanecen en el período de nuestro estudio, aunque actualizados, asociados a una visión de la EF como puro hacer.

Investigaciones como las de Aisenstein (1995), Bracht (2000), Crisorio y Bracht (2003), Kirk (1990), Paso y Garatte (2011) y Ron (2003) muestran que el problema de la legitimidad y el reconocimiento académico de la EF, así como su relación con otras disciplinas, es relevante en la tradición crítica de la disciplina, tanto latinoamericana como anglosajona, constituyendo un acicate para nuestra investigación.

\section{La emergencia de la Educación Física universitaria}

Dentro de este apartado consignaremos aquellos trabajos que han abordado la construcción e instalación de la EF a nivel universitario, con especial referencia a La Plata, así como su devenir en el tiempo.

Las dos primeras experiencias universitarias en EF en Argentina surgieron en 1953, en la provincia de Tucumán y en la ciudad de La Plata (Carballo, 2009; González De Álvarez, 2012). Ambas fundaciones se dieron en el marco del segundo mandato justicialista, presidido por Juan Domingo Perón. Este gobierno le otorgó a la actividad física y los deportes un lugar destacado en las políticas públicas, como medio para la capacitación física y el mejoramiento de la salud, la formación del "nuevo ciudadano", la organización civil y comunitaria y la propaganda política, en un modelo estatal que se planteaba el acceso de las grandes masas a la recreación y al deporte, antes restringido a sectores sociales minoritarios (Calvo Etcheverry, 1998; Mamonde, 2008; Orbuch, 2016).

El antecedente más significativo de la carrera de EF en la UNLP lo constituye la Dirección General de EF, creada en 1946, y encargada de coordinar las disciplinas físicas en toda la universidad. Su mentor y fundador, Alejandro Joaquín Amavet, era egresado de la Escuela e ingresó a trabajar a la universidad con el rango de capitán del Ejército ${ }^{12}$.

\footnotetext{
12 Para profundizar en la vida, obra y trayectoria del profesor Alejandro Amavet, ver: Di Paolo (1993), Ron y Levoratti (2015) y Villa $(2003,2007)$. Nuestro propio abordaje será desplegado en el capítulo 1.
} 
Una investigación podríamos decir fundacional sobre la carrera de EF en la UNLP, ha sido la de Di Paolo (1993). Como especialista del área, el autor reconstruye los antecedentes de la EF en el ámbito de la UNLP, la creación de la carrera universitaria en 1953, y la influencia y concepción de su fundador, el Profesor Alejandro Amavet. Este trabajo nos aporta un relato nativo acerca de la carrera de EF en la UNLP, y la vida, obra e influencia de su fundador. Lo consideramos nativo en tanto el propio autor señala en el título que es una "semblanza" hacia Amavet ${ }^{13}$, es decir, como una especie de homenaje en registro biográfico, que rescata sobre todo hechos e informaciones, distinto al tipo de registro de las investigaciones siguientes, que al ser también analistas del propio ámbito institucional, lo hacen desde un esfuerzo de distanciamiento y relevando diferentes y variadas fuentes teóricas y empíricas.

Otros estudios que se han realizado sobre la carrera de EF de la UNLP son los de Galak y Simoy, 2015; Giles, 2012; Giles, Mamonde y Simoy, 2012; Ron y Levoratti, 2015; Villa $(2003,2007,2011)$ y Visciglia, 2016. Estos autores coinciden en señalar a la concepción de Amavet como innovadora en el campo disciplinar de EF, ya sea denominándola como "posición renovadora" o de "ruptura epistemológica", estableciéndose como una especie de tercera posición en la disputa entre la visión cívico pedagógica y la militar. No obstante, las articulaciones y filiaciones que se construyeron con la matriz fundante de la carrera son diversas, en función de las disputas que se establecen en la actualidad en el campo.

En el caso de dos de los trabajos de Villa (2003; 2007) se analizan las lógicas y discursos que configuraron la formación docente en EF en la UNLP, desde la perspectiva de los docentes, en los inicios del 2000. Este análisis se efectúa a través del diálogo con la "escena fundante" de la carrera, con su fundador, su legado y "tradición inventada". La autora hace una reconstrucción de la creación de la carrera, en el marco de la historia de la UNLP y de la FaHCE, señalando la relevancia que tuvo dicha creación en la configuración de la profesionalización de la EF (dado que la formación docente en EF, en general, estuvo hegemonizada por los Institutos Nacionales de Educación Física y la Escuela del Ejército). De estos trabajos rescatamos especialmente como aportes a nuestra investigación, el análisis sobre la identidad de la EF en la FaHCE, como la escasa valoración institucional y departamental a los estudiantes de la carrera, y el lugar de los docentes como "reproductores" de saber, más que como productores de

\footnotetext{
${ }^{13}$ Se trata de la publicación "Historia de la creación del Profesorado Universitario en Educación Física: Semblanza de vida y obra del Profesor Alejandro Amavet", galardonada con el premio Humanidades en el año 1992.
} 
conocimiento. Un elemento que Villa (2007) destaca y que resulta relevante para nuestra investigación, se vincula con la disputa histórica entre la formación en EF de los Institutos Superiores de Formación Docente y las Universidades, o entre la concepción normalista y universitaria, tensión que atraviesa toda la historia de la disciplina, incluso hasta la actualidad. En el primer caso, no solo el objetivo central está puesto en la formación de docentes, sino que prevalece una formación que pone el eje en lo deportivo y la salud, y en el otro caso, una formación más vinculada a las Humanidades y las Ciencias Sociales. Otro elemento que destaca, de carácter más local, refiere a la cuestión sobre las condiciones que la EF debía tener para alcanzar el estatuto de carrera universitaria. Los análisis de estos elementos se constituyen en antecedentes para nuestro estudio, ya que es en el marco de una institución como la FaHCE, definida por las Humanidades y las Ciencias Sociales, que los universitarios de EF buscan construir una identidad que los distinga de la formación tradicional en la disciplina y obtener reconocimiento por los otros actores institucionales de carreras con mayor trayectoria académica.

La disputa señalada más arriba entre la concepción cívica y militarista, se actualiza en el proceso de legitimación disciplinar en el período estudiado, en la medida en que se reconoce a la creación de la carrera en la UNLP como un punto de quiebre de esta contienda (Galak y Simoy, 2015; Giles, Mamonde y Simoy, 2012). Los autores que investigan la cuestión, sitúan el conflicto entre la corriente pedagógico-científica de corte biologicista y la corriente militarista en el período fundacional de la disciplina. No obstante, ambas corrientes compartían el mismo concepto de cuerpo, el cuerpo de las ciencias médicas, que pretendían imponer en el campo disciplinar. Los autores destacan la creación de la carrera en 1953 como un punto de inflexión, al menos en la discusión teórica, de esta hegemonía simbólica. Esta fundación, representada por la figura de Amavet, tuvo el propósito de colocar a la disciplina en otro lugar con respecto a la construcción del saber y vincularla más directamente con las Humanidades (Galak y Simoy, 2015; Giles, Mamonde, Simoy, 2012).

Algunos de estos autores, como Galak y Simoy (2015), definen a la carrera de EF de La Plata como una posición renovadora en la formación disciplinar ${ }^{14}$. Este rasgo se explicaría por la decisión de Amavet de instalar a la EF en una facultad de Humanidades y Ciencias Sociales, y de esta forma diferenciarse del destino seguido por otras experiencias universitarias en EF en Argentina. Por caso podemos mencionar la

\footnotetext{
${ }^{14}$ El adjetivo "renovadora" es retomado del "fundador" de la EF en la UNLP, Alejandro Joaquín Amavet, quien denominó su perspectiva EF renovada y así lo manifestó en algunas de sus obras. Nos referimos a los Cuadernos de Educación Física Renovada I, II y III, publicados en 1967, 1968 y 1969, respectivamente.
} 
experiencia de Tucumán, que por unos días adelantó a La Plata y fundó la primera carrera universitaria del país. Esta iniciativa fue una mixtura entre las posturas cívicas y militaristas, así como retomó elementos de la Asociación Cristiana de Jóvenes y su misionero estadounidense, Federico Dickens, y estuvo fuertemente influida por la perspectiva de Romero Brest, quien fuera convocado como asesor técnico y luego como interventor del Departamento Universitario de Educación Física desde el año 1953 a 1961 $\left(G o n z a ́ l e z\right.$ De Álvarez, 2012) ${ }^{15}$. Cabe mencionar que esta propuesta académica se recostó en la Fisiología como argumento legitimador y fue inicialmente ubicada en el área médica de la universidad (Galak y Simoy, 2015).

En cuanto a la carrera de la UNLP, tanto en el período fundacional como en años recientes, el problema de la denominación reviste una centralidad para esta comunidad académica. El hecho de llamarse "Profesorado Superior Universitario en EF" es evidencia de ello, así como la disputa de fines de los años '90, sobre si llamarse "Educación Física" o "Educación Corporal" (Carballo, 2015; Crisorio, 2015; Galak y Simoy, 2015; Giles, 2012). Estas tensiones dan cuenta de que el aspecto nominal del reconocimiento constituye una preocupación persistente en esta comunidad, extendiéndose hasta el presente, incluso en políticas académicas recortadas para esta tesis, como son el Congreso y la Revista de EF, acompañados en su título de la palabra "ciencia"16. La elección de esta palabra no es un dato menor para esta investigación, ya que evidencia al menos cierta preocupación de esta comunidad por legitimarse como disciplina científica. En el caso de la propuesta de denominar a la carrera como "Educación Corporal", se manifiesta el interés por diferenciarse de la visión biomédica dominante en la disciplina e instalar perspectivas más sociales y culturales. Esa visión es discutida en relación a su concepción de cuerpo entendido como natural, innato, dado, que tiene un modo de ser que le es propio y que puede -y debe- conocerse tal y como es, y que ha sido tratado aisladamente como elemento anatómico-orgánico-funcional. Al respecto, autores como Crisorio (2015) y Giles (2012), son tributarios de una concepción de cuerpo socialmente construido, articulado necesariamente a un sujeto, que se constituye en el orden de lo cultural y lo simbólico, y no de la naturaleza. Esa forma de pensar a la EF, constituye lo

\footnotetext{
${ }^{15}$ Para profundizar sobre la creación e ideario de la carrera de EF en la Universidad Nacional de Tucumán, ver González de Álvarez (2012), La educación física en Latinoamérica. Orígenes y trayectorias de la formación de profesores, particularmente el capítulo "Instituto de Educación Física de la Universidad Nacional de Tucumán. La institución universitaria argentina abre las puertas a la formación del profesorado de Educación Física" (pp. 128-162).

16 Tanto el congreso como la revista fueron dos políticas académicas de producción y divulgación científica desarrolladas por esta comunidad para el período 1992-2004. El primer congreso fue en el año 1993 y la revista se edita en 1995. Ambos proyectos llevan por nombre "Congreso Educación Física y Ciencia" y "Revista Educación Física y Ciencia".
} 
que se ha dado en llamar "educación corporal", y formó parte de las discusiones del proceso de cambio curricular en el período seleccionado para esta tesis. ${ }^{17}$

En el ámbito local hemos relevado un trabajo de Carlos Carballo (2010) quien destaca el fuerte y sostenido crecimiento que viene experimentando la Educación Física académica, como campo laboral y de saber específico a partir de la década del ' 90 . Algunas investigaciones específicas vinculan dicho impulso al $\mathrm{PI}$, que formó parte de la agenda de reformas de la Educación Superior en el período analizado. Dicho impulso tuvo que ver con varios procesos en paralelo: la acreditación de proyectos y sucesiva consolidación y creación de equipos de investigación, el fomento al posgrado, la formación de recursos a nivel nacional, y la consolidación de la sede de La Plata como referente de producción teórica (Macario, 2007; Levoratti y Macario, 2013).

En los trabajos reseñados puede reconocerse -aunque con distintos recortes, alcances y enfoques- que esta nueva carrera tenía un conjunto de características que la distinguían de la EF universitaria en Tucumán y de la formación en los institutos superiores. Sin embargo, cabe destacar que la mayoría de estos trabajos se centran específicamente en el período fundacional de la mencionada carrera o en la apropiación de ese legado en tiempos más actuales, siendo escasos los estudios sobre la EF en la UNLP a partir de los años 1990. La tesis de Villa (2003) es el antecedente más cercano en este sentido, dado que comparte un lapso del contexto histórico-temporal de esta tesis. Más allá de este trabajo, sólo encontramos algunos artículos que abordan aspectos como las concepciones disciplinares en el último plan de estudios 2000 de la carrera (Giles, 2012; Giles, Mamonde y Simoy, 2012; Vallina y Rodríguez, 2015) y en tres casos (dos artículos y una tesis de grado) sobre la investigación en EF (Carballo, 2009; Levoratti y Macario, 2013; Macario, 2007). Si bien se reconoce la producción académica sobre EF en la UNLP en el período de nuestro estudio, cabe señalar que esta investigación se propone explorar dimensiones en las que estos estudios no han recalado, como el proceso de legitimación disciplinar entre los años 1992 y 2004, desde un enfoque centrado en los actores, trayectorias, políticas y estrategias académicas desplegadas en ese recorte temporal.

\footnotetext{
${ }^{17}$ En el capítulo 3 de esta tesis se profundiza en el análisis de las políticas mencionadas (Congreso, Revista, reforma curricular, entre otras).
} 


\section{Propósito general de la investigación y objetivos específicos}

La investigación se propuso como objetivo general analizar y comprender el proceso de legitimación disciplinar de la Educación Física en la UNLP, a partir del desarrollo de políticas académicas y estrategias ligadas a la revisión curricular, la formación académica y la producción científica entre los años 1992 y 2004.

Los objetivos específicos de nuestro trabajo fueron:

-Reconstruir el problema de la pertinencia y legitimidad académica y disciplinar de la Educación Física en la UNLP en la creación de la carrera en el año 1953 y sus manifestaciones en el período 1992-2004.

-Reconocer y analizar las políticas académicas y estrategias ligadas a la revisión curricular, la formación académica y la producción científica desarrolladas por los universitarios de EF en el período 1992-2004, así como las valoraciones que estos actores realizan en torno a sus procesos y resultados.

-Identificar las trayectorias, rasgos identitarios, prácticas académicas y redes de relaciones sociales de los universitarios que participaron de las políticas académicas y estrategias mencionadas en el objetivo anterior.

-Analizar las formas de apropiación, resignificación y/o resistencia que los universitarios de EF objeto de estudio realizaron respecto de las políticas educativas de los '90 y su incidencia en la legitimación disciplinar de la EF en la UNLP.

-Reconstruir los acuerdos, desacuerdos, tensiones y disputas ligados al proceso de legitimación disciplinar de la EF en la FaHCE, desplegados entre los años 1992-2004.

Además, elaboramos algunas preguntas que orientaron la investigación:

¿Cuáles fueron las políticas académicas ligadas a la revisión curricular, la formación académica y la producción científica en EF de la UNLP desarrolladas entre los años 1992 y 2004 ? ¿Cuáles sus motivaciones, objetivos y dificultades? ¿Cuáles fueron los cambios que esas políticas introdujeron en la EF de la UNLP y cuál su incidencia en las políticas y estrategias que los universitarios de EF impulsaron desde el gobierno universitario?

¿Quiénes fueron los actores que participaron de las políticas académicas de EF en la UNLP arriba mencionadas a partir de la década del 90 y en los primeros años del 
2000? ¿Cuáles fueron sus trayectorias, formas de sociabilidad y redes de relaciones que favorecieron su participación en esas políticas?

¿Qué perspectivas construyeron los actores que participaron de las políticas académicas de EF en la UNLP acerca de esas políticas y las discusiones disciplinares para el período 1992-2004?

¿Cómo se definen a sí mismos los universitarios de EF? ¿Cómo son definidos por docentes, graduados y estudiantes de otras carreras y disciplinas de la FaHCE?

¿Cuáles fueron las estrategias que desplegaron los universitarios de EF para legitimarse institucionalmente? ¿En qué medida esas estrategias se relacionaron con los criterios de legitimidad institucionales? ¿Cómo son percibidas esas estrategias de legitimación por los universitarios de otras disciplinas? ¿Cuáles fueron los acuerdos, tensiones, controversias y conflictos ligados al proceso de legitimación disciplinar de los universitarios de EF de la UNLP suscitados entre los años 1992-2004?

\section{Perspectivas teóricas de la investigación}

El territorio teórico seleccionado para la presente investigación, se construye desde una perspectiva heterodoxa, y se nutre de enfoques disciplinares y metodológicos diversos, provenientes de los estudios sobre Educación Superior, la Historia, la Antropología Social, la Sociología de la Cultura y la Pedagogía.

En primer lugar, ubicamos a nuestro problema de investigación dentro del campo de estudios de la educación superior (Krotsch, 2001; Krotsch y Suasnábar, 2002), y desde allí recogemos los aportes que en ese campo han realizado los enfoques organizacionales (Clark, 1983, 1998, 2011; Peterson, 2007) y la sociología de la cultura (Becher, 2001; Bourdieu, 1990, 2000, 2008). Específicamente, nos permitieron entender a la universidad como un campo social con reglas propias, y el rol activo de los académicos en la construcción de su ambiente de trabajo y su capacidad de incidencia en el medio externo, asumiendo que la organización del trabajo en este campo va cimentando fidelidades, lealtades, opciones éticas, posicionamientos ideológicos, actitudes corporativas, que intervienen en el procesamiento de los cambios.

De los enfoques organizacionales en particular, retomamos el concepto de universidad como organización compleja (Clark, 1983) con distintos perfiles de autoridad, que se organiza en función de una síntesis no exenta de conflictos entre los distintos aportes e intereses que hacen los grupos particulares que la conforman. La literatura 
especializada refiere a esta organización como una "anarquía organizada" de "acoplamiento laxo" (Krotsch, 2001).

En relación al procesamiento de los cambios en la universidad, esta perspectiva nos permite comprender tanto la dinámica que adopta esta organización, como las estrategias que los actores desarrollan a partir de posiciones que asumen en función de la distribución de poder relativo de sus agentes. En relación a este punto, también nos valemos de las formas de crecimiento institucional que desarrolla este enfoque. Al respecto, Clark (1998) señala que las instituciones tienen dos modalidades de crecimiento: reactivo y sustantivo. El primero, definido fundamentalmente por el crecimiento matricular de una institución o carrera o la propia fundación de una carrera (es decir, a partir de demandas exógenas), y el segundo, el crecimiento que deviene de la producción de conocimiento.

Una categoría central para nuestra investigación es la de políticas universitarias y académicas. Siguiendo a Camou (2002) diferenciamos entre políticas universitarias y políticas académicas, entendiendo que las primeras hacen referencia a la toma de decisiones emanadas desde las autoridades gubernamentales para el sector, y las segundas, a iniciativas de los órganos de gobierno o autoridades de una universidad, facultad, departamento o asociaciones institucionales, es decir, las construidas desde la "base del sistema" (Clark, 1983). Estas políticas, en términos generales, son aquellas seleccionadas para la tesis: de revisión curricular, de formación académica y de producción científica.

En cuanto a los estudios de la sociología de la cultura, desde la perspectiva de Bourdieu (2008), el campo universitario guarda una lógica y estructura análoga al campo del poder, en la medida en que es un espacio de relaciones de diferenciación que reproduce las dinámicas y posiciones propias de aquel. Serán retomadas de Bourdieu aquellas nociones que permitan reconstruir las determinaciones sociales en el acceso a posiciones ocupadas por los universitarios en estudio en el campo institucional y de la EF en la FaHCE/UNLP: su capital cultural y social heredados, capital académico, de poder universitario, poder y prestigio científico, notoriedad intelectual, poder político y las disposiciones políticas en sentido amplio (Bourdieu, 2008: 60).

Recuperamos los estudios sobre profesión académica de Becher (2001) y aquellos que abordan sus rasgos específicos para el caso argentino (García de Fanelli, 2009; Marquina, 2013). La noción de campos de conocimiento de Becher resulta potente para dar cuenta de las formas en que las disciplinas contribuyen a la formación de una 
profesión académica. El autor propone estudiar a esta profesión en su diversidad y plantea la relación entre los aspectos epistemológicos y sociales de una disciplina, como las formas de conocimiento, los patrones intelectuales y códigos de conducta, aunque también existan dentro de cada una variaciones o "segmentos". Según Becher, las disciplinas académicas son una combinación entre formas de conocimiento y agrupamientos sociales, que implican un conjunto de aspectos como la existencia de departamentos con cierta autonomía en las instituciones, aunque esto no garantice per se la constitución de una disciplina. Es por ello que a una estructura organizativa independiente, deben agregarse aspectos como la credibilidad académica y el prestigio. En este sentido, algunos elementos que evidencian la existencia de una disciplina tienen que ver con la conformación de una comunidad de pertenencia, redes de comunicación, al menos una tradición, una modalidad de investigación, una estructura conceptual, entre otros.

Según el autor, el reconocimiento es un factor decisivo en el mundo académico, y si bien los criterios de ese reconocimiento pueden variar en distintos campos disciplinares y contextos sociales, en general está asociado a obtener una "buena reputación" hacia dentro del propio campo a través del aporte en la investigación, fundamentalmente mediante publicaciones (Becher, 2001) o al "deseo de renombre" en palabras de Bourdieu (2008).

La oposición planteada por Bourdieu entre el capital académico y el capital intelectual de los profesores, semejante a la diferencia entre el poder y el prestigio, puede entrar en diálogo con la construcción de liderazgos y perfiles de autoridad en la vida universitaria, planteadas por Becher y Clark. Para Becher (2001), allí se constituyen dos tipos generales de liderazgo, el organizativo y el intelectual. El primero podría entenderse como figuras que tienen una destreza mayor para la articulación política, obtención de recursos, organización de espacios e infraestructura, aunque podríamos decir más lábil y transitorio; y el último, representado en figuras reconocidas en el ámbito de la docencia y, más aún, que ostentan un desarrollo mayor de la investigación, traducida fundamentalmente en la producción científica y publicación de resultados, otorgándole a este liderazgo un carácter más estable. Estos liderazgos se asientan sobre todo en el reconocimiento del grupo de pares, pero se ha demostrado que exceden los aspectos intelectuales, entrando en juego aspectos personales y sociales -relaciones de afinidad, enemistad, devolución de favores, competencia, etc.-. Por otro lado, y retomando la idea de campo universitario, analizamos cómo se dan en este caso, las oposiciones 
planteadas por Bourdieu (2008) entre autonomía y heteronomía, mirando la relación de la EF con otros campos disciplinares y con el campo político más general, y entre ortodoxia y herejía para entender el comportamiento de los universitarios ante situaciones de cambio e innovación en sus paradigmas disciplinares o en su proyecto de formación, entre otros eventos críticos.

Las perspectivas puestas en juego hasta aquí, nos advirtieron acerca de que no siempre los sucesos de orden macro-social nos permiten explicar o comprender cómo se producen los cambios a nivel micro-social, sustentados en intereses, valores y creencias difícilmente aprehensibles desde lecturas más estructurales. En este sentido, rescatamos la potencialidad de la perspectiva teórico-metodológica que ofrece el análisis a escala micro-social propuesta por Revel (2005). Perspectiva consistente con el desarrollo de pesquisas que puedan atender a dimensiones sociales reducidas, centradas en la trayectoria de individuos y grupos, en el marco de un determinado espacio social y, en consecuencia, en las acciones de un número limitado de actores. De este modo, el análisis de individuos y grupos en procesos de "contextualización múltiple" (2005: 53) y que se mueven en distintos ámbitos (cátedras, oficinas del Estado, posgrados, grupos informales de estudio, agrupamientos políticos) (Neiburg y Plotkin, 2004), así como la reconstrucción de sus trayectorias académicas, resultan piezas fundamentales para comprender su acceso a posiciones institucionales como miembros del gobierno universitario, la configuración de lealtades políticas, de perspectivas disciplinares con relación a la formación de los estudiantes, y su participación en el diseño de estrategias y el procesamiento local de determinadas políticas estatales. Entendemos que en esas redes de relaciones se construyen compromisos morales y políticos, proyectos institucionales, se mantienen relaciones de competencia, colaboración, conflicto, entre otras, se comparten sentidos, se establecen acuerdos y alianzas, y que esta dimensión social resulta clave para interpretar cómo luego estos actores construyeron estrategias con diversos fines y sus formas de procesamiento de las políticas, en qué medida las resignificaron, si se apropiaron de ellas o no, y de qué modos.

En suma, dicha perspectiva nos permitió conectar dos dimensiones de análisis que atraviesan la tesis: por un lado, el análisis de las políticas seleccionadas, su apropiación, resignificación y/o resistencia, así como la fase más productiva de los agentes en la generación de políticas y estrategias académicas y, por otro lado, la ubicación y comprensión de esos actores en el marco de trayectorias profesionales, 
académicas, políticas e intelectuales, y de redes de relaciones sociales que exceden al tiempo presente.

En una línea similar, y reconociendo la importancia de investigaciones que retoman la orientación de las políticas públicas para la ES del período y su procesamiento por parte de los actores objeto de estudio, así como de aquellas que describen los rasgos del ideario social de la época, también consideramos que las acciones de esos actores no pueden explicarse sólo en referencia a un contexto general, unificado y monolítico, sino que debemos rastrear la pluralidad de contextos sociales en los que estos actores se inscriben y por medio de los cuales construyen y dan sentido al mundo. Es por ello que destacamos las categorías y métodos que nos aportaron pesquisas desarrolladas por antropólogos/as sociales, historiadores/as y pedagogos/as preocupados/as por el estudio de las perspectivas y experiencias sobre la política y usos cotidianos de determinados actores y grupos sociales (Caldo y Fernández, 2012; Carrera, 2014; Frederic y Soprano, 2009; Garatte, 2008, 2012; Garatte y García Clúa, 2013; Guber, 2001a; Soprano, 2011). A partir de estas líneas de investigación, reconocemos la importancia de identificar los ámbitos y formas específicas de sociabilidad de un grupo de académicos elegidos para este trabajo, sus identidades políticas, los vínculos de amistad y camaradería en las redes de relaciones cotidianas de las que participaron, los compromisos académicos y morales que se fueron cimentando en esos entramados sociales, y que les han permitido acceder a posiciones influyentes en el plano disciplinar e institucional. De aquí que, sin ninguna pretensión de generalización, el estudio que emprendemos intenta mejorar nuestra comprensión situacional de unas ciertas formas de sociabilidad de un grupo acotado de universitarios, los académicos que participaron de las políticas y estrategias académicas de EF en la FaHCE-UNLP durante el período 1992-2004, tanto dentro como fuera de la institución universitaria. En este último caso consideramos todas aquellas relaciones y prácticas que guardan poder explicativo sobre algún conflicto suscitado a nivel disciplinar o institucional, o que han tenido eficacia social para la ocupación de posiciones o la definición de políticas académicas.

Retomamos el concepto de prácticas académicas (Carrera, 2014; Rocha Pinto, $2000,2009)$ que nos permite pensar en todas aquellas prácticas que se sostienen en el marco de un sistema de relaciones sociales, que dan lugar a ciertas acciones e interacciones en el campo académico. Concebidas de este modo, las prácticas académicas exceden el ámbito de la enseñanza, e involucran relaciones institucionales, interpersonales, espaciales, en las que nosotros nos detendremos. Las formas de 
comunicación de la comunidad en estudio, el modo en que se reconocen, los elementos por los cuales el resto de la comunidad institucional los identifica, el sentido de sus acciones y códigos, el modo en que interactúan con otros académicos de otras disciplinas, los objetos que utilizan (ropa deportiva, accesorios y elementos para el juego, el deporte, la gimnasia, etc.), los atributos con los que se caracterizan (habilidades, cualidades, prácticas del oficio), las narrativas que construyen y por medio de las cuales se sostienen y justifican, entre otras, conforma el mundo de las prácticas académicas de esta comunidad. Este concepto se complementa con el de sociabilidad ya desarrollado, y nos permite dar cuenta de todas aquellas prácticas e intercambios que hacen a la vida cotidiana de las universidades, adquiriendo características específicas en cada disciplina, con identidades académicas y profesionales que las atraviesan.

Del enfoque pedagógico consideramos los aportes de De Alba (1998) para el estudio de políticas de cambio curricular, entendidas como procesos conflictivos, donde entran en juego relaciones de poder, y en donde el curriculum es el resultado de un proceso complejo. La potencialidad del estudio de procesos de cambio curricular alude a su condición de situación social en donde los académicos entran en un particular clima de conflicto, eficaz para estudiar la dinámica de relaciones de poder entre individuos y grupos con intereses encontrados, las visiones y perspectivas que distintos actores sostienen acerca de la carrera y la disciplina, y las estrategias y prácticas que despliegan para incidir en la formación de sus estudiantes, entre otros aspectos. Dentro de este enfoque, consideramos también investigaciones "de" y "en" la universidad (Remedi, 2013) que miran a los sujetos universitarios en sus prácticas y cómo construyen sus espacios cotidianos. Para Remedi (2004), la institución es entendida en una triple dimensión intertextual o "entrecruzamiento de textos": la institución como historia vivida, expresada en una trama argumental que la sostiene; la cultura institucional en su manifestación como institución de vida (prácticas situadas); y la cultura experiencial, conformada por los sujetos institucionales, sus trayectorias y prácticas expresivas (2004: 27). Institución que en tanto sistema cultural con reglas y valores propios, tiene para los sujetos una existencia imaginaria y simbólica, y que es constituyente de su identidad, es decir, es un lugar de "identificación", aunque inestable. En esa conferencia en donde analiza particularmente estas expresiones en el ámbito institucional universitario, Remedi (2013), retomando a Enriquez (1993), considera a la universidad como "institución de vida", en la medida en que allí sus protagonistas transitan su existencia, sufren, se alegran, se comprometen en tareas y proyectos, establecen relaciones de amistad, pareja, militancia; 
es decir, no se constituye como un mero espacio de trabajo, sino y necesariamente, como espacio de construcción de identidad para estos actores. Un núcleo de estas investigaciones indaga acerca de la institucionalización de disciplinas e identidades académicas, a partir del entrecruzamiento de variables como la conflictividad institucional, la trayectoria de los académicos, las identidades disciplinares y profesionales, los proyectos y variaciones curriculares, en vinculación con procesos políticos nacionales y locales (Coria, 2015; Landesmann, 2006; Remedi, 2004, 2006, 2013). Una de las potencialidades de estos estudios reside en entender los fenómenos que suceden en la universidad como hechos de sentido, es decir, como espacio de lucha simbólica. El elemento de estas investigaciones que reviste particular interés para nuestro trabajo es la relación que se construye entre los sujetos y la institución. Así, se comprende que los sujetos están de modo particular y heterogéneo afectados por normas, regulaciones y valores que posibilitan o limitan el desarrollo de prácticas, sean éstas de carácter dominante o emergente, es decir, que tiendan a reproducir los modos de hacer legítimos o a subvertir el orden institucional, aunque siempre en diálogo o en respuesta a esa forma institucional. Los procesos de institucionalización que estos autores trabajan hacen especial referencia a este aspecto, ya que aluden a procesos de legitimación de prácticas, formalizadas o no en documentos o normativas, que tienen un poder de regulación no menor en el accionar de los sujetos. De este modo, los enfoques y categorías puestas en juego hasta aquí nos permitirán relacionar las trayectorias académicas de estos actores, el campo institucional universitario en el que se reúnen y actúan y la disciplina académica en la que se inscriben, dimensiones todas atravesadas, aunque de modo cambiante y diverso, por el campo político. Por otro lado, y en función que esta tesis se propone, entre otros objetivos, relevar la perspectiva de los actores acerca del proceso de legitimación de la EF en la FaHCE en un particular momento histórico, la puesta en relación de las trayectorias académicas de estos actores permitirá dilucidar diferentes modos de apropiación del entramado sociopolítico cultural que los contiene (Coria: 217 en Remedi, 2004). 


\section{Consideraciones metodológicas}

El diseño de la investigación se construyó desde una estrategia de estudio de caso de tipo instrumental único (Stake, 1995). Es decir, se eligió el caso porque permitió analizar el proceso de legitimación de una disciplina de orientación profesionalista en la universidad, y las dinámicas que se generan al interior de la institución y comunidad en dicho proceso. No obstante, el caso en sí mismo es paradigmático ya que la EF de la UNLP se constituyó, en el período de nuestro estudio, en una referencia nacional que merece ser estudiada. Esta decisión metodológica supuso adentrarse en el conocimiento de lo particular, de lo idiosincrásico (Stake, 1995) de ese proceso y de los universitarios que, en calidad de docentes, graduados y estudiantes, desarrollaron políticas y estrategias disciplinares desde el año 1992 al 2004, atendiendo a los diferentes planos del escenario institucional (UNLP-FaHCE-DEF) ${ }^{18}$. El tipo de estudio diseñado apela a que los hallazgos obtenidos puedan constituir un aporte para analizar procesos similares en otras carreras, disciplinas e instituciones, es decir, posibilitar una "generalización analítica" a partir del caso (Yin, 1989).

La metodología combinó una variedad de recursos y técnicas, entre las que se destacó el trabajo con fuentes primarias, a través de la realización de entrevistas semiestructuradas a informantes clave de EF y de otras disciplinas con la finalidad de reconstruir el proceso de legitimación de aquella en el ámbito de la FaHCE/UNLP. Los/as entrevistados/as fueron en su mayoría docentes y graduados que cumplieron funciones como autoridad y/o gobierno en la carrera. ${ }^{19}$ También se entrevistó a funcionarios y docentes de otras disciplinas de la Facultad en el período seleccionado. Con las entrevistas se buscó reconstruir las políticas académicas en EF desarrolladas en el

\footnotetext{
${ }^{18}$ Cabe señalar aquí que los términos universitarios y académicos no son utilizados como sinónimos en todo el escrito. Por universitarios entendemos al conjunto de la comunidad universitaria: estudiantes, graduados, docentes y no docentes (estos últimos no incluidos en este estudio), y académicos, en un sentido más restringido, referido a los profesores con dedicación full time a la universidad. En las políticas y estrategias relevadas participaron (y según los diferentes momentos que se reconstruyen en la tesis) actores que cumplieron funciones en esos diferentes roles (estudiantes, graduados y profesores), y se selecciona para estudiar en profundidad a un grupo específico que tuvo un protagonismo central, decisivo en esas políticas, y que fue referenciado como tal por los actores con los que dialogamos, que devienen de universitarios en académicos en el período de nuestro estudio. Esta decisión de ningún modo podía efectuarse de antemano, es por ello que en los objetivos planteados para la investigación nos referimos a universitarios en sentido amplio, aunque luego se focalice en un grupo en el que sus integrantes se constituyen como académicos.

19 Se intentó rastrear a estudiantes que hayan actuado en las políticas académicas de EF en el período seleccionado, pero la base de información del Departamento de Enseñanza de la FaHCE sólo tenía el estado de situación académica de la persona (abandonó, egresó, etc.), y se carecía de datos personales o los mismos se encontraban desactualizados (teléfono, dirección). Hay que tener en cuenta que estamos hablando de por lo menos hace 15 años atrás. Los estudiantes en cuestión no mantienen vínculo actual con la Facultad. La participación de los estudiantes en la construcción y desarrollo de las políticas y estrategias será analizada en la tesis.
} 
período seleccionado, tendientes a legitimar el campo disciplinar en la FaHCE, así como a conocer las perspectivas de los actores que intervinieron en ellas en ese ámbito institucional. En este sentido, las entrevistas tendieron a capturar la complejidad y diversidad de interpretaciones del contexto político e institucional respecto de las posiciones asumidas en ese momento y en la actualidad, así como a aprehender las valoraciones y adscripciones construidas en el presente sobre aquellos años y del lugar de la disciplina en la institución.

A su vez, parte de este proceso de investigación contó con restricciones propias del trabajo de campo, dadas por informantes que se negaron a brindar su testimonio o que ya no se encontraban disponibles para la consulta, representando un desafío para la investigación, ya que hay perspectivas que no tienen el mismo peso que otras.

Se realizaron entrecruzamientos entre la dimensión de la trayectoria individual del sujeto y la trayectoria colectiva del grupo. Es decir, las trayectorias individuales se enmarcaron en redes más amplias de construcción de legitimidad de la EF en la FaHCE, reconstruyendo influencias, modos de hacer, relaciones, prácticas académicas, solidaridades, compromisos, disputas, que incluyen a la vez que exceden a los sujetos particulares.

Por otro lado, se trabajó con fuentes primarias, tanto en la forma de documentos institucionales (memorias de gestión, publicaciones institucionales, expedientes), departamentales (fundamentalmente, proyectos y planes de estudio), normativa (con especial interés en la LES y el Estatuto de la UNLP de 1996), resoluciones, actas de Consejo Directivo y legajos docentes, así como con fuentes secundarias en la forma de artículos y producciones académicas de los actores en estudio, entendiendo que lo que los autores dicen en sus escritos, se constituyen en testimonios y nos permiten reconstruir sus perspectivas. Tanto las entrevistas como las producciones académicas plasmadas en documentos son consideradas estrategias de construcción de un relato interesado, de "producción de sí mismo" (Bourdieu, 2011: 122, 127), en el que los entrevistados seleccionan deliberadamente acontecimientos sobre el pasado institucional y disciplinar, en un tiempo presente en el que se encuentran disputando sentidos y posiciones.

Aun formando parte del mismo ámbito institucional, la concertación de encuentros con los docentes de EF y de otras disciplinas de la institución no fue tarea sencilla, por lo cual, la posibilidad de contar con estas producciones académicas de algunos de ellos constituyó un elemento fundamental para complementar el análisis. 
Además, desde el año 2015 hasta el 2017 participé de actividades académicas como charlas, congresos, seminarios, y mantuve conversaciones informales con muchos de estos actores. La información que surgió de esas interacciones complementó la de las entrevistas y documentos.

Por último, se relevaron fuentes audiovisuales y documentos hemerográficos provenientes de diarios locales (Diario Hoy, Diario El Día) y entrevistas radiales, que sirvieron para incorporar otras fuentes de contextualización del período y del caso.

Asimismo, en cuanto a la elección metodológica de la estrategia de estudio de caso, ciertas técnicas de recolección de datos amigables con este enfoque como la entrevista semi-estructurada, permitió que la cantidad de testimonios relevados se pudieran triangular entre sí y con el análisis documental efectuado. Además, la decisión de adoptar un tipo de caso instrumental resultó provechosa para, a futuro, poder pensar otras situaciones y procesos similares en la FaHCE o en otras instituciones.

La unidad de estudio fueron las políticas y estrategias académicas ligadas a la revisión curricular, la formación académica y la producción científica desarrolladas por universitarios de EF en el período 1992-2004, para analizar el proceso de legitimación disciplinar de esa comunidad en la FaHCE -UNLP.

\section{Sobre algunas decisiones metodológicas y de escritura}

Una mención aparte merece la apelación al uso del nombre propio como una decisión crucial en esta investigación, al menos por dos cuestiones. Por un lado, y en cuanto al enfoque teórico-metodológico micro-social que asumimos en esta tesis, trabajar sobre el nombre, "la referencia más individual, la menos repetible" (Revel, 2005: 47), habilita la construcción de una historia social (en este caso, de las universidades) solidaria con el estudio de los individuos en sus relaciones con otros individuos. Es decir, en el planteamiento de Revel, el estudio de la dimensión individual no se contradice con la dimensión social ya que, "ella debe hacer posible un enfoque diferente, siguiendo el hilo de un destino particular -el de un hombre, de un grupo de hombres- y con él la multiplicidad de espacios y de tiempos, la madeja de relaciones donde se inscribe" (2005: 47). Por otro lado, el recurso del nombre propio es relevante cuando se trata de figuras públicas, que lograron un reconocimiento específico y para destacar la trascendencia de ciertas personalidades en procesos particulares, en acciones concretas, y la resonancia que adquieren en discípulos, "herederos" o en otros/as académicos/as que los colocan en 
un peldaño superior, el del "superman" de la investigación (Remedi, 2006: 79). En este sentido, "la obtención de un nombre" (Bourdieu, 2008), que deviene en la adquisición de un peso e influencia específicos, forma parte de las prácticas propias de la academia.

\section{Población y muestra:}

Se definió una muestra intencional basada en criterios o según propósitos (Patton, 1990 en Maxwell, 1996). Ésta es una estrategia en la cual escenarios particulares, personas o eventos son seleccionados deliberadamente con el fin de obtener información que no puede ser conseguida de otra forma. Teniendo en cuenta que las carreras de EF de la UNLP constituyen el escenario particular de esta investigación, seleccionamos intencionadamente a los actores de EF que participaron de manera reiterada en políticas académicas de la especialidad ligadas a la revisión curricular, la formación académica y la producción científica en la FaHCE entre los años 1992-2004, así como a otros actores institucionales de la FaHCE que han tenido un rol activo en el diseño e implementación de las políticas académicas que resultaron objeto de estudio en la tesis. Estos fueron: directores del Departamento, secretario/s, integrantes de la Junta Asesora Departamental, miembros de la Comisión Curricular, profesores, graduados, estudiantes de EF, consejeros en el Consejo Directivo de la Facultad y Superior de la Universidad, autoridades institucionales, etc. Para la selección de los actores nos basamos en el estudio de documentos como la Resolución de aprobación del último Plan de Estudios del Departamento, las Actas de Consejo Directivo del período, los expedientes y resoluciones de cargos docentes y creación de posgrados, actas de congresos, publicaciones, proyectos de investigación, y la información brindada por actores institucionales, entre otras fuentes.

Del congreso organizado por la comunidad de EF, fueron seleccionados quienes desempeñaron tareas dentro del Comité Organizador, como presidente, secretarios y prosecretarios $^{20}$.

\footnotetext{
${ }^{20}$ Nos referimos al Congreso Argentino de Educación Física y Ciencia. La organización del congreso estaba estructurada en torno a un Comité Organizador, compuesto por Presidente, Secretarios, Prosecretarios, Tesorero, Vocales (definidos por la propia comunidad de EF), y la Coordinación técnico-administrativa, Coordinación de Extensión Cultural y Coordinación de Asuntos Estudiantiles de la FaHCE. Contaba además con un Comité de Honor compuesto por personalidades destacadas de la política nacional, provincial y local de la UNLP y la FaHCE, y un Comité de Lectura, conformado por el Secretario de Investigación y Posgrado de la FaHCE, Comisión de Investigación y Posgrado de la FaHCE (compuesta por cinco consejeros académicos, tres docentes, un graduado y un estudiante), dos profesores titulares de la carrera, y los directores de departamentos de la FaHCE en la figura de Consultores.
} 
En el caso de la revista de producción académica de EF, consideramos la figura del director y comité editorial ${ }^{21}$.

De los proyectos de investigación del Programa de incentivos, seleccionamos a quienes desempeñaron tareas como director/a y codirector/a, que fueran de EF.

Esta selección de actores permitió identificar y luego profundizar en las trayectorias de sujetos que tomaron decisiones clave y orientaron las políticas de la EF en la FaHCE.

\section{Tipo de análisis}

La estrategia de análisis comprendió datos provenientes de: 1) fuentes primarias y 2) fuentes secundarias:

Análisis de fuentes primarias: El análisis de las entrevistas se orientó a caracterizar las trayectorias de los universitarios de EF en la UNLP, así como sus prácticas, estrategias y formas de sociabilidad en el período 1992-2004. Además, condujo a comprender los acuerdos, controversias y conflictos suscitados entre los actores con relación a las políticas académicas ligadas a la revisión curricular, la formación académica y la producción científica desplegadas en el período 1992-2004. Una vez obtenido el corpus empírico, se analizó la información obtenida a fin de codificar para establecer relaciones e interpretaciones. Se relacionaron las entrevistas entre sí y los documentos escritos previendo la construcción de categorías teóricas.

Análisis de fuentes secundarias: Los datos provenientes de estas fuentes fueron utilizados para contextualizar y comparar los datos obtenidos a través de las fuentes primarias, por ejemplo, en relación a las trayectorias de los académicos de EF en la UNLP y las políticas académicas ligadas a la revisión curricular, la formación académica y la producción científica desarrolladas en el período estudiado. Asimismo analizamos la información relevada, a través de la inmersión en los datos, su reducción y organización según el tipo de política seleccionada o estrategia relevada. Este tipo de fuentes posibilitó el análisis de las políticas académicas en EF de la UNLP llevadas adelante en el período 1992-2004 y la relación entre la normativa nacional, institucional y su apropiación en la

\footnotetext{
${ }^{21}$ Hacemos alusión a la Revista Educación Física y Ciencia, también desarrollada en el período en estudio. Esta Revista se organizaba en torno a un "Staff", compuesto por la figura de un director, comité editorial, diseño y diagramación, diseño de tapa, asesor legal y colaboradores. Para el volumen №5, del año 2001, se incorporó un Comité Asesor, conformado por profesores de EF locales y del exterior, y por profesores de otras disciplinas de la facultad, que actuaban como evaluadores de los trabajos presentados.
} 
EF de la UNLP. Es decir que, para contextualizar el caso, se utilizaron además de las entrevistas, otras fuentes primarias.

\section{Estructura de la tesis}

La tesis está compuesta por tres capítulos, un apartado de conclusiones finales y un anexo donde se presentan las fuentes documentales consultadas, las producidas durante el trabajo de campo y las entrevistas realizadas.

El primer capítulo retoma uno de los objetivos de la investigación, en tanto reconstruye históricamente el problema de la pertinencia y legitimidad de la carrera de EF en la FaHCE/UNLP. Para ello, se reconstruye la trayectoria social y académica de la disciplina desde su creación como asignatura escolar, los inicios en la formación de profesionales en la especialidad, y su expresión en el ámbito universitario en las dos primeras carreras creadas en los años 1950, en la UNT y la UNLP. Identificamos sus perspectivas disciplinares, sus principales fuentes de legitimidad en términos de conocimiento, las figuras fundadoras, orientaciones y estructuras institucionales. Luego, nos detenemos a analizar el escenario en el que se desarrolla la mayor parte de la tesis: la carrera de EF de La Plata. Allí distinguimos su matriz de formación, actores protagonistas y reconstruimos los principales posicionamientos acerca de su pertinencia y legitimidad. Sobre el final, recuperamos el itinerario profesional, académico e intelectual del denominado "fundador" de la carrera, Alejandro Joaquín Amavet, para comprender esa matriz específica y las significaciones más actuales sobre su figura y su accionar en académicos consolidados.

En el capítulo dos, emprendemos un análisis de la configuración social y política de un grupo de académicos de EF que cumplieron funciones como autoridad y/o gobierno de la carrera en un período de mediano plazo comprendido entre 1984 y 2004, para comprender la ocupación de posiciones a nivel del DEF y de la FaHCE, y la construcción de perspectivas y orientaciones político-académicas. Allí, identificamos liderazgos y perfiles de autoridad que se fueron constituyendo desde la creación de la carrera en 1953 hasta el período de nuestro estudio. Por otra parte, describimos el contenido y analizamos prácticas, estrategias, trayectorias, redes y formas de sociabilidad características del grupo seleccionado, así como procesos de refundación de la carrera que acompañan a las diferentes gestiones al frente del DEF. 
En el capítulo tres, reconstruimos y analizamos un conjunto de políticas y estrategias académicas desarrolladas por el grupo de profesores de EF descripto en el capítulo anterior, y su incidencia en la legitimación de la disciplina en la FaHCE. Para ello, se identifican tanto políticas nacionales e institucionales, como políticas y estrategias académicas diseñadas por la comunidad estudiada. En la reconstrucción realizada, identificamos una etapa prolífica en cuanto al desarrollo de iniciativas de fuerte repercusión para la EF de la UNLP, como fueron el congreso Educación Física y Ciencia, la Revista Educación Física y Ciencia, las primeras investigaciones formales en el marco del Programa de Incentivos a los docentes-investigadores, y la reforma curricular de los años '90, que dio lugar a una nueva propuesta formativa y a la inclusión de una carrera de licenciatura en la especialidad. En este sentido, incluimos además, el análisis de la discusión de esa reforma en el marco del Consejo Académico de la FaHCE, e identificamos posicionamientos y disputas de orden disciplinar, epistemológico y político tanto de actores de la propia disciplina como de otras disciplinas. En este abordaje, analizamos el procesamiento de dichas políticas y estrategias a partir de las perspectivas de los actores institucionales que participaron en su elaboración, los cuales adoptaron concepciones singulares en un marco institucional específico. Además, y en línea con otro de los objetivos, indagamos acerca de los acuerdos, desacuerdos, tensiones y disputas suscitados entre los actores o grupos en relación con esas políticas, sus objetivos, alcances y valoraciones.

Por último, las conclusiones finales se constituyen en una síntesis de los principales hallazgos obtenidos y su discusión en relación con los enfoques teóricos y metodológicos seleccionados, así como la apertura de líneas prospectivas de la investigación. 


\section{CAPITULO 1}

\section{La institucionalización y legitimación de los estudios universitarios en Educación Física (1953-1983)}

\section{Presentación}

En este primer capítulo presentamos una reconstrucción histórica de la institucionalización universitaria de la Educación Física (EF) en Argentina a partir de la década de 1950. Para ello, en un inicio, retomamos los orígenes de las carreras de EF en el marco de dos universidades nacionales tradicionales ${ }^{22}$ como La Plata y Tucumán, sus rasgos salientes, actores principales en la "saga fundacional" y perfiles de formación, para luego detenernos en la carrera de EF de la UNLP, a partir del análisis del contexto de surgimiento de la carrera en 1953, los debates sobre su creación y la orientación que la formación fue asumiendo. De sus comienzos, puntualizaremos las posiciones y debates presentes en el acta fundacional de la carrera, y el problema de su pertinencia, relevancia y legitimidad. Esta reconstrucción nos permitirá comprender cómo fue procesado ese problema en la FaHCE en el contexto de creación de la carrera en la década del '50 y las vinculaciones de esos debates con el escenario de discusiones durante nuestro período de estudio, 1992-2004.

En el primer apartado, analizamos algunas características de la EF y el derrotero de creación de instituciones de formación superior en EF, que devienen en dos perspectivas contrapuestas sobre la disciplina. En el segundo apartado, puntualizamos en las primeras experiencias de carácter universitario emplazadas en la UNT y la UNLP. Indagamos en el contexto de creación de ambas carreras, así como también analizamos los rasgos que asumió la formación en esas universidades. En el tercero, nos detenemos en el caso que nos ocupa: la EF en la FaHCE/UNLP, mediante el análisis de documentos ligados a la creación de la carrera y entrevistas a docentes que fueron estudiantes en esos años. En el cuarto apartado, identificamos y profundizamos en la trayectoria profesional y académica del primer Director de la carrera, Alejandro Joaquín Amavet, para poder introducirnos en las concepciones y preocupaciones de la época, y en las

\footnotetext{
22 Son consideradas tradicionales y según su año de creación: la Universidad Nacional de Córdoba (1613), la Universidad de Buenos Aires (1821), la Universidad Nacional de La Plata (1905), la Universidad Nacional del Litoral (1919) y la Universidad Nacional de Tucumán (1921). Estas cinco instituciones, aún con orientaciones y proyectos institucionales diversos, forman parte de la primera ola de creación de universidades nacionales en el país, y acaparan la mayoría de la población estudiantil (Buchbinder, 2005; Krotsch, 2001).
} 
marcas distintivas de la EF en la UNLP. Esta caracterización nos permitirá luego reconstruir las filiaciones y diálogos que se desarrollaron entre la matriz fundante de la carrera y las orientaciones que asumió la misma en períodos posteriores a su creación. En el quinto apartado, retomamos qué aspectos de la cuestión de la pertinencia y legitimidad de la EF en la FaHCE son problematizados en los años posteriores al alejamiento y posterior fallecimiento de Amavet. Por último, presentamos las conclusiones de este capítulo que recogen las principales discusiones y conceptualizaciones sobre la institucionalización y legitimación de la EF en la UNLP en el contexto histórico de su creación y en la inmediata recuperación democrática.

\section{La formación profesional en Educación Física a partir de su configuración como disciplina escolar a comienzos del siglo $\mathrm{XX}$}

En nuestro país, la formación profesional en EF surgió a comienzos del siglo XX y estuvo orientada centralmente a la provisión de docentes para el sistema educativo nacional. La formación universitaria, en cambio, se instaló recién a mediados del mismo siglo. La primera institución formadora fue la Escuela de Gimnasia y Esgrima del Ejército, creada en 1897 (en adelante, la Escuela). Llamada inicialmente "Escuela Militar de Esgrima", estaba destinada exclusivamente a miembros de la corporación militar (Galak, 2012b). Su contenido estaba centrado en la enseñanza de la Esgrima, con la función de ser aprendida por los oficiales, no así para ser enseñada. En 1901 se modificó su nombre por "Escuela de Gimnasia y Esgrima", se incorporó la Gimnasia como contenido, se abrió la inscripción a estudiantes civiles, y en 1905 se modificó el título que expedía por el de "Maestro de Gimnasia y Esgrima" (Galak, 2012b). La Gimnasia transmitida por la Escuela combinó elementos de las corrientes alemana e italiana. De la primera sobresale la influencia del programa de Jahn, que utilizaba grandes aparatos y depositaba en el movimiento corporal un ideal de belleza, virilidad y patriotismo; y de la segunda, proveniente de los esgrimistas italianos que llegaron al país a fines del siglo XIX, se destaca que se abocaba centralmente a la formación del carácter (Galak, 2012b: 60).

A diferencia de la anterior, la segunda institución de formación de profesores en EF que se creó en el país perteneció al ámbito civil: el Instituto Nacional Superior de Educación Física fue creado en 1912 (en adelante, INEF). El referente principal en esta creación fue Enrique Romero Brest, un joven médico egresado de la UBA, que mantenía relaciones con funcionarios del Consejo Nacional de Educación de fines del siglo XIX y 
primeros años del XX (entre ellos, el inspector Pablo Pizzurno). ${ }^{23}$ Los antecedentes del INEF fueron una serie de cursos temporarios dictados a maestros normales en los primeros años del siglo $\mathrm{XX}$, y tanto éstos como el propio Instituto buscaban una EF distintiva de la formación militar. Esta corriente es denominada por algunos analistas como "cívico-pedagógica", y se fundamentó en la Fisiología para la búsqueda de una EF racional, metódica, natural y placentera (Galak, 2012b). Señalaba Romero Brest que "la aplicación racional de la cultura física debe basarse forzosamente en la Fisiología en primer lugar (...)" (Romero Brest, 1917: 75). Aquí advertimos un primer atisbo de la estrecha relación entre la EF y las corrientes fisiologistas que efectuaron la "reforma de la gimnástica" en la segunda mitad del siglo XIX en Europa Continental (Crisorio, 2007), que dieron origen a la Educación Física y de las que se extrajeron los argumentos para fundamentar la misma a nivel local.

Hasta la creación del INEF en 1912, y por disposición ministerial, el sistema educativo de nuestro país se nutría de los egresados de la Escuela, así como de especialistas extranjeros y aficionados deportistas para la enseñanza de la EF. Unos años más tarde, y a partir de los cursos temporarios que se dictaban en las recientes Escuelas Normales creadas, como vimos, también enseñaban EF los graduados de esas instituciones, mayoritariamente mujeres, las "maestras normales".

Varios autores (Galak, 2012a, 2012b; Galak y Simoy, 2015; Scharagrodsky, 2011) identifican a la Escuela y el INEF de Romero Brest con dos concepciones distintas y en disputa por la hegemonía del campo de la EF en el primer cuarto del siglo XX. ${ }^{24}$

Los años '30 en la Argentina representan una etapa dinámica en la definición de políticas educativas vinculadas a la EF. El gobierno de facto, de carácter conservador ${ }^{25}$, realizó un diagnóstico sobre la dirección que estaba asumiendo la EF y la formación de profesores. Como resultado y para solucionar la ausencia de unidad metodológica en su enseñanza que derivaba de la existencia de las dos concepciones diferenciadas que describimos antes, se creó la Dirección General de EF. Ese organismo se anexaría al ya existente Consejo Nacional de EF que funcionaba desde 1937, y se ocuparía de

\footnotetext{
${ }^{23}$ Para una mayor referencia sobre la vida, obra y trayectoria de Enrique Romero Brest (1873-1958) ver Galak, 2012b; Scharagrodsky, 2006.

${ }^{24}$ Un análisis del sentido y objetivos que asumió esta disputa a comienzos del siglo XX puede encontrarse en Galak, 2012b. Un elemento central en esta contienda lo constituyó el proyecto de ley sobre "batallones escolares" de 1908. Si bien este proyecto quedó trunco, sí se implementaron luego los batallones infantiles, impregnados por el clima de fomento a lo nacional, en el marco del Centenario de la Patria.

${ }^{25}$ El golpe de Estado se suscitó el 06 de septiembre de 1930 y se extendió hasta el 04 de junio de 1943. Este golpe constituye el primero de una sucesión extensa de interrupciones del orden constitucional en la Argentina del siglo XX.
} 
centralizar y coordinar la enseñanza de la disciplina (Feiguin, Cobiella y Aisenstein, 2015).

Como parte del proyecto de gobierno mencionado, se fundó en 1939 el Instituto Nacional de Educación Física "General Manuel Belgrano", con asiento en la localidad bonaerense de San Fernando (INSF). Esta institución tenía como finalidad, entre otras, contrarrestar la primacía de las mujeres en la enseñanza de la EF (González de Álvarez, 2012). Esta feminización de la EF estaba vinculada al proceso homónimo de la docencia en general en Argentina (Morgade, 1997; Scharagrodsky, 2006). Se explica, entre otras razones, por las condiciones de admisión presentes en el INEF (poseer el título de maestro normal o bachiller), siendo las mujeres el $85 \%$ del total de las maestras normales en el primer decenio del siglo XX (Scharagrodsky, 2006). Para el año 1939, se produjo la separación definitiva entre hombres y mujeres estudiantes del profesorado (que ya habían sido "separados" en los cursos previos y en las actividades realizadas durante la formación), y todos los hombres fueron trasladados al nuevo INSF, y el INEF quedó establecido para mujeres (Scharagrodsky, 2006: 183). Las características del ideario y propuesta formativa del INSF fueron singulares: de origen civil, se configuró como internado, con becas completas para estudiantes que eran reclutados en todo el país, y con estrictas condiciones de ingreso vinculadas a las capacidades físicas individuales. Allí se formarían figuras que, desde la perspectiva de algunos de nuestros entrevistados, luego se constituyeron en referentes de la disciplina, y que en el período de recuperación democrática de los años '80 ejercerían una influencia sustantiva en el grupo de EF de la UNLP, como es el caso de Mariano Giraldes. ${ }^{26}$

\section{La Educación Física ingresa a la Universidad: itinerarios y marcas de origen en La Plata y Tucumán.}

La situación de la formación de profesores en EF permaneció sin variaciones relevantes hasta el año 1953, dado que en el mes de diciembre de ese año abrieron sus puertas las dos primeras instituciones de formación de profesores en Educación Física de carácter universitario: el 11 de diciembre se creó el Instituto de Educación Física de la Universidad Nacional de Tucumán, con la influencia del Dr. Enrique Romero Brest, y

\footnotetext{
${ }^{26}$ Mariano Giraldes, profesor de EF egresado del Instituto Superior de San Fernando, se especializó en Gimnasia Formativa, y fue el promotor de una serie de encuentros de formación en los que participaban profesores de la UNLP en la década del 80. En los próximos capítulos desarrollaremos con mayor profundidad su trayectoria e influencia en La Plata. Entrevista realizada a Ricardo Crisorio el 26 de octubre de 2015 en Ensenada.
} 
cuatro días después, el 15 de diciembre, el Instituto de Educación Física del Departamento de Educación Física de la Universidad Nacional de La Plata, dirigido por el capitán del Ejército, Alejandro Amavet (González de Álvarez, 2012).

Ambas fundaciones se dieron en el marco del segundo mandato justicialista, presidido por el general Juan Domingo Perón, en el año 1953. Algunos analistas coinciden en señalar que este gobierno le había otorgado a la actividad física y a los deportes un lugar destacado en las políticas públicas, como medio para la capacitación física y el mejoramiento de la salud, la formación del "nuevo ciudadano"27, la organización civil y comunitaria y la propaganda política. Se trataba de un modelo estatal que se planteaba el acceso de las grandes masas a la recreación y al deporte, antes restringido a sectores sociales minoritarios (Calvo Etcheverry, 1998; Mamonde, 2008; Orbuch, 2016). ${ }^{28}$

En este sentido, si bien las fundaciones de las primeras carreras de EF a nivel nacional compartieron un escenario sociopolítico similar, se distanciaron en cuanto a la estructura, influencias y orientaciones que asumieron en su matriz de formación.

Corresponde aquí señalar que la Universidad Nacional de Tucumán surgió, también como la de La Plata, como Universidad Provincial, en el año 1914, y tuvo como principal impulsor al abogado Juan Benjamín Terán ${ }^{29}$, quien ya había presentado el preproyecto a la Legislatura en 1907, siendo fuertemente resistido en el recinto y por sectores políticos de peso de la Capital Federal (Pucci, 2013) ${ }^{30}$. Su pretensión fue crear una casa de estudios influenciada por los modelos norteamericanos y europeos, diferenciada de las existentes en Buenos Aires y Córdoba, en tanto que éstas se centraban en "enseñanzas abstractas" y en estudios doctorales (ibídem). Al respecto, la UNT se propuso como una universidad experimental, con vocación científica y técnica,

\footnotetext{
${ }^{27}$ En múltiples discursos de gobierno, el propio Perón se refiere así al sujeto que necesita la "Nueva Argentina" que se pretendía refundar, con características particulares, tales como: sano, fuerte, movilizado. Un ciudadano que mediante su esfuerzo individual contribuiría al bienestar colectivo (Orbuch, 2016).

${ }^{28}$ Si bien, como dijéramos más arriba, el desarrollo de la EF es previo al ascenso del peronismo en el poder, el proceso que se inicia con la primera presidencia de Perón entre 1946 y 1952, fue el más prolífico en cuanto a la promulgación de normativas relacionadas al área (Gómez, 2006).

${ }_{29}$ Juan B. Terán (1880-1938) fue un abogado, devenido historiador y educador tucumano, Ministro de la Corte Suprema de la Nación, que perteneció al grupo de la "Generación del Centenario", Círculo intelectual perteneciente a la Sociedad Sarmiento, una entidad conformada por docentes de colegios nacionales, intelectuales del interior del país, dedicada al estudio historiográfico desde fines del siglo XIX (Vignoli y Cardozo, 2013). Terán fue Rector de la Universidad de Tucumán, entre los años 1914 y 1921 , y ya como Universidad Nacional entre 1923 y 1929 (Pucci, 2013).

${ }^{30}$ Es preciso señalar que la resistencia de Buenos Aires a la creación de la Universidad de Tucumán fue enérgica y se mantuvo desde su aprobación como Universidad Provincial en 1914 a través de campañas en los medios gráficos como el Diario La Nación, entre otras estrategias y, en su nacionalización en 1921, negándole los fondos nacionales por diez años posteriores (Pucci, 2013).
} 
que se dedicara al estudio científico de la realidad local, aunque sin abandonar los conocimientos de tipo especulativos.

La carrera de EF de la UNT se creó dentro de la Escuela Universitaria de Educación Física (E.U.D.E.F) dependiente del Instituto de Educación Física que, a su vez, dependía en forma directa del gobierno central de la Universidad Nacional de Tucumán ${ }^{31}$. Su antecedente más inmediato había sido el Departamento de EF creado en 1947, a instancias del entonces rector interventor de la UNT, Dr. Horacio R. Descole quien, desde la perspectiva de estudiosos de esta fundación, fue una figura central en su promoción y sostenimiento ${ }^{32}$. Desde la visión de algunos de nuestros entrevistados, esta experiencia tuvo algunas notas singulares:

“...Es un caso especial Tucumán, porque Tucumán es una escuela de Educación Física creada en la Universidad, pero se crea bajo los preceptos, podría decirse, del INEF de Romero Brest....Entonces el INEF es el que marca la cancha, podría decirse en términos deportivos, a Tucumán; y es más, no tenía las cursadas como teníamos nosotros por materias sino por deportes; es decir, era una copia fiel de lo que era el INEF de Buenos Aires, el Romero Brest..."33

El testimonio anterior da cuenta de cierta especificidad en la configuración institucional de la carrera en la UNT que, a juicio de Carlos Parenti (Director del Departamento de EF en la inmediata posdictadura), la diferencia del perfil asumido por la misma carrera en la UNLP.

\footnotetext{
${ }^{31}$ El 11 de diciembre de 1953 se crea el Instituto por parte del Dr. Carlos Aguilar quien, según González de Álvarez (2014), continuó los postulados del II Plan Quinquenal del peronismo. Comienza a funcionar el 02 de mayo de 1954 y su primer Director fue el Prof. José Nicolás Russo, egresado del INSF. Sobre las motivaciones que llevaron a crear la carrera de EF en la UNT señala no sólo el contexto y las perspectivas políticas de la universidad, sino la convicción en el crecimiento de la EF por parte de los principales referentes de la época (Romero Brest, por ejemplo), y las iniciativas de los primeros profesores del ya instalado Departamento de EF de la UNT. Como parte de ese contexto político, señala la Reunión de Profesores de Educación Física Sudamericana que tuvo lugar en Buenos Aires en 1950, en donde se destacó la necesidad de crear en cada universidad nacional formación de profesores en EF con "jerarquía académica" y "organización autónoma". Por otro lado, se veía a la UNT como un lugar geográficamente estratégico por su alcance e influencia en todo el Noroeste (2014: 3).

32 Horacio Descole (1910-1984) era biólogo y fue designado Rector Interventor de la UNT en dos oportunidades: entre 1946 y 1948 y 1948 y 1951 (Pucci, 2013). Se le atribuye un proyecto de reestructuración de la universidad, vinculado a la ley N ${ }^{\circ} 13031$ de 1947, que incluyó un "Sistema Educacional Residencial" por el que estaba previsto crear una Ciudad Universitaria en las sierras San Javier, denominada luego y en su honor, Horco Molle. Este proyecto se encontró muy vinculado a la creación de la carrera de EF, ya que retomó tres elementos centrales de la formación en esta disciplina presentes en el INEF y el INSF así como en otras universidades internacionales hasta la década de 1970: el contacto directo con la naturaleza, las grandes instalaciones deportivas y el sistema de "internado" con becas para los estudiantes. Por crisis políticas y económicas, este proyecto no pudo sostenerse, y a partir de 1955 los estudiantes pasaron de cursar en ese predio a plena ciudad de San Miguel de Tucumán, en la sede del Departamento de Educación Física (González de Álvarez, 2014).

${ }^{33}$ Entrevista № 1 a Carlos Parenti, realizada en La Plata el día 23 de septiembre de 2016. La trayectoria de Parenti será abordada en el capítulo 2 de la tesis.
} 
Por su parte, la Universidad Nacional de La Plata surgió como universidad provincial en 1897. Se configuró a partir del proyecto político-académico de su mentor y primer rector, Joaquín V. González. Según Buchbinder (2005) la UNLP fue la primera universidad que se constituyó a partir del diseño de un proyecto institucional ${ }^{34}$.

La Facultad de Humanidades y Ciencias de la Educación (FaHCE) de la UNLP surgió en 1914, de la mano de Víctor Mercante, y tuvo como antecedente institucional la Sección Pedagógica de la Facultad de Ciencias Jurídicas y Sociales, creada en 1906. En 1909 se configuró además la Sección de Filosofía, Historia y Letras. La primera denominación que tuvo la institución fue la de Facultad de Ciencias de la Educación en 1914. Luego, en 1920, incluyó en su denominación el término Humanidades, para pasar a llamarse "Facultad de Humanidades y Ciencias de la Educación", denominación que conserva hasta la fecha (Finocchio, 2001).

En un artículo publicado con motivo del centenario de la Revista Archivos de Ciencias de la Educación, Ana Barletta (2011) reconstruye y analiza, desde una perspectiva socio-política, las diferentes épocas de la Revista al calor de los distintos momentos de la historia y gobierno institucional de la FaHCE. Allí queda claro que, si bien en sus orígenes la Facultad se constituyó como formadora de docentes, se dieron procesos de cambio institucionales importantes que le fueron imprimiendo nuevos perfiles. Por lo pronto, la palabra "Humanidades" no estuvo desde el inicio, y su incorporación condensó un debate que se inicia en la década de 1920, de la mano del historiador -aunque abogado- Ricardo Levene (Bisso, 2009) ${ }^{35}$, en un movimiento de creciente instalación de las perspectivas antipositivistas e idealistas que cuestionaban el positivismo que había estado en el origen de los profesorados y en la concepción de

\footnotetext{
${ }^{34}$ Dicho proyecto significó un intento por distanciarse del claro perfil profesionalista que había asumido la formación universitaria argentina de fines del siglo XIX y principios del XX. Las diferencias pretendían marcarse con las dos universidades nacionales existentes, la Universidad Nacional de Córdoba (UNC) y la Universidad de Buenos Aires (UBA) -dado que a nivel territorial ya existía la Universidad Provincial de Santa Fe desde 1889, aunque la UNLP fue la tercera en ser nacionalizada-. La UNC, fundada en la época colonial, muy vinculada al clero y a los sectores políticos conservadores y la UBA, asociada al tipo de universidad napoleónica, orientada a la formación de las élites políticas rioplatenses y a dotar de los cuadros profesionales necesarios para una nación incipiente. En cambio, la UNLP asumió como propia la misión de constituirse como una universidad "nueva", de carácter moderno, científico y experimental, con una fuerte vinculación con la sociedad de la que formaba parte, a través de la función de extensión (Buchbinder, 2005).

${ }^{35}$ Ricardo Levene (1885-1959), inauguró los estudios históricos en la ciudad de La Plata y fue presidente de la UNLP entre 1932 y 1935 . Fue uno de los fundadores de la Nueva Escuela Histórica y decano de la Facultad de Ciencias de la Educación cuando en 1920 se antepuso el nombre de Humanidades, y fundador de la revista Humanidades. Fue un personaje muy relevante en la historia institucional de la FaHCE, y a quien se le atribuye el inicio del estudio científico de la disciplina histórica (Bisso, 2009). Fue nuevamente decano de la FaHCE entre 1926 y 1930, gestión durante la cual creó el Archivo Histórico de la Provincia de Buenos Aires, que lleva su nombre. También fue presidente de la Academia Nacional de Historia (UNLP, 2017, Sección "Institucional-Historia-Legados"). Simultáneamente, fue profesor de Historia en la Facultad de Filosofía y Letras de la UBA, en la cual creó en 1940 el Instituto de Sociología.
} 
Mercante. El enfoque de las Humanidades fue muy fuerte en la carrera de Historia, lo que se tradujo además en un cambio de mando en el gobierno de la institución, que pasó hacia los años '20 de la exclusividad de la carrera de Ciencias de la Educación a la de Historia, en un marco de convivencia con múltiples y diversas disciplinas. En este sentido, y a partir de la discontinuidad en la publicación de la Revista Archivos en 1919, Barletta señala que,

"el lugar exclusivo que ostentaba será reemplazado por la Revista Humanidades, que hará gala de las nuevas orientaciones promovidas desde entonces por el nuevo Decano, el historiador Ricardo Levene, llevando el nombre de la nueva Facultad. Es tal vez aquí donde se inicia el trayecto de las CE [Ciencias de la Educación] dentro de un conglomerado más amplio de disciplinas que le disputarán la conducción institucional" (2011: 21).

Según la misma referencia, en las décadas posteriores, la centralidad del enfoque de las Humanidades persiste y en el caso de Ciencias de la Educación, hacia los años 60 , se matiza con el positivismo científico de los inicios de la Facultad, que estimamos, alcanzó a la creación y armado de la carrera de EF, que dependía del Departamento de la carrera citada anteriormente.

El antecedente más significativo de la carrera de EF en la UNLP lo constituye la Dirección General de EF de esa misma institución, creada en 1946, y encargada de coordinar las disciplinas físicas en toda la Universidad. Su mentor y "fundador"36, Alejandro Joaquín Amavet, había egresado de la Escuela e ingresado a trabajar a la UNLP, como vimos, con el rango de capitán del Ejército.

No es casual que esta fundación se efectuara en simultáneo a la de la UNT, en 1953. Durante los últimos años del peronismo, según relató el profesor y ex director de la carrera, Ricardo Crisorio:

"...viene de visita al país un alemán muy conocido, celebre, celebérrimo que es Carl $\mathrm{Diem}^{37}$, que era el tipo que había lanzado la idea de una ciencia deportiva, y de esa visita surgen dos universidades: UNLP y UNT, primeras dos por mucho tiempo. Tucumán la hace Escuela Superior dependiente del Rectorado y obviamente (está

\footnotetext{
${ }^{36}$ El término "fundador" se trata de una categoría nativa, ya que los interlocutores se refieren a Amavet con esa adjetivación. Al respecto, parte del análisis desplegado en este capítulo evidencia que el proceso de apertura de la carrera de EF fue bastante más diverso y en el que intervinieron múltiples actores. Es en este sentido que la figura de Amavet como "fundador" de la carrera es una construcción de sus discípulos y sucesores.

${ }^{37}$ Carl Diem (1882-1962) fue Doctor Honoris Causa en Medicina de la Universidad de Berlín, en 1921, en reconocimiento a su labor como creador del Instituto Universitario de Educación Física en Alemania. Fue Secretario General del Comité Organizador de los Juegos Olímpicos de Berlín 1936 y creador de la tradición de la antorcha olímpica. Es considerado uno de los más influyentes historiadores del deporte, especialmente en materia de los Juegos Olímpicos (Ministerio de Educación y Justicia, Dirección General de Educación Física, 1961), entre otros títulos, cargos y condecoraciones que obtuvo, buena parte de ellos en el contexto del nacionalsocialismo alemán, comandado por Adolf Hitler.
} 
mal que uno hable así de los colegas, pero es así) toda la gestión es opaca y ligada a lo más tradicional de la EF y Amavet la pone como sección del Departamento de Ciencias de la Educación...Si vos decís a nivel estructural los tucumanos fueron infinitamente más vivos y estaban mucho más arriba, dependían directamente del Rector de la Universidad, acá se dependía del Director del Departamento de Ciencias de la Educación, que a su vez dependía del Decano de la Facultad, que a su vez dependía del Consejo Superior de la Universidad...entonces, si vos lo pones a nivel escalafón, Amavet era un tonto....". 38

Con relación a la configuración institucional de la FaHCE y a la importancia del enfoque humanista desde los años 1920 y hasta avanzados los años 1950 que mencionábamos más arriba, en ese mismo pasaje de la entrevista, Crisorio señaló que la inserción de la EF en la FaHCE, aunque no la colocó en un lugar político-institucional estratégico, como había sido el caso de la carrera homónima en la UNT,

"...le dio una impronta totalmente muy distinta...poner el centro en la educación y no en lo físico, a los 6 años, en 1959, crea el Instituto de Educación Física, que se suponía que el campo de deportes iba a ser un instituto de investigación, nunca funcionó como tal exactamente, pero esta era la idea que él tenía...entonces ahí nosotros tenemos una impronta muy fuerte, de donde parar a la Educación Física. En Tucumán también se llamaba profesorado y en Educación Física, pero con dos orientaciones muy distintas, una absolutamente biológica, orgánica, tradicional en relación con el deporte, la gimnasia...Amavet por ejemplo crea las gimnásticas, que es una materia china pero finalmente yo la defiendo, porque es tener todas las prácticas (básquetbol, vóleibol, etc.) en una sola materia, que a su vez tiene teóricos...".

El testimonio anterior da cuenta que en un comienzo, lo que podría haber parecido un dislate de Amavet de colocar a la EF en Humanidades, finalmente terminó por configurarse no sólo en un acierto por parte del "fundador" desde las perspectivas de los profesores actuales de la carrera, sino que constituyó además una señal distinta que ponía el centro en la educación y no en lo físico. Además, el entrevistado indica que esa señal fue un factor que diferenció a la carrera de la UNLP de la de la UNT.

Tanto la impronta institucional de la FaHCE, el peso del enfoque de las Humanidades, así como la labor y el pensamiento de Amavet -que desarrollaremos más adelante en este capítulo-, son elementos que evidencian la particularidad que asume la carrera de La Plata desde sus comienzos.

\footnotetext{
${ }^{38}$ Entrevista $\mathrm{N}^{0} 2$ a Ricardo Crisorio el 13 de septiembre de 2016. Su trayectoria profesional, política y académica será abordada en el próximo capítulo. Sobre la especificidad de la carrera de EF en la UNLP haremos mayor referencia en el siguiente apartado.
} 


\section{El problema del reconocimiento y la legitimidad en la creación de la} carrera: Educación Física en la Facultad de Humanidades y Ciencias de la Educación en los años 1950

En los años previos a la creación de la carrera de EF en la FaHCE, las actividades y ejercitaciones físicas del estudiantado si bien se consideraban importantes, se confinaban al espacio de lo extracurricular, es decir, limitando al lugar de "subsidio" o "compensación", rasgo que se constituirá en una marca insignia de la disciplina ${ }^{39}$. La primer presencia de un espacio institucional dedicado a actividades y ejercitaciones físicas lo constituye la creación de la Casa del Estudiante en 1921 para la recreación y actividad física de los estudiantes, que fue extinguida en 1923, cuando se creó el Departamento de Cultura Física, dependiente del Colegio Nacional "Rafael Hernández". Este Departamento contaba con las diversas instalaciones deportivas y recreativas y se independizó años más tarde como dependencia anexa al Colegio Nacional. Este Departamento, a diferencia de la Casa del Estudiante, tenía como misión organizar y desarrollar todas las actividades deportivas llevadas a cabo en el ámbito de la UNLP, así como también la orientación de la enseñanza de la - por entonces - denominada Cultura Física. Esto es, no sólo la organización de los campeonatos, preparación de los equipos, exhibiciones, concursos al interior de la Universidad, sino también cierta prédica respecto a la metodología que debía seguir la enseñanza de la disciplina en las escuelas (Di Paolo, 1993). Ese lugar que tuvo la Cultura Física en la UNLP se mantuvo hasta después de creada la carrera de EF en Humanidades. Es decir, ese Departamento continuó, aunque con distintas denominaciones, hasta la fecha, y con algunas de sus atribuciones. Y de algún modo, la carrera de EF fue asumiendo con el tiempo, un camino paralelo a esta presencia, aunque utilizando sus instalaciones ${ }^{40}$.

En 1953, cuando se creó la carrera, la FaHCE comenzaba a adquirir una estructura por departamentos, en línea con la normativa de la época. EF surgió inicialmente como una sección, luego como Instituto dependiente de Ciencias de la Educación, y a partir de 1976 se constituyó en Departamento autónomo.

\footnotetext{
${ }^{39}$ La misma situación caracterizó a los comienzos de la disciplina en el ámbito escolar, a fines del siglo XIX y principios del XX. La presencia de la formación física se encontraba desperdigada en distintos momentos y espacios escolares, sin tener una existencia explícita como asignatura. Por otro lado, a partir que se configuró como tal, era confinada al tiempo de los recreos o por fuera del horario escolar, y típicamente en el patio y no en el aula donde se desarrollaban el resto de las actividades (Aisenstein, 2006).

${ }^{40}$ El Departamento de Cultura Física de la UNLP -terminología muy propia de las políticas sociales y educativas de los años '40 y '50 en Argentina (Orbuch, 2016)- pasó a llamarse Instituto de Educación Física, y luego Dirección General de Deportes, denominación que conserva hasta la fecha (http://deportes.unlp.edu.ar, última consulta: 05 de octubre de 2017).
} 
Para la creación formal de la carrera, se constituyó una Comisión Especial Asesora, a instancias del por entonces rector, el Dr. Francisco Marcos Anglada. ${ }^{41}$ Esa Comisión tenía como objetivo analizar la posibilidad de contar con un Profesorado en EF en el ámbito de la UNLP y debía elaborar un anteproyecto de carrera y condiciones de admisión.

En el acta del Consejo Superior que dio origen a la carrera, quedó plasmado el debate que suscitó el proyecto encargado a esa Comisión para la creación de la carrera de Profesorado en EF en la UNLP. En esa sesión ordinaria se encontraban presentes el rector y nueve consejeros: Ing. José María Castiglioni, Ing. José J. Vidal, Dr. Antonio E. Rodriguez, Dr. Pedro G. Paternosto, Prof. José Fortunato Molfino, Prof. Rodolfo M. Agoglia, Dr. José Ramón Mayo, Dr. Carlos M. Harispe, Dr. Nicolás Gelormini, y los delegados interventores por la Facultad de Ciencias Médicas, Dr. José María Castillo Morales, por la Facultad de Ciencias Naturales y Museo, Dr. Joaquín Frenguelli, y por la Escuela de Ciencias Económicas, Dr. Luis B. Cos Cardoso. ${ }^{42}$

En la sesión mencionada, el consejero Agoglia (1920-1995) fue una figura destacada y tuvo una intervención favorable a la creación de la carrera de EF. ${ }^{43}$ Fue él, como miembro participante de la Comisión Especial, quien lo presentó ante el resto de los consejeros. En este proyecto se destacaban como aspectos favorables "las posibilidades docentes de la Universidad" ${ }^{44}$, en la medida en que se consideró que ésta contaba con todos los elementos necesarios y suficientes para poder formar especialistas en EF, "en línea con el prestigio de la UNLP".

A partir de la lectura del proyecto, es posible describir la concepción de EF que sustentaban los creadores de la carrera homónima. Se la mencionaba como una disciplina "complementaria" a una educación de tipo integral: intelectual, moral y física, y se presentaba como un "anexo" a la cultura y la educación, siguiendo los preceptos establecidos en el Segundo Plan Quinquenal (Ley 14.184) del gobierno peronista. Por

\footnotetext{
${ }^{41}$ Esta comisión estaba compuesta por el Prof. Alejandro Amavet (Director General de Educación Física de la UNLP), el Prof. Rodolfo Agoglia (Decano de la FaHCE) y el Dr. José M. Castillo Morales (Delegado interventor de la Facultad de Ciencias Médicas) (Di Paolo, 1993).

${ }^{42}$ Acta No 609 del Consejo Universitario del 6 de julio de 1953.

${ }^{43}$ Agoglia fue Profesor de Filosofía por la FaHCE y Dr. egresado de la UBA, profesor titular durante los años 50', director del departamento de Filosofía y decano de la FaHCE entre los años 1953 y 1955 . En mayo de 1973, luego de la intervención estatal a las universidades durante el tercer gobierno peronista, fue nuevamente designado como decano, cargo que abandonó para desempeñarse como rector de la UNLP. También fue docente de otras universidades nacionales como la UBA, UNCuyo, UNSL, entre otras (Alí Jafella, 2002 en Paso, 2012). Días previos al golpe de Estado de 1976, grupos armados asesinaron a su hijo y se exilia en el Ecuador (Rodríguez, 2015).

${ }^{44}$ Los términos entrecomillados en este párrafo fueron extractados del anteproyecto de plan de estudios de la carrera de EF elaborado por la comisión especial designada para ello en 1953, presente en el acta citada.
} 
otro lado, se retomaban informes comparados en relación a lo realizado en materia análoga en otros países de Europa y de América.

La comisión especial designada para evaluar la pertinencia de incorporar una carrera de EF en la UNLP, consideraba oportuno incluirla en la Facultad de Humanidades y Ciencias de la Educación, y denominarla "Profesorado Superior Universitario de Educación Física", con una propuesta de plan de estudios en el que las materias serían dictadas por la FaHCE, la Facultad de Ciencias Médicas, la Facultad de Ciencias Naturales y la Dirección General de EF de la UNLP. Esta última se encargaría fundamentalmente de la enseñanza de los aspectos prácticos de la disciplina, y prestaría las instalaciones contiguas al Colegio Nacional. En numerosas oportunidades durante la sesión, se mencionó que la implementación del proyecto no implicaría gastos adicionales para la UNLP, debiéndose sustentar con los recursos disponibles. En respuesta a lo planteado por el consejero Paternosto, acerca de si los programas especiales para EF iban a ser dictados por los profesores de las facultades o significarían creaciones de cátedras nuevas a futuro, Agoglia señalaba:

"Precisamente una de las razones que ha tenido en cuenta la comisión es esa, si bien, claro está, ha concebido el proyecto del profesorado no solamente en función de esa circunstancia, pero ha dado la coincidencia de que las materias establecidas como necesarias, se dicten, precisamente en las Facultades, lo que significa que no se producirán nuevas erogaciones; por otra parte, las materias de carácter técnico, serán dictadas por los profesores de Educación Física; de manera que no habría ningún problema y me parece ventajoso que se comience este año". (UNLP, 1953: 8).

El plan de estudios que esta comisión propuso era de cuatro años de duración, compuesto por veinticinco asignaturas, de las cuales catorce se cursarían en Humanidades, tres en Ciencias Médicas (Anatomía funcional -programa especial-, Fisiología, Química biológica y de la nutrición -programa especial), una en Ciencias Naturales (Antropología Física), y siete en la Dirección General de EF. A este plan se agregaba un trayecto obligatorio inicial para todas las carreras, dispuesto por ordenanza del Consejo Universitario, de Formación y Cultura Argentina.

A continuación veremos un cuadro en donde están distribuidas las asignaturas del plan de estudios inicial de 1953, según su espacio institucional de cursada. 
Tabla 1

Plan de estudios del Profesorado en EF (1953)

\begin{tabular}{|c|c|c|c|c|}
\hline & \multirow{2}{*}{\multicolumn{4}{|c|}{ Espacio institucional de cursada }} \\
\hline & & & & \\
\hline \multirow{15}{*}{ Asignaturas } & Humanidades & Ciencias Médicas & $\begin{array}{l}\text { Ciencias } \\
\text { Naturales }\end{array}$ & $\begin{array}{l}\text { Dirección } \\
\text { General de EF }\end{array}$ \\
\hline & Introducción a la filosofía & $\begin{array}{l}\text { Anatomía funcional } \\
\text { (Prog. Esp.) }\end{array}$ & $\begin{array}{l}\text { Antropología } \\
\text { Física }\end{array}$ & $\begin{array}{l}\text { Teoría general } \\
\text { de la Gimnasia }\end{array}$ \\
\hline & Historia de la educación & Fisiología & & Gimnástica I \\
\hline & Psicología general & $\begin{array}{l}\text { Química biológica } \\
\text { y de la nutrición } \\
\text { (Prog. Esp.) }\end{array}$ & & Gimnástica II \\
\hline & Ética (Prog. Esp.) & & & Gimnástica III \\
\hline & Sociología Argentina & & & Gimnástica IV \\
\hline & $\begin{array}{l}\text { Psicología de la niñez y la } \\
\text { adolescencia }\end{array}$ & & & $\begin{array}{l}\text { Teoría Especial } \\
\text { de la Gimnasia }\end{array}$ \\
\hline & Didáctica general & & & $\begin{array}{l}\text { Gimnasia, } \\
\text { juegos y } \\
\text { deportes }\end{array}$ \\
\hline & $\begin{array}{l}\text { Ciencia y Filosofía de la } \\
\text { Educación }\end{array}$ & & & \\
\hline & $\begin{array}{l}\text { Política educacional y } \\
\text { organización escolar }\end{array}$ & & & \\
\hline & Historia del Arte & & & \\
\hline & $\begin{array}{l}\text { Didáctica asistencial y de } \\
\text { escuelas diferenciales }\end{array}$ & & & \\
\hline & $\begin{array}{l}\text { Historia del Pensamiento y } \\
\text { de la Cultura Argentina }\end{array}$ & & & \\
\hline & Pedagogía & & & \\
\hline & $\begin{array}{l}\text { Didáctica especial y } \\
\text { práctica de la enseñanza } \\
\text { en educación física }\end{array}$ & & & \\
\hline Total & 14 & 3 & 1 & 7 \\
\hline
\end{tabular}

Referencia: elaboración propia en base a la lectura del Plan de Estudios de EF $1953^{45}$.

\footnotetext{
${ }^{45}$ En el plan de estudios 2000, vigente hasta la actualidad, se incorpora a la carrera de Profesorado, la de Licenciatura, con 31 asignaturas para la primera, y 33 asignaturas para la segunda (incluyendo la tesina). Los espacios institucionales de cursada respecto al proyecto inicial de 1953 se modifican sustancialmente: las asignaturas obligatorias son dictadas por distintos Departamentos Docentes de la FaHCE y la Dirección General de Deportes (conocida como "Campo de Deportes" de la UNLP), abandonando las cursadas en la Facultad de Ciencias Naturales y Museo y de Ciencias Médicas (Plan de Estudios del Prof. y Lic. en Educación Física, FaHCE, 2000). Cabe destacar que, desde el año 2017, con la inclusión de un Polideportivo en el predio de la FaHCE, se unificó el dictado de clases en la institución, a excepción de atletismo y natación, ya que al momento de la escritura de esta tesis, no se encontraban en condiciones. Para consultar sobre esta inauguración, ver: https://unlp.edu.ar/obras/nuevo polideportivo marzo 2017-927.
} 
A partir del análisis del cuadro, podemos afirmar la existencia de cierta preponderancia del área humanística y pedagógica en la carrera, que permitía vincular a la EF con saberes históricos, psicológicos y pedagógicos (14 materias de 25 en total). Esto podemos vincularlo con el testimonio anterior de Crisorio, cuando señala que uno de los objetivos de Amavet fue "poner el centro en la educación y no en lo físico", rasgo que le otorgó una orientación particular a la carrera, en contraste con la de la UNT.

Podemos también encontrar en las discusiones iniciales de la carrera tensiones referidas a la definición y selección de saberes legítimos en la propuesta de formación de EF. Esas tensiones se evidenciaban en los intercambios acerca de cuáles eran los saberes que debían entrar en juego en la formación, cuál el espacio y peso que cada uno de ellos debía tener, en los argumentos sobre su inclusión o exclusión, etc. Sobre este punto, señalaba el consejero Mayo: "Estoy en un todo de acuerdo con el proyecto. Sólo quiero formular dos preguntas. La primera si se ha considerado la parte de Higiene". A lo que el consejero Agoglia, respondió: "En todo momento se consideró que puede ir anexa a Anatomía Funcional y también constituir una parte de la Fisiología. De modo que no creímos conveniente ponerla como una asignatura separada". Allí intervino el consejero Castillo Morales: "También está incluida o se va a incluir en los programas de cultura gimnástica”. Luego, introdujo Agoglia:

\footnotetext{
"Aun cuando no hay una asignatura especial Higiene, sabemos que existe la práctica de unirla con Anatomía o Fisiología, cosa que en este caso también se haría, de modo que en la confección de los programas respectivos se le dará a esta materia la importancia que tiene. En principio el Dr. Castillo Morales manifestó que era mejor incluirla en la especialidad de Fisiología, sin descartar la posibilidad de que incorpore también Anatomía" (UNLP, 1953: 10).
}

Allí, el consejero Mayo manifestó "darse por satisfecho" con el asunto de la Higiene, y preguntó si se había tenido en cuenta en el proyecto de carrera la "personalidad cultural del futuro profesor", y si no resultaría conveniente la inclusión de una materia vinculada al área de Letras. A lo que Agoglia respondió:

"En principio aceptamos la idea de que la formación debía ser integral y en ese sentido habíamos decidido hacerlo. Por eso es que el programa tiene algunas asignaturas de Filosofía y además habíamos pensado en Estética, pero como esa materia se dicta solamente en Humanidades y desde un punto de vista muy metafísico pensamos que no sería del caso. Luego preferimos no recargar el profesorado con materias literarias porque también contribuye a esa formación cultural la Historia del Pensamiento y de la Cultura Argentina que integra todos los profesorados, además de los cursos de Formación recientemente creados" (UNLP, 1953: 11). 
La apelación a la concepción de educación integral como argumento legitimador en los debates de creación de la carrera, evidencia la relevancia de este discurso en todo el sistema educativo y en particular en la disciplina EF desde sus comienzos como disciplina escolar en las postrimerías del siglo XIX y primeros años del XX (Aisenstein, 2006; Galak, 2013a). La presencia del término integral en las discusiones acerca de la creación de la carrera, así como en los escritos de su "fundador", dan cuenta de cierta apropiación y uso de una concepción muy extendida en la educación moderna, aunque desde posicionamientos pedagógicos diversos tales como el positivismo y el escolanovismo (Pineau, Dussel y Caruso, 2001).

Por otro lado, en los pasajes anteriores pueden advertirse preocupaciones comunes en torno a qué áreas del conocimiento incluir en la formación del profesor de EF en la UNLP. Las preocupaciones manifestadas por uno de los consejeros referían al área de Higiene y de la "formación cultural" del profesor. En el primer caso, se proponía incluirla dentro de las materias dictadas en el espacio institucional de la Facultad de Ciencias Médicas y, en el otro, con el cursado general del espacio de historia del pensamiento y cultura argentina para todos los profesorados de la FaHCE, además del resto de las asignaturas de corte humanístico. En este sentido, más allá del intercambio sobre en qué espacio institucional debían cursarse estas asignaturas, el acuerdo en su inclusión da cuenta de la impronta humanística que se pretendió asignar al Profesorado en EF.

En otro pasaje del acta fundacional, y en relación a las exigencias de tipo físico para estudiar EF, puede leerse que el consejero Castillo Morales expresaba:

"De esto he hablado largamente para evitar que ocurriera lo que había observado
muchas veces, de personas con algún defecto físico o funcional que actuaban como
profesores de educación física y sé del caso de un profesor que está actuando en una
institución de esta ciudad que no sabe respirar, más bien ha dicho que no puede
respirar, dándole a este concepto de su falta de aptitud para respirar como es
necesario cuando se practica cultura física; este profesor respira por la boca y eso es
no saber respirar. Para que no pueda suceder nada semejante, es necesario que el
examen médico de los aspirantes sea riguroso". (UNLP, 1953: 11) (la cursiva es
propia).

Respecto de ese examen de aptitud física que deberían exigir a los aspirantes, el consejero Castiglioni señalaba:

"Pero se me ocurre que tal vez lo más interesante es el exámen médico de aptitud para ser profesor. No vaya a darse el caso de un rengo o de un corto de vista que supere el examen porque sabe saltar la garrocha o hacer alguna otra cosa. En este caso, más que en ningún otro, el maestro debe enseñar con el ejemplo, y entonces 
me parece que sería conveniente tomar un examen de aptitud desde el punto de vista médico". (UNLP, 1953: 11) (la cursiva es propia)

En expresiones tales como "no sabe respirar", "es necesario que el examen (...) sea riguroso" "no vaya a darse el caso de un rengo o de un corto de vista que supere el examen", identificamos que quienes discutieron las condiciones de admisión a la carrera, pensaron la aptitud desde un criterio de normalidad física. Es así como una persona renga o con alguna discapacidad visual no podría ingresar a la carrera, desde justificaciones asociadas a un parámetro físico, emparentadas con la orientación deontológica de la carrera, del profesor de EF también como ejemplo físico. Aquel que tuviera alguna discapacidad, aunque demostrara dominio de la técnica, no podría superar el examen de aptitud médico.

Analistas actuales que abordan este proceso de creación y estudian la matriz de formación de la carrera señalan que el perfil que se pretendió imprimirle fue de carácter "deontológico" (Galak y Simoy, 2015). Es decir, se promovió la idea del docente como ejemplo, como seguidor y representante de un deber-ser. Si bien ese carácter es propio de la docencia desde su pasaje de profesión libre a profesión de Estado hacia fines del siglo XIX y fundamentalmente comienzos del XX (Birgin, 1999), en el caso de la EF adquirió formas particulares. Por su especificidad relacionada al uso del cuerpo como recurso, el docente de EF se configuró como un ejecutante, capaz de mostrar con destreza aquello que el alumno debía aprender. Este rasgo se evidenció durante la sesión del Consejo Superior, a propósito del examen propuesto para el ingreso de los aspirantes.

La expresión "en este caso, más que en ningún otro, el maestro debe enseñar con el ejemplo" da cuenta de cierta especificidad en el caso de la EF, que la diferencia de otros profesorados. La docencia en EF asumió en la intervención del consejero Castiglioni características particulares vinculadas fuertemente al grado de exposición del cuerpo en la práctica. Aquí podemos advertir la influencia de discursos sociales, médicos y pedagógicos como el positivismo, el higienismo y el normalismo que impactaron de manera singular en esta disciplina. ${ }^{46}$ Esta influencia puede advertirse en la introducción de mecanismos de control y modos de hacer legítimos con el cuerpo en las instituciones educativas, de la difusión y entronización de una idea de cuerpo sano y la asociación entre la EF y la salud de la población (Carballo, 2010, Galak, 2014).

\footnotetext{
${ }^{46}$ Sobre la influencia de estos discursos en el campo pedagógico y más específicamente en la configuración del sistema educativo argentino, ver Milstein y Mendes, 1999; Pineau, Dussel y Caruso, 2001 y Puiggrós (1990, 2002). Para análisis específicos sobre sus implicancias en el campo de la EF, ver Aisenstein, 1995; Aisenstein y Scharagrodsky, 2006, y Galak, 2014.
} 
Estas perspectivas sobre las características que debían tener los profesores de EF y las maneras de concebir y evaluar la aptitud desde un criterio de normalidad física fueron parte de visiones extendidas sobre el cuerpo y la educación del cuerpo, entre las que se encuentra el dualismo u oposición entre cuerpo/mente, concepción que descansa en estos discursos.

El normalismo fue la corriente pedagógica de formación de maestros que se inició a fines del siglo XIX en Argentina, junto con la implantación del sistema educativo y las primeras instituciones de formación, Escuelas "Normales", inspiradas en esa corriente (Puiggrós, 1990).

La concepción del docente como ejemplo moral, de conducta, propia del normalismo, se combinaba con elementos del discurso positivista (1990, ibídem). En el caso de la EF, se configuró una idea de docente con habilidad y destreza, capaz de demostrar en la práctica un determinado desempeño, y que pudiera irradiar una imagen de normalidad física a los estudiantes. Es decir que, en este caso, "más que en ningún otro", el docente de EF enseña y predica con el ejemplo, un ejemplo que a su vez tiene el respaldo médico, un respaldo brindado por el saber médico que avala esa imagen y esa práctica.

Por su ubicación dentro de la FaHCE, la carrera adoptó también influencias de la corriente humanista, con una importante carga teórica, que la va a distinguir de otras carreras universitarias en la disciplina. En cierto modo, el humanismo que asumió la formación justificó su inclusión en esa Unidad Académica, y diferenció a la carrera no sólo de su coetánea de Tucumán, sino del perfil asumido por los institutos superiores (no universitarios). La diferenciación con las matrices de formación que sustentaban otras instituciones ingresaban en los debates sobre la creación de la carrera:

\footnotetext{
"Se pueden conceder equivalencias a alumnos que hayan egresado de los institutos mencionados en el proyecto, quienes tendrán que completar sus estudios con las materias que figuran en estos planes. Es un profesorado quizá un poco riguroso, pero me parece que si la universidad lo toma a su cargo no puede hacer otra cosa. Además, ha sido muy bien visto y he recibido opiniones muy favorables y creo que contiene grandes ventajas, inclusive sobre los profesorados que existen en otras partes del mundo, ya que éste incluye una formación filosófica y pedagógica perfectamente aunadas con el aspecto psicológico y el biológico de tal manera que el proyecto contempla todas las cuestiones que deben estar comprendidas en un profesorado de esta índole, con el agregado que se puede implantar sin mayores trastornos. Si los señores consejeros lo estiman conveniente se puede aprobar tal como está". (UNLP, 1953: 10) (Las cursivas son propias)
} 
En las manifestaciones anteriores, Agoglia refiere a que serían aceptados aquellos egresados que, conjeturamos, provinieran del INEF, el INSF o la Escuela del Ejército $^{47}$, siempre que completaran su formación con una serie de materias en un régimen de equivalencias a establecer. Según los testimonios relevados, en la práctica esta situación no llegó a darse. Es decir, no vinieron egresados de esas instituciones a completar su formación a la FaHCE. Tanto el virtual reconocimiento de esos profesores (tenían que ser "egresados") como su no concurrencia a las aulas de la UNLP, evidencian una relación no articulada entre las ofertas de formación superior de profesores de EF.

Por otro lado, desde la perspectiva de Agoglia, la cuestión de la rigurosidad del Profesorado se configuraría en torno de la formación humanística y sería una marca de distinción de esta carrera con respecto a otras de carácter terciario y a la presente (aunque recientemente) en la UNT. Así, la diferenciación de la carrera de la UNLP estaba dada por el prestigio conferido en torno a la articulación de los saberes biológicos con preeminencia de perspectivas humanísticas (lo filosófico, pedagógico y psicológico).

Además, en esta intervención de uno de los actores participantes en la creación de la carrera, es claro que la exigencia de cursadas adicionales para quienes vinieran de institutos, le confería a la carrera de la UNLP cierta superioridad o jerarquía, pues no sería considerado equivalente el título de un terciario. El consejero consideraba que el profesor de un terciario no estaba en igualdad de condiciones en cuanto a formación respecto del universitario, y es por ello que proponía se le exigiera realizar más materias.

En el siguiente apartado reconstruiremos la trayectoria profesional y académica, pensamiento y labor de Alejandro Amavet, mentor y primer director de la carrera de EF de la UNLP. Este recorrido nos permitirá comprender el perfil que fue asumiendo la formación de los estudiantes y la particularidad de esta carrera por sobre otras, con una acentuada orientación humanística, a partir del análisis de su legajo institucional, sus propios escritos, programas e intervenciones públicas.

\footnotetext{
${ }^{47}$ Cabe señalar que la Escuela del Ejército cierra sus puertas en el año 1934, siendo su última promoción del año 1937 (Galak, 2012b). Aun así, es reconocida como institución superior en tanto el propio "fundador" de la carrera de la UNLP, Amavet, provenía de la misma. Por tanto, suponemos, otros egresados de allí podrían estar interesados en completar su formación en la FaHCE.
} 


\section{5. ¿Quién fue Alejandro Amavet? Trayectoria profesional y académica del "fundador" de la carrera de EF en Humanidades}

Alejandro Amavet nació en Capital Federal el 05 de julio de 1906, y se graduó como Profesor de Educación Física en la Escuela de Gimnasia y Esgrima del Ejército en $1928^{48}$. Ejerció la docencia dentro de este ámbito desde su graduación y hasta el año 1934. También desempeñó otros roles dentro de la Fuerza y en organismos nacionales siempre vinculados a la disciplina, hasta su retiro con el grado de capitán ${ }^{49}$, momento a partir del cual se dedicó de lleno a la docencia universitaria. Se desempeñó además en la función pública en el Consejo Nacional de Educación Física entre los años 1948 y 1953. Su formación en el ámbito civil se inició dentro de la propia FaHCE, como Profesor Superior Universitario en Educación Física, título que obtuvo en 1954 a partir de la presentación de su tesis denominada "Apuntes para una introducción al estudio de la Educación Física". En la década del 60, se graduó como Consejero Humanista Social y Licenciado en Eugenesia Integral en el Museo Social Argentino (títulos obtenidos en 1961 y 1962 , respectivamente $)^{50}$.

Su trayectoria académica se inició en el año 1947 como Director General de Educación Física de la UNLP (aquel espacio que hoy conocemos como el Campo de Deportes, y que en la estructura institucional, como dijimos, se denomina Dirección General de Deportes). Desde allí, se coordinaba la enseñanza de la asignatura en las escuelas dependientes de la UNLP, se organizaban los equipos y exhibiciones que representaban a la universidad en torneos y competencias, así como también se desarrollaban las actividades deportivas extracurriculares de los estudiantes de la institución que así lo requerían (Di Paolo, 1993). Como docente, su trayectoria se desplegó entre los años 1953 y 1973, y su actividad estuvo vinculada a las cátedras Introducción a la Educación Física, Seminario de investigación en Educación Física y Teoría Especial de la Gimnástica. En esos espacios compartió la docencia junto al Profesor Anselmo Barros, y fueron ayudantes en sus cátedras Norberto "Chiquito" Assali, Raúl Acosta, Ernesto Rogg, Marta Demarta, Fulvia Veronelli, Néstor Mazzarello, Pedro Nogareda, Eduardo Nanni, Nidia Corrales, Elisabeth Tobal de Chambon, Alicia Padros,

\footnotetext{
${ }^{48} \mathrm{La}$ información de este párrafo y los subsiguientes fueron extraídos del legajo de Amavet, en el Departamento de Personal de la FaHCE.

${ }^{49}$ Según Parenti, no se conoce la fecha exacta del retiro efectivo del Ejército por parte de Amavet (en Kopelovich, 2013). No se cuenta tampoco con esa información en la FaHCE.

${ }^{50}$ Otros análisis sobre la vida, obra y trayectoria del profesor Alejandro Amavet, pueden encontrarse en: Di Paolo, 1993; Ron y Levoratti, 2015 y Villa, 2003; 2007.
} 
Ofelia S. M. de Regé, Elena Makaruk, Myrtha Lucero de Capelli, Jorge Fridman, Carlos Parenti, entre otros (Legajo de Amavet, folios 18, año 1956; folio 124, año 1966, FaHCE).

En cuanto a su participación institucional, fue Director de la carrera en su configuración inicial como Sección, luego, a partir del 28 de septiembre de 1959, en el mismo cargo convertido en Instituto de Educación Física, siempre dependiente del Departamento de Ciencias de la Educación (DCE) de la $\mathrm{FaHCE}^{51}$, razón por la cual en 1964 reemplazó por un tiempo al por entonces Jefe del DCE, Ricardo Nassif, mientras éste último se encontraba de licencia ${ }^{52}$. Esta tarea la complementó en los años ' 60 con su desempeño como Consejero Académico.

La participación de Amavet en la docencia y gestión institucional se discontinuó a partir de agosto de 1973, cuando fue limitado en sus funciones, bajo el argumento de la edad $^{53}$

Según Parenti, la jubilación de oficio de Amavet en 1973, estuvo vinculada a un "pase de factura" desde el Ejército, su institución de procedencia, de donde había renunciado para dedicarse tiempo completo a la universidad:

“...él fue compañero de Onganía y mucha gente. Nosotros nos movilizamos mucho en el '69 porque, no sé si sabés que en el '69 se cerró la inscripción a la carrera... bueno, este es otro dato. En el '69 viene un decano interventor, Ballbé, y cierran la inscripción porque no podía haber transpiradores en las humanidades. Esos eran los argumentos, no sé si están escritos pero orales seguro porque nosotros digamos...entonces movilizamos como Centro de Estudiantes de la Facultad de Humanidades. Hasta que en el '70 se abre la inscripción nuevamente, y ahí ya uno estaba con cierto poder, podría decirse, de haber participado activamente en esto; Amavet por supuesto estaba con la reincorporación y movía sus contactos políticos y nosotros con la ebullición, no?...". ${ }^{54}$ (La cursiva es propia).

\footnotetext{
${ }^{51}$ En una nota con fecha 02 de marzo de 1967 dirigida al por entonces Decano interventor, Ingeniero Luis Bonet, Amavet, en tono de agradecimiento por su designación como Director y prestando su colaboración, relata de algún modo ese derrotero en la estructura y dependencia institucional de la carrera de EF (Legajo de Amavet, FaHCE, folio 118, p.1). Como dijimos, desde su creación en 1953, dependió del Departamento de Ciencias de la Educación. Inicialmente se constituyó como Sección, de la cual Amavet también fue Director, y a partir de 1959 siguió desempeñándose como tal en su configuración como Instituto. En 1976 se constituye como Departamento Docente como el resto de los Departamentos, con capacidad propia para decidir sobre los asuntos académicos y curriculares de su carrera.

${ }^{52}$ Res. 1067 del $1^{\circ}$ de septiembre de 1964 (FaHCE).

${ }^{53}$ Res. 685/73 de la FaHCE. A Amavet se le aplica el límite de edad fijado por el Art. $33^{\circ}$ de la Ley Orgánica de las Universidades Nacionales № 17.245, promulgada en 1967 (Legajo de Amavet, FaHCE). El artículo mencionado señalaba: "Los Profesores Titulares, Asociados y Adjuntos serán relevados de sus funciones a los sesenta y cinco años de edad y podrán ingresar en las categorías fijadas en los artículos 24 y 25 ” (Ley Nº 17.245). Es preciso tener en cuenta el escenario de violencia política que se había configurado en los años del tercer gobierno peronista que se extendió entre 1973 y 1976, siendo las universidades instituciones sometidas a una profunda inestabilidad (Rodríguez, 2014).

${ }^{54}$ Cabe señalar aquí, que Amavet no renuncia a su cargo en EF en el Departamento de Ciencias de la Educación en 1966, como sí lo hiciera su Director, Ricardo Nassif (Garatte, 2012).
} 
Si bien se desconocen las verdaderas razones de la limitación de Amavet, del testimonio de Parenti podemos inferir que su participación o aval a las movilizaciones de estudiantes para la reapertura de la carrera, puede haber sido un factor que gravitó en su salida anticipada, con la aplicación de la normativa referida a la edad jubilatoria. Según la reconstrucción realizada por Di Paolo (1993), esa salida fue intempestiva, durante el desarrollo de una clase. Así lo relató el por entonces alumno Francisco Barón, quien mantuvo contacto con Amavet y presenció la situación:

\begin{abstract}
"Estábamos en plena clase de Seminario e Investigación en Educación Física (Septiembre del $\left.73^{\prime}\right)$; en pleno desarrollo, en el pizarrón, de todas las pruebas objetivas para el trabajo de psicomotricidad:...cuando abre la puerta el profesor Raúl $\operatorname{Acosta}^{55}$, con un papel y le pide al Profesor Amavet si puede interrumpir la clase. Amavet no contesta; Acosta entonces dice que viene con la triste misión (de parte del Decanato, el Decano de Humanidades en ese entonces era el Profesor Gómez) de comunicar que se disponía su paso a retiro para que se jubilara. Ese día le dijeron que a partir de ese momento quedaba cesante, que era su última clase, que cesaba como profesor de la Universidad (era titular). La resolución estaba firmada por Gómez. Para nosotros fue un golpe muy fuerte, yo me acuerdo que nos paramos en la clase con otros compañeros...nos habíamos quedado tan impactados que nadie atinó a nada...y preguntamos por qué ocurría esto, en base a qué se tomaba tal decisión. No hubo respuestas.

El final de Amavet en la carrera fue triste. Tuvo una trayectoria brillante. El sentía que era su final, no quería volver, tenía su ética...Sentía mucho respeto por la institución, más allá de los hombres, y sentía que ya había cumplido su cometido y no se merecía este final" (citado en Di Paolo, 1993: 65).
\end{abstract}

La salida de la FaHCE afectó emocionalmente a Amavet, quien falleció en julio de 1974 (Di Paolo, 1993).

El pesar que este estudiante expresa respecto de la limitación del profesor Amavet y su forma intempestiva puede comprenderse si tomamos en cuenta la posición que ese docente había construido alrededor de las cátedras en las que se desempeñaba como profesor titular. Organizaba reuniones periódicas a las que asistían los ayudantes y los estudiantes en general, y que se constituyeron en espacios de formación. Realizaba encuentros en su casa y préstamos de bibliografía de su biblioteca personal. Así lo manifestaba la por entonces alumna, María Lucía Gayol: "Amavet era un tipo tan abierto y tan culto... conocí a su señora, fui a su casa muchas veces, hice uso de su biblioteca. Después esa trayectoria la siguieron Parenti y Fridman porque ellos después sí fueron también ayudantes de la cátedra de Amavet" ${ }^{\prime 56}$. Era un tipo de formación artesanal, que

\footnotetext{
${ }^{55}$ Raúl Acosta fue profesor de la carrera de EF en la FaHCE durante los años 70, y nombrado interventor de la misma en el año 1973 (Entrevista realizada a Carlos Parenti).

${ }^{56}$ Entrevista №1 a María Lucía Gayol el día 02 de septiembre de 2016 en La Plata.
} 
no estaba formalizado, pero que funcionaba de modo regular y sistemático, en un contexto de fuerte cercanía entre profesores y estudiantes, y que se constituía alrededor de prácticas tales como la lectura colectiva de bibliografía, los seminarios internos, las reuniones periódicas y la socialización de los referentes de su biblioteca particular. Podríamos asociar este esquema con una concepción de la práctica docente como espacio de formación muy frecuente en los años '60 y que caracterizó también a otras carreras y espacios, tales como las cátedras de Ricardo Nassif o de Guillermo Savloff en Ciencias de la Educación (Garatte, 2012).

\section{1. La consolidación de una EF de corte humanista e integral}

Durante su trayectoria en la UNLP, Amavet se nutrió de diferentes autores y enfoques que acompañaron un proceso de transición en su perspectiva teórica y mediante los cuales construyó una concepción de Educación Física "renovada" (Amavet, 1967). Así lo manifestó Parenti:

“...cuando uno compara a Romero Brest, que es el iniciador de la educación física que trae todo esto, pero el médico, entonces trae todo su sistema médico que históricamente es correcto, por qué, porque en ese momento en Europa la condición higiénica, fisiológica era la predominante y la que marcaba; y bueno, trae eso y está bien. Uno podría decir un positivista, y bueno sí, si estaba en el positivismo; no estar en esa línea, era, digamos, estar ligado, pero además era una visión de la educación física sobre el rendimiento. Uno podría hacer historia desde los ejércitos, desde Esparta a Atenas y demás, y siempre estuvo el hecho corporal como un hecho de lucha como un hecho de poder; cuando se inicia aquí el poder estaba en el cuerpo en términos orgánicos, la fisiología era la que sustentaba esto. $Y$ por supuesto Amavet cuando es egresado y da clases en la escuela de Gimnasia y Esgrima del Ejército eran las posiciones que también tomaba Romero Brest. Pero ya empieza a haber, digamos, yo lo pongo ahí en un escrito en el año '98 porque tengo esa información, él empieza a viajar y demás y ve que hay otro cambio, que hay una corriente filosófica como el existencialismo, los nuevos pensamientos europeos de la posguerra de la primera guerra y de la posguerra de la segunda guerra mundial, y bueno, abre..."

En ese proceso de transición cobra especial relevancia un viaje que Amavet realizó a Suecia en el año 1949, a propósito de su función como Secretario del Consejo Nacional de Educación Física (Parenti, 2006). Alli tomó contacto con los nuevos enfoques filosóficos europeos como la fenomenología y el existencialismo, así como en materia específica de la Gimnasia y la Educación Física. Autores como Werner Jaeger, Platón, Max Scheler, Karl Jaspers, Erich Fromm, Merleau Ponty y Aldous Huxley fueron incorporados progresivamente a las propuestas programáticas de Amavet, en las que combinaba aportes de la Psicología, la Psiquiatría, la Historia, la Antropología, y la Filosofía junto a la Gimnástica griega (Programas de Introducción a la EF 1962, 1963 y 
1964, Legajo de Amavet, FaHCE). Este desplazamiento puede ser interpretado como un "viaje de conocimiento" (Alfonso, 2016; Carli, 2013; Larrosa, 2000), en tanto que representó una inmersión cultural para el "fundador" y un viraje significativo en su perspectiva teórica, que luego redundó en modificaciones de sus propuestas de cátedra y en sus escritos. No obstante, Amavet no abandonó totalmente relaciones entre la EF y la Biología. Cabe mencionar, en este sentido, la presencia en las propuestas de otras referencias teóricas como el enfoque del psicólogo norteamericano William Herbert Sheldon. Este autor construye la teoría del "somatotipo" en la cual se asocian tipos de cuerpos humanos con temperamentos, a través de una clasificación de los cuerpos mediante la cual se podían establecer y predecir las características mentales de los individuos, como forma de explicar las diferencias entre los mismos (Sheldon, 1972).

Las influencias mencionadas resultaron claves para definir en Amavet una concepción humanista de la EF, que comenzaría a distanciarlo de la concepción dominante en la disciplina. Sobre esta cuestión, Parenti señaló:

“...La formación que Amavet tenía era acorde con el pensamiento de la época; si bien hoy uno pueda discutirlo, pero en ese momento era de avanzada; claro confrontaba con otro pensamiento del rendimiento en el cual no se tenía ningún acceso..."

Parenti se refirió a la formación del "fundador" como "de avanzada" y en contraposición a la concepción dominante en la enseñanza de la EF, asociada al rendimiento. Cuando manifiestó que sobre esa concepción "no se tenía ningún acceso", hace referencia a la primacía institucional que el INEF tenía por sobre la carrera de la UNLP para influir en la orientación de la disciplina. Esa primacía estaba vinculada fundamentalmente a la relevancia de su creador, Romero Brest, y a la afluencia de estudiantes que aspiraban a ingresar a sus aulas, en comparación con la carrera universitaria de La Plata.

Al respecto, de producciones académicas recientes de la propia comunidad de EF de la FaHCE y testimonios relevados, se desprende que en sus inicios y hasta el retorno democrático en 1983, la carrera fue una de las más pequeñas de la facultad, con 70/80 estudiantes en total en todos los años (Ron y Levoratti, 2015). La competencia con el INEF ubicado en la Capital Federal, fue un factor que dificultó su arraigo y consolidación institucional:

"...lo que pasa que la Educación Física en Argentina estuvo siempre dirigida, o como una especie de rector de la Educación Física que fue el Instituto de Educación Física Romero Brest. Entonces el INEF era el faro que iluminaba la Educación Física y el único que tenía el poder porque, además, todas las agremiaciones y las instituciones oficiales, la Dirección Nacional de Educación Física y demás estaban los egresados 
de allí. Con el cual acordábamos en ciertas cosas y en otros enfoques eran totalmente distintos. Pero qué pasa, el conflicto venía en la relación de poder. Entonces, el poder es el que presenta la mejor información y la que hace consumir esa información, ellos ejercían el poder institucional y nosotros podíamos pensar de otra forma y de hecho pensábamos de otra forma, pero no teníamos espacio institucional para dar el pensamiento..."

La cita anterior da cuenta de la primacía del INEF no sólo en cuanto a la matrícula estudiantil, sino además en la influencia de sus egresados en distintos espacios de definición disciplinar a nivel nacional. Es por ello que Parenti destaca que, aunque los enfoques entre el INEF y la FaHCE eran bien distintos, este último no tenía ámbitos donde recalar y expandirse.

Según Galak (2013b), la perspectiva de Amavet fue "endogámica" por cuanto no logró trascender los muros de la FaHCE. Al respecto, podemos conjeturar que esta influencia restringida estuvo vinculada a la dimensión pequeña de la carrera en términos matriculares hasta la reapertura democrática, y al quiebre sufrido a partir de la jubilación y posterior fallecimiento de Amavet, así como por la limitación de parte de sus colaboradores entre el año 1974 y la última dictadura cívico-militar de 1976. En capítulos siguientes abordaremos cómo esta situación de desventaja de la EF de la UNLP respecto del INEF fue transformándose radicalmente, hasta llegar a ser la carrera más masiva de la FaHCE, con un promedio sostenido de entre 500 y 1500 ingresantes por año desde 1986 (Dirección de Enseñanza, FaHCE, 2017).

En cuanto a los argumentos por los cuales Amavet creía necesaria la inclusión y permanencia de EF en la FaHCE, se vinculaban a nociones acerca de la educación y de la formación docente en términos amplios. Al respecto, sostenía que si la EF formaba parte del curriculum escolar y los docentes de otras disciplinas se formaban en las Humanidades, el docente de EF también debía formarse con los conocimientos que aportaban disciplinas como Historia, Filosofía, Antropología, Ciencias de la Educación, complementado con la actividad investigativa. Así lo señalaba en un escrito de 1972: “...Necesitamos una formación y una preparación universitaria, superior, humanística y científica, sin la cual nos quedaríamos en la simple tarea de 'antropotécnicos'. Deben comprender, por esto mismo, los alumnos del Profesorado, que nuestra misión es muy vasta y nuestra 'imagen' mucho más amplia que la del educador físico común" (comillas en el original, la cursiva es propia) (Amavet, 1972: 6-7). Aquí Amavet planteaba que la carrera de la UNLP debía distinguirse de las dictadas en los Institutos Superiores, desde

\footnotetext{
${ }^{57}$ Entrevista №1 a Carlos Parenti, en la ciudad de La Plata, el 23 de septiembre de 2016.
} 
una concepción en la que los estudiantes de la primera no serían "comunes" o meros "antropotécnicos". Aunque, si bien, como mencionábamos más arriba, la perspectiva que construyó se mantuvo en los márgenes, es decir, no tuvo gran impacto por fuera de los muros de la FaHCE, a partir de los años 1980 se constituyó en referencia en tanto postura contrapuesta a la dominante en la disciplina en el primer cincuenteno del siglo $X X$.

Algunas de las ideas que sostenía Amavet tenían que ver con revitalizar las humanidades clásicas y su relación con la disciplina. Así lo expresaba en una entrevista que otorgó a Radio Universidad a cinco años de la creación del Profesorado, el 15 de mayo de 1958: “...la carrera de Educación Física (...) fue ubicada intencionalmente en la Facultad de Humanidades porque era indispensable recuperar para la misma la jerarquía y el contenido que poseía en la cultura clásica. Así considerada, como "cultura de la Educación Física" se aparta totalmente de la orientación biológico-pragmática que se le ha dado corrientemente en nuestra época" (Legajo de Amavet, folio 29, FaHCE). En el mismo sentido, señalaba más claramente: "Formar los nuevos profesores de Educación Física dentro de las Humanidades no es una antinomia ni una osadía, como muchos creen. Es comulgar con la propia esencia de las Humanidades, puesto que al afirmar la dignidad del espíritu humano no puede dejarse de afirmar la dignidad de su cuerpo". (Amavet, 1957:19). En función de su concepción de EF y la contribución de la misma a la educación del individuo, Amavet se mostraba reticente a la escisión moderna entre la educación intelectual y la educación física, y proponía su articulación. Al respecto, en esa misma entrevista, cuando el periodista le preguntó si la carrera de EF era una parte de la formación de los estudiantes de Humanidades y trabajaba con los mismos estudiantes de otras carreras, Amavet respondió:

"Ese sería el planteo ideal. Es evidente que los alumnos de Humanidades deberían cursar materias de Educación Física para interpretar cabalmente las humanidades clásicas. Desgraciadamente, la tarea actual de esta carrera no es la de completar la formación del universitario humanista, sino la de proveer profesores humanísticos de educación física, problema nacional apremiante que debe resolverse antes que nada" (Legajo de Amavet, folio 27, FaHCE).

En la cita precedente puede advertirse la concepción de educación integral sostenida por Amavet. El "fundador" de la carrera de EF en la UNLP, rechazaba que esa formación integral fuera sólo para los estudiantes de EF, y no así para el resto de los profesores formados en la FaHCE. Allí resulta evidente la crítica que realizaba a la separación del conocimiento en intelectual y físico, y la lucha que emprendía por su 
articulación. Para Amavet, la formación de un profesor, era una formación "integral" y necesariamente "humanística", más allá de la disciplina específica, es decir, un "profesor humanístico".

Por otro lado, interesa destacar la diferenciación que desde el inicio de la carrera, se proponía construir entre la formación en la UNLP y la brindada por los institutos. AI respecto, Amavet señalaba:

"Hasta la fecha, la enseñanza de esta disciplina en el país se realiza en gran parte por profesores improvisados: personas que carecen de formación y título. Si se piensa que ese pseudoprofesor entra en contacto con niños y adolescentes, con toda la fuerza que le brinda su ubicación docente, sin tener nociones siquiera elementales de los problemas de la educación, y de la alta y fina responsabilidad de un maestro, se comprenderá la magnitud de este conflicto. Entre los actuales profesores de educación física hay una minoría de auténticos profesionales. Pero aún entre estos falta casi siempre lo fundamental: el conocimiento del sentido humanístico de su materia. Así formado el elenco de los profesores de educación física, no es de extrañar que el prestigio de esta enseñanza haya decaído notablemente. Se la excluye progresivamente de los planes educacionales del país y se la confunde por culpa de los malos profesores, con una verdadera exaltación del cuerpo. Ya hemos dicho lo erróneo y hasta nefasto que tiene esta interpretación. A esta concepción biológico-pragmática se vincula el auge de la gimnástica en los países totalitarios. Una correcta educación física no sirve nunca a sistemas que desprecian y mecanizan al hombre desarrollándolo unilateralmente" (Legajo de Amavet, folios 27-26, FaHCE).

En la cita anterior, Amavet desarrollaba un diagnóstico sobre los profesores de EF en ejercicio de la docencia hacia finales de los años 50 que, como vimos anteriormente, eran fundamentalmente aquellos egresados del INEF y en menor medida del INSF, así como del Ejército o aficionados deportistas. Esa formación "improvisada" y "errónea", según Amavet, condujo a un perfil de docente biológico y pragmático que terminó por ser funcional a regímenes totalitarios. En este sentido, su postura fue crítica cuando los denomina "pseudoprofesores" y manifiesta la relevancia de formar docentes en EF desde una perspectiva humanística. Aquí resulta evidente la lucha encarada por Amavet en torno a la orientación que debía asumir la EF incluso más allá de la FaHCE, en relación a los saberes con los que debía dialogar, y la legitimidad que a partir de ese diálogo se intentaba construir. Esa lucha va a ser retomada luego por sus colaboradores más cercanos y generaciones más jóvenes, con distintos matices, luego del retorno democrático de 1983. Por otro lado, el propio Amavet liga el desprestigio de la enseñanza de la EF del momento a la ausencia de una formación humanística. Es decir, la formación humanística para él va a constituirse como una condición excluyente que prestigia a la enseñanza de la disciplina. Formación humanística que iría a contrapelo de las posturas 
mecanicistas que restringen el alcance de la formación, al plantear el desarrollo unilateral del hombre. Décadas después planteos similares pueden encontrarse en autores considerados críticos en el campo de la EF, como Valter Bracht (1996), quien denominaría a esta postura un entendimiento "biológico" de la enseñanza de la EF.

Con estas ideas, Amavet desarrollaba una concepción sobre la EF y sobre su función social y política. Resaltaba la contribución de la misma a procesos formativos y sociales más amplios que la mera especialidad técnica y humanista. Es decir, en la intervención de Amavet podemos dar cuenta de la importancia que le atribuía a la EF y su función para la conformación de una sociedad democrática. Aquí las humanidades no eran pensadas como un instrumento ampliatorio o complementario de la formación, que sirvieran como argumento legitimador, sino que el perfil de formación en la UNLP respondía a una "correcta EF" que no contribuyera a sistemas totalitarios sino que, por el contrario, garantizara la plena realización de una sociedad democrática.

A su vez, señalaba que la Educación Física era "ante todo, EDUCACIÓN" (mayúscula en el original, Amavet, 1967: 89). Las expresiones e ideas de Amavet señalan diferencias de concepción con el INEF no sólo en torno a la EF sino a la educación en sí misma. Por otro lado, Amavet consideraba que la docencia era una necesidad y "la formación debía preparar al profesor para detectar las inclinaciones positivas y negativas de sus alumnos, para alentar las favorables y reorientar las desfavorables" (citado en Villa, 2007:137).

Además de que estos profesionales fueran educadores con "personalidad cultural" y conocimientos de materias "pedagógicas y culturales", Amavet instaló la prédica del rol como investigadores que indagaran de manera sistemática al cuerpo desde una "perspectiva educativa". El enfoque educativo que asumió la carrera de la UNLP y su fundamentación pedagógica y cultural se diferenciaba de la expuesta por Romero Brest, para quien, como vimos, la EF debía basarse en la fisiología "en primer lugar (...)" (Romero Brest, 1917: 75).

\section{El procesamiento de la pertinencia y legitimidad de la carrera de EF en los años posteriores al fallecimiento de Amavet}

A partir del alejamiento forzado de Amavet en 1973, la carrera adoptó una forma de gobierno propio, diferente a la de otras carreras de la FaHCE, en una modalidad de co- 
gobierno tripartito, del que participaban docentes, graduados y estudiantes en forma relativamente proporcional. Así lo caracterizó Parenti en la entrevista,

“....nosotros en el año, cuando gana el peronismo en el '73 éramos unos anárquicos, yo participaba en cuanto conflicto había, estábamos ahí prendidos. Hoy me río de esto y recuerdo que Marcelo [Giles] y Ricardo [Crisorio] siempre me lo criticaron, pero era una forma de protección. Teníamos un co-gobierno, habíamos decidido tener un co-gobierno, no respetábamos ninguna característica de la Universidad ni de la Facultad."

En cuanto a la composición de ese co-gobierno y al clima institucional de la época, señaló:

“...Era el grupo de graduados, alumnos y docentes éramos los directores. Y lo que yo te decía hoy en el inicio que Ricardo y Marcelo siempre me achacaron "nunca escribiste esa historia" la tenía escrita, pero la tuve que tirar porque en el momento después del golpe no sabías si podían venir por vos. Yo ya vivía en Varela, los libros escondidos, enterrados y demás, pero esos documentos que estaban escritos y demás de toda la historia esta era material subversivo. Entonces desapareció, yo tengo la historia oral, pero digamos, no puede ser más que ésta; "sí, sí, escribila". No, no, puedo contarla y que la escriba otro y bueno bárbaro. En el '74 se cierra la facultad y bueno..."

Para comprender esta forma de gobierno y los hechos que se suscitaron luego, recordemos que la carrera de EF surgió inicialmente como una sección, luego como Instituto dependiente de Ciencias de la Educación, y a partir de 1976 se constituyó en Departamento autónomo. Según el entrevistado, protagonista en los primeros años '70, esa "anarquía" surgió como oposición a la conducción de la carrera de Educación entre los años 1973 y $1974^{58}$, y a una voluntad de soberanía en las decisiones de EF respecto a la planta docente, los contenidos de la formación, entre otros aspectos,

“...Por ejemplo, había que reformular todo lo que eran los contenidos de los programas, así que (...) nosotros éramos un poco anárquicos por todo, no respetábamos nada y Educación Física como una hija descuidada, podría decirse, claro, con Ciencias no estábamos bien, porque además Ciencias, en ese momento tenía cierto pensamiento muy sesgado. Nosotros podíamos tener diálogos y demás, pero sabíamos que, por ejemplo, no era el pensamiento de Nassif ni de Savloff ni de muchas personas pero; con esto no quiero decir que eran algo muy contrario o negativo. Pero había sí un pensamiento totalmente distinto, mucho más de respeto

\footnotetext{
58 El director del Departamento de Ciencias de la Educación entre 1973 y 1974 fue Héctor Mendes (Hernando, 2015). Cabe señalar que en esos conflictivos años entre 1973 y 1976, los cambios en la dirección del Departamento mencionado fueron constantes (Garatte, 2012). La resistencia planteada por este grupo no estaba dirigida específicamente a la figura de Mendes, quien duró poco en el cargo y tenía una perspectiva que podía resultar afín a los profesores de EF que aquí estamos mencionando, sino a quienes lo sucedieron luego (Entrevista a Parenti).
} 
por lo institucional muy arraigado y con conflictos internos incluso en Ciencias por supuesto, y claro, nosotros estábamos en la vereda, no sé si opuesta pero no...".

En el testimonio anterior, Parenti da cuenta de diferencias políticas e ideológicas con un sector que conducía a la carrera de Ciencias de la Educación, y de la que EF dependía en ese momento. Esas diferencias también estaban vinculadas a la necesidad del grupo "anárquico" de poder decidir sobre los asuntos académicos y programáticos de su carrera, y que devino en la constitución del Departamento de EF en 1976, aunque ya no con la presencia de estos docentes, y en otro contexto institucional y nacional.

Algunos de los que participaban de ese co-gobierno de hecho, fueron: Carlos Parenti, María Lucía Gayol, Jorge Fridman, Enrique Ferrairo (alumno), Norberto Asali, Jorge Sbarra, y Enrique López Osornio.

En el año 1974, con la Universidad ya intervenida, y previo a la limitación de Parenti y otros profesores, se le pidió a este grupo que se ajustara a las normativas institucionales, bajo la amenaza de que iba a ser cerrada la carrera,

“...en el '74 cuando vienen ya las autoridades de la facultad nos dicen "o sacamos la carrera o se encuadran dentro de lo que son las normas de la Facultad de Humanidades". Bueno, en estos términos es como la película "Alguien tiene que ceder", cedimos nosotros. No podemos estar tan anárquicos...”.

En un artículo presentado en agosto de 1983 por el entonces director del Departamento de EF, Ernesto Rogg ${ }^{59}$, con motivo del Primer Encuentro de Graduados en Educación Física de la UNLP, él mismo señalaba: "La Universidad, con su tradición antes humanística que técnica, era el natural ámbito para propiciar una renovación de enfoque de la educación física", en alusión a la figura de Amavet, como un renovador en la disciplina, hasta entonces orientada a una expresión "dinámico-técnica" (Di Paolo: 1993: $67)$.

\footnotetext{
${ }^{59}$ Ernesto Rogg (1930-2006) nació en Capital Federal y fue el primer graduado de EF de la FaHCE. Ingresó a trabajar allí en el año 1959 como Ayudante Ad-Honorem en la cátedra Gimnástica I, pasando a desempeñar el cargo de Profesor Adjunto interino al año siguiente y en 1962 en la misma función en la cátedra de Didáctica Especial y Práctica de la Enseñanza en EF, cargos que titularizó por concurso a fines del año 1963. Fue Jefe de la por entonces denominada Sección de Educación Física dependiente del Departamento de Ciencias de la Educación en reemplazo de Amavet entre los años 1968 y 1970, y luego del recientemente creado Departamento de EF en los años de la dictadura cívico-militar entre 1976 y 1983 y consejero académico en el año 1982 (Legajo de Rogg, FaHCE). De descendencia alemana, si bien fue un colaborador casi "natural" de Amavet tanto por ofrecerse a colaborar en el Profesorado, como por ser el primer egresado de la carrera y ayudante en sus cátedras, con los años será fuertemente cuestionado por otros de los ayudantes de aquél, debido a prácticas "fraudulentas" y sospechas de colaboración con el "proceso" (Entrevista a Carlos Parenti, 2016). Renuncia a sus cargos docentes en junio de 1973 (Res. 501/73), y regresa a la Facultad también en ese mes del año 1976 (Res. 321/76). Fue cesanteado en sus cargos como Profesor Titular Interino en Introducción a la EF y Gimnástica I y Profesor Adjunto Interino de Didáctica Especial y Práctica de la enseñanza en EF el 15 de noviembre de 1988, luego de pasar por una instancia sumarial (Res. 890/88).
} 
En relación al procesamiento de la pertinencia, relevancia y legitimidad de la EF dentro de la FaHCE, en el mismo documento, y a propósito de la implementación de la carrera en el segundo semestre de 1953, el mismo docente señalaba para 1983 que,

"Todo, o casi todo, surgía de la nada, pues no había antecedentes universitarios en el país que pudieran orientar los primeros pasos en una estructura académica no demasiado dispuesta a acoger en su seno a esos representantes de la transpiración y la fuerza bruta. La intelectualidad se resistía a compartir sin más a este intruso de poca o ninguna perspectiva académica. La prédica científica y la docencia formadora de desarrollo por Amavet, acompañado por el profesor Anselmo Barros, han coadyuvado a la progresiva superación de actitudes encontradas, producto de incomprensión por falta de información" (Rogg citado en Di Paolo: 1993: 68) (la cursiva es propia).

La intervención precedente de Rogg, da cuenta nuevamente de que el procesamiento de la pertinencia y legitimidad de la EF al interior de la FaHCE fue un proceso conflictivo y persistente. Nótese que en el cierre provisorio de la carrera en 1969 relatado previamente, así como en este evento de 1983, la cuestión del sostenimiento y relevancia de una carrera de EF en la Universidad, era motivo de controversias y de posiciones encontradas. Las alusiones a los estudiantes y profesores de EF como "representantes de la transpiración y la fuerza bruta", o la calificación de la EF como "intruso de poca o ninguna perspectiva académica" da cuenta de una percepción devaluada de la disciplina a nivel de algunos personajes de la institución, a la vez que la revalorización de la figura de Amavet como un "predicador" en favor de su inclusión y mantenimiento en la FaHCE.

\section{Conclusiones}

En este capítulo abordamos algunos rasgos históricos de la EF como disciplina y su origen escolar, para luego caracterizar a las primeras instituciones de formación superior en este campo de conocimiento, que dieron lugar a dos perspectivas contrapuestas y en disputa a comienzos del siglo XX (la corriente denominada militarista y la cívico-fisiológica). En esta línea, identificamos el triunfo de esta última en la medida en que la identidad disciplinar y su fundamentación se constituyó en estrecha ligazón con la Fisiología y la Biología, como símbolo de estatus, reconocimiento y legitimidad.

Luego, analizamos la institucionalización universitaria de la EF en la década del 50 del siglo pasado, a partir de analizar los casos de Tucumán y La Plata, con especial referencia a éste último, caracterizado como el escenario de desarrollo de nuestro 
problema de investigación. Analizamos cómo ambas propuestas de formación se diferenciaron en cuanto a su perfil, espacio institucional, referentes, perspectivas teóricas y concepciones disciplinares. Estas diferencias pueden señalarse como marcas de distinción de la carrera de la FaHCE frente a otras propuestas formativas de carácter universitario y/o terciario presentes en ese momento. Básicamente, la diferencia fundamental estuvo dada por la decisión de los actores que participaron en el proyecto inicial de ubicar la carrera en una Facultad de Ciencias Humanas y de la Educación. Esa inserción institucional posibilitó que la misma asumiera rasgos particulares a partir de la relación directa con otras disciplinas como Ciencias de la Educación, Historia o Filosofía. Por otro lado, las Ciencias Médicas y Biológicas que conformaban la matriz disciplinar, si bien estaban presentes en la formación, en este caso no definían los rasgos identitarios del perfil de la carrera. Vimos cómo esta identidad particular fue posible no sólo por la decisión de ubicarla en la FaHCE, sino por el pensamiento y la labor de Amavet que repondremos en breve.

Además reconstruimos cómo, en el contexto del segundo mandato del gobierno peronista, se conformó una Comisión Especial que analizó la posibilidad de contar con un profesorado de EF en la UNLP, en línea con las orientaciones políticas y normativas de la época. Destacamos una de las justificaciones para crear esta carrera: un entendimiento acerca del aporte que la EF podía realizar a la educación "integral" del "nuevo ciudadano", y específicamente en la contribución más general de extender los saberes prácticos y físicos al conjunto de la sociedad, en una concepción generalizada que aún ligaba a la EF con la higiene y salud de la población.

En cuanto a la estructura institucional, nos preguntamos en qué medida los cambios disciplinares en materia de reconocimiento coincidieron o no con cambios políticos más amplios. En este sentido, encontramos que la carrera obtiene autonomía institucional en el marco de la última intervención autoritaria, en 1976, con un gobierno de facto. Habría que preguntarse qué sentido o intencionalidad implicó esa autonomía, o si la EF tuvo, en su desarrollo disciplinar, una funcionalidad para ciertas políticas autoritarias, a contrapelo de las ideas de su primer Director quien ya no estaría en ese proceso de autonomización.

Vimos cómo durante el proceso de constitución de la carrera de EF, el problema de su pertinencia y legitimidad se dirimió en torno a factores como su denominación, el lugar que ocuparía en la estructura institucional, la orientación formativa que adquiriría, las condiciones que debían reunir quienes quisieran estudiar la carrera, entre otros 
aspectos. Sobre este último punto las fuentes documentales permiten dar cuenta que en aquel momento no todos iban a poder ser profesores en EF. Aquellos aspirantes debían reunir una serie de requisitos ligados a un concepto de "aptitud física". Entendemos que los fundadores de la carrera apelaron a un criterio de normalidad, entendida como normalidad física, al pensar en los posibles ingresantes a la misma. Por otro lado, aquellos que sí pudieran ser profesores de EF, debían reunir otras cualidades. Esta especialidad iba a asumir características particulares en la FaHCE. Sería un profesor con una extensa formación teórica humanista, con amplio conocimiento de su disciplina, pero además formado en conocimientos contextuales, culturales y pedagógicos. Las preocupaciones de los fundadores, en este sentido, rondaban en torno a configurar un profesorado que tuviera como pilares el rigor, el prestigio académico, la aptitud y destreza físicas, como aspectos que aparecen de manera regular en los documentos fundacionales de la carrera.

Por último, hemos caracterizado la trayectoria del "fundador" de la carrera de EF, Alejandro Joaquín Amavet, desde los años previos a la creación de la misma en 1953 y hasta su limitación en 1973. Caracterizamos la conformación de sus equipos docentes, algunos de los cuales persistieron a partir de la intervención universitaria de 1974 y su continuidad por las autoridades a partir de la dictadura militar de 1976, y otros fueron exonerados o decidieron alejarse. Observamos que tanto la influencia del pensamiento de Amavet, así como la pertenencia institucional de la carrera al Departamento de Ciencias de la Educación (DCE), y las relaciones mantenidas con otras carreras y esquema de cursadas compartidas, favoreció la configuración de una orientación teórica de preeminencia humanista y pedagógica.

Caracterizamos, desde la visión de sus discípulos y sucesores, la construcción de la figura de Amavet como "fundador" de la carrera de EF a modo de contar una historia y posicionarse en ella, dando cuenta que en lugar de haber un único fundador, o figuras fundantes, más bien de lo que se trató es de un proceso de creación mucho más amplio y diverso, en el que intervinieron múltiples actores.

Además, dimos cuenta cómo la problemática de la relevancia y legitimidad de la EF en la FaHCE fue persistente en distintos momentos de la carrera, más allá de los cambiantes contextos sociales, y de cómo el enfoque de las Humanidades fue progresivamente vinculado a la construcción de esa legitimidad. Este enfoque no era entendido por Amavet como una simple adición de materias al plan de estudios, sino desde una concepción de la educación en general y de la educación física en particular 
distintiva de las existentes, y que rediscutía el lugar de la EF en la generación de conocimiento y su contribución a la sociedad. De este modo, caracterizamos su perspectiva como un intento de despegarse de una idea física-biológica-pragmática dominante en la disciplina, y su propuesta y desarrollo de una concepción de EF humanística, que era colocada dentro del universo de la "EDUCACIÓN". Además, Amavet construyó una perspectiva sobre la EF que fue más allá de la formación de sujetos en aspectos técnicos y humanísticos, para abrevar en una concepción sociopolítica sobre la misma. En este sentido, sostenía que una "correcta EF" no debía contribuir a sistemas totalitarios, sino más bien a la conformación y fortalecimiento de una sociedad democrática.

Por otro lado, evidenciamos que el alejamiento y posterior fallecimiento de Amavet posibilitó el ascenso de docentes muy jóvenes en las estructuras de las distintas cátedras que coordinaba, como Carlos Parenti y Jorge Fridman, que se desempeñaban hasta ese momento como ayudantes, aunque discontinuaron su participación a partir de 1974, para retornar en 1984. Además, según los distintos testimonios recogidos y las versiones reconstruidas por otros analistas de la misma institución, señalan que la ausencia de Amavet dejó un vacío intelectual y organizacional significativo, que influyó en la orientación de la carrera en los años siguientes.

Para finalizar, consideramos que la cuestión de la pertinencia, relevancia y legitimidad de la EF en la FaHCE, ha sido retomada y problematizada por los actores participantes del gobierno de la carrera, entendiendo que su sola instalación y permanencia en la institución, no garantizó per se que fuera reconocida y valorada por los pares de otras disciplinas. Al calor de la recuperación democrática, hacia fines de los años 80 , comenzaron a emerger nuevas perspectivas disciplinares, traducidas en cambios curriculares, políticas académicas y estrategias, gestadas desde quienes fueron los colaboradores más cercanos de Amavet y las generaciones más jóvenes, formados mayormente en la última dictadura o en la transición a la democracia. Esos actores iniciaron un proceso de discusión acerca de la asociación histórica entre la EF y disciplinas como la Medicina, la Fisiología o la Biología y la concepción del cuerpo como "natural", y empezaron a disputar otro lugar de mayor identificación en la FaHCE y en la UNLP. En este sentido, en el capítulo siguiente, nos proponemos reconstruir quiénes fueron esos docentes, graduados y estudiantes que desarrollaron políticas académicas y estrategias, cuáles fueron las perspectivas que construyeron en torno a la disciplina y al lugar de la misma en la institución, y en qué medida esas políticas y estrategias les 
permitieron posicionar a la EF en un lugar de mayor reconocimiento y legitimidad a nivel institucional y disciplinar. 


\section{CAPITULO 2}

\section{Redes de relaciones, estrategias y trayectorias de académicos de Educación Física en Humanidades (1992- 2004)}

\section{Presentación}

En este capítulo describimos y analizamos las redes de relaciones sociales, estrategias y trayectorias académicas de un grupo de actores de EF de la UNLP que intervinieron en políticas académicas disciplinares e institucionales entre los años 19922004. Estos académicos habían comenzado su participación en el gobierno de la carrera y de la FaHCE en los años del retorno democrático desde 1984, y tuvieron un rol protagónico en las políticas desarrolladas en el período seleccionado. El capítulo se focaliza en la perspectiva de esos actores que, como buscaremos mostrar a lo largo de nuestra argumentación, procuraron a través de las políticas mencionadas legitimar su campo disciplinar en ese ámbito institucional.

El enfoque teórico y metodológico de nuestra investigación dialoga con investigaciones históricas, antropológicas y pedagógicas (Caldo y Fernández, 2012; Carrera, 2014; Frederic y Soprano, 2009; Garatte, 2008; 2012; Garatte y García Clúa, 2013; Guber, 2001a; Soprano, 2011) que han puesto a prueba algunos de los supuestos centrales de nuestro objeto de estudio. En particular, la idea de analizar las redes de relaciones de contenido diverso (disciplinares, profesionales, académicas, personales) en las que diversos actores, en nuestro caso académicos de $E F$, se inscriben y sus formas de sociabilidad, como una vía para comprender de manera holística y situada sus perspectivas y experiencias.

En ese marco, el análisis micro-social de individuos y grupos en procesos de "contextualización múltiple" (Revel, 2005) y que se mueven en distintos ámbitos (cátedras, oficinas del Estado, posgrados, grupos informales de estudio, agrupamientos políticos) (Neiburg y Plotkin, 2004), así como la reconstrucción de sus trayectorias académicas, resultan piezas fundamentales para comprender su acceso a posiciones institucionales como miembros del gobierno universitario, la configuración de lealtades políticas, de perspectivas disciplinares con relación a la formación de los estudiantes, y 
su participación en el diseño de estrategias y el procesamiento local de determinadas políticas estatales. Entendemos que en esas redes de relaciones se construyen compromisos morales y políticos, proyectos institucionales, se mantienen relaciones de competencia, colaboración, conflicto, entre otras, se comparten sentidos, se establecen acuerdos y alianzas, y que esta dimensión social resulta clave para interpretar cómo luego estos actores construyeron estrategias con diversos fines y sus formas de procesamiento de las políticas, en qué medida las resignificaron, si se apropiaron de ellas o no, y de qué modos.

Sostenemos que esas relaciones tienen una cierta eficacia social para explicar luego las posiciones ocupadas por estos actores y las perspectivas y experiencias que desarrollaron con relación a las políticas. Nos preguntamos: ¿Quiénes participaron de las políticas académicas de EF en la UNLP a partir de la década del 90 y en los primeros años del 2000? ¿Cuáles fueron sus trayectorias, formas de sociabilidad y redes de relaciones que favorecieron su participación en esas políticas? ¿Qué perspectivas y experiencias construyeron estos actores en relación a su participación en políticas académicas de EF en la UNLP entre los años 1992-2004? ¿De qué forma esa participación incidió en el proceso de legitimación disciplinar de la EF en la UNLP en el período en estudio?

En el primer apartado, analizamos el contexto del retorno democrático a nivel del gobierno institucional de la UNLP y de la FaHCE, para comprender el escenario en el que ingresaron los académicos de EF a la política universitaria en esa Unidad Académica y algunos sucesos destacados por nuestros entrevistados, acontecidos en los años '80 con relación a la gestión departamental de EF. En el segundo apartado, indagamos un espacio político académico que se configuró en la FaHCE a fines de los años '80, el Frente Amplio de Graduados, del que participaron graduados de EF en el período de nuestro estudio, 1992-2004. Analizamos las articulaciones entre distintas figuras de ese espacio y su participación en las políticas disciplinares a partir de los años '90. En el tercer apartado, describimos las distintas gestiones del DEF desde el año 1984 hasta el 2004, sus rasgos salientes y las perspectivas de otros actores de la institución sobre ese proceso. En esta caracterización, destacamos las visiones y relaciones que se construyeron entre actores de EF y de otras disciplinas de la institución. En el cuarto apartado, desplegamos las trayectorias académicas de este grupo de EF que condujo las políticas y estrategias disciplinares en el período de nuestro estudio, y que es identificado 
de esa manera por otros actores de la comunidad ${ }^{60}$ más amplia de EF y de la institución. En el último apartado, analizamos una estrategia de formación de posgrado de estos actores en el exterior, como un viaje de intercambio y de construcción de una nueva perspectiva disciplinar, distinta a la fundante, que luego se desplegó en producciones académicas y se discutió en el marco de la última reforma curricular del año 1997. Para finalizar, recogemos los principales hallazgos y conclusiones del análisis realizado.

\section{La configuración social de los académicos de EF y su participación en el gobierno institucional de la FaHCE y de la carrera entre los años 1983 y 1992}

En el año 1982, el por entonces Ministro de Educación y Justicia, Dr. Carlos R. S. Alconada Aramburu, integró una organización que había sido constituida en esos años por profesionales y académicos cercanos al radicalismo, la "Fundación Eugenio $\mathrm{O}$. Blanco". Particularmente, Aramburu formaba parte de un grupo dentro de la "Fundación" que era coordinado por quien había sido rector de la UNLP en los años de la reapertura democrática, el Ingeniero Raúl Adolfo Pessacq ${ }^{61}$. Ese grupo nutrió de cuadros políticos a la gestión institucional de la UNLP y a algunas de sus unidades académicas durante el período denominado de "normalización universitaria" en el gobierno de Raúl Alfonsín (Garatte, 2008). ${ }^{62}$

Desde la perspectiva de uno de los actores políticos que jugó un rol protagónico en esas decisiones por esos años, la UCR, como partido gobernante, no contaba entre sus miembros con la cantidad de personas necesarias para nutrir a todas las unidades académicas de la UNLP ${ }^{63}$. En principio, se resolvió la gestión a nivel central, y luego fueron definiéndose los decanos de las distintas facultades. El elegido como decano

\footnotetext{
${ }^{60}$ Corresponde señalar aquí que la utilización de los términos comunidad y grupo en todo el capítulo no son equivalentes. El término comunidad refiere a la totalidad de los docentes, graduados y estudiantes de EF, y el de grupo, a un conjunto reducido de profesores que serán estudiados en profundidad por su protagonismo en las políticas disciplinares e institucionales durante los años 1992 y 2004.

${ }^{61}$ Pessacq fue el rector normalizador de la UNLP entre los años 1983 y 1986. Desde su participación activa en la fundación mencionada, vinculada a la UCR, se diseñaron las bases para una reforma de la universidad, que fueron tenidas en cuenta por el gobierno de Alfonsín (Garatte, 2008). Para los dos períodos siguientes (1986-1989/1989-1992) el rector fue el Dr. Ángel Luis Plastino, producto de la primera Asamblea universitaria tras el retorno a la democracia en 1986 (UNLP, 2017).

${ }^{62}$ La "normalización universitaria" mencionada se inició a partir del decreto número 154 con fecha 13 de diciembre de 1983. En dicho decreto se establece la intervención de las Universidades Nacionales con el fin de designar Rectores Normalizadores. Los Decanos de cada Facultad serían designados por el Ministerio de Educación y Justicia a propuesta del Rector Normalizador, y se aplicarían los estatutos universitarios vigentes al 29 de julio de 1966 (Decreto 154/83). Última consulta el 18 de octubre de 2017, en: http://www.coneau.edu.ar/archivos/570.pdf.

${ }^{63}$ Entrevista a Luis Menucci, el 8 de julio de 2007 en La Plata realizada por Luciana Garatte. En Garatte, 2008.
} 
normalizador de la FaHCE en 1984 fue el Dr. en Letras David Lagmanovich, quien estuvo poco más de tres meses en el cargo y renunció prontamente "por diferencias con la Presidencia de la UNLP" (Garatte, 2008: 54). Luego, las autoridades de la universidad designaron como decano al historiador José Panettieri (1926-2012), no vinculado al radicalismo, pero con un perfil académico prolífico, y que había tenido una importante trayectoria en los años previos a la dictadura de 1976 (Garatte, 2008).

Panettieri había comenzado a militar desde muy joven en el Partido Socialista, desde donde formaba a sus pares en Historia (UNLP, $2012^{64}$ ). Comenzó su desempeño como docente tempranamente en distintas facultades de la UNLP, y como investigador fue un pionero de los estudios historiográficos sobre el mundo del trabajo. Estuvo exiliado en Bolivia durante la última dictadura cívico-militar, y al retorno democrático se desempeñó como director del Departamento de Historia de la FaHCE y como decano normalizador, siendo electo por dos períodos consecutivos más, entre 1986 y 1992 (UNLP, 2017).

Desde su gestión, y acompañado por figuras muy ligadas al partido gobernante (como el caso de la vicedecana Blanca Sylvia Pena), se propuso una política que, en los documentos de la época, fue catalogada como de "reparación académica", y que incluyó la recomposición de la planta docente y la reactivación del cogobierno universitario (Buchbinder, 2005; Garatte, 2008). Esto supuso el regreso de docentes cesanteados, exiliados y otros que habían abandonado la actividad a partir de la violencia política en 1974 y del terrorismo de Estado entre 1976 y 1983, la regularización de la planta docente y la apertura al acceso estudiantil luego de años de restricciones como cupos, exámenes de ingreso o aranceles (Paso, 2012).

Durante el proceso de "normalización universitaria" de los años '80, desde la gestión central de Pessacq se inició una serie de búsquedas para la gestión del DEF, según señala Carballo ${ }^{65}$, "en el proceso anterior al golpe de Estado, de personajes potables, que no estuvieran vinculados a la dictadura", y así surgió el nombre de Carlos Parenti. Había ingresado a trabajar a la FaHCE en la cátedra Teoría Especial de la Gimnástica en el año 1973, siendo limitado en sus funciones en diciembre de 1974, mediante la resolución № 24. Fue Director del DEF entre los años 1984 y 1990, y se desempeñó como docente en distintas asignaturas, llegando a ser profesor titular de

\footnotetext{
${ }^{64}$ Última consulta el 25 de agosto de 2017 en: http://unlp.edu.ar/articulo/2012/11/22/la palabra noviembre 2012 jose panettieri historiador pionero del mundo del trabajo.

${ }^{65}$ Carlos Carballo fue entrevistado en dos oportunidades, en la ciudad de Ensenada el 13 de abril y el 28 de septiembre de 2016.
} 
Teoría de la Educación Física III hasta su jubilación a comienzos de 2016 (Legajo de Parenti, FaHCE) ${ }^{66}$. Parenti fue uno de los profesores que se formó con el Director de la Carrera desde su creación en 1953 hasta 1969, Alejandro Amavet, participando de sus cátedras y en distintas instancias de formación que él mismo propiciaba. A su vez, con el retorno democrático, Parenti mantenía relaciones personalizadas con personajes muy cercanos al radicalismo universitario en distintos ámbitos de sociabilidad. Eran vínculos de amistad mantenidos por fuera del ámbito profesional y universitario, durante los fines de semana en comidas y encuentros con compañeras de promoción de la carrera y sus parejas, todas figuras centrales ligadas al gobierno radical de aquellos años. Esas mismas compañeras, militantes del radicalismo, fueron quienes lo sugirieron como director del Departamento. En sus palabras, "en ese momento que gana el radicalismo, mis compañeras eran todas militantes radicales, vinieron un día y me dijeron 'Carlos el que está más en condiciones de tomar esto sos vos...". Cabe señalar que Parenti no se encontraba afiliado a la UCR. Sobre las motivaciones que pudieron llevar a sus compañeras radicales a proponerlo como director del DEF, Parenti relató:

"yo había estado en lucha constante contra el régimen de los años 1968 desde mi ingreso hasta el 1974, fecha en la que constantemente participábamos con otros compañeros en desacuerdo con la política universitaria de esa intervención, sumado a que a partir del '69 fui ayudante alumno en Introducción a la Educación Física, materia de $1^{\circ}$ año, con el profesor Alejandro Amavet, titular y fundador de la carrera en la UNLP, y Norberto Assali (Ayudante diplomado). Participaba con Jorge Fridman, dúo de estudios en todas las materias y amigo. A partir de 1973, año de mi titulación, fui ayudante diplomado de dos materias más, de las cuales Amavet era Titular "Teoría Especial de la Gimnástica" de 3er año y "Seminario de Investigaciones en Educación Física" 4to año; de las cuales pasé a ser Titular por ser el Profesor Amavet jubilado de oficio. Quizás por eso la propuestas de mis compañeras al ser el que tenía mayor vínculo con los postulados de nuestra Carrera en la Facultad".

Como parte de ese proceso de definición de los elencos de gobierno del radicalismo durante la "normalización universitaria", podemos mencionar a la figura de Ana Lía Machado, militante de Franja Morada (FM, organización estudiantil de la UCR) en aquellos años, quien fue designada como secretaria del DEF.

Del testimonio anterior, es posible suponer que aunque Parenti no integraba las filas del radicalismo, los vínculos personalizados que mantenía con algunas compañeras que sí militaban en ese espacio, tuvieron cierta eficacia social al momento de proponerlo para la dirección del Departamento. A ese rasgo, se sumaba una trayectoria política

\footnotetext{
${ }^{66}$ Carlos Parenti fue entrevistado en dos oportunidades, en la ciudad de Ensenada el 23 de septiembre de 2016, y en La Plata, vía electrónica, el 23 de mayo de 2017. Esos testimonios nos permitieron reconstruir la historia de su ingreso a la Facultad y a la gestión del DEF, relatada en los párrafos que siguen.
} 
crítica con la intervención autoritaria de 1974 y una experiencia académica extensa vinculada a un referente histórico de la carrera como había sido Amavet. Con todos estos elementos, podemos hipotetizar que su figura resultaba confiable y legítima para las autoridades de la Facultad aunque, como veremos, eso no significó que su gestión estuviera exenta de conflictos y desacuerdos.

Parenti caracterizó su experiencia de gobierno como un esfuerzo por "desmontar todo lo que era el proceso", mediante el despliegue de "estrategias pedagógicas e ideológicas" para restarle poder a personajes y grupos vinculados a la dictadura, a la vez que reorientar la formación académica de los estudiantes.

En este sentido, Parenti destacó que tuvo dificultades relacionadas con los profesores que continuaban desde la dictadura y, durante nuestra entrevista, mencionó los objetivos que se trazó para su gestión:

"Los objetivos iniciales y principales consistían en democratizar la carrera, ya que el ingreso desde el '76 al '83 era con cupo, aproximadamente 100 alumnos, y examen de ingreso con pruebas atléticas y deportivas que establecían escalas de aprobación antojadizas, además existía un régimen de cursadas en las materias Gimnásticas que exigía en las prácticas el uso de un uniforme que sólo se vendía en la Cooperadora, al igual que los apuntes de cátedra, que funcionaba en el Departamento, cuyos integrantes eran el Director de la carrera Ernesto Rogg y varios profesores del cuerpo docente: No tener el uniforme era ausente, tanto en las prácticas de campo como en las "Prácticas de la Enseñanza" materia de fin de cursada. Sin dudas los inicios fueron de constantes interferencias por los docentes afincados desde el proceso" ${ }^{67}$

La gestión del DEF no fue sencilla, y rápidamente comenzaron a emerger tensiones con el Instituto de Educación Física ${ }^{68}$, con parte del cuerpo de docentes y con la vicedecana, Blanca Sylvia Pena. Pena pertenecía a las filas del radicalismo, y había comenzado su militancia allí a partir de la inserción en el "grupo de Gonnet”, en referencia a la localidad platense en la que residían sus participantes. Fue designada vicedecana de la FaHCE durante el período conocido de "normalización", y tenía asignadas como tareas la coordinación de las carreras de Psicología, Ciencias de la Educación y Educación

\footnotetext{
${ }^{67}$ Una situación similar se registró en el mismo período en el Departamento de Ciencias de la Educación de la FaHCE: la convivencia conflictiva entre los profesores que regresaban y los profesores que se mantenían del "proceso" militar (ver Garatte, 2012).

${ }^{68}$ Se conoce como Instituto de Educación Física a la coordinación de las actividades deportivas y recreativas de la UNLP no vinculadas a las carreras de Profesor y Licenciado en el área de la FAHCE. Está localizado en el Campo de Deportes de la Universidad, actualmente se denomina Dirección General de Deportes de la UNLP y no sólo gestiona la enseñanza de los colegios de su dependencia, sino también las actividades de la comunidad universitaria en sus instalaciones (información reconstruida mediante los testimonios). El conflicto entre el Profesorado y este Instituto, según el testimonio de Parenti, estuvo dado por la intención de las autoridades del nivel central de que el DEF de la FAHCE coordinara de forma unificada ambas dependencias, cuestión a la que miembros del Instituto se opusieron abiertamente. Este es el mismo espacio institucional en el que se inició Amavet a fines de la década del '40, denominado en ese momento Dirección General de Educación Física (Legajo de Amavet).
} 
Física (Garatte, 2008). Los conflictos que Parenti relata estuvieron vinculados a la "intromisión constante" de Pena con relación al apoyo solapado de algunas autoridades de la FaHCE a una especie de alianza que se había configurado entre docentes que continuaban desde el "proceso" y un profesor con aspiraciones personales de director. Parenti señaló que ese grupo de docentes desarrolló acciones "obstruccionistas" a su gestión.

A comienzos del año 1990, el decano Panettieri solicitó la renuncia a Parenti como un modo de, en palabras de Carballo, "calmar las aguas" 69 , y asumió como directora María Lucía Gayol ${ }^{70}$, quien completó el mandato hasta 1992 con un perfil, en sus propias palabras, de "interventora". Según Parenti "la profesora Gayol se hace cargo a partir de mi renuncia y consultado por las autoridades, consideré que estaba en condiciones de dirigir la carrera por su gran apoyo inicial y constante a mi gestión, y fue aceptada". La figura "administrativista", no vinculada a grupos políticos de Gayol, fue bien recibida por la comunidad de docentes de EF, y tuvo como objetivo central "ordenar" cuestiones de la planta docente, en un contexto de renuncias y abandono de cargos, y de restricción de la información sobre el estudiantado. Es que si bien, según Parenti, el número de docentes que renunciaron o abandonaron los cargos no fue tan considerable ("solo se fueron inicialmente tres, los que eran Titulares Interinos y luego otros por no presentarse a los Concursos iniciados en 1985, caducidad automática"), se llevaron consigo la información del desempeño de los estudiantes, situación que tuvo que ser subsanada por Gayol, quien convocó a nuevos docentes.

Según el testimonio de Gayol, a Parenti "le serrucharon el piso" por motivos políticos, en una disputa que se remontaba a los primeros años de 1970, con el grupo que mantenían los profesores Ernesto Rogg y Marta Demarta ${ }^{71}$. El relato es coincidente con el de Parenti en cuanto a que se produjo una situación de descontrol en el cuerpo docente, en el que muchos de sus profesores se enfrentaron abiertamente, algunos de ellos llevándose toda la información de los estudiantes y abandonando sus cargos. Gayol

\footnotetext{
${ }^{69}$ La resolución de aceptación de renuncia presentada por Parenti es la № 522 con fecha 7 de septiembre de 1990, aunque, su renuncia, comenzó a regir a partir del 15 de agosto del mismo año.

${ }^{70}$ María Lucía Gayol, tiene una extensa trayectoria en el campo de la Educación Física, tanto a nivel universitario como en otros niveles educativos, y en la gestión de la Provincia de Buenos Aires. Ingresó a estudiar EF en 1965, y egresó en 1968 como Maestra Especial en EF y como Profesora en 1969. Fue directora del DEF entre 1990 y 1992. Mientras fue entrevistada en el año 2016, se encontraba en trámite para jubilarse como profesora titular de Observación y prácticas de la enseñanza en EF I y II, asignaturas que se dividen según los distintos niveles del sistema educativo. Fue entrevistada en la ciudad de La Plata el 02 de septiembre de 2016.

${ }^{71}$ Rogg fue el primer egresado de la carrera de EF de La Plata y director del DEF durante la última dictadura. Demarta también fue una de las primeras egresadas y colaboradora cercana del primero (Legajo de Rogg, FaHCE; Entrevista a Carlos Parenti el 23 de septiembre de 2016).
} 
señala que cuando tuvo que hacerse cargo del DEF, la mayoría de las materias se encontraban sin profesores y no disponía de las calificaciones de los estudiantes. Es por ello que una de las primeras tareas que acometió fue la de nutrir de nuevos profesores a las cátedras y así regularizar la situación académica.

El sucesor de Gayol fue Ricardo Crisorio y para comprender las características que asumió su gestión en el DEF es preciso hacer referencia a un movimiento político renovador que se gestó en el claustro de graduados de la FaHCE a fines de los años 1980. Dicho movimiento resultó triunfante en las elecciones de 1988, y tendrá un protagonismo central tanto en la orientación de la carrera de EF luego de la gestión de Gayol, como a nivel de toda la institución. Sobre esta cuestión nos explayaremos en el siguiente apartado.

\section{El Frente Amplio de Graduados y la participación de actores de EF en un nuevo proyecto institucional}

Luego del retorno democrático, como mencionamos, la FM era la fuerza política hegemónica en el claustro de estudiantes, con la mayoría estudiantil en el Consejo Académico y el Centro de Estudiantes, y el claustro de profesores articulaba políticamente con esta agrupación y con el Partido Radical. Además, algunos de los funcionarios en la gestión de la FaHCE se encontraban vinculados al radicalismo -a pesar de no estar el decano identificado con esa fuerza política, sí lo estaba la vicedecana-. A fines de los años 80 , la situación no era la misma para el caso del claustro de graduados y comenzaron a perder peso en el de profesores ${ }^{72}$.

Dentro del claustro de graduados, se conformó el Frente Amplio de Graduados (FAG), compuesto por auxiliares docentes de Historia, Filosofía, Geografía, Educación Física, entre otras carreras, que provenían de dos listas estudiantiles independientes: el Movimiento Autónomo Estudiantil (MAE) y el Movimiento Independiente de Humanidades (MIH). A este agrupamiento inicial se sumaron otros graduados procedentes de agrupaciones políticas como el Partido Comunista (PC) o identificados con el radicalismo a nivel nacional, pero críticos de la gestión de la UNLP, según pudimos reconstruir a partir de testimonios de actores de EF y otras disciplinas ${ }^{73}$, que cumplieron funciones legislativas y ejecutivas en el gobierno de la Facultad, entre los años 1992 y 2004. Cabe

\footnotetext{
${ }^{72}$ Entrevista №2 a Carlos Carballo el 28 de septiembre de 2016.

${ }^{73}$ Entrevistas a Carlos Carballo el 28 de septiembre de 2016, a Marcelo Giles el 17 de diciembre de 2015 y a José Luis De Diego el 27 de septiembre de 2016.
} 
destacar que las significaciones presentes en esta reconstrucción, provienen de los fundadores del FAG.

Sobre la participación activa de actores de EF en la fundación del FAG, según Carlos Carballo ${ }^{74}$, él participó desde los comienzos y Marcelo Giles y Ricardo Crisorio “acompañaron". Carballo había ingresado a estudiar EF en el año 1981, en plena dictadura militar, y egresado en 1984, un año después de recuperada la democracia. Su vinculación con la política universitaria se inició tempranamente, antes de su graduación, y en estrecha relación con estudiantes de otras carreras de la FaHCE. Así lo manifestaba en una de las entrevistas:

"Nos empezamos a conocer con algunos como estudiantes de las agrupaciones en el '82, aunque estábamos en agrupaciones distintas. Chacho [por Antonio Camou] y yo estábamos en la misma agrupación, y en la otra estaban Alberto Pérez de Filosofía y Miguel Dalmaroni de Letras, o Laura Agratti que también es de mi generación, que es la Prosecretaria Académica de la universidad en este momento. $Y$ después confluimos en la creación del Frente Amplio de Graduados".

Como mencionamos, otro de los actores de EF que en el período objeto de nuestra investigación cumplió roles disciplinares e institucionales importantes, fue Marcelo Giles ${ }^{75}$, quien, según su testimonio, participó activamente del armado del FAG y sus iniciativas. Giles señaló que el FAG se formó "contra el espanto radical y la represión a los jóvenes", y era un agrupamiento sumamente heterogéneo, formado por "católicos y comunistas, gente del socialismo, comunismo, radicales disidentes". Algunos de esos radicales disidentes, según Giles, y que militaban en la FM de aquel momento, luego formaron parte del FAG, como los historiadores Guillermo Banzato y Alejandro Simonoff ${ }^{76}$. En el año 1988 ganaron la primera elección como FAG. Este triunfo fue un acicate para luego, en 1991, lanzarse en el claustro de profesores. Una de las principales consignas con las que se identificaban los integrantes del FAG era, en palabras de Carballo, que "las políticas universitarias se deciden dentro de la universidad y no en los comités", en referencia a los dispositivos de toma de decisiones de la UCR que desde su perspectiva

\footnotetext{
${ }^{74}$ Carlos Carballo fue entrevistado en dos oportunidades en la ciudad de Ensenada: el 13 de abril y el 28 de septiembre de 2016. Su trayectoria profesional y académica será abordada más adelante en el presente capítulo.

75 Marcelo Giles fue Director del Departamento de Educación Física en dos oportunidades, entre los años 1998 y 2004. Se desempeñó en las cátedras de Educación Física I y II. En la actualidad es profesor titular de Educación Física I, una cátedra multitudinaria que recibe más de mil estudiantes por año. Fue entrevistado en la ciudad de La Plata el 17 de diciembre de 2015.

${ }^{76}$ Tanto Guillermo Banzato como Alejandro Simonoff tuvieron un rol destacado en la política universitaria e institucional, desde su participación como militantes estudiantiles en la FM a partir del retorno democrático. Banzato fue presidente del Centro de Estudiantes de la FaHCE durante la "normalización", y Simonoff participó de la comisión organizadora del mismo y fue delegado por esa Unidad Académica ante la Federación Universitaria de La Plata (FULP) en esos años (Garatte, 2008; 2012).
} 
habían dominado la escena de definiciones políticas hasta ese momento. Él mismo lo definía en este sentido como un "partido académico, de centro izquierda pero académico". Desde la perspectiva de Ana María Barletta ${ }^{77}$, la FM representaba para el FAG, "nuestra contradicción principal, porque la Franja Morada era una agrupación estudiantil que articulaba fuertemente con el rectorado y con toda la hegemonía radical en la Presidencia".

Para las elecciones de 1992, buena parte de estos graduados que en los primeros años de formación del FAG se habían desempeñado como auxiliares docentes, revistaban en ese momento ya la categoría de profesores, y se dio una situación inédita en la política institucional de la FaHCE, que fue la presentación de tres listas diferentes de profesores, con candidatos a Decano. Los candidatos eran: Luis Viguera (padre del último decano) -al que apoyaban los profesores de EF-, José Luis De Diego y Ural Pérez, a quien el radicalismo había definido como su candidato. En esa elección resultó triunfante De Diego, y las otras dos listas empataron en el segundo lugar con la misma cantidad de votos. En el mismo Estatuto no estaba contemplado qué hacer frente a una situación como esa. Lo que sí se encontraba previsto era que la lista con mayoría de votos obtenía cuatro de los seis consejeros docentes, y la segunda los otros dos consejeros $^{78}$. De Diego decidió armar una alianza con el sector de Viguera para fortalecer y legitimar su gestión, y éste último fue designado como su vicedecano. Esta "alianza" entre el sector de De Diego y el del denominado "viguerismo auténtico" ${ }^{79}$, fue referenciada por Carballo como una estrategia de "entrismo": es decir, tener la garantía de los votos en

\footnotetext{
${ }^{77}$ Ana María Barletta es platense, egresó en 1979 de la carrera Profesorado de Historia en la FaHCE. Se fue de La Plata junto a su hermana el 12 de marzo de 1976 a la ciudad de Buenos Aires, unos días antes del golpe militar, a raíz de su participación política en "organizaciones de la izquierda internacionalista". En 1979 viajó a Europa para intervenir en instancias de formación política. Participa de la gestión académica de la universidad desde el año 1984 cuando fue designada secretaria del Departamento de Historia hasta 1986, y en 1992 fue elegida secretaria académica de la FaHCE hasta 1998, y decana de la misma entre los años 2004 y 2010. De su participación en los elencos de gobierno tanto de la FaHCE como de la UNLP, se destaca su desempeño como Vicepresidenta Académica desde el año 2014 hasta abril de 2018, siendo la primera profesora de Humanidades en ocupar un cargo ejecutivo en la Presidencia (entrevista realizada el 20 de octubre de 2017 y reconstrucción propia en base a las páginas web de las respectivas instituciones).

${ }_{78}$ Cabe señalar que según el Estatuto de la "normalización" de diciembre de 1983 -que reestablece los Estatutos vigentes a 1966-, la composición de los Consejos Académicos era la siguiente: 12 integrantes, de los cuales 6 eran profesores -4 por la mayoría, 2 por la minoría-, 2 graduados y 4 estudiantes.

${ }^{79}$ Según los testimonios de Carballo y Giles, este sector comandado por Luis Viguera, en años posteriores a la creación del FAG, fue denominado de este modo por sus adeptos, en clara alusión a un viguerismo subsiguiente, referenciado en la figura del hijo de Luis, Aníbal Viguera, quien fuera luego secretario académico en 2004, vicedecano entre los años 2006-2010 y decano de la FaHCE entre los años $2010-2014$ y 2014 hasta abril de 2018.
} 
profesores, a la vez que diluir las posibilidades del radicalismo en ese claustro, todavía mayoritario en estudiantes ${ }^{80}$.

Para las elecciones de 1995, la correlación de fuerzas se inclinó más claramente hacia esta alianza y el FAG, y se presentaron en una lista "de unidad": De Diego fue reelegido como decano y obtuvieron mayoría en profesores. Si bien la FM ganó las elecciones en estudiantes, perdió los cuatro consejeros por la mayoría, cediendo un consejero a la segunda fuerza, la Agrupación Unidad para la Lucha Estudiantil (AULE) creada en 1992. Cabe señalar que particularmente Carlos Carballo, durante las distintas entrevistas mantenidas, se explayó extensamente sobre lo sucedido entre fines de los años 1980 y primeros años de 1990, específicamente en cuanto a su participación en el espacio del FAG y el gobierno institucional. Tal es así que, ante la pregunta acerca de si era sólo él quien participaba de EF en ese espacio, respondió "el referente por ahí sí, había otros que acompañaban, como Marcelo Giles, no integró la lista pero acompañó obviamente con el voto, Santiago Achucarro, Laura Chiani, ellos no estaban en la lista, y Marcelo [por Giles] no recuerdo si estaba en la lista". Podríamos suponer que el hecho de constituirse en el representante de EF del espacio político-académico que gobernaba la Facultad, puede haber contribuido en el reconocimiento del grupo de pares de otras carreras y el posterior acceso a posiciones institucionales.

El proceso que se extiende entre los años 1992 y 2004 fue referenciado por Carballo como "de fuerte resistencia al menemismo y al limismo [en referencia al Rector Luis Julián Lima] en la universidad". Esta resistencia se tradujo en las tres asambleas en las que la gestión de Humanidades apoyó a candidatos propios para la presidencia de la universidad, que emergieron de alianzas con otras facultades ${ }^{81}$.

Según Carballo, la alianza en la FaHCE apostó en 1998 por Ana Barletta como candidata a decana, pero por circunstancias personales Barletta decidió no aceptar. Frente a la ausencia de candidatos posibles, surgió la posibilidad de Guillermo Obiols, quien no era parte de la estructura del FAG y sus aliados, y con quien establecieron una serie de acuerdos para garantizar una continuidad en la perspectiva de trabajo ${ }^{82}$. La

\footnotetext{
${ }^{80}$ La información sobre esta alianza brindada por Carballo es coincidente con la presente en el Acta del Consejo Académico No 107 del 12 de mayo de 1992. En ese acta, el decano entrante De Diego informa la composición de los cuadros de las distintas secretarías y áreas y señala que ese acuerdo se estableció "para evitar una ruptura institucional y la transparencia de lo actuado" (FaHCE, 1992:1).

${ }^{81}$ Uno de ellos fue Isidoro Schalamuk, ex decano de la Facultad de Ciencias Naturales, y José Luis De Diego (decano de la FAHCE entre 1992-1995, 1995-1998, y 2001-2004) en las dos siguientes oportunidades.

82 Una de las condiciones que puso Obiols para ser candidato a decano fue la de poder designar a sus colaboradores más cercanos (vicedecana y secretario académico). Esto fue comprendido por el FAG quienes a cambio designaron parte de los secretarios, entre ellos, al de Investigación y Posgrado y al de Extensión,
} 
gestión de Obiols se extendió desde 1998 a 2001. En 2001 volvió De Diego por tres años más. Allí, este grupo de EF ingresó por primera vez a la función ejecutiva de la gestión institucional, con Carballo como Secretario de Extensión, quien desempeñó este cargo desde 1998 a 2004 (en la gestión de Obiols y la última de De Diego).

Una vez caracterizada la participación de actores de EF en la configuración del FAG, y la recomposición de los claustros a nivel institucional producto del triunfo electoral de este espacio, a continuación nos detendremos en el contexto institucional y departamental en la llegada de Crisorio a la gestión del DEF.

\section{Política universitaria, redes de relaciones y gestión académica en el Departamento de Educación Física en los años '90}

Para el año 1992, el presidente de la UNLP era el ingeniero Luis Julián Lima, quien ejerció ese cargo por tres períodos consecutivos, hasta el año 2001. Lima provenía de las filas del radicalismo, y había participado de la "Fundación Eugenio O. Blanco" que, como mencionamos más arriba, nutrió de cuadros políticos a la gestión institucional de la UNLP desde los años $80^{83}$. Lima había tenido que competir con dos contrincantes, en una tríada de ingenieros: con el rector "normalizador" Pessacq y con Guillermo Hang, de la Facultad de Ciencias Agrarias y Forestales; todos ellos, aunque con matices, críticos de la gestión universitaria desplegada por el Poder Ejecutivo Nacional a cargo del presidente Menem $^{84}$. En la Asamblea de abril de 1992, resultó triunfante Lima. Con respecto a la composición política del claustro estudiantil, la hegemonía de FM era indiscutible: para 1994, gobernaba ocho de las catorce unidades académicas ${ }^{85}$.

En mayo de 1992, desde la flamante gestión de la Facultad, se propuso como director del DEF al profesor Ricardo Crisorio ${ }^{86}$. Uno de los propósitos de la nueva gestión

que fueron Miguel Dalmaroni y Carlos Carballo, respectivamente. En palabras de Carballo, estas designaciones oficiaron como un "reaseguro político" para la gestión anterior.

83 Según la bibliografía de referencia y los testimonios relevados, para los años '90, las principales universidades nacionales, UBA, UNLP y UNC, se encontraban gestionadas por el radicalismo (Buchbinder, 2005).

${ }^{84}$ Este posicionamiento crítico frente a la gestión del PEN, fue relevado de una entrevista realizada a los aspirantes al Rectorado por Radio Universidad Nacional de La Plata, en abril de 1992. ver: "Debate de candidatos a Presidente de la UNLP en 1992" http://sedici.unlp.edu.ar/handle/10915/34972.

${ }^{85}$ Estas unidades académicas fueron: Ciencias Económicas, Ciencias Jurídicas y Sociales, Odontología, Humanidades y Ciencias de la Educación, Agronomía, Naturales y Museo, Bellas Artes y Arquitectura (Talamonti Calzetta, 2008).

${ }^{86}$ Ricardo Crisorio es Profesor en Educación Física y Doctor en Educación por la FaHCE. Ingresa a trabajar como ayudante diplomado en la cátedra Gimnástica I (actual Educación Física I) en el año 1984, y actualmente es profesor titular de la asignatura Educación Física V. Fue director del DEF entre los años 1992 y 1998 y vicedecano de la FaHCE entre 2001 y 2007, durante el tercer mandato de De Diego -2001/2004- y el 
fue priorizar departamentos docentes "con muchos inconvenientes" como Psicología y Educación Física, los más numerosos ${ }^{87}$. A partir de esa idea se definió "reforzar" la dirección del DEF con la figura de un colaborador, ya presente en Psicología en la forma de un consejo con dos profesores. Para el caso de EF el decano De Diego propuso a María Lucía Gayol, directora saliente, en el cargo de coordinadora para el trabajo, "en estrecha colaboración" con Crisorio, en "áreas pendientes" como la de investigación, reforma del plan de estudios, y la relación entre el DEF y el Instituto de EF de la UNLP. Tanto en esta situación como en la definición del resto del plantel de gestión institucional, el Claustro Estudiantil representado por la FM y una de las consejeras por el Claustro de Profesores, María Celia Agudo de Córsico, se mostraron resistentes y en general opositores a las determinaciones de De Diego. Tal es así que la propuesta de Crisorio como director del DEF, obtuvo siete votos a favor y cuatro abstenciones del bloque estudiantil y Córsico, y la abstención de los estudiantes a la designación de Gayol como colaboradora (FaHCE, 1992: 5).

En relación a la gestión del DEF que se inició en 1992, Crisorio se propuso, según sus propias palabras, "academizar la carrera". Para ello, diseñó una estrategia con la consigna de "aprender" de las disciplinas más tradicionales de la FaHCE -como Historia, Filosofía, Letras o Ciencias de la Educación-. En ese momento Crisorio ya era Profesor Titular Interino y, según Parenti, fue designado como director,

"a propuesta de la Lista Frente Amplio integrada por Docentes y Graduados donde participaban Carballo, Giles y otros ayudantes diplomados de la carrera, con acuerdo de los representantes de los demás Departamentos Docentes integrantes de la Lista. Cabe mencionar que Carballo, Giles, Achucarro, Chiani, se recibieron a finales de 1984 y al año próximo se los designó ayudantes Diplomados Ad Honorem, igual que otros como ayudantes alumnos por tener el $80 \%$ de las materias aprobadas".

El testimonio de Parenti da cuenta de la eficacia social que tuvo la participación de miembros de la carrera de EF en el FAG al momento de elegir al sucesor de Gayol en la dirección del Departamento. Es posible suponer que el cambio en el gobierno institucional en favor de este nuevo agrupamiento político en la FaHCE favoreció las condiciones para que los miembros del FAG se convirtieran en los electores del nuevo director del DEF.

Con relación al perfil de la gestión de Crisorio, según sus propias palabras,

primero de Ana Barletta (Legajo de Crisorio, R., FaHCE). Fue entrevistado en dos oportunidades en la ciudad de Ensenada: el 26 de octubre de 2015 y el 13 de septiembre de 2016.

${ }^{87}$ La información y orientación de la gestión institucional presente en este y los siguientes párrafos fue extraída del Acta de Consejo Académico №107 del 12 de mayo de 1992 (FaHCE, 1992).

${ }^{88}$ Esta visión es coincidente con la relevada en la entrevista a Carlos Carballo el 28/09/16. 
"el departamento tenía que salir a buscar, que salir de ser la prima pobre pero numerosa, que entonces era valorada políticamente por la cantidad de votos que traíamos en las elecciones, decir bueno no, yo quiero constituir un campo, y eso solo se puede hacer si se investiga seriamente, si se publica, si se hacen congresos que sirvan para debatir y para traer a los tipos que están en el candelero y bueno, veamos, veamos lo que dicen, no es para creerles, justamente por eso la idea de un congreso, entonces las tres grandes marcas fueron la investigación, los congresos y la revista". (Las cursivas son propias).

El testimonio anterior da cuenta de la impronta que asumió la gestión de Crisorio al frente del DEF, de proactividad de sus agentes en el diseño e instrumentación de políticas tendientes a acrecentar la posición de la EF dentro del campo científico de la FaHCE, reconociendo la existencia de una jerarquía instituida previa de carreras más tradicionales que ya conocían y practicaban las reglas del juego y a quienes quisieron imitar para mejorar su estatus en esas relaciones de poder. Cabe destacar aquí la potencia de la reconstrucción que hace el actor -y seguramente muchos de los que lo acompañaron- respecto al concepto de campo de Bourdieu. En este caso, dicha definición se convierte tanto en una categoría nativa o práctica de los actores desde la cual intentan explicar sus acciones y relaciones, así como en una categoría teórica o analítica, que nos permite a nosotros abstraer los dichos y comprender el sentido que tienen para los actores (Guber, 2001a; Rockwell, 2009). Para Crisorio, un campo es un espacio en el que tienen lugar una serie de posiciones y actividades que se desarrollan de forma "seria" que es como se hacen en Humanidades. Es decir, para él un campo es propiamente lo que hay en Humanidades. De este modo, su definición de campo no se ajusta estrictamente al concepto de Bourdieu, sino a sus expectativas y las de sus aliados, y por sobre todo se ajusta a las reglas de juego de la FaHCE.

En el mismo sentido, Crisorio señaló "asumimos el rol de prima pobre para salir de él, no para llorar, para hacerse el pobrecito". En ese sentido, asumió que EF "es una disciplina de la que no se espera", y que pensaban "tenemos que ser una carrera como cualquier otra y aprovechar oportunidades políticas y académicas". Esta situación, indicó Crisorio, recién comienza a darse a partir del año 1984, e identificó a la gestión de Parenti como "más política aunque necesaria", y a la suya como "más académica", posible gracias a esa gestión anterior.

Las relaciones de poder a las que aludimos en la FaHCE, se remontan a la creación de la institución a comienzos del siglo XX y, como señalara Barletta (2011) en un trabajo ya citado en el capítulo anterior, esas relaciones sufrieron modificaciones en distintos momentos de la historia institucional. La preeminencia de Ciencias de la Educación en la 
primera fundación como "Facultad de Ciencias de la Educación" en 1914, el cambio en la conducción institucional y en el desarrollo investigativo hacia la Historia en 1920, que se tradujo en la incorporación del término Humanidades en el nombre de la institución ("Facultad de Humanidades y Ciencias de la Educación"), precediendo al de Ciencias de la Educación, a un desarrollo y participación más diverso hacia fines de los años '50 y '60 con la modernización académica. Con todo, esa historia institucional marca el traspaso del protagonismo de las Ciencias de la Educación de corte positivista, al de la Historia, las Letras y la Filosofía, en una paulatina revalorización de las disciplinas humanísticas de corte clásico, y fundamentalmente de la Historia en el gobierno de la institución que se conserva hasta la fecha, aunque más matizada con la participación de la carrera de Sociología, creada en 1985 (Carrera, 2014). Las últimas disciplinas mencionadas concentraron el desarrollo de la investigación y los distintos fondos para su financiamiento (tanto a nivel de la UNLP como del Consejo Nacional de Investigaciones Científicas y Técnicas -CONICET-), y tuvieron los primeros Doctorados (incluyendo al más antiguo, el de Ciencias de la Educación, aunque de modo marginal por su matrícula) con reconocimiento local e internacional.

Al respecto, señaló Carballo:

"[...] en algún momento la punta de lanza del desarrollo académico, investigativo, en esta Facultad, estoy hablando de los años '40-'50 fueron claramente Historia y Ciencias de la Educación. Los dos primeros institutos de investigación, institutos, con ese rango, que es una cosa que tipifica el Estatuto de aquel momento...que tipificaba como núcleo de investigación fue Historia. Historia tiene una larguísima tradición con este Barba padre [por Enrique Barba ${ }^{89}$ ]...Larguísima tradición. $Y$ en el campo de las ciencias de la educación también, ni hablar de Víctor Mercante y los anteriores; sino, simplemente refugiándonos en los '50-'60 en la figura de Ricardo Nassif $\left.{ }^{90}[\ldots]\right]^{\prime}$. ${ }^{1}$

\footnotetext{
${ }^{89}$ Enrique Barba (1909-1988) fue oriundo de La Plata y se graduó en 1932 de "Profesor de Historia e Instrucción Cívica" de la FaHCE. Combinó la tarea docente con la de investigador, junto a una prolífica participación en la vida política institucional como director del Departamento de Historia, Vicedecano, Decano, así como profesor en la UBA y una destacada trayectoria en organismos nacionales sobre su disciplina (Presidente de la Academia Nacional de Historia, Director del Archivo General de la Nación y el Archivo Histórico de la Provincia de Buenos Aires). Fue discípulo de Ricardo Levene, quien es considerado el "fundador" de los estudios históricos en La Plata, y su trayectoria académica se inicia en 1934 -ya doctorado en España durante ese año- como adscripto en Historia Americana Contemporánea. Su participación institucional fue interrumpida en 1946, mientras se desempeñaba como Vicedecano de la FaHCE, a partir de la intervención universitaria por parte de las autoridades nacionales. Pidió sucesivas licencias a sus cargos docentes, hasta que en 1952 fue separado definitivamente. Regresa en 1955 para desempeñarse luego como Decano entre 1958 y 1961, siendo reelegido para el período 1961-1964 (Reitano, 2009).

90 Ricardo Nassif (1924-1985) nació en San Luis y egresó como Profesor de Filosofía y Ciencias de la Educación en la FaHCE en 1948. Fue un destacado pedagogo que se insertó inicialmente como docente y director del Instituto de Pedagogía de la Universidad Nacional de Tucumán entre los años 1952 y 1955, y participó activamente de la vida académica y política en la FaHCE y la UNLP. Desde 1957 como Profesor de Pedagogía, Director del Departamento de Ciencias de la Educación (DCE) y del Instituto de Investigaciones Educativas entre los años 1958 y 1966, Consejero Académico y Superior y Vicedecano entre 1961 y 1964 ,
} 
En la cita precedente, Carballo reconoció la primacía de ciertas carreras en el contexto institucional de la FaHCE, en distintos períodos históricos, y fundamentalmente el prestigio de la carrera de Historia en el desarrollo de la investigación hasta avanzados los años '60, que también se combinó con una destacada participación en el gobierno de la FaHCE, tal como lo demuestran otros analistas del propio ámbito institucional (Barletta, 2011; Reitano, 2009).

Respecto a estas relaciones, la distinción efectuada por Bourdieu entre el poder universitario y el poder científico, puede resultar apropiada para comprender aspectos de la configuración del poder y el prestigio en la FaHCE, y el lugar de la EF en esa configuración. Como señalábamos en la introducción de esta tesis, el poder universitario alude a un poder alojado en el "cuerpo profesoral" de las universidades, propio de un capital que se adquiere, que tiene valor y se reproduce dentro de los límites de la universidad. Por el contrario, el poder científico está vinculado al prestigio científico, a la dirección de grupos y proyectos de investigación; es decir, es un poder que excede los límites de la universidad, para expandirse a nivel internacional (Bourdieu, 2008).

En este sentido, en la entrevista realizada, Crisorio asoció un primer reconocimiento institucional de la EF en la FaHCE al capital político -o, podríamos señalar, poder universitario- que tenían como comunidad más que por su legitimidad, prestigio o autoridad científica. Cuando señaló "el departamento...tenía que salir de ser la prima pobre pero numerosa, que entonces era valorada políticamente por la cantidad de votos que traíamos en las elecciones", reconstruyó la posición de la EF en la institución en el momento en que el asumió como director, al considerar la masividad y el cuerpo de profesores como factores que -al menos, hacia fines de los años 1980- habría favorecido el reconocimiento de las otras disciplinas en la FaHCE, en términos de su necesidad para el gobierno universitario. Asimismo, el testimonio de Crisorio da cuenta de su configuración como actor clave en el armado de la estrategia para disputar poder científico, con un conocimiento de las particularidades de ese campo, cuando señaló sus propósitos de aquel momento: "yo quiero constituir un campo". Esa no era una mera expresión de intenciones, sino, para él, la única manera de lograr el reconocimiento, legitimidad y autoridad científica en el contexto de Humanidades. Al respecto, Crisorio

compartiendo la gestión de Barba como Decano. Fue exonerado de sus cargos en marzo de 1975, luego de la intervención nacional a las Universidades de 1974 y previo a la última dictadura militar de 1976. Luego de la cesantía, continuó su inserción profesional como asesor en la Organización de las Naciones Unidas para la Educación, la Ciencia y la Cultura (UNESCO), cargo que desempeñó desde 1962 (Garatte, 2008; 2012). En reconocimiento a su trayectoria, el DCE lleva su nombre.

${ }^{91}$ Entrevista a Carlos Carballo el 13 de abril de 2016 en Ensenada. 
enunció las reglas que, según él, estaban funcionando en la FaHCE: "investigar seriamente", "publicar" y "difundir" en congresos aquello que se produce. Si bien esas reglas pueden tener coincidencias con las planteadas por el propio Bourdieu (2008) cuando señala que lo más importante para un académico es "hacerse un nombre", y por Becher (2001), cuando indica que el reconocimiento es un factor clave en el mundo académico -asociado a la producción científica-, estas reglas operaron en la práctica a partir de una historia y configuración institucional y disciplinar singular. La expresión "investigar seriamente" de Crisorio da cuenta de significaciones propias y particulares de la institución sobre qué es investigar en la FaHCE. Otros trabajos han explorado estas significaciones, al señalar de algún modo, que el modelo de investigación extendido es fundamentalmente el de la Historia y en los últimos años el de la Sociología (Carrera, 2014). Las políticas de investigación, circulación y publicación del conocimiento de la comunidad de EF serán analizadas específicamente en el próximo capítulo.

4. 1. La reconstrucción de una "gesta épica" en el Departamento de EF desde el relato oficial a partir del año 1984: sentidos, tendencias y contradicciones.

En una intervención pública del año 2003, de quien fuera Secretario Académico de la FaHCE entre los años 1988 y 1992 y Decano entre 1992/1998 y 2001/2004, José Luis De Diego, y a propósito del cincuentenario de la carrera de EF, señalaba:

"[...] Participé, por lo tanto, en la reconstrucción de los Departamentos de la Facultad luego de los años duros de la dictadura; de modo que estuve muy cerca de la gestión de Carlos Parenti al frente del Departamento de Educación Física. Creo que la tarea de aquellos años merecería un justo reconocimiento; fue el momento diría épico (cursiva en el original) de la transformación del Departamento, plagado de tensiones y decisiones difíciles. [...] Pero es necesario decir que la mayoría de la generación que hoy representa al Departamento reconoce en aquellos días sus años de formación y a Carlos Parenti como el hombre clave en un momento de inflexión en la historia de la carrera. [...] Carlos Parenti y yo sabemos que fue injustamente desplazado de la Dirección. La gestión de la Profesora Marilú Gayol procuró aplacar los conflictos y diseñar una estructura de cátedras más racionalizada. Fue una gestión diría administrativista, y quienes trabajan en esta complejísima Facultad saben hasta qué punto ese adjetivo es un elogio y no tiene nada de peyorativo. En el '92 tuve la fortuna de que el Consejo Académico de la Facultad me eligiera Decano de la misma, y designo al Profesor Ricardo Crisorio al frente del Departamento. Con Crisorio transcurrimos buena parte de los complejos años del menemismo. El problema que nos planteamos fue cómo crecer en situaciones adversas, adversas en la Nación y, debo decirlo, adversas en la Universidad. Y el Departamento creció, y creció notablemente. Logró mejorar las dedicaciones de la mayoría de sus profesores, consolidó el perfil de la carrera, comenzó su política de publicaciones, incorporó 
proyectos de investigación en el Programa de Incentivos, inició el exitosísimo ciclo de los congresos bianuales [...]". (Las cursivas son propias) ${ }^{92}$

En estos pasajes, De Diego realizó una valoración de la transformación del DEF que califica como "épica", es decir, reconociendo un trabajo de mucho esfuerzo, heroico del grupo de EF. Un trabajo que les significó una lucha contra tensiones y los colocó ante decisiones difíciles. Allí, no sólo se reconoce que llegaron al punto del reconocimiento sino que el proceso fue muy laborioso. Decir que fue épico indica que requiere de un reconocimiento mayor, por el esfuerzo que significó. También evoca a Parenti cuando destacó que fue "un hombre clave en un momento de inflexión [...] en la carrera" y que fue "injustamente desplazado" de la dirección. Cuando expresó "él y yo sabemos que fue injustamente desplazado", da cuenta de una confianza y una relación que va más allá de la formalidad institucional. Asimismo reconoce a la gestión de Gayol como más "racionalizada", que ordenó asuntos administrativos y aclara que eso, lejos de ser "peyorativo" es un "elogio", en la complejidad de una institución como Humanidades. Por último, señaló que con Crisorio "nos planteamos [...] cómo crecer en situaciones adversas", ese "nos planteamos" significa que la direccionalidad del proyecto de gestión de Crisorio contaba con total respaldo del Decano. Si bien puede resultar evidente que el director de un Departamento Docente y el Decano van a estar en sintonía porque la elección de los colaboradores es una elección política por parte del Decano, se pueden definir rumbos que luego no se cumplen. Aquí no sólo está indicando que se propusieron hacer "crecer" académicamente al Departamento, sino que además lo cumplieron: mejoraron las dedicaciones de buena parte de sus docentes, consolidaron el perfil de la carrera, comenzaron la política de publicaciones y la participación activa en proyectos de investigación, la realización de los congresos, entre otros.

Por otro lado, distinguió a las distintas gestiones del DEF desde 1984 con Parenti hasta el breve interregno de Gayol, quien completó su gestión por dos años, y la gestión Crisorio entre 1992 y 1998. En este sentido, asoció a las primeras con un trabajo más preocupado por imprimirle un carácter pedagógico a la formación y enmendar algunas dificultades políticas entre el cuerpo de docentes, y la segunda, más preocupada por el crecimiento académico de la disciplina, de los actores y las instituciones productoras del conocimiento en EF. A partir de la interpretación del ex Decano, podríamos vincular la preocupación de los años '80 y principios de los ‘90 por la formación pedagógica con el legado fundacional de Amavet registrado en sus colaboradores más estrechos que

\footnotetext{
92 Discurso pronunciado por José Luis De Diego con motivo del aniversario número $50^{\circ}$ de la carrera de Educación Física en la FaHCE, 2003, Mimeo.
} 
retomaron esa tendencia, y avanzados los años '90, la clave del reconocimiento y legitimidad significaba, en los términos anteriormente expresados por Crisorio, "academizar" la carrera de EF.

En el mismo sentido, De Diego identificó y valorizó a las gestiones del DEF en la entrevista, al señalar que,

"Parenti-Gayol son los que cada vez le ponen el peso a la cuestión pedagógica "no, miren, nosotros no formamos deportistas, eso se forma en otro lado, nosotros formamos profesores". Ahí, yo creo que hay una especie de énfasis en la docencia, y después viene ya la etapa Crisorio, que la etapa Crisorio es un paso más todavía, es la etapa en donde se dice "bueno, además tenemos que tener un proyecto académico, de investigación" de diseño de un objeto de conocimiento. Entonces, yo advierto el caos hasta el '92 [...]".

Para De Diego, este grupo de EF supo trascender la visión desprestigiada que le devolvían otras disciplinas de la institución, en un contexto político nacional "adverso", en el que la EF "creció notablemente", a partir de la configuración de un "proyecto académico" en diálogo con las reglas de esas otras disciplinas: investigar, escribir, publicar, discutir, difundir. Asimismo, el testimonio anterior da cuenta de dos etapas de la "gesta heroica": la primera, lograr un reconocimiento social como formadores de educadores y no como técnicos o deportistas, y la segunda, un reconocimiento académico dentro de la universidad, a partir de jugar, y hasta aquí parece que muy bien, las reglas de la academia.

En el año 1998, y en una línea de continuidad con la gestión anterior ${ }^{93}$, asumió la dirección del DEF, el Profesor Marcelo Giles. Según la perspectiva de Giles,

"[...] yo reformé el plan de estudios, creé una maestría, una figura política en ese momento...Imagináte que el primer plan de estudios que se cambia es el de Educación Física, jel primero! Me querían matar, nosotros presentamos la Maestría, termina el congreso, lo cierra Ricardo, yo y Gonzalo de Amézola que era el secretario académico de Obiols, es mayo 2001, a punto de terminar el período de Obiols, en diciembre terminaba, por ahí, y Gonzalo que se copó con el congreso, decía 'y esperamos que la primera carrera de posgrado de Argentina sea del Departamento de Educación Física', cierro yo diciendo 'Gonzalo, te agradezco por el desafío, antes de fin de año tenés el plan de estudios de la Maestría en Educación Corporal, con nombre y todo y esperemos que la aprueben'...noviembre de ese año presento el

\footnotetext{
${ }^{93}$ Marcelo Giles fue secretario de Crisorio durante toda su gestión al frente del DEF. Fue un colaborador fundamental en el diseño de estrategias como la última reforma curricular, en una especie de división del trabajo, mientras Crisorio se abocaba al reconocimiento disciplinar a nivel nacional y académico en la FaHCE, aunque claro, con el apoyo constante de Giles. Un indicio muy gráfico de este hecho es la afirmación sostenida por Giles en la entrevista, cuando señala haber hecho un acuerdo con Crisorio, respecto a la formación y escritura académica, en donde Giles le dice: "Vos escribí, yo lo gestiono" (Entrevistas a Ricardo Crisorio el 26 de octubre de 2015 y a Marcelo Giles el 17 de diciembre de 2015). Su trayectoria académica será abordada en el próximo apartado.
} 
plan de la Maestría en Educación Corporal, con Ricardo escribiéndola, y ahí pasa una cosita graciosa, la Maestría en Ciencias Sociales no está terminada, entonces se atrasa la aprobación de Educación Corporal para que la primera Maestría que se aprobara sea la de Ciencias Sociales, porque políticamente al interior, no era bien visto que Educación Física volviera a ser la primera, y hoy las dos Maestrías con más egresados de la Facultad son la Educación Corporal y la de Ciencias Sociales, creo que tienen 24 cada una..." (Las cursivas son propias).

En la cita precedente, Giles da cuenta de una estrategia política en continuidad con la desarrollada por Crisorio, a quien acompañó directamente como secretario del DEF, aunque destaca algunas notas singulares de sus propias gestiones: la reforma del plan de estudios y la creación de la carrera de posgrado "Maestría en Educación Corporal". Podemos rescatar al menos dos aspectos salientes de su testimonio. Por un lado, si bien el cargo de Director lo detentaba Giles, Crisorio continuaba teniendo un papel central como redactor de la carrera de Maestría, desde una concepción disciplinar novedosa como lo es la "Educación Corporal". Por otro lado, Giles evidencia tensiones y conflictos interinstitucionales hasta aquí solapados en los testimonios e intervenciones precedentes, cuando señala que "lo querían matar" porque "el primer plan de estudios que se cambia es el de Educación Física", y que se retrasó la aprobación de la Maestría en Educación Corporal porque "políticamente al interior, no era bien visto que Educación Física volviera a ser la primera". El cambio de plan de estudios al que alude se aceleró y ajustó en base a las modificaciones y el financiamiento ofrecido por la SPU a través del programa FOMEC, que fue una de las políticas universitarias que se desplegaron en los '90. Es decir que no sólo no era bien visto que EF volviera a ser la primera por una cuestión de jerarquías disciplinares, sino que además refiere a que en el contexto adverso de los '90, EF era la carrera que mayor aprovechamiento estaba realizando de las políticas estatales que en ese momento significaban una inyección de recursos: la reforma curricular, el diseño de un posgrado, la formación de docentes, etc.

Es decir que esa afirmación nos permite interpretar que EF no terminaba de ser reconocida en el espacio social de la FaHCE como para ser la pionera de lo que en Humanidades se identifica con "lo académico": el posgrado, en un momento en que el contexto universitario general presionaba para la apertura de posgrados. "Al interior" de la institución generaba tensiones y controversias que sea EF la primera porque "para afuera" no es la imagen que la FaHCE esperaba tener; el primer posgrado de la FaHCEUNLP tenía que ser en Ciencias Sociales, no en EF, tal como se terminó aprobando.

En el discurso de De Diego del año 2003 citado anteriormente, expresaba sobre la gestión de Giles, 
"[...] Quienes conocen a Marcelo comprenderán por qué la estrategia del Decanato debió variar 180 grados: el problema ya no era cómo promover acciones en el Departamento, sino cómo atenuarlas. La endiablada actividad que imprimió al Departamento el Profesor Giles dio un nuevo y decisivo paso a la historia de la carrera: la apertura a otras instituciones. En una primera etapa, el Departamento salió a ofrecer su capacidad acumulada en recursos humanos. En una segunda etapa, se dio cuenta que debía parar, ya que esa exitosa política había desbordado sus posibilidades; dicho de un modo bien claro: ya no había que ofrecer nada porque nos llamaban de todos lados, del país y del extranjero. Se puso en marcha la llamada Licenciatura Extraordinaria en Educación Física y se comenzó a articular con instituciones de Educación Superior no universitarias. El proceso fue verdaderamente vertiginoso, y al llegar al décimo proyecto de articulación, Giles -en un gesto desconocido en él- entró a mi despacho y, resignado, me dijo: 'Me parece que vamos a tener que parar'. [...]".

Aquí, De Diego introduce un nuevo elemento que se constituyó en una estrategia política central para el crecimiento de la comunidad académica de EF en la FaHCE y que reportó beneficios para la institución: la creación de la Licenciatura Extraordinaria en EF, para egresados de institutos terciarios no universitarios. Si bien la articulación entre instituciones de nivel superior universitario y no universitario, estaba estipulada por la nueva normativa, Ley de Educación Superior (LES) sancionada por el gobierno de Menem en 1995, este grupo diseñó una carrera nueva, "extraordinaria" como se la denominó, para egresados de EF de institutos terciarios que quisieran obtener el título de Licenciados. Desde la perspectiva de Barletta, con esta carrera "se proyectaron mucho hacia afuera", permitiéndoles

"tener un rol político, educativo, académico en el conjunto del territorio de la Argentina
[...] Y esto lo hicieron ellos, crear la Licenciatura Extraordinaria en Educación Física
que es solamente para los egresados de instituciones terciarias y que por esta vía
tienen un título de nuestra universidad, eso es muy fuerte como perspectiva educativa
de ellos, y de política educativa hacia el conjunto del sistema educativo. [...]". ${ }^{94}$

La cita precedente nos permite agregar que la comunidad de EF además de aprovechar las políticas académicas específicas provenientes de los lineamientos de política nacional (FOMEC, posgrados, PI, etc.), también tuvo la capacidad de resignificar esas políticas y construir líneas propias como la Licenciatura Extraordinaria en EF, cuando expresa "esto lo hicieron ellos", y "es muy fuerte como perspectiva educativa de ellos", que los proyectó desde la FaHCE hacia el conjunto del sistema educativo y del territorio nacional.

\footnotetext{
${ }^{94}$ Entrevista a Ana Barletta el 20 de octubre de 2017 en la ciudad de La Plata.
} 
Según las palabras de Osvaldo Ron ${ }^{95}$, el proceso que atravesó EF en la FAHCE durante los años 90 se gestó con el "ímpetu transformador" de un grupo de estudiantes a mediados de los años 80 en cuanto a las condiciones de inscripción, modalidades de cursada, evaluación y orientaciones de enseñanza. Ese ímpetu se vincula con lo que Carballo enunció en una de las entrevistas: "teníamos una motoneta", en relación a la energía y a la fuerte voluntad de cambio por parte de estos graduados y docentes. Por otra parte, desde su perspectiva, la motivación central que caracterizó a esa etapa estuvo vinculada con lograr una "integración académica, política y afectiva" con la institución, de la que hasta ese momento se sentían outsiders. En palabras del entrevistado, "nosotros formábamos parte de la institución sin ser parte".

Diferentes testimonios como el de Gayol, dan cuenta de otros significados acerca de la condición de outsider. Al respecto señaló que, si bien advertían que como carrera "no estaban visibilizados", sí participaban de la política académica como estudiantes desde los primeros años '70, aunque eran pocos en comparación a otras carreras. Es decir, por aquellos años, ser outsider era no estar visibilizado, reconocido por los demás. En ese sentido, cuando se le recuerda el calificativo de "bicho raro" que Ron utilizó para definir a quienes estudiaban EF en los ' 80 -entre quienes se encontraba él mismo-, Gayol respondió:

“....Nosotros también lo éramos, porque, vos imagínate, año '65, voy a hablar del mío. Por primera vez circulando por los pasillos de lo que es el Rectorado, que por ahí estaban las aulas en ese entonces y después una entrada que había para la parte de atrás (que después se convirtió en el Liceo) andábamos en buzo, con bolso y todos los alumnos en general andaban con una carpeta y una lapicera, en cambio nosotros no. Ya andábamos distintos, ya éramos distintos...". (La cursiva es propia).

El testimonio anterior da cuenta de un nuevo sentido sobre el ser outsider. La expresión "bichos raros" es indicativa de una identidad diferente y disonante en el paisaje institucional de la FaHCE y refuerza la idea, que proviene de la fundación de la carrera y los años '60, que quienes estudiaban EF y luego en menor medida se graduarían, eran sujetos institucionales que se encontraban "por fuera de la norma", en la medida en que no andaban con libros, apuntes y lapiceras, y sí con buzos, bolsos y pelotas. Esto constituía la "cara visible" de una diferencia que radicaba también en el tipo de conocimiento con el que trabajaban: más "práctico", que requería de cierta vestimenta y

\footnotetext{
${ }^{95}$ Osvaldo Ron es actualmente profesor titular de Educación Física II, estudió la carrera entre los años 1984 y 1988, e ingresó como ayudante ad-honorem en la cátedra Gimnástica III (actual EF III) durante ese mismo año. Luego, se incorporó como rentado a Gimnástica I (actual EF I). Fue consejero académico por el claustro de graduados entre los años 1994 y 1996 y director del Departamento de EF entre los años 2004 y 2010 (Legajo de Ron, Osvaldo, FaHCE). Fue entrevistado en la ciudad de Ensenada, el 01 de septiembre de 2016.
} 
objetos, más "físico" y menos "intelectual". También, podemos recordar aquí el testimonio de Parenti sobre el cierre de la carrera en 1969 señalado en el capítulo anterior, cuando sostenía que cerraron la inscripción porque "no podía haber transpiradores en las humanidades". En el mismo sentido, Rogg, director del DEF durante la última dictadura y hasta 1983, como ya señalamos, expresaba que la Facultad se resistía "a acoger en su seno a representantes de la transpiración y la fuerza bruta".

La expresión outsiders merece que nos detengamos un momento para analizar su significación en los discursos que los propios miembros de EF producen sobre su posicionamiento en la FaHCE.

De este modo, relacionamos las expresiones de Ron y de Gayol con la condición de "outsider" que plantea Becker (2009), en cuanto a que es el resultado de un proceso de etiquetamiento de otros, ante el cual los "desviados" reaccionan de algún modo. Es decir, es una categoría relacional y el producto de una interacción y una construcción social, más no una cualidad o propiedad que los sujetos traen consigo o por el mero hecho de incumplir las reglas. No obstante, para Becker, los etiquetados como "outsiders" pueden, desde su perspectiva, no aceptar las reglas que le son impuestas o impugnar la legitimidad de quien los juzga, es decir, considerar a los propios jueces como "outsiders". Para el caso que nos ocupa, los académicos de EF (profesores con mayor dedicación), pertenecían a un grupo social determinado (los académicos de la FaHCE), aunque no habían logrado el reconocimiento social esperado: eran parte de la institución "sin ser parte". En esta dirección, existía aquí una clara intención de "formar parte" de la institución y, en ese sentido, dejar de ser "outsiders". En resumen, no había una trasgresión a las reglas, un hacer "algo prohibido" sino justamente un no hacer correctamente lo que, según ese grupo, había que hacer. Por otro lado, es interesante pensar en aquello que Becker señala sobre el tratamiento de un acto desviado en relación a quién lo comete y a qué consecuencias acarrea. Al respecto, el no cumplimiento de ciertas reglas por parte del grupo de EF no afectaba sino colateralmente a la institución en sí misma, y sí fundamentalmente a su propio grupo. Es decir, para lograr un mejor reconocimiento y legitimidad social y académica dentro de la FaHCE, este grupo de profesores de EF hizo uso de las reglas de la academia, es decir, reformar el plan de estudios de grado, escribir una carrera de posgrado, armar un congreso y una revista, diseñar e implementar proyectos de investigación, etc. 


\section{La conformación de un grupo de profesores en EF y sus trayectorias académicas en Humanidades en los años '90}

5.1. "Ellos remaron": la construcción del grupo de profesores protagonista de la "gesta épica".

Como mencionamos anteriormente, Parenti renunció a la dirección del DEF por pedido del entonces decano Panettieri, en el año 1990. El clima de tensión y conflictividad entre el cuerpo de profesores determinó su salida anticipada. Mediante el testimonio de Carballo, pudimos reconstruir una versión de esa historia y del clima institucional previo a su salida:

"Había asambleas de profesores de EF, nosotros, Marcelo [por Giles], Ricardo [por Crisorio], Osvaldo [por Ron], varios...Santiago Achucarro, que con Carlos [por Parenti] decíamos: ¿qué van a plantear? Bueno, esto, esto...había mucha reacción, mucha gente con posturas reaccionarias, que decían ¿pero cómo nosotros tenemos que aguantar que los estudiantes planteen estas cosas? [Por el reclamo para el acceso a exámenes recuperatorios, $u$ otros reclamos]...Así como te lo digo...entonces nos conjurábamos, éramos seis, siete locos que nos conjurábamos. Nosotros decíamos: 'A nosotros lo que nos interesa es poder controlar y neutralizar a estas personas, pero lo que tenemos que salir de esta asamblea diciendo nosotros es que 'a Parenti no le pega nadie, que nos peguen a nosotros, porque si le pegan a Parenti es la manera de entrada que tienen por Panettieri y que bueno, así terminó, ¿no es cierto? [Por el pedido de renuncia a la dirección del DEF del por entonces decano Panettieri a Parenti] Un profesor terminó haciendo todo el trabajo finito para que Parenti tuviera que renunciar...gente que no entendía nada, que no sabía lo que era la democracia" (la cursiva es propia).

La cita anterior da cuenta de, al menos, dos elementos relevantes tanto para el análisis de la salida de Parenti como para entender la configuración social de un grupo hacia el interior de la comunidad de EF en la FaHCE. En cuanto a la primera cuestión, evidencia el respaldo y acompañamiento que ciertos docentes -en su momento graduados y ayudantes diplomados- brindaban a la figura de Parenti como director del DEF, como una figura que garantizaba, según Carballo, "el reaseguro de una EF de orientación progresista”, y a la que este mismo grupo de docentes abonaban. ${ }^{96}$ En cuanto a la segunda cuestión, la composición de un grupo con relativa cohesión, que comienza a formarse por esos años. La composición de ese grupo está nominalizada en la cita de

\footnotetext{
${ }^{96}$ La renuncia de Parenti puede vincularse a un proceso similar acaecido en el DCE por esos años con su directora, Julia Silber. Silber tuvo un conflicto de alta resonancia institucional con un profesor que venía desempeñándose desde la dictadura, razón que precipitó su salida de la dirección del Departamento (Garatte, 2012). Ambas renuncias son evidencias del procesamiento de conflictos durante la "normalización universitaria" en la FaHCE, y de las tensiones sobre las que se tramitó la transición a la democracia.
} 
entrevista: el propio Carlos Parenti, Carlos Carballo, Ricardo Crisorio, Marcelo Giles, Osvaldo Ron y Santiago Achucarro, como las figuras más salientes. Por otro lado, la apelación reiterada al "nosotros" y aquella mención de "a Parenti no le pega nadie, que nos peguen a nosotros" dan cuenta de una identidad colectiva que respaldaba a Parenti, y que, como veremos, se sostuvo en los años siguientes, aunque alrededor de otras figuras. Esta caracterización es coincidente con la brindada por Marcelo Giles, cuando señaló:

"nosotros [por él y Crisorio] conformamos un grupo con Carlos Parenti que fue el director del departamento, Carlos Carballo, Osvaldo Ron, Jorge Fridman, Adrián Casas, Diky Bertsch, viejo profesor de la casa, como un grupo que fue por el cambio de plan, que fue por el crecimiento..."

Los testimonios anteriores dan cuenta del armado progresivo de un grupo de graduados y docentes nóveles de mediados de los años 80 , que egresaron relativamente en la misma época (a excepción de Parenti y Crisorio), compartieron sus inicios en la docencia por esos años formando parte de determinados tipos de asignaturas que describiremos a continuación, que comenzaron a militar políticamente en la Facultad en los mismos años, y que además luego gravitarían en la política institucional y departamental. ${ }^{97}$ Aquí, nuevamente, la apelación reiterada al "nosotros" en las citas precedentes, es un indicio de la conformación de un grupo que compartía una serie de espacios y proyectos, y que participó intensamente en la política departamental e institucional entre los años 1992 y 2004 . También es de destacar que el grupo se fue conformando en torno de un proyecto: "ir por el crecimiento" académico de la EF en la FaHCE. En nuestro análisis buscamos mostrar que este grupo no se constituyó simplemente por la adición de individualidades afines, sino con el objetivo preciso de posicionarse como punta de lanza del "crecimiento".

En línea con este planteo, Barletta sostuvo:

"[...] yo tengo más la idea de ellos todos juntos en ese momento muy afines en la transformación de la carrera y en eso, yo creo que eran un grupo fuerte, un grupo poderoso, ellos crecieron ahí, poderoso estratégicamente. [...]"

Si bien los testimonios que pudimos recoger son consagratorios del desarrollo de la carrera y de este grupo, como veremos en el próximo capítulo, las políticas y estrategias académicas desarrolladas evidencian una etapa dinámica y de crecimiento. Aunque,

\footnotetext{
${ }^{97}$ Para conocer la composición de este grupo, sus años de nacimiento, cohortes de estudio de la carrera, año de graduación, año de ingreso como docentes en la FaHCE, etc., ver tabla 2 en el anexo de la tesis: "Los profesores que participaron en políticas académicas de EF entre los años 1992 y $2004 "$.
} 
como veremos, ese proceso no se dio sin tensiones y contradicciones al interior de la carrera y la institución.

En el testimonio siguiente de Gayol, puede advertirse también la composición de este grupo:

"...Yo no tengo palabras para ninguno en contra, yo creo que gracias a ellos y se los he dicho a ellos, a lo mejor no públicamente sino a cada uno en particular...Si ellos no hubieran remado como remaron, el profesorado no estaría en el lugar que está; ellos remaron para que el profesorado tenga presencia en el consejo académico, en el consejo superior, en cargos de conducción como secretarios de extensión, secretarios académicos. Ellos remaron para que el profesorado esté presente en el país, ya sea con los ciclos de licenciatura o con convenios en otros lugares. Ellos remaron, cada uno en mayor o menor medida pero todos con mucho esfuerzo, para que el profesorado tenga presencia en el Ministerio de Educación de la Nación, en el Ministerio de Educación de la Provincia; es decir que ese reconocimiento, yo lo objetivo, lo pongo ahí y lo analizo: estamos donde estamos porque ellos se aburrieron, si ellos no se hubieran aburrido no estaríamos donde estamos y a lo mejor estaríamos transitando un devenir sin mucha trascendencia pero no, ellos se han movido...". (Las cursivas son propias)

Aquí la apelación cambia de significante, del nosotros al "ellos" y evidencia, por un lado, la referencia a un grupo en el que, en principio, Gayol no se incluye, y en el que se materializa además la masculinidad de la composición grupal, coincidente con la nominalización de los actores aludidos anteriormente. Por otro lado, Gayol le reconoce a este grupo un rol fundamental, decisivo en la configuración de una posición de la EF tanto en la FaHCE como a nivel nacional, y en un punto de llegada constituido por la "presencia" y proactividad de estos agentes en numerosos y diversos espacios institucionales. Además, es preciso destacar algunas apreciaciones de Gayol sobre estos actores. Cuando señaló "estamos donde estamos porque ellos se aburrieron, si ellos no se hubieran aburrido no estaríamos donde estamos", utiliza la metáfora del aburrimiento para dar cuenta de una situación de tedio, de fastidio o desmotivación que los llevó a "moverse", a "remar" para cambiar el estado de cosas. Llegados hasta aquí, podemos arriesgar que ese fastidio también fue un elemento de cohesión del grupo por cuanto, como hemos relatado en el primer capítulo y en párrafos anteriores, estos profesores se encontraban en su mayoría descontentos con la formación que habían recibido y fueron estudiantes y graduados entusiastas por la transformación de la carrera. Por último, cabe enfatizar en la asociación del sentido común con el movimiento de remar como una acción que requiere de mucha dedicación y esfuerzo. Tal la frase popular de procedencia incierta "remar contra la corriente", como una serie de acciones e iniciativas que deben luchar por imponerse, por lograr un espacio en un contexto surcado de dificultades. 
Algunos de los hechos relatados previamente evidencian estas vicisitudes y los esfuerzos políticos y académicos que estos actores tuvieron que emprender: la aprobación de la reforma del Plan de Estudios de la carrera de grado, la de la carrera de Maestría, la ocupación de posiciones importantes en el gobierno institucional como veremos en breve, entre otras.

5.2. Trayectorias profesionales, políticas y académicas de los protagonistas de la "gesta épica”.

A continuación analizaremos las trayectorias profesionales, políticas y académicas de este grupo, ya que creemos que su reconstrucción nos permitirá entender no sólo su conformación como colectivo y la ocupación de posiciones a nivel disciplinar e institucional, sino además la gestación de nuevas orientaciones y perspectivas para la carrera y la disciplina.

El orden en el que aparecen no sigue necesariamente un criterio temporal -por ejemplo, generacional-, sino que busca retomar e ir hilando a los actores con redes sociales de contenido diverso y políticas y estrategias disciplinares en el marco de la FaHCE y por fuera de ella, que guardan relaciones con los procesos políticos locales y nacionales. En la presentación se considera también como criterio la participación de estos actores en la política institucional en cargos ejecutivos, por orden de asunción de los cargos.

Carlos Parenti, oriundo de Florencio Varela (Provincia de Buenos Aires), ingresó a estudiar la carrera de EF en 1968 y egresó en 1973. De sus comienzos como estudiante, señala cierta sorpresa respecto a la expectativa frente a la carrera, y las clases efectivas. En un momento pensó "le erré, esto es filosofía, ¿dónde estoy?", en alusión a las charlas introductorias y luego asignaturas de quien fuera, según él, el "creador" de la carrera, Alejandro Amavet. Sobre esta figura, expresa que le resultaba "muy atrapante" por "su prestancia" y "por cómo involucraba a los alumnos".

Respecto a su graduación, recordó:

"[...] Podría haberme recibido antes, venía al día con la carrera, pero fallece mi padre y bueno a trabajar. En realidad, yo podía haberme recibido en el '71 pero me recibí en el '73, me había quedado prácticas de la enseñanza. Pero no tenía tiempo, había que contribuir a la olla familiar. [...] Recién pude culminarla en el '73 las Prácticas de la Enseñanza y bueno, ahí está. Junio del '73 fue mi graduación". 
Su primera entrada a la docencia fue como ayudante alumno en las cátedras de Amavet, en el año $1969 .^{98}$ Recordemos que Parenti fue alumno de Amavet y, según su testimonio, este último le pidió ser ayudante en sus cátedras. Luego, como graduado, se insertó tempranamente en cargos y asignaturas relevantes de la carrera. La primera resolución docente a la que tenemos acceso es la №58 del 19 de octubre de 1973, como Profesor Titular interino en la cátedra "Teoría Especial de la Gimnástica". Ese mismo día, y bajo resolución №59, fue designado como Profesor Titular interino en "Seminario de Investigación en Educación Física", de cuarto año del mismo Plan de Estudios. Respecto a ese ingreso formal como docente graduado, menciona que resultó una "cosa insólita" de esas que sucedían en ese momento en la Universidad, en donde todo era "un caos". Lo de insólito se encontraba vinculado a su incursión directa como Profesor Titular en las asignaturas en las que se desempeñaba previamente como ayudante alumno. A partir de la jubilación de oficio de Amavet en 1973, y por ser su colaborador más estrecho en sus cátedras, fue designado Titular interino a fines de ese año. Su participación como docente se discontinuó en octubre de 1974, durante la llamada "Misión Ivanissevich" en un contexto de intensa violencia institucional (Izaguirre, 2011; Rodríguez, 2014; Silber, García Clúa y Fava, 2011). ${ }^{99}$ Durante esos conflictivos años, se "refugió" en otros niveles del sistema educativo, y se alejó de la universidad hasta el año 1984, cuando fue contactado por ex compañeras de promoción.

Como vimos en apartados anteriores, durante esos años tuvo lugar el proceso denominado de "normalización universitaria" (Buchbinder, 2005; Garatte, 2008), y Parenti fue designado director del DEF. Desde esa posición, inició un proceso de reconstrucción del Departamento y la carrera, luego de la última dictadura, en que la estrategia de reclutamiento de docentes fue un rasgo saliente. ${ }^{100}$

Al respecto, Parenti caracterizó los inicios de su gestión como de "constante interferencia de los docentes afincados desde el Proceso", y en ese sentido señala que,

\footnotetext{
${ }^{98}$ Para conocer en detalle y gráficamente las funciones que estos profesores desempeñaron en la docencia en la FaHCE, su situación actual, cambios de dedicación, categorías de investigación, ver Tabla 3 en el anexo de la tesis "Funciones que desempeñaron en docencia entre los años 1992 y 2004, situación actual, dedicación, categoría de investigación".

${ }^{99}$ En octubre de 1974, y luego de una serie de asesinatos a militantes estudiantiles y gremiales, como los casos de Rodolfo Achem (Asociación de Trabajadores de la Universidad Nacional de La Plata -ATULP-) y Carlos Miguel (dirigente de la Juventud Peronista y Director del Departamento Central de Planificación de la UNLP), la Universidad se cerró hasta mediados de noviembre, y fue designado como nuevo Interventor Pedro Arrighi. Una de las medidas más importantes seguidas por el nuevo Rector fue dejar cesantes todas las promociones docentes realizadas a partir de mayo de 1973, y el cese de otros docentes nombrados con anterioridad, fundamentadas en la Ley $N^{\circ} 20.654 / 74$. Según CTERA, los afectados en la UNLP fueron unos 3.700 , lo que representó el $60 \%$ de los docentes (Rodríguez, 2014).

100 Un detalle de las posiciones ocupadas por este grupo en el ámbito del DEF, pueden ser consultadas en la Tabla 4 de la presente tesis: "Funciones desempeñadas en el Departamento de Educación Física".
} 
"los docentes que estaban designados entre el '76/83 no fueron removidos, se les pidió acompañamiento. Básicamente los integrantes de la cooperadora no lo hicieron, igual que otros, renunciaron en desacuerdo con los objetivos anunciados en reunión con todo el claustro docente al inicio de la gestión. Se tuvo que cambiar el plan de estudios de 5 años (sin aprobación del Ministerio de Educación de la Nación) por uno de 4 años, ya que todos los planes de estudios en la Facultad de Humanidades eran de 4 años. Propuse hacer énfasis en materia de contenidos más actualizados y de iniciación a la investigación. Inicialmente se fueron tres docentes, los que eran Titulares Interinos y luego otros por no presentarse a los concursos iniciados en 1985, caducidad automática".

El conflicto más destacado fue el que Parenti y sus allegados mantuvieron con Ernesto Rogg. Como mencionáramos en el capítulo anterior y aquí mismo, Rogg dirigió el DEF durante los años de la última dictadura, entre 1976 y $1983^{101}$, y se desempeñaba en varias materias importantes del Plan de Estudios, como Introducción a la EF, Gimnástica I y Didáctica y Prácticas de la Enseñanza en EF. Fue cesanteado en sus cargos luego de pasar por una instancia sumarial en 1988 (Res. 890/88, FaHCE). Este sumario se trató de una estrategia de desplazamiento -según los actores entrevistados, con justos argumentos- ${ }^{102}$, que posibilitó la ascendencia de docentes nóveles que pertenecían al grupo de apoyo de Parenti. Un ejemplo claro lo constituye el concurso de la asignatura "Introducción a la EF" en 1990, en donde Rogg era titular, Fridman -compañero de estudios y amigo de Parenti- adjunto, y Carballo JTP interino. Según Parenti, las estrategias constaban de "rodear" al docente con otras personas "para quitarle poder", estrategias que definió como "pedagógicas e ideológicas", ya que desde el Rectorado se estableció que no había que echar a los docentes que venían de la dictadura, sino "tratar de ir corriéndolos en términos académicos, por supuesto políticos y demás".

Sobre la estrategia de desplazamiento de Rogg, Carballo relató:

\footnotetext{
${ }^{101}$ Res. 642/83, por la que cesa en el cargo de Director a partir del 29 de diciembre de 1983. Cabe señalar que Rogg había tenido una experiencia previa como Jefe de la por entonces denominada Sección de EF, dependiente del Instituto de Psicopedagogía y Didáctica del Departamento de Ciencias de la Educación, entre 1968 y 1970, en reemplazo de Amavet (Res. 564/68, Res. 1037/69, Res. 120/70, Res. 661/70).

${ }^{102}$ A comienzos de 1983, cuando todavía era Rector Guillermo Gallo -quien se desempeñó en el cargo durante la última dictadura militar, y algunos meses del gobierno constitucional de la UCR, entre 1976 y fines de 1983-, se tramitó el concurso para cubrir el cargo de Profesor Titular con dedicación simple en Introducción a la EF. Por Res. 92 de la UNLP del día 01 de marzo de 1983, se aprueba ese concurso y se designa a Rogg en el cargo, por el término de 7 años tal como lo establecía el Art. 20 del Estatuto vigente al momento (Res. 2/83 de la FaHCE). Ya con el cambio de Rector y Decano, Rogg es suspendido en sus cargos a partir de las Res. 531 y 594 del año 1985 de la FaHCE. En la Res. 531 se invoca a la Res. 623/85 de la UNLP, por la cual se ordena la instrucción de sumario para investigar lo actuado en la Asociación Cooperadora de EF, en donde estaba involucrado con otros dos docentes. Como antecedente a esta suspensión, se le limita la dedicación exclusiva en Introducción a la EF, por Res. 651/84, por "no satisfacer los requerimientos básicos establecidos para cargos de esa naturaleza". En la Res. 25 del 7 de febrero de 1986, en vistas que hasta esa fecha no se había resuelto definitivamente su situación sumarial, el Decano Normalizador, Panettieri, resuelve reponer a Rogg en sus cargos docentes. A fines de 1988 finalmente es dejado cesante por la Res. 890 anteriormente citada.
} 
"[...] Y el director normalizador del Departamento de Educación Física, que acaba de jubilarse, Carlos Parenti, que nos conoció, él era profesor en cuarto año, que conoció al grupo de jóvenes que estábamos participando activamente en el centro, íbamos con frecuencia a verlo al departamento y teníamos, bueno, habíamos tenido muchas situaciones de confrontación en el ' 83 con el último decano de la dictadura, etc. Él me dice en un momento: "mira Carlos yo sé que vos querés trabajar en Gimnástica I, en el Eje Gimnasia Formativa, pero yo te necesito en Introducción a la Educación Física porque estamos preparando un sumario para sacar al profesor titular ahí...", que fue el tipo que fue director del departamento en las últimas dos dictaduras, coincidentemente... [Por Rogg] Entonces, entré a esa materia por una cuestión básicamente de militancia. De bueno, hace falta acá, hace falta sacarse de encima esto, hace falta ir modificando la lógica de los contenidos, y qué sé yo. Y de esa manera entré... [...] Es más, yo iba a competir con ese Ernesto Rogg que estábamos empujando, él se había presentado, me decían "tenes que impugnarlo, él tipo estuvo en la dictadura, la mayor parte de los antecedentes los consiguió en la dictadura" y yo decía "no, yo quiero ganar el concurso", qué pendejo idiota era. Después el tipo sabe que lo pierde porque ningún jurado iba a..." ¿a avalarlo?, le pregunto, y Carballo contesta: "y...'no te impugnó tu competidor, te bajamos nosotros'. Yo creo que el tipo leyó eso y finalmente fui yo solo al concurso".

Desde una perspectiva más cercana a esos años, en el discurso de De Diego pronunciado en el año 2003, se reconoce esa estrategia en la cobertura de los cargos docentes, así como el liderazgo ejercido por Parenti,

"[...] En medio de esos conflictos, uno no sabía nunca cuando Parenti podía transformar su paciencia en apariencia infinita en furor itálico. [...] El perfil de carrera que imprimió, a quiénes promovió y a quiénes, con absoluta justicia, desplazó, marcaron el futuro de la disciplina en nuestra Facultad. [...]". (Las cursivas son propias). ${ }^{103}$

Las expresiones anteriormente citadas, tales como "a quiénes promovió y a quiénes, con absoluta justicia, desplazó, marcaron el futuro de la disciplina en nuestra Facultad", dan cuenta de, por un lado, un proceso de transformación definitivo de la EF en la FaHCE, así como por otro lado -aunque en vinculación necesaria con lo primero, el armado progresivo de un plantel docente acorde al proyecto político-académico de Parenti y su grupo de aliados, así como del apoyo que tuvo por parte de otros actores políticos y académicos de la institución, opositores a la conducción del radicalismo a nivel de la UNLP y con alguna presencia en la FaHCE. Asimismo, dan cuenta, siguiendo a Becher (2001), de la capacidad de liderazgo organizacional ejercida por Parenti, reconocida por su grupo de pares.

Parenti se encontraba motivado a efectuar estos cambios con cierta urgencia dado que se había suscitado, según su testimonio, un cambio exponencial en la matrícula del

\footnotetext{
${ }^{103}$ Discurso pronunciado por José Luis De Diego con motivo del aniversario número $50^{\circ}$ de la carrera de Educación Física en la FaHCE, 2003, Mimeo.
} 
Profesorado entre el año 1983 y 1984. Cuando reingresó como docente a fines de 1983, había alrededor de 100 estudiantes, y en febrero, cuando se hizo cargo de la dirección del DEF, se inscribieron cerca de $500 .{ }^{104} \mathrm{Si}$ bien el número no es coincidente con el ofrecido por la Dirección de Enseñanza de la FaHCE para ese año, sí es cierto que se produjo una expansión matricular en la carrera hacia el año 1986 que, con oscilaciones según las distintas épocas, mantuvo su carácter masivo hasta la actualidad. Para la resolución de esta demanda, Parenti solicitó la colaboración de egresados afines a su gestión, ex estudiantes, que tuvieran cercanía a la orientación que pretendía dar a la carrera y que se contraponía respecto de la que había asumido en la dictadura militar precedente. Esos docentes trabajaron ad honorem durante, al menos, todo el ciclo lectivo 1984 en materias troncales como Introducción a la EF y Gimnástica I del Primer Año, donde hubo mayores refuerzos, y Seminario de Investigación en EF, Gimnástica IV, entre otras. ${ }^{105}$ Meses más tarde, en buena parte del año 1985, lo hicieron otros recientes graduados. ${ }^{106}$ Entre estos últimos, una figura destacada fue la de Carlos Carballo, quien había ingresado a la carrera de EF en la FaHCE en el año 1981 y se había graduado un año después del retorno democrático, en 1984. Comenzó a participar tempranamente en la política de la Facultad, en el año 1982, en lo que fue, según sus propias palabras, la "reorganización del Centro de Estudiantes", de forma aún clandestina. Se identifica con la generación en la que "el detonante no fueron los desaparecidos, sino Malvinas". ${ }^{107}$ Esta "marca" en su identidad, luego explicará su inclinación por la política. Señala que al ser "el grueso de los que viajaron a las Islas del ‘62” y el nacido en el '63, "vivió la muerte" y afectación física y emocional de compañeros del secundario y la Facultad.

Durante sus primeras experiencias en política universitaria, se conoció e interactuó con estudiantes y graduados de otras disciplinas como Filosofía, Historia, Ciencias de la

\footnotetext{
${ }^{104}$ Según los datos aportados por la Dirección de Enseñanza de la FaHCE, para 1983 los ingresantes de EF eran 125, en 1984, 282, en 1985, 279, produciéndose tal expansión recién en 1986 y 1987, con 582 y 735 ingresantes respectivamente, sobre una matrícula total de 2.346 ingresantes (FaHCE, consulta 2017). Este fenómeno de crecimiento de las matrículas no fue exclusivo de EF, sino que tuvo lugar en buena parte del resto de las carreras de la FaHCE (Garatte, 2008).

${ }^{105}$ Res. № 641 del 12/12/84 en el que se le reconocen "con carácter 'ad honorem' los reales y efectivos servicios prestados" a docentes como Jorge Fridman, Ricardo Crisorio, Patricio Calvo Etcheverry y Adolfo Bertsch, en el período comprendido entre el 01 de abril y el 31 de diciembre de 1984.

${ }^{106}$ Res. N ${ }^{\circ} 494$ del 30/08/85. En este caso, la condición ad honorem fue por un período más breve, entre el 01 de abril y el 31 de julio de 1985. Carballo lo hizo en Introducción a la $E F$, y también se incluyeron en la resolución Marcelo Giles y Santiago Achucarro por Gimnástica I, entre otros tantos profesores que no conforman la planta docente actual de las carreras (FaHCE, 2017).

${ }^{107}$ Carballo hizo alusión a la guerra desatada entre el Reino Unido de Gran Bretaña e Irlanda del Norte, y Argentina por la recuperación de las Islas del Atlántico Sur. La guerra fue alentada por los militares al mando del gobierno de facto en nuestro país y fue cruenta, en términos tanto de la falta de recursos como de fundamentalmente, los centenares de argentinos muertos en combate. Para profundizar sobre esta guerra y sus efectos, consultar Guber, 2001b.
} 
Educación y Letras. Con ellos configuraría, más tarde, a fines de los 80 , el agrupamiento del FAG.

Su ingreso a la docencia en la FaHCE fue como ayudante diplomado sin renta, al año siguiente de su graduación, en 1985, cuando tenía tan sólo 21 años. Según su propio relato, su ingreso como docente en EF puede interpretarse dentro de esas estrategias de reclutamiento del por entonces director del DEF, Carlos Parenti, quien le presentó a Jorge Fridman, su compañero de formación y amigo, y luego le dijo a Carballo:

"'mira yo quiero que hagas tándem con esta gente'...Entonces, entré a esa materia por una cuestión básicamente de militancia. De bueno, hace falta acá, hace falta sacarse de encima esto, hace falta ir modificando la lógica de los contenidos, y qué sé yo. $Y$ de esa manera entré. Bueno, termine mi primer concurso como adjunto de esa materia, tenía 27 años, era otra época. En esa época fui el profesor más joven del claustro de profesores [...]".

Allí Carballo relató lo que fue una carrera "meteórica" en la FaHCE, ingresando en 1985 como Ayudante Diplomado Ad-Honorem, pasando a Ayudante Diplomado interino, luego a JTP y Profesor Adjunto, concursando por primera vez y ganando ese último cargo en Introducción a la EF en $1990^{108}$, "con tan sólo 27 años". Situación que, desde su perspectiva, "cuenta como anécdota", ya que no le "genera ningún orgullo", sino que lo define más bien como producto de una situación de "debilidad" de las instituciones. Ante la pregunta sobre si ese había sido su primer concurso, señaló,

"[...] sí, porque yo había hecho toda la carrera con cargos interinos porque era toda la época de la normalización, costaba mucho hacer concursos. Entonces yo había sido estudiante diplomado de honor, después me consiguieron una renta simple, después me promovieron a JTP simple, después me dieron la semi dedicación; y en determinado momento que yo era JTP e interino todavía, a Jorge Fridman, que era el adjunto interino a cargo de la materia, le piden que se haga cargo de otra materia. Entonces como yo quedé al frente de la materia me dijeron "te nombramos adjunto porque te llamamos el concurso, porque no podés seguir avanzando..." no, está bien. No, un inconsciente... [...]".

Mientras desarrollaba la docencia en la FaHCE ya como profesor y continuaba participando activamente en la vida política de la institución, Carballo combinaba la actividad académica con el desempeño profesional por fuera de la Universidad, fundamentalmente la docencia en escuelas públicas de la Provincia de Buenos Aires, aunque también en "un club de tenis y dos gimnasios". En 1995, fue elegido por sus

\footnotetext{
${ }^{108}$ Esta información fue extraída del CV de Carlos Carballo, y es coincidente con la presente en su legajo en la Oficina de Personal de la FaHCE, 2017.
} 
compañeros del FAG, como Consejero Académico titular por el Claustro de Profesores. ${ }^{109}$ En 1998, cuando lo nombraron autoridad superior como Secretario de Extensión de la FaHCE, pudo "juntar" las dos dedicaciones y "armar" una exclusiva (la semi-exclusiva de su cargo docente y la simple del cargo ejecutivo). Carballo destaca en varias oportunidades que fue la primera vez, desde la creación de la carrera en 1953, que alguien de EF accedió a una posición de gestión institucional, y asocia esa entrada a la posibilidad de "ser parte de un grupo que trabajó de una manera determinada", es decir, según su perspectiva, al empeño de un conjunto de graduados y profesores que sostuvieron un proyecto en común desde mediados de los años '80. Desempeñó ese cargo entre 1998 y 2001 y fue designado nuevamente para esa función entre 2001 y $2004 .{ }^{110}$

Para analizar su propia trayectoria, en la entrevista tomó como referencia a Eduardo Remedi ${ }^{111}$, quien, según él, sostiene que para poder comprender a un docente, hay que poder sopesar tres elementos: su formación, su trayectoria profesional y su historia personal. En este último sentido, señaló:

"[...] hay cosas de la historia personal que tienen que ver, que yo lo emparento más la historia personal no tanto con la historia familiar, porque a mí me ha tocado como a tantos ser los primeros egresados universitarios de una familia, la primera generación de universitarios, ¿no? Sino que lo vinculo con esta experiencia histórica que tuvo que ver con la salida de la dictadura, el pasaje a la democracia, haber militado políticamente, haber construido vínculos en ese contexto. Eso es un caudal, es un capital político, humano, ético que yo no tengo que envidiarle nada a nadie [...]".

En el párrafo precedente, Carballo reconoce la importancia de las relaciones personalizadas y políticas construidas desde su militancia como estudiante en los primeros años ' 80 , su adscripción a la generación que vivió la "salida de la dictadura" y que haber militado políticamente en ese contexto le dio una experiencia de formación que él denomina "capital político" que lo posicionó favorablemente, a tal punto que "no tiene

\footnotetext{
109 Compartió la representación del claustro con María Celia Agudo de Córsico (Ciencias de la Educación), Telma Piacente (Psicología), Rosa Pisarello (Bibliotecología), Alicia Alliaud (Lenguas Modernas) y Fernando Barba (Historia).

${ }^{110}$ Para ver las posiciones asumidas por este grupo tanto en el plano ejecutivo como legislativo en la FaHCE, ver tabla 5 "Funciones desempeñadas en la Facultad de Humanidades y Ciencias de la Educación (FaHCE)" en el anexo de la tesis.

${ }^{111}$ Eduardo Remedi (1949-2016) fue un pedagogo cordobés de reconocida trayectoria en el campo educativo local y nacional. Cabe destacar que durante la última dictadura militar se exilió muy joven en México, y gran parte de esa trayectoria la construyó una vez allí y en sus viajes a la Argentina luego del retorno democrático. Fue profesor de la Universidad Nacional Autónoma de México (UNAM) y en otras instituciones mexicanas, y en 1983 se incorporó al Departamento de Investigaciones Educativas del Centro de Investigación y Estudios Avanzados del Instituto Politécnico Nacional (DIE-CINVESTAV) donde permaneció hasta su fallecimiento en 2016 (Alfonso, 2017). En una de sus estadías en nuestro país, realizó una estancia posdoctoral en el Instituto de Investigaciones en Ciencias de la Educación en la UBA en 2002. Su conocimiento e influencia en el grupo de EF que estamos describiendo, será desarrollado luego en este mismo capítulo.
} 
que envidiarle nada a nadie", a pesar de ser él primera generación de universitarios en su familia. Todos estos elementos, combinados con su vinculación a una "generación determinada de gente" que trabajó intensamente para el crecimiento del DEF, le permitieron acceder a un cargo ejecutivo en la FaHCE. Desde allí y bajo un conjunto de estrategias como el fortalecimiento del Programa de Educación Permanente para Adultos Mayores (PEPAM) ${ }^{112}$, la EF comenzó a ser protagonista de la política institucional.

Con la reformulación del plan de estudios de 1984 por el actual plan 2000, la asignatura "Introducción a la EF" en la que se desempeñaba Carballo, se "dividió" en dos: Teoría de la EF I (Primer Año) y Teoría de la EF II (Segundo Año), materias en las que se desempeñaría, hasta su definitiva migración a ésta última. En el último plan de estudios 2000, estas materias fueron incluidas dentro del "trayecto de la formación teórico-práctica de la EF", tramo en el que, como veremos, se concentrarían todos los profesores de este grupo académico. ${ }^{113}$

Durante su segundo mandato como Secretario de Extensión, Carballo compartió la gestión institucional con otro personaje relevante de EF en la UNLP, Ricardo Crisorio. Crisorio provenía del interior de la Provincia de Buenos Aires, de la localidad de General Arenales, y al terminar el secundario viajó a La Plata para estudiar Arquitectura. Allí se mantuvo unos cinco años, y rápidamente se incluyó en la militancia estudiantil universitaria, en un grupo de izquierda denominado Tendencia Comunista. En 1976, año que definió como "malo" para tomar decisiones, se cambió a EF, de donde egresó en 1979. Es decir que su formación en la carrera fue en plena dictadura militar. Los motivos

\footnotetext{
112 EI PEPAM es, junto con la Escuela de Lenguas, uno de los Programas de Extensión más vigorosos de la FaHCE, tanto por los recursos financieros que requiere, como por la cantidad de docentes y participantes que moviliza. Se fundó en septiembre de 1994, cuando todavía no existía la Secretaría de Extensión de la FaHCE, y dependía de un Área de Extensión Universitaria a cargo de María Teresita Minellono. En ese momento se crearon los tres principales Programas de Extensión de la FaHCE que funcionan hasta la actualidad: el PEPAM, el Centro de Orientación Vocacional y la Escuela de Lenguas. Recién en la gestión 1995-1998 se creó la Secretaría de Extensión. En 1995, la primera secretaria fue Adriana Boffi; de 1998 a 2001, y de 2001 a 2004 fue Carlos Carballo. El PEPAM funcionó en tres espacios físicos, hasta que se adquirió y estabilizó a fines de 2002 en la casa de la calle 50 e/ 17 y 18. Consta de talleres temáticos destinados a adultos mayores desde los 55 años que se dictan en 8 sedes de distintas localidades de La Plata y Gran La Plata, y no requieren conocimientos previos. El dictado es de frecuencia semanal, las clases tienen una duración de una hora y media, y abarcan múltiples temáticas, tales como: Transformaciones del Envejecer, Talleres Literarios, de Expresión Corporal, Filosofía y Cine, Economía y Sociedad Contemporánea, Estimulación de la memoria, entre muchos otros. Los docentes que dictan los talleres son cerca de 30 -dictando un docente, en algunos casos, más de un taller-, y su estructura administrativa consta de un director, una asesora en Psicogerontología y seis coordinadores por áreas temáticas y territorios geográficos. Cuenta además con una plataforma virtual PEPAM Virtual. Cabe destacar que desde su creación, la participación de graduados y docentes de EF, tanto en el dictado de talleres como en la gestión, ha sido intensa y constante. (Datos obtenidos de la Entrevista a Carlos Carballo del 13 de abril de 2016 y de la consulta a la página web institucional. Última consulta: 26 de enero de 2017: http://www.fahce.unlp.edu.ar/extension/areas/pepam)

${ }^{113}$ En el siguiente capítulo abordaremos los distintos planes de estudio y en particular las discusiones sobre este último plan.
} 
del cambio de carrera los asocia a una práctica deportiva y recreativa infanto-juvenil intensa, que hacía que lo corporal no le implicara mayor esfuerzo, y a imágenes de disfrute que observaba desde los talleres de Arquitectura en el Campo de Deportes de la UNLP. Sobre esas razones del cambio de carrera, expresó:

"[...] Por un lado, era que en el pueblo el patio era la Pampa, eso era así...en ese tiempo al menos, te estoy hablando de los años ' 60 , ahí yo tenía 8 años...mi vieja no tenía que preocuparse por donde estábamos por ejemplo... eso hacía que hiciéramos muchísima actividad corporal de todo tipo, había dos clubes, yo iba a uno, del cual mi viejo me hizo socio al minuto...pero nunca jugué al futbol, no me gustaba, jugaba mucho al básquet, pelota paleta, además andaba muchísimo a caballo, porque a su vez la familia de mi mamá tenía campo, después mi viejo compró campo, compramos caballos... y la verdad, que cuando yo empecé a dudar de la arquitectura, en ese tiempo los talleres de arquitectura...que todavía siguen estando en un medio nivel hacia abajo, eran como muy lóbregos, muy oscuros, y yo miraba donde estaban las canchas de paleta del nacional y los veía muy felices...".

Esa circunstancia lo alentó a cambiarse y, aunque el contexto no tenía nada de divertido, sí sostuvo como factores facilitadores que no tenía dificultades corporales, además de contar con un fuerte capital intelectual forjado en esa primera experiencia como estudiante en Arquitectura y por la militancia universitaria. Ambas instancias facilitaron su tránsito por las materias teóricas de EF que desvelaban al resto de sus compañeros.

De esa época recordó,

“[...] A partir del '76 para mí y para el grupo en que estaba, la militancia pasó a ser nuevamente mucha lectura y muchísimo cuidado...la diferencia con mis compañeros de EF era que yo sabía exactamente lo que estaba pasando en el país y ellos no y no querían saber tampoco; de hecho, yo tengo muy pocos amigos de mi época de EF, muy pocos amigos [...]".

Este pequeño relato pone de manifiesto una cuestión que va a ser un rasgo que caracteriza, desde la perspectiva de algunos de nuestros entrevistados, a los estudiantes de EF, que es su exigua participación política en una comunidad de Humanidades muy movilizada y activa que, aunque fue cambiando hacia comienzos de los años 2000, los militantes de EF hasta ese año fueron una proporción mínima dentro del estudiantado de la FaHCE en relación a otras carreras. Así lo señaló también Carballo en la entrevista,

"[...] si yo me tuviera que referir al colectivo de estudiantes de educación física de acá, yo no diría que la primera característica negativa o no tan positiva tenga que ver con desempeños intelectuales. Como colectivo en general, es el colectivo más despolitizado respecto de los colectivos de otras carreras, eso sí lo veo. Y eso me preocupa mucho a mí. [...]". (Las cursivas son propias) 
Aquí, Carballo da cuenta de una representación dominante negativa doble sobre los estudiantes de EF relativa a su desempeño intelectual, aunque señale que "no diría que la primera característica negativa o no tan positiva tenga que ver con desempeños intelectuales", la reconoce y, por el otro lado, su falta de participación política.

Estas referencias también son indicativas de diferencias entre el colectivo estudiantil y el grupo de profesores que estamos analizando. Es decir, estamos rescatando para el análisis un grupo de docentes, una "generación determinada" en palabras de Carballo, que se caracterizó por su participación efectiva en espacios de política estudiantil y académica.

Crisorio entonces, egresó de la carrera en 1979, con pocas expectativas de ingresar a trabajar en la Facultad por la orientación político-ideológica de la carrera durante la dictadura y la figura de su director, Ernesto Rogg. Se fue de vacaciones a su ciudad natal y luego regresó a La Plata para trabajar de taxista un tiempo, ya que tenía muy claro que no quería volver a Arenales en forma definitiva. A pesar de ello, luego tuvo que hacerlo ya que obtuvo cargos docentes en escuelas de la zona, aunque lo hizo de forma itinerante entre ambas ciudades, hasta que a los pocos meses se instaló definitivamente en La Plata al obtener un cargo docente en una escuela primaria. Apasionado por el básquetbol y su enseñanza, en 1980 conoció a Armando de los Santos, a quien señala como un referente en la enseñanza de esta disciplina deportiva y, en 1981, a Mariano Giraldes, una figura que cambiaría su concepción de la EF: "fue como hacer la carrera de nuevo", y que resultó clave para varios de los profesores de este grupo. Giraldes se había graduado como Profesor de Educación Física en el INSF, y luego se formó en Alemania, España, Francia, Suecia y Estados Unidos. Autodefinido como "maestro del cuerpo", se especializó en Gimnasia Formativa, y con los años configuró lo que denominó "Gimnasia en los márgenes", para aludir a una gimnasia que esgrime una contracultura corporal. ${ }^{114}$ Crisorio compartió varios años de formación con Giraldes, en grupos de estudio que éste último formó en la Ciudad de Buenos Aires. El trabajo en esos grupos tenía una duración de tres años, y luego sus integrantes pasaban a ser coordinadores de otros grupos. Crisorio desempeñó ese rol durante diez años. Participaron de esos grupos de estudio, entre otros, Marcelo Giles y María Eugenia Villa, y funcionaron como esquemas de trabajo que luego establecerían en La Plata.

\footnotetext{
114 Información extraída del blog personal de Giraldes y de la página del Gimnasio Olimpia, del que fue fundador, última consulta el 10/11/2017, disponibles en: http://marianogiraldes.blogspot.com.ar/2007/11/miperfil.html, http://www.gimnasioolimpia.com.ar/hacia-una-gimnasia-los-margenes/
} 
Crisorio consideró tanto a De los Santos como a Giraldes sus "referentes", el primero en la disciplina básquetbol, y el segundo, en la formación general en EF.

Sobre su ingreso como docente en la FaHCE, definió que pasó por una etapa en la que estaba virtualmente "prohibido" ${ }^{115}$, y relató en ese sentido un episodio mantenido con el director de la carrera en dictadura, Rogg, que luego se constituirá como una estrategia que facilitó su entrada en la reapertura democrática,

"[...] yo había tenido la lucidez, tampoco sé por qué, de mandarle una carta a Rogg que era en ese momento el Director de la carrera, ofreciéndole mis servicios. Le había mandado una carta sabiendo lo que me iba a decir, pero yo me guardé la carta y la respuesta, con eso me presenté a Carlos [por Parenti], y de ahí empezamos a laburar, hicimos todo el trabajo básicamente político, en primer lugar, y todo el momento de la normalización fue bueno como sacar toda la rémora de la dictadura, terrible, y como empezar a pensar otras cosas. Yo ingrese ahí la gimnasia formativa que era lo que yo estudiaba con Mariano [por Giraldes]..."

Su carrera como docente la desplegó en la cátedra de Gimnástica ${ }^{116}{ }^{117}$, primero como Ayudante Diplomado Ad-honorem en el año $1984^{118}$, para pasar directamente a Profesor Adjunto interino con dedicación simple en 1985 y a partir de 1988 con dedicación semi-exclusiva ${ }^{119}$, y como Profesor Titular con igual dedicación primero interino y luego ordinario en 1991, producto del concurso que se realizó en $1990^{120}$. El salto de Ayudante diplomado ad-honorem a Profesor Adjunto es un dato a destacar, en tanto puede interpretarse por dos vías: en un sentido, da cuenta de la "debilidad" de las instituciones académicas durante esos años ${ }^{121} \mathrm{y}$, por otro, de la urgencia y estrategia en la cobertura de cargos por parte de la gestión del DEF en la "normalización".

\footnotetext{
${ }^{115}$ La expresión "prohibido" se encuentra entrecomillada no sólo porque es propia del entrevistado, sino porque además hace referencia a una situación que no estuvo plasmada en ningún documento o normativa. Es decir, se sentía prohibido por el relato que se anticipa a continuación.

${ }^{116}$ Luego, con el cambio de plan en 1998, dicha materia pasó a llamarse Educación Física I, aunque con varias modificaciones, en la que Crisorio permaneció hasta su pase a Educación Física $V$ en el año 2004 (Res. 620/04, Res. 988/04). Es decir que, estuvo 20 años en la misma materia de primer año, hasta pasar a la docencia en el último año del Prof. y Lic. en EF.

${ }^{117}$ Crisorio tuvo una incursión de 8 años en la cátedra de Didáctica Especial y Prácticas de la Enseñanza en EF, en su primer cargo concursado como Profesor Adjunto Ordinario entre 1986 y 1994, con licencias sin goce de sueldo durante varios meses en el transcurso en distintos años (Res. 166/86, Res. 385/90, Res. 93/91). Evidentemente su interés estaba colocado en la otra asignatura y en otros ámbitos, ya que terminó renunciando a "Didáctica..." (Res. 143/94) para dedicarse de lleno a Gimnástica I y a la investigación. En esas resoluciones de licencia sin sueldo no se invocan los motivos de las mismas.

${ }^{118}$ Res. 641/84, FaHCE.

${ }^{119}$ Res. 206/88, FaHCE, dedicación asignada a partir del 01 de abril de 1988 y luego prorrogada por Res. 181/89, Res. 213/90.

${ }^{120}$ Res. 769/90, FaHCE.

${ }^{121}$ Entrevista a Carlos Carballo el 13 de abril de 2016 en Ensenada. La interpretación sobre la "debilidad" de las instituciones al retorno democrático es compartida por otros profesores que, como Carballo, habían tenido por esos años saltos "meteóricos" en sus carreras académicas.
} 
También es de destacar su participación en el Curso de Nivelación (luego, en 1992, denominado Curso de Ingreso, y en 1998 Estrategias de Ingreso) al Profesorado en EF durante los años 1990, 1992 y 1998 como Profesor Titular y Coordinador (Res. 23/90, Res. 31/92, Res. 51/98).

Finalmente, obtuvo dedicación exclusiva en $1994^{122}$, a partir de su participación en trabajos de investigación en el marco del Programa de Incentivos para docentes universitarios de la recientemente creada SPU. ${ }^{123}$

Producto de la incursión en otros ámbitos no académicos, hacia los años '90, Crisorio se constituyó en un referente central de la EF a nivel nacional. Esta situación fue posible gracias a la visibilidad que adquirió como Coordinador en la definición de los Contenidos Básicos Comunes ( $\mathrm{CBC}$ ) de EF del -en aquel momento- Nivel Polimodal para el país. Cabe señalar que durante la reforma estructural del sistema educativo de los años 1990, llevada adelante por la gestión del entonces presidente Carlos Saúl Menem, y a partir de la aprobación de la Ley Federal de Educación № 24.195, se estableció que todos los niveles y disciplinas presentes en la escuela obligatoria debían definir sus contenidos básicos comunes. Esta fue la primera vez que la EF como disciplina escolar era definida por "expertos" ${ }^{124}$ en un trabajo que implicó el recorrido del coordinador y colaboradores por todo el país y el establecimiento de acuerdos a nivel disciplinar. Crisorio accedió a esta importante posición en el por entonces Ministerio de Cultura y Educación (MCE), a partir de relaciones personalizadas y académicas mantenidas con Ana Barletta, Secretaria Académica de la FaHCE entre los años 1992 y 1995 quien, a través de un pedido de la entonces Coordinadora del Programa, Cecilia Braslavsky ${ }^{125}$, lo recomendó para esa labor. Según el propio Crisorio, Barletta era su "íntima amiga".

La participación de Crisorio en la formulación de los contenidos básicos comunes es un indicio de la influencia que la EF universitaria de La Plata también ejerció en las políticas educativas de los ministerios nacionales y provinciales durante los años 90 . Por otro lado, aquí se ponen en evidencia algunas articulaciones entre el campo académico y el político: podríamos interpretar que la visibilidad y legitimidad que Crisorio obtuvo por circular por todo el país le permitió construir una figura de autoridad en la especialidad

\footnotetext{
${ }^{122}$ Res. 919/94, FaHCE.

${ }^{123}$ Este Programa y sus implicancias en el posicionamiento institucional de la carrera de EF serán analizados en el siguiente capítulo.

${ }^{124}$ El entrecomillado se debe a que se trata de una categoría muy usada en el contexto estatal de esos años, cuyas significaciones e implicancias para la construcción y utilización del conocimiento social fue analizada, entre muchos otros, por Neiburg y Plotkin, 2004.

${ }^{125}$ Braslavsky se desempeñaba en el MCE como Directora General de Investigación y Desarrollo (Fuente: Nota enviada por la misma a Ana Barletta, presente en el Acta $N^{\circ} 160$ del 23/11/95 de la FaHCE).
} 
que probablemente facilitó la difusión de sus ideas por fuera de la FaHCE. Además, este hecho podría haberle reportado beneficios intramuros en la academia, al ser el coordinador de los CBC y de, como veremos en el próximo capítulo, el director del primer congreso y revista académica de la disciplina en los años 1993 y 1995 respectivamente, del primer grupo de investigación en La Plata en 1994, entre otros eventos que lo colocaron en el centro de la escena institucional.

Volviendo a la FaHCE, en el año 2001, durante la tercera gestión de De Diego luego de un intervalo de tres años-, Crisorio fue elegido vicedecano hasta 2004, y reelegido en la gestión como decana de Ana Barletta, entre 2004 y 2007, ya que, según Giles "no puede ser decano". Esta última expresión de Giles alude a una anécdota según la cual, sobre el fin del último período de gestión de De Diego en 2004 y ante la negativa inicial de Barletta del año 2001 de ser candidata, existió una posibilidad de que Crisorio fuera decano, pero que se vio frustrada por resistencias internas. ${ }^{126}$

Luego del desempeño de Carballo en Extensión, esta posición de Crisorio en el Vicedecanato significó la segunda vez que el grupo de EF logró acceder a una función ejecutiva en la Facultad.

En el año 2003, a partir de una estrategia política del grupo ${ }^{127}$, Crisorio trasladó su cargo docente y dedicación en Educación Física I a la asignatura Educación Física $V^{128}$ del último año de las carreras, que había sido recientemente incorporada en el nuevo Plan 2000, cargo que concursó a mediados de ese año.

Marcelo Giles fue un colaborador estrecho y "amigo" de Crisorio, lazo que, según sus testimonios, conservan hasta la actualidad. Giles es unos años más joven que Crisorio, y compartió su formación como estudiante con Carlos Carballo, con quien además forman parte prácticamente de la misma generación.

Carballo y Giles fueron compañeros de estudio y de militancia mientras fueron estudiantes, y se formaron fundamentalmente durante la dictadura, graduándose en 1984 con el retorno democrático. Otro rasgo que los liga es que ingresaron a trabajar en la

\footnotetext{
${ }^{126}$ Guardamos confidencialidad, a pedido de nuestro entrevistado, sobre los pormenores de esa resistencia y sus participantes, aunque no podemos dejar de mencionar la circunstancia ya que hace a nuestro problema de investigación porque pone de manifiesto arreglos de poder y tensiones en torno a la legitimidad de la EF para ocupar posiciones en el gobierno institucional, y da cuenta del sostenimiento de jerarquías disciplinares.

${ }^{127}$ En breve analizaremos esa estrategia, que luego, conflicto mediante, funcionará como antecedente de la diáspora que más tarde sufrirá el grupo.

${ }_{128}$ De esta migración de cátedra, contamos con el acto resolutivo Providencia № 210 del 28/11/2002 mediante la cual el Decano De Diego dispone su pase a Educación Física $V$ a partir del $1^{\circ}$ de febrero de 2003. Luego, concursa el cargo de Profesor Titular en la cátedra mediante Res. 620/04 del 27/08/2004, y es puesto en funciones por Res. 988/04 de diciembre de 2004, y por el término de siete años a partir del $30 / 11 / 2004$.
} 
FaHCE el mismo año, 1985, un año después de Crisorio. Como mencionáramos más arriba, Carballo lo hizo en Introducción a la EF, y Giles en Gimnástica I, asignatura coordinada por Crisorio. La primera incursión de Giles en la docencia fue como Ayudante Alumno, luego como Ayudante Diplomado Ad-Honorem, Ayudante Diplomado en 1985 y JTP. A fines del año 1990 concursó y ganó como Profesor Adjunto y accedió entonces a la categoría de Profesor Ordinario de la FaHCE. ${ }^{129}$ Compartió buena parte de su carrera docente con la asignatura Gimnástica II, correlativa de la anterior, y presente en el segundo año del Plan 1984. En esa cátedra accedió primero al cargo de JTP aunque, como veremos, avanzados los años 2000, concentraría su dedicación en Educación Física I (Ex Gimnástica I). Es decir que se desempeñaría en dos de las cátedras más grandes de la carrera y de la Facultad, teniendo en cuenta la masividad que fue adquiriendo la carrera de EF a partir de los 2000. También muy joven, a los 29 años, reemplazó a otro Profesor en el cargo de Adjunto en Gimnástica II en el año 1991, cátedra en la que hasta ese momento, y desde 1987, cumplía funciones como JTP. ${ }^{130}$

La relación entre Giles y Crisorio no se configuró en el ámbito académico, sino previamente en el plano personal. A partir de la inquietud de Giles de tener una mejor formación a la brindada por la FaHCE en tiempos de dictadura y por intermedio de otro profesor con el que trabajaba en el Club Estudiantes de La Plata, se conocieron a fines del año 1981 en un evento social, y establecieron un vínculo muy estrecho, que mantienen hasta la actualidad. En 1982 se integró a grupos de estudio conformados por Crisorio, de los que participó hasta 1985, ya como graduado, momento en que ingresó en los grupos de Mariano Giraldes en Buenos Aires, donde Crisorio era coordinador. Esos espacios resultaron muy significativos para ambos, tanto por los temas tratados como por la dinámica que asumían. Ante mi pregunta sobre para qué se juntaban, si a leer o a debatir, Giles expresó:

\footnotetext{
"No, las lecturas las hacía cada uno por separado, el sistema de los grupos de estudio toma el sistema de los grupos operativos de Pichon Riviere, tenés una guía de lectura que todos completábamos con cierta rigidez, definir los conceptos del texto, pensar otras ideas complementarias a las que apunta el autor, tenían ocho puntos, y teníamos un coordinador y una especie de observador, el coordinador coordinaba la temática, el debate, y el observador hacia como devoluciones medio psicoanalíticas, de la psicología social, como funcionaba el grupo, si había alguno que se callaba...".
}

\footnotetext{
${ }^{129}$ Res. 731/90.

${ }^{130}$ Res. 326/91, Res. 771/90.
} 
En esas instancias rigurosas de formación, entablaron una relación de amistad entre Giraldes, Crisorio y Giles, junto a otros compañeros, que excedió el grupo de estudio.

Su cercanía personal y académica con Crisorio construida en el trabajo en la misma cátedra, podríamos suponer le posibilitaría ser elegido por éste último como Secretario del DEF, durante sus gestiones entre 1992 y 1998. Allí su relación se afianzó aún más y fueron los generadores y alentadores de iniciativas como el Congreso, la Revista, la reforma curricular y la participación en proyectos de investigación, entre otros eventos, que analizaremos más adelante. Esta experiencia previa le permitió ser elegido como sucesor de Crisorio al frente del DEF en 1998, y confirmado nuevamente en 2001 hasta 2004. Otro de los secretarios de Crisorio durante un tiempo e integrante del grupo que estamos analizando fue Osvaldo Ron. ${ }^{131} \mathrm{Si}$ bien Ron es de la misma generación que Carballo y Giles (Ron es del 63' al igual que Carballo, y Giles del 62'), es "el más joven" del grupo, en tanto ingresó a la carrera de EF en 1984, año en que los dos últimos egresaron, y culminó en 1988. Según Giles, esto sucedió porque Ron "estudió de grande". Ron ingresó a la docencia en la FaHCE como Ayudante Diplomado Ad-Honorem en mayo de 1988, en la cátedra de Gimnástica I de primer año, en la que estaban Crisorio y Giles. A los pocos meses, tuvo una participación en Gimnástica III, y fue nombrado Ayudante con renta en Gimnástica I. Compartió la docencia en ambos espacios hasta 1992, año en el cual fue designado en Gimnástica II (Segundo Año), luego denominada con el cambio de plan, Educación Física II, donde permaneció hasta la actualidad como Profesor Titular. Es decir que compartió muchos años la docencia con Giles en Gimnástica I y II, cátedras en las que se desempeñó como JTP desde comienzos de los años '90 en forma interina, hasta que concursó en 1998. En Gimnástica I se desempeñó como auxiliar de Giles hasta el año 2000 que fue designado como Profesor Adjunto con dedicación exclusiva. ${ }^{132}$ En julio del 2001 concursó junto a Giles dos cargos de Profesor Adjunto en Gimnástica II. ${ }^{133}$ Es decir que, para el año 2001, Ron revistaba en ese cargo en ambas asignaturas. Por otro lado, se desempeñó en la gestión institucional como Secretario del DEF tanto de Crisorio como de Giles. En este último caso, entre los años 1998 y 2004. Durante los años 2003 y 2004 comenzó a tomar fuerza un "quiebre político" en este grupo, producto de "diferencias teóricas". Ese "quiebre" fue definido por Giles como "una hecatombe" en la que él junto a Crisorio ya comenzaban a

\footnotetext{
${ }^{131}$ Res. 196/96, Res. 18/97.

132 Res. 373/00.

${ }^{133}$ Res. 669/00, Res. 512/01.
} 
hablar de la disciplina como "Educación Corporal" y el resto -por Carballo y Ron principalmente- "no querían dejar de ser Educación Física". Para darle una alternativa de solución al conflicto, y según la perspectiva de Giles, llegaron a un acuerdo en el que éstos últimos "se quedaban con el Departamento de Educación Física, y manejaban el Departamento, el congreso y la revista, todo, y nosotros [por Giles y Crisorio] nos quedábamos con el posgrado y el Ciclo Extraordinario de Licenciatura". Este relato es indicativo de una estrategia política del grupo frente a un "conflicto de crecimiento", como lo definiría De Diego, que además implicó un reacomodamiento de los cargos docentes, de manera que cada uno pudiera tener su espacio de cátedra. Como Giles había desplegado su trayectoria fundamentalmente en Gimnástica I, actual Educación Física I, siendo Crisorio el Profesor Titular, y también se desempeñaba como Adjunto en Gimnástica II junto a Ron, cuando se cambió el plan y las cuatro Gimnásticas se convirtieron en las cinco Educación Física, Crisorio migró a Educación Física V, permitiendo que Giles pudiera ser Titular en I, y habilitando a Ron a ser Titular en II. ${ }^{134}$

La conformación y devenir de este grupo, su vinculación con la política académica institucional, y el despliegue de una serie de políticas y estrategias disciplinares, son indicios de una etapa de dinamismo propios de la constitución de un campo de conocimiento, que intentó poner en entredicho esa visión desprestigiada de la EF en la institución y en el campo científico, relatada en el capítulo anterior. En el siguiente apartado veremos una de esas estrategias que consistió en el cursado de una Maestría en Chile por buena parte de los integrantes del grupo.

\section{El viaje a Chile: una experiencia colectiva de formación y el armado de una nueva concepción disciplinar}

En el año 1993, el grupo de graduados y docentes descripto anteriormente junto a otros adherentes, organizó el primer congreso nacional de EF, denominado Educación Física y Ciencia ${ }^{135}$. Allí asistieron varios centenares de personas y especialistas en la materia y de otras disciplinas de Argentina, América Latina y el mundo. Entre ellos, Eduardo Remedi, un pedagogo cordobés que durante la última dictadura militar se exilió en México, y que fue presentado anteriormente. Remedi fue identificado por Carballo como un promotor incansable de la realización de una carrera de posgrado por parte de

\footnotetext{
${ }^{134}$ Entrevista a Marcelo Giles el 17 de diciembre de 2015.

${ }^{135}$ Las motivaciones, valoraciones y contenidos de este congreso, serán analizados en el siguiente capítulo.
} 
este grupo de EF. Al respecto de su viaje a Argentina con motivo del congreso, Carballo señaló:

“...Yo creo que al principio dijo [por Remedi] "bueno, son todos de educación física, seguro que no entienden nada, vengo igual porque de todas maneras..." pero se encontró con una comunidad viva, interesada... Remedi después de esa experiencia dijo "tienen que venir a la UNAM, tienen que venir a México, tienen que hacer la maestría allá, tienen que dejarse de joder". Todos ya teníamos familia o más o menos, no a México yo dos años no...Nadie podía decir "hago las valijas y me voy a México dos años". Y después, volvió a venir en el congreso del '95 y nos dijo "bueno, ahora no zafan. La gente que se formó conmigo: Mirta Abraham, Verónica Edwards", bueno nos fue nombrando gente "...y esa gente abrió una maestría en Santiago. Si ustedes dicen que están dispuestos a viajar y es gente piola porque es cada 5 meses, ustedes viajan y se instalan allá, no tienen que dejar el trabajo de acá, a ustedes ahora el cambio les conviene". Bueno, la verdad es que no podíamos decir que no."

La expresión del entrevistado "son todos de Educación Física, seguro que no entienden nada" da cuenta de la asunción por parte de estos docentes de EF de esa mirada desprestigiada o subordinada de la disciplina, ya no sólo a nivel de la FaHCE, sino a nivel del campo académico, a escala internacional. Es decir, podemos interpretar que lo manifestado por Carballo habla más de lo que pensaban ellos sobre sí mismos en aquel momento, que de lo que pensaba Remedi sobre la EF. Por otro lado, esta y otras citas dan cuenta que las condiciones para hacer posgrados están atravesadas no sólo por historias académicas, sino por las historias personales y familiares de cada uno de los actores.

Es así como un grupo de ocho docentes de la carrera de EF de la FaHCE emprendieron en 1996 este itinerario de formación, que los llevó a permanecer durante dos estancias cortas pero intensas en la ciudad de Santiago, en Chile ${ }^{136}$, en una Maestría en Investigación Educativa, de la Universidad Humanismo Cristiano, dictada, entre otros, por profesores formados por el equipo de Remedi ${ }^{137}$. Esos docentes eran: Ricardo Crisorio, Marcelo Giles, Osvaldo Ron, Abel Patricio Calvo Etcheverry, Carlos Carballo, María Eugenia Villa, Mónica Dorato y Alicia Villa, las dos últimas egresadas de Ciencias de la Educación. De ellos, lograron graduarse los últimos cuatro en diferentes etapas de los primeros años 2000. Es decir que, podemos interpretar que la experiencia de formación trascendió para al menos la mitad de ellos, el hecho de la obtención del título.

\footnotetext{
${ }^{136}$ Según el testimonio de uno de los viajantes, Marcelo Giles, las estancias eran de 20 días cada una durante enero y julio.

${ }^{137}$ Los entrevistados recuerdan especialmente al propio Eduardo Remedi, a la coordinadora de la Maestría, Mirta Abraham, a Verónica Edwards, José Ricardo García, entre otros.
} 
Para Giles, el posgrado en Chile significó un "hito" que les permitió replantearse su formación de grado y armar una nueva concepción disciplinar, denominada luego "Educación Corporal". Con respecto a la experiencia en Chile, relató:

"...ahí tomamos contacto con estas dos epistemologías, esta de que lo individual todavía tiene alguna importancia y... pero hay un tipo ${ }^{138}$, que nos abre un poco la cabeza que es un filósofo chileno, que nos presenta a Wittgenstein y los juegos del lenguaje, y empezamos a leerlo, y fuimos haciendo un recorrido por algunos sociólogos pero ya nos dábamos cuenta que la cuestión etnográfica tampoco era el camino, y aparece Foucault, en el viaje previo a México creo que nos compramos como 10 libros de Foucault, lo vendían en los bares, y la relación en ese momento era muy beneficiosa, era el 1 a 1 , y un peso argentino eran no sé...40 mexicanos...todos se costearon el posgrado de manera personal, y ahí se produce el quiebre, Wittgenstein, Foucault, y Lacan como tres cosas que empiezan a aparecer, pero nosotros ya estábamos hablando de educación corporal".

En el relato anterior, Giles da cuenta de un proceso de adopción progresivo de referencias canónicas de otros campos disciplinares: la Lingüística, la Sociología y el Psicoanálisis. Esos insumos teóricos, según el testimonio, fueron centrales para replantearse epistemológicamente su disciplina y, dentro de ella, sus objetos de estudio. Por otro lado, da cuenta de relaciones personales mantenidas con un referente de peso como Remedi, quien les insistió para que realizaran ese posgrado, y de un momento propicio para realizar esa experiencia: el tipo de cambio económico y la posibilidad no sólo de viajar a México, sino también de comprar libros.

Sobre las motivaciones para realizar el posgrado en Chile, Carballo relacionó la situación de este grupo con el contexto político y académico más general en los '90:

“...no, no...teníamos que hacerlos afuera porque, de hecho, eran más baratos...no había oferta de posgrado acá. Y acá no era ni siquiera artesanal, o sea, eran los doctorados. Entonces, maestrías y especializaciones no existían. Maestría empezaban a ofrecer países como México, o quienes se habían formado en esos lugares como la UNAM y ahí estaban los chilenos con los que terminamos nosotros en Santiago. Después nos avivamos nosotros, pero para eso teníamos que tener una mínima base crítica de gente que ya había recibido una formación de posgrado, que no la teníamos..." (Las cursivas son propias).

De las expresiones anteriores retomamos la trascendencia de obtener formación de posgrado y construir una "masa crítica" de gente, como condición para desarrollar una maestría propia. Esa es una de las estrategias de formación que desplegaron para poder

\footnotetext{
${ }^{138}$ El "tipo" al que hace referencia Giles fue el filósofo argentino José Ricardo García quien, según sus propias palabras y las de Crisorio, "les mostró otra epistemología, lingüística, no materialista. Él nos mostró el poder del lenguaje”. En ese momento, García se encontraba radicado en Chile.
} 
estar en condiciones de diseñar luego, a su regreso, su propia política de formación con sus maestrías y especializaciones.

Como vimos, la modalidad de cursada era flexible, veinte días intensivos en enero y veinte en julio, aunque se quedaran sin vacaciones. Las cursadas las realizaron entre 1994 y 1996, aunque se graduaron, como mencionamos, algunos pocos y esa graduación fue muy dificultosa. Así lo relató María Eugenia Villa ${ }^{139}$ :

“...Nos costó mucho después recibirnos porque la maestría era en dólares, era el 1 a 1 , cuando nos tocaba la tesis, la defensa de tesis salía 1000 dólares, en ese momento eran 1000 pesos; después te costaba más juntar los mil dólares que hacer la tesis. Era como, bueno, hago la tesis pero no la puedo pagar y entonces te iba como demorando. De hecho, no todos se recibieron, se recibieron Alicia, Mónica, Carlos, Patricio y yo. Marcelo, Ricardo y Osvaldo no, no terminaron. $\mathrm{Y}$ yo, por ejemplo, terminé pagando la defensa de tesis 3000-4000 pesos, solo la defensa y pagarla antes de rendir. Pagala "¿y si me va mal?" decía yo..."

Es interesante resaltar del relato previo cómo fueron cambiando los costos y las condiciones estructurales para realizar posgrados por parte de los docentes universitarios, condiciones que en este caso incidieron para que algunos demoraran en recibirse o no se recibieran.

Ante la pregunta de por qué Chile, y si había otros posgrados para realizar aquí en Argentina sin tener que viajar, Villa señaló:

"de posgrados así, en los que nosotros pudiéramos acoplarnos como profes de Educación Física sin ser vistos como bichos raros no había nada. Y esa maestría era muy buena, muy buena, nos la recomendó Eduardo Remedi y de ahí nos fuimos. Era como una, yo no me olvido más mi cuñada, la esposa de mi hermano que es profe de francés de acá de la Facultad también, me decía "pero, ¿para qué vas a hacer un posgrado? ¿Y allá? ¿Vas a ganar más plata?" "No - le decía- pero bueno..." después ella terminó haciendo posgrado acá, en Francia. Mis sobrinas están en Francia estudiando y le digo "mira vos, que me cuestionaste tanto cuando yo me fui" era visto como "¿para qué? ¿Vas a ganar más plata con eso?" No, qué sé yo, en ese momento no sabíamos, era para formarnos en investigación "¿y te van a pagar por investigar?" "No, no sé, supongo que no" decía yo...". (La cursiva es propia)

El hecho que la Facultad avalara esta instancia de formación por medio de las licencias concedidas ${ }^{140}$, interpretamos puede haber sido un doble juego entre la internacionalización de la formación brindada y el reporte de beneficios a nivel disciplinar

\footnotetext{
${ }^{139}$ María Eugenia Villa es Prof. de Educación Física de la FaHCE, Magíster en Investigación Educativa (UAHC-Chile) y Profesora Adjunta en Didáctica Especial I (para los niveles educativos Inicial, EGB1 y EGB2, estos dos últimos ya extinguidos con la Ley de Educación Nacional sancionada en 2006). Fue entrevistada en Ensenada el 03 de marzo de 2017.

${ }^{140}$ Cabe destacar que la Facultad le concedió a este grupo de docentes licencias con goce de sueldo para poder realizar los estudios (Algunas resoluciones que evidencian tal acción institucional son la Res. 365/96 Giles-, Res. 383/97 -Crisorio-, Res. 385/97 -Ron-).
} 
e institucional, por cuanto esos docentes retornarían a sus funciones en las cátedras que se encontraban, para esa carrera, desprovistas de formación de posgrado. Además, el testimonio anterior también es indicativo de cómo fue cambiando el campo académico en los últimos años: el mismo familiar que le cuestionaba a ella el sentido de la realización del posgrado, más adelante termina haciendo uno en Francia. Es decir que, el proceso de profesionalización de la carrera académica hacia los años '90, era un hecho que había llegado -aunque más tardíamente en Argentina que en otros países de la región- para quedarse (Marquina, 2013), dentro del cual el posgrado comenzaba a configurarse como una condición sine qua non para la permanencia y la promoción. Para este grupo, tanto la obtención del título como el hecho de retornar a la Argentina con el cursado completo fue una puerta que les habilitó, entre otras cuestiones, empezar a materializar con hechos concretos este objetivo de armar un "campo académico".

Por último, cabe destacar que esta experiencia de formación nutrió de argumentos a estos actores para la reforma curricular que se vendría en breve, al armado y aprobación de la primera carrera de posgrado en EF -Maestría en Educación Corporal-, a la generación de proyectos de investigación y de redes regionales, a la vez que significó la posibilidad de mejorar las condiciones de esos profesores para su proyecto académico en el campo científico. En este sentido, en el próximo capítulo desarrollaremos las políticas y estrategias de circulación y producción científica y curricular, desplegadas por estos actores para legitimar y prestigiar académicamente a la EF de la FaHCE.

\section{Conclusiones}

En este capítulo describimos la composición social y política de un grupo de académicos de EF, sus vínculos, redes de relaciones y formas de sociabilidad, para comprender la ocupación de posiciones en el ámbito del DEF y de la FaHCE y la adopción de perspectivas y orientaciones político-académicas y disciplinares entre los años 1984 y 2004. Esta reconstrucción permitió visibilizar la conformación de un "linaje" o estirpe que se originó con la fundación de la carrera en 1953 y en torno a la figura de su "fundador", Alejandro Amavet, que luego fue legado a una generación intermedia liderada por Carlos Parenti, discípulo del primero, quien encabezó una refundación de la carrera en la recuperación democrática a partir de 1984. En esos años y por iniciativa del propio Parenti, ingresó en la escena institucional un grupo de estudiantes avanzados y jóvenes graduados que, si bien se reconocen herederos de ese linaje fundacional, fueron 
delineando una perspectiva disciplinar crítica de la intervención autoritaria de los '70, que a su vez, paulatinamente se fue distanciando de la perspectiva fundante de Amavet anclada, según el testimonio de estos actores, en una visión de la EF humanista, de vanguardia en ese momento, pero anacrónica para los nuevos tiempos que se avecinaban en las Ciencias Humanas y Sociales.

Luego, caracterizamos a un espacio político-académico renovador en la FaHCE, dentro del Claustro de Graduados, el Frente Amplio de Graduados (FAG) surgido en el año 1988. En dicho espacio se congregaron graduados recientes y auxiliares docentes de diferentes carreras y orientaciones político-ideológicas, opositoras a la conducción radical de la UNLP, también presente en parte del gobierno de la FaHCE. La participación de actores de EF en ese agrupamiento se dio desde un inicio, con el antecedente en espacios de militancia estudiantil durante los años previos a la reapertura democrática, y que confluyen en el FAG. Dicho espacio se constituyó como central en la escena institucional, ganando la elección en el Claustro de Graduados en 1988 y, luego, en 1991, a partir de la alianza con otra lista de corte crítico, accedieron al gobierno ejecutivo de la FaHCE en el que permanecerán hasta la actualidad.

Una vez reconstruida la recomposición de los claustros y el gobierno institucional, analizamos la gestión del DEF de Crisorio iniciada en 1992, en el contexto de la política universitaria estatal de los años '90. Alli dimos cuenta de que, si bien el gobierno del DEF se nutrió de gran parte de los cuadros del equipo de Parenti, es decir, que buena parte de aquellos graduados y auxiliares jóvenes permanecieron y aún ascendieron en sus cargos, los diferentes testimonios identificaron a la gestión de éste último como "más política" y a la de Crisorio como "más académica".

Vimos cómo, en el contexto de reforma de la educación superior de carácter internacional, aunque en el país tomó forma a partir de la década del '90, este grupo de profesores de EF supo apropiarse y resignificar las políticas nacionales en su propio beneficio. En esa línea, se diseñaron una serie de estrategias conjuntas y confluyentes al objetivo principal de "academizar" la carrera, a partir de "aprender" de las disciplinas más tradicionales en la FaHCE, como Historia, Filosofía, Letras o Ciencias de la Educación. Fundamentalmente, en lo referido a cómo hacer investigación "seriamente": publicar, difundir, debatir, formarse, etc. bajo la forma en que se hacía en Humanidades. Aquí nos resultó particularmente útil la diferenciación planteada por Bourdieu (2008) entre poder universitario y poder científico. Así, pudimos reconocer que por las características de masividad de la matrícula de EF avanzados los años '80, y el simple hecho de 
permanecer como carrera en la universidad, los profesores disponían de un relativo poder universitario. Desde ese punto de inicio, el grupo de profesores que describimos tomó la iniciativa de ir por más y acumular los capitales necesarios para disputar poder científico, única forma de proyectarse por fuera del ámbito institucional.

Asimismo, hemos reconstruido lo que para actores de otras disciplinas constituyó un momento de "refundación" o de "transformación épica" en la historia de la carrera. Una transformación que se extendió desde la "normalización universitaria" en 1984 hasta comienzos de los años 2000 , en la que se reconoció un trabajo de mucho esfuerzo por parte de las distintas gestiones al frente del DEF, que redundaron en un crecimiento académico de la EF. De los testimonios pudimos establecer dos etapas de la "gesta heroica": la primera, focalizada en distanciarse de orientaciones más técnicas presentes en otros profesorados de otras instituciones y durante la dictadura en la UNLP, y fortalecerse como formadores de formadores; y la segunda, dirigida al logro de un reconocimiento científico dentro de la universidad a partir de jugar y disputar con las reglas de la academia.

Luego, evidenciamos que este proceso de legitimación académica no estuvo exento de conflictos y tensiones interinstitucionales. A los conflictos ya mencionados en el capítulo anterior, podemos agregar la disputa, traducida en un retraso en su aprobación, por la apertura de la Maestría en Educación Corporal, ya que políticamente "al interior" no era bien visto que EF, luego de ser la primera en modificar su propuesta curricular de grado, volviera a ser la primera, y con una carrera de posgrado. Esta situación es indicativa del mantenimiento de jerarquías disciplinares en la institución, en donde la EF todavía tenía mucho camino por recorrer.

Asimismo, a partir del testimonio de actores clave, caracterizamos a las distintas gestiones al frente del DEF entre 1984 y 2004. En este sentido, las gestiones de Parenti y Gayol, que se extienden entre 1984 y 1992, fueron definidas como más "pedagógicas", preocupadas por reorientar la formación, hasta ese momento predominantemente técnica, hacia una perspectiva educativa, que tuviera como propósito fundamental la formación de docentes. Por otro lado, vimos cómo estas gestiones se dirimieron en torno a un reordenamiento o recomposición de la planta docente, en un contexto de creciente conflictividad entre los profesores. La gestión siguiente de Crisorio, entre los años 1992 y 1998, fue identificada con una etapa de "crecimiento académico" de la carrera, de diseño de un objeto de conocimiento, que se profundizaría luego con las dos gestiones de Giles entre 1998 y 2004. 
Hasta 1992, muchos profesores se sentían "outsiders" o distintos en el paisaje institucional de la FaHCE, y se inició desde la Dirección de la carrera una etapa de diseño de estrategias de integración y reconocimiento al interior y exterior de la institución, que redundaron en un crecimiento disciplinar. Un ejemplo de estrategias a nivel institucional fue la cobertura de cargos docentes desde el año 1984, que también se destaca para los años '90 y comienzos de los 2000. Por otro lado, en cuanto a la incidencia por fuera de ese ámbito, se subraya la participación de estos actores en la función pública y en el proceso de definición de los Contenidos Básicos Comunes (CBC), y una estrategia surgida en el marco de la FaHCE pero con el objetivo de configurar a la EF local en referencia nacional como fue la Licenciatura Extraordinaria en la disciplina homónima, para egresados de carreras terciarias. Esta "apertura a otras instituciones" les permitió una proyección hacia el conjunto del sistema educativo y la difusión de su perspectiva educativa y académica en todo el territorio nacional. Ambas acciones contribuyeron en extender la influencia de la EF de la FaHCE por fuera de los muros institucionales.

En el cuarto apartado, reconstruimos la conformación del grupo de profesores protagonista de esa "gesta épica". En este sentido advertimos que, si bien en esas políticas y estrategias académicas desarrolladas en el marco de las carreras de EF participó un grupo numeroso de actores, y que la propia organización de la universidad así lo establece con dispositivos como la Junta Consultiva Departamental -actualmente Asesora- o la Comisión Curricular, fue un grupo reducido de profesores quienes tuvieron un protagonismo central en la definición de esas políticas. Según la reconstrucción que pudimos realizar en torno al análisis de documentos y entrevistas, estos actores aparecieron en forma reiterada en la definición de la orientación y gobierno de las carreras, apelan a un "nosotros", "ellos", en alusión a la configuración de un grupo académico, y fueron referenciados por otros informantes clave de la carrera como la "mesa chica" de la comunidad más amplia de profesores de EF de la FaHCE ${ }^{141}$. La expresión proveniente del sentido común, hace mención al poder concentrado en un pequeño grupo de docentes que supieron orientar la política académica disciplinar entre los años 1992 a 2004. Este grupo se caracterizó por compartir su formación inicial mayormente en dictadura, por confluir en un mismo espacio político institucional y por

\footnotetext{
${ }^{141}$ Nota de campo derivada de una conversación informal en junio de 2016 mantenida con una auxiliar docente de EF de la FaHCE que se desempeña en un grupo de investigación que dirige uno de los actores estudiados. Esta percepción adquiere relevancia en la medida en que es coincidente con la de otros/as docentes con los que mantuve contacto durante el trabajo de campo entre los años 2015 y 2016 en la FaHCE. Si bien los significantes cambian ("Ios cinco fantásticos", los "muchachos") la representación es compartida e incluso coincide la nominalización de los actores aludidos.
} 
desplegar sus trayectorias docentes en espacios troncales de la carrera: los de la formación teórica y práctica disciplinar (Introducción a la EF -luego distribuida en Teoría de la EF I y II- y las Gimnásticas -luego denominadas Educación Física I a V-).

Luego abordamos las trayectorias profesionales, políticas y académicas de los profesores de este grupo. Identificamos en qué contextos históricos estudiaron, qué formación recibieron, cómo fueron ingresando a la docencia universitaria, y la participación y configuración de otros espacios de formación que dieron cuenta de un descontento por la formación recibida y de una clara intención de diferenciarse de la misma y construir otra alternativa. Además, vimos cómo el acceso de los actores de EF analizados a la función ejecutiva y legislativa del gobierno institucional de la FaHCE, fue resultado de la eficacia de una trama de relaciones personalizadas y políticas, y de la adscripción a un grupo particular, de las que se valieron para asumir posiciones encumbradas y reorientar la política disciplinar. En este sentido, la pertenencia de algunos profesores de EF al espacio político-académico del FAG resultó clave para su ingreso y permanencia en la función ejecutiva y legislativa del gobierno institucional.

Por último, reconstruimos una experiencia de formación central para este grupo, como fue el viaje a Chile a realizar una Maestría en Investigación Educativa, que les permitió tomar contacto con docentes, autores y perspectivas novedosas en el campo de las Ciencias Sociales y Humanidades, que redundó en sustento teórico para el viraje político-académico que la carrera ya estaba asumiendo. Por otra parte, esta experiencia nutrió a la reforma curricular que se vendría en breve, al armado de la primera carrera de posgrado en EF, el comienzo de redes regionales, a la vez que significó la posibilidad de mejorar las condiciones de esos profesores para su proyecto de disputar en el campo científico.

A partir de la identificación y caracterización de las gestiones del DEF entre los años 1984 y 2004, y de los actores de EF que ingresaron como docentes a la Facultad en 1984 , sus trayectorias académicas, redes de relaciones y adscripciones políticoinstitucionales, en el siguiente capítulo avanzaremos sobre las distintas políticas y estrategias que los mismos desarrollaron en torno a la producción científica de su campo disciplinar y la revisión curricular del proyecto de formación de grado de sus estudiantes. 


\section{CAPITULO 3}

\section{Políticas de producción científica y de revisión curricular en Educación Física}

\section{Presentación}

En el capítulo anterior identificamos a un grupo de graduados y profesores que dentro de la comunidad más amplia de EF de la FaHCE participaron activamente en las políticas y estrategias académicas de su disciplina entre los años 1984 y 2004. Caracterizamos sus trayectorias, rasgos identitarios, prácticas de sociabilidad y redes de relaciones sociales que nos permitieron entender las posiciones que ocuparon en la gestión institucional y departamental, y las perspectivas y orientaciones que asumieron en función de esas políticas y estrategias desplegadas.

En este capítulo analizamos los modos de implementación de ciertas políticas universitarias y académicas ${ }^{142}$ desarrolladas por estos actores, preguntándonos en qué medida esas políticas funcionaron como modos de legitimación en la construcción de un campo de conocimiento. Por un lado, analizamos las formas de apropiación, resignificación y/o resistencia que los mismos realizaron respecto de las políticas universitarias de los '90, así como el desarrollo de políticas académicas y estrategias, y su incidencia en la legitimación e institucionalización académica de la EF en la UNLP. Por otro, reconstruimos los acuerdos, desacuerdos, tensiones y disputas ligados a ese proceso, desarrollados entre los años 1992-2004. Las políticas y estrategias recortadas para el análisis son aquellas vinculadas a la producción científica y la revisión curricular emprendidas por este grupo de académicos presentados en el capítulo anterior. La revisión de los planes de estudio fue una de las políticas centrales durante la "transformación"143 del conjunto del sistema educativo en los años '90 (Nosiglia y Rebello, 2005; Paviglianiti, 1995). La "adecuación" de los planes de estudio de la FaHCE a la nueva estructura del sistema, fue una de las motivaciones centrales de la gestión

\footnotetext{
${ }^{142}$ Siguiendo a Camou (2002) diferenciamos entre políticas universitarias y académicas, entendiendo que las primeras hacen referencia a la toma de decisiones emanadas desde las autoridades gubernamentales para el sector, y las segundas, a iniciativas de los órganos de gobierno o autoridades de una universidad, facultad, departamento o asociaciones institucionales, es decir, las construidas desde la "base del sistema" (Clark, 1983).

${ }^{143}$ Las referencias entrecomilladas aluden a expresiones relevadas en documentos institucionales, proyectos curriculares, testimonios de actores y bibliografía de referencia.
} 
institucional para encarar las reformas curriculares (Obiols, 1997; Plan de estudios del Prof. y Lic. en EF, 1998).

En ese sentido, para este capítulo nos abocamos a demostrar la trascendencia de cuatro políticas universitarias y académicas que la comunidad en estudio desplegó. En el primer apartado, retomamos algunos testimonios e intervenciones públicas de actores que nos condujeron a seleccionar esas políticas. En el segundo, caracterizamos el proceso de diseño del Congreso Educación Física y Ciencia, como una instancia que gravitaría en el reposicionamiento de esta comunidad en el espacio institucional de la FaHCE y la UNLP. En el tercer apartado, analizamos el armado de la primera revista académica de la disciplina a nivel nacional, la Revista Educación Física y Ciencia, y retomamos las valoraciones que los actores realizan en el presente en torno a ambos procesos y sus resultados. Se consideran para el análisis las actas de las dos primeras ediciones del Congreso disponibles y los seis números editados de la Revista en el período (1992-2004). El análisis de esos documentos nos permitirá reconocer su alcance como políticas académicas de legitimación disciplinar de la EF en la FaHCE y por fuera de ese ámbito institucional. En el cuarto apartado, se estudian los inicios en la actividad de investigación de esta comunidad, en el marco del Programa de Incentivos del Ministerio de Educación de la Nación, las dificultades y avances asociados a este proceso, así como los modos de incorporación al Programa. En el quinto apartado, se caracteriza la última reforma curricular de la carrera iniciada en 1997, y que dio lugar a un cambio de plan de estudios del Profesorado y a la incorporación de la Licenciatura (denominados Plan 2000). En este sentido, se retoman las discusiones en torno a la creación de la Licenciatura y se identifican cuáles fueron los ajustes al plan de estudios 1984 que el grupo presentado en el capítulo anterior propuso para prestigiar o "academizar" la carrera. Por último, se recapitulan los principales hallazgos y conclusiones del análisis realizado.

\section{2. "La prepotencia de trabajo": el proceso de legitimación de EF en Humanidades en los años '90}

"En el '92 tuve la fortuna de que el Consejo Académico de la Facultad me eligiera Decano de la misma, y designó al Profesor Ricardo Crisorio al frente del Departamento. Con Crisorio transcurrimos buena parte de los complejos años del menemismo. El problema que nos planteamos fue cómo crecer en situaciones adversas, adversas en la Nación y, debo decirlo, adversas en la Universidad. Y el Departamento creció, y creció notablemente. Logró mejorar las dedicaciones de la mayoría de sus profesores, consolidó el perfil de la carrera, comenzó su política de 
publicaciones, incorporó proyectos de investigación en el Programa de Incentivos, inició el exitosísimo ciclo de los congresos bianuales. En este sentido, quiero destacar algo que no suele destacarse. Durante muchos años, el Departamento de Educación Física, hay que decirlo, tuvo una especie de complejo de hermano menor frente a disciplinas de tradición prestigiosa y reconocido mérito -Historia, Letras, Filosofía-, el hermano menor pudo haberse escondido y procurar crecer en los restringidos límites de su disciplina. El orgulloso aislamiento hubiera sido la respuesta más sencilla. Pero Crisorio y su gestión hizo lo contrario, como si dijera: "está bien, somos el hermano menor, pero queremos estar en la misma mesa de discusión". Porque sabían que contra el prestigio secular tenían un arma definitiva: para usar la célebre fórmula de Roberto Arlt, "la prepotencia de trabajo". Toda vez que le echaban en cara su condición de hermano menor $-\mathrm{y}$, obviamente, este reproche nunca era directo sino elíptico- Crisorio escribía el doble; discutía, y muchos debieron reconocer que sus argumentos a menudo eran irrefutables". (Las cursivas son propias). ${ }^{144}$

Las palabras de José Luis De Diego, quien se desempeñó como Decano de la FaHCE en los períodos 1992/1995, 1995/1998 y 2001/2004, fueron pronunciadas en 2003, con motivo del cincuentenario de la creación de la carrera de Profesorado en EF. Nos interesa dar inicio al análisis con estas palabras porque nos permiten dar cuenta de cómo actores institucionales de peso por aquellos años, reconocen como eventos significativos una serie de políticas e iniciativas del DEF. De Diego se refiere a las políticas de publicaciones, los proyectos de investigación, los congresos, entre otros, como actividades que les fueron permitiendo a los actores de EF "entrar a la mesa de discusión" institucional, junto con las carreras "de prestigio secular" y a pesar de ser "la hermana menor".

Asimismo, este pasaje inicial, nos permite rescatar un relato consagratorio del proceso de legitimación de la EF en la FaHCE, ubicado temporalmente a partir de 1992. En este sentido, se reconocen ciertos logros que son atribuidos al trabajo esforzado en un contexto "adverso" por parte del Director del DEF y su equipo. Esta afirmación es coincidente con lo planteado en el capítulo anterior, cuando reconstruimos la conformación de un grupo determinado de trabajo, con relativa cohesión, y la ubicación de Crisorio como figura aglutinante en ese proceso.

Otro actor, en este caso profesor de EF, como Carballo, señaló sobre ese proceso de institucionalización académica de la EF en la FaHCE:

“[...] ahí sí me parece que hay una cantera más rica acá en La Plata porque no es una historia totalmente compartida por todas las universidades; tiene que ver con una generación determinada de gente y son muchas acciones, digamos. Tiene que ver con el cambio del plan de estudios, y la aparición de la licenciatura, tiene que ver con

\footnotetext{
${ }^{144}$ Expresión acuñada por José Luis De Diego en el discurso pronunciado con motivo del aniversario número $50^{\circ}$ de la carrera de Educación Física en la FaHCE, 2003, mimeo.
} 
la aparición de los primeros congresos, tiene que ver con tener una revista que hoy es una de las mejores indexadas de la Facultad, tiene que ver con la aparición de los primeros equipos de investigación, con los primeros categorizados que pueden empezar a dirigir proyectos de investigación, los primeros estuvieron acá en La Plata. De hecho, los únicos categoría II en el Programa de Incentivos que somos de Educación Física, estamos acá en La Plata, porque hay otros que están en Rosario pero ya se pasó al ámbito de las Ciencias de la Educación y otra en Buenos Aires que ya se pasó a las Ciencias Sociales [...]".

Ambas citas recrean el panorama de estrategias y políticas académicas que desarrolló esa "generación determinada de gente" para lograr reconocimiento a través de la academización. Es decir, lo que este capítulo se propone es analizar cómo ciertas políticas universitarias y académicas funcionaron como plataforma de acceso a la legitimidad institucional y, en palabras de Crisorio, en el proceso de construcción de un "campo" de conocimiento. ${ }^{145}$

\subsection{El escenario del proceso de legitimación: Política nacional y universitaria en los años} '90

Luego de una profunda crisis económica, política y social, a mediados del año 1989, se precipitó la salida del gobierno nacional de Raúl Alfonsín (UCR) y asumió el Presidente electo Carlos Saúl Menem del Partido Justicialista (PJ). En agosto de ese mismo año, Menem proclamó una profunda reforma del Estado de carácter integral. ${ }^{146} \mathrm{En}$ nombre de la "emergencia" -recordemos el proceso hiperinflacionario de años previos-, se produjo finalmente una política de "reingeniería estatal" (Oszlak, 1997), que trastocó la matriz tradicional de relación entre el Estado y la sociedad, de carácter estado-céntrica.

Los principales elementos de esta reforma fueron la privatización, descentralización y tercerización de los servicios públicos y las empresas del Estado,

\footnotetext{
${ }^{145}$ Para una aproximación gráfica sobre las políticas seleccionadas en este capítulo ver Tabla 6, "Políticas académicas en EF para el período 1992-2004", en los anexos de esta tesis. Cabe aclarar que se incluyen dentro de esta tabla la creación de dos carreras de Maestría en el año 2001 y 2004, por haber sido relevadas en el trabajo de archivo, aunque no son analizadas en profundidad en la tesis.

${ }^{146}$ Esta reforma fue rubricada en la Ley de Reforma del Estado № 23.696, sancionada el 17 de agosto de 1989. Esta ley declaraba la emergencia de la totalidad de los entes y servicios públicos, y autorizaba su intervención por parte del PEN con el fin de su extinción, fusión o privatización. Se excluía expresamente de esta intervención a las universidades nacionales. El Ministro de Obras y Servicios Públicos en esos primeros años del menemismo fue Roberto Dromi, actor fundamental de esta reforma, popularmente conocido por su "fallido" en un discurso público en la Casa de Gobierno en 1989 en el que manifestó: "Nosotros hemos ideado un decálogo, que dentro de unos días se conocerá, que es el decálogo menemista de la Reforma del Estado, el mandamiento uno, son palabras de Menem, él no lo conoce aún, el mandamiento uno está extraído de muchos de sus discursos y dice así: 'Nada de lo que deba ser estatal permanecerá en manos del Estado'". Fuente: Especial 30 años de Democracia: Las privatizaciones/El "decálogo menemista". El cronista comercial. Disponible en: [https://www.youtube.com/watch?v=yqaN2nxQqM8], última consulta 07 de febrero de 2018.
} 
incluyendo un proceso de desregulación económica y el debilitamiento de mecanismos de protección de la producción local.

En materia educativa, este proceso impactó de manera profunda y desigual en cada uno de los niveles educativos, así como tuvo sus contradicciones y matices. Una política clave fue la descentralización del sistema de educación secundaria y terciaria del año 1993, a través de la transferencia de las instituciones educativas de jurisdicción nacional a las provincias -ya con la dictadura militar se habían transferido las escuelas primarias sin los respectivos recursos- ${ }^{147}$, generando una fragmentación en materia de infraestructura, salarios, propuestas formativas como en el proceso de toma de decisiones entre el poder central y los poderes provinciales (Paviglianiti, 1995; Puiggrós, 1995; Tiramonti, 2001).

Durante el autodenominado proceso de "Transformación Educativa" iniciado en 1992, se sancionaron una serie de leyes que modificarían la fisonomía y funciones del Sistema Educativo en su conjunto, y que impactarían luego en las actitudes y formas de hacer de sus actores. Nos referimos puntualmente a la Ley Federal de Educación (LFE), sancionada en 1993, y la Ley de Educación Superior (LES), de 1995.

El nivel universitario fue objeto de una profunda intervención estatal que introdujo nuevas lógicas y mecanismos de funcionamiento en las instituciones académicas (Krotsch, 2001; Suasnábar y Rovelli, 2011; Marquina, 2013), que lo modificarían hasta nuestros días. Desde la Reforma Universitaria de 1918, y al calor de las sucesivas interrupciones del orden constitucional, la relación entre el Estado y las Universidades en la Argentina osciló entre extremos de "benevolencia" (Brunner, 1994) y represión. Esa actitud indulgente por parte del Estado se cristalizó básicamente en la distribución del presupuesto en forma incremental o histórica, sin mayores controles. A partir de los años '90, desde el gobierno nacional se diseñaron e implementaron nuevas formas de regulación académica y se reordenaron jurídicamente las instituciones de educación superior, estableciendo un Sistema de Educación Superior (SES). Esta actitud proactiva por parte del Estado en materia de políticas de regulación de las universidades fue inédita. En un escenario de creciente desconfianza y desprestigio hacia lo público, desde el PEN se iría delineando una imagen de universidad ineficiente y costosa, a partir de la cual generar consenso social para la implementación de funciones de control centralizado y en donde el financiamiento se asumía como algo a ser corregido (Krotsch, 2003).

\footnotetext{
${ }^{147}$ Para una revisión sobre los efectos de la última dictadura en el sistema educativo argentino, ver Tedesco, Braslavsky y Carciofi, 1983.
} 
La evaluación fue el eje transversal de las propuestas de reforma de la ES, entendida como un mecanismo eficaz para el control y regulación de las instituciones y de los individuos que las componen. Por esos años se constituyó, siguiendo a Krotsch (2001) un "Estado evaluador", que entendería a la calidad de la educación en un sentido economicista, de eficacia en la distribución y uso de los recursos, y en la obtención de resultados cuantificables. Uno de los organismos centrales que se creó para garantizar la instrumentación de estos cambios fue la Secretaría de Políticas Universitarias (SPU) en el año 1993, que reemplazó a la Dirección General de Asuntos Universitarios. Esta Secretaría tuvo un rol destacado en la creación de consensos para la aprobación de la LES, además de tener funciones en el otorgamiento, seguimiento y evaluación de los recursos financieros brindados, tanto públicos como privados (Krotsch, 2001).

Durante los años '90, en los espacios de gobierno de la FaHCE, los temas de discusión centrales estuvieron vinculados a la cuestión del presupuesto/financiamiento de las universidades, y a los programas que se configuraron desde el Estado Nacional como el Programa de Incentivos a los docentes-investigadores (PI) y el Fondo para el Mejoramiento de la Enseñanza y la Calidad (FOMEC), entre otros. ${ }^{148}$ EI FOMEC había sido aprobado en 1995 y comenzó a funcionar en 1996, y formó parte de un programa más general, denominado "Programa de Reforma de la Educación Superior" (PRES), financiado por el Banco Mundial -Banco Internacional de Reconstrucción y Fomento(BM/BIRF) y una contrapartida nacional aportada por las universidades, que se propuso revisar áreas como la enseñanza y la investigación. EI PI fue creado a través del decreto presidencial 2427 del año 1993, instrumentándose en 1994, y tuvo como objetivo impulsar la investigación en las universidades nacionales, a través de mecanismos de evaluación y control de la producción científica de los docentes y el otorgamiento de un incentivo económico. ${ }^{149}$

\footnotetext{
${ }^{148}$ Los temas de discusión centrales y la cuestión de estos programas fue extraída de las Actas de Consejo Académico de la FaHCE №135 del 24 de marzo de 1994 y No137 del 09 de junio de 1994 (FaHCE, 1994). La primera vez que se discutió el PI en el marco de la FaHCE fue en la sesión del Consejo Académico del 04 de noviembre de 1993, cuando el decano presentó el decreto elaborado por el PEN (FaHCE, 1993). El debate sobre la cuestión presupuestaria se estructuró alrededor del decreto No2034/94 del PEN y está presente en el Acta $\mathrm{N}^{\circ} 145$ del 1 de diciembre de 1994, y a propósito del documento "Política Presupuestaria para el Sector Universitario (Año 1994)" de septiembre de 1993 elaborado por el PEN (FaHCE, 1994). También el tema se dirimió en el Acta №157 del 28 de septiembre de 1995 con motivo de la reducción presupuestaria a las universidades nacionales en un $2 \%$ a través del decreto 290/95 (FaHCE, 1995).

${ }^{149}$ Este programa tiene continuidad hasta el presente. El análisis de estos programas y sus implicancias en EF en la FaHCE serán abordados en el presente capítulo.
} 
Ana María Barletta, quien se desempeñó como Secretaria Académica de la FaHCE entre los años 1992 y 1998, se manifestó sobre estas políticas en un documento institucional de 1995:

“[...] El año 1994 resultó para la Universidad argentina un año especialmente crítico en lo que se refiere a las embestidas del Ministerio de Cultura y Educación de la Nación con iniciativas verticalmente proyectadas sobre las Universidades, con exigencias de urgente resolución y con demandas de información detallada en plazos perentorios: Decreto 1610 sobre aumentos de salarios diferenciados al personal docente; Decreto 2427 sobre Incentivos a Docentes-Investigadores; Implementación del sistema de opción previsional; Reforma del sistema administrativo; Financiamiento de programas de posgrado; Programa Nacional de Capacitación Docente...[...] La UNLP no estuvo exenta de estas presiones y la Facultad de Humanidades, particularmente, sufrió transformaciones a partir de la implementación de estas iniciativas cuyo alcance todavía no llega a mensurarse completamente. [...] Tal vez, a esta Secretaría [Académica], por la índole de su gestión específica, le toque estar más cerca de las contradicciones que plantea esta nueva situación política de la Universidad en la que resulta frustrante -pese a ser indispensable- defender retóricamente los principios que organizaron la Universidad Reformista cuando el jaque está planteado en el terreno de las iniciativas concretas de las autoridades nacionales. [...]". (Las cursivas son propias) ${ }^{150}$

Las expresiones de Barletta refuerzan esta idea de un contexto político novedoso en las universidades nacionales, con un Estado que se mostraba muy activo en el diseño e implementación de políticas para el sector y que, en el caso de la FaHCE, significaron alteraciones profundas, a partir de "iniciativas verticalmente proyectadas" sobre la Universidad. Por otro lado, señala que esos cambios representaron exigencias de urgente resolución para los actores y que su alcance aún no podía medirse completamente. En un artículo publicado en 2010, también manifestaba que el padecimiento mayor:

"era que las universidades públicas no habían sabido reaccionar ante una fórmula de
intervención sobre ellas, que obligaba a los funcionarios universitarios a hacerse
cargo de una engorrosa actividad administrativa al servicio de los proyectos
gubernamentales con la amenaza de ver esterilizadas, simultáneamente, sus propias
iniciativas. Se veía claramente entonces cuán difícil era pensar en los pormenores de
una gestión universitaria posible sin afrontar los desafíos que provenían de estas
contradicciones" (2010: 5-6).

En relación a las "contradicciones" a las que alude debido a la tensión entre la verticalidad y celeridad de las reformas implementadas y el gobierno diario de la institución, cabe señalar el panorama en el que se encontraba la planta docente de la

${ }^{150}$ Facultad de Humanidades y Ciencias de la Educación, FaHCE-UNLP (1995). Memoria de Gestión (19921995). La Plata. Mimeo. 
FaHCE en comparación a otras unidades académicas de la UNLP para el año 1992. En el citado documento se evidencia una relación desfavorable de la FaHCE: la ocupación del primer puesto en dedicaciones simples y el noveno en mayores dedicaciones, con una planta docente compuesta por 886 cargos, de los cuales casi el 92\%, es decir, 813, eran de dedicación simple (1995: 37, 39). Este escenario constituido tanto por las políticas estatales del gobierno de Menem como también por la historia de la relación entre Estado Nacional y Universidades, es parte de las condiciones en que la EF se fue "consolidando" en la FaHCE. En principio porque, como veremos en el análisis de las diferentes políticas, los actores de EF hicieron una lectura particular de ese escenario, dándole carácter de "oportunidad", y valiéndose de tácticas, saberes locales y recursos autogenerados o por competencias (como los fondos provenientes del FOMEC, el PI, entre otros), procuraron posicionarse como una carrera en pie de igualdad con las otras presentes en Humanidades.

\section{3. "Una bisagra": El armado del Primer Congreso de Educación Física y Ciencias}

A comienzos del año 1993 el grupo a cargo de la gestión del DEF organizó el primer congreso disciplinar a nivel nacional y universitario. Según consta en los documentos, dicho congreso tenía como principal objetivo "el pensamiento y discusión de la problemática actual de nuestra disciplina desde su propio campo y/o desde diversos marcos teóricos y diferentes perspectivas científicas". ${ }^{151}$ Fue denominado "Primer Congreso Argentino de Educación Física y Ciencias"152, y quienes lo organizaron pretendieron proyectarse por fuera de los muros de la FaHCE e incluso del país. Evidencias de ello fueron el fuerte poder de convocatoria y la presencia de referentes locales en esa primera edición como Adriana Puiggrós, y referentes externos de peso como Eduardo Remedi (argentino exiliado en México desde los años '70), Jean Le Boulch $^{153}$, Pierre Parlebas ${ }^{154}$ o André Lapierre ${ }^{155}$, pudiendo colaborar para traccionar

\footnotetext{
${ }^{151}$ Nota enviada por el Director del DEF Ricardo Crisorio al Decano José Luis De Diego, el 05 de marzo de 1993, compartida en el marco del Consejo Académico (Anexos del Acta № 121 del 25 de marzo de 1993, FaHCE). El Congreso se desarrolló entre los días 8 y 11 de septiembre de ese año.

${ }^{152}$ La información presente en este y los siguientes párrafos fue extraída de las Primeras Actas del Congreso, editadas en 1993 por la FaHCE. Dicho material está compuesto por "la desgrabación de conferencias, mesas redondas y paneles que tuvieron lugar en el Congreso e incluye el intercambio de preguntas y respuestas entre especialistas y asistentes que generó cada una de ellas" ("Palabras iniciales", 1993: 15).

153 Jean Le Boulch (1924-2001) fue un profesor de Educación Física francés, Lic. en Psicología, estudió Medicina y se especializó en Kinesiología. Fue creador del método de la Psicokinética y un referente en la
} 
público atraído por la presencia de figuras internacionales. En este sentido, Ron señaló que el Congreso "fue el punto de vinculación", "empezamos a vincularnos con gente de otras instituciones y del resto del mundo", como expresión de las primeras redes que comenzaron a tejerse con otros actores de referencia en el campo y otras instituciones.

Sobre la pregunta acerca de por qué denominaron al Congreso "Educación Física y Ciencias", María Eugenia Villa sostuvo:

\begin{abstract}
"sí, el primero fue 'Educación Física y Ciencias' porque era como que, bueno, nos abríamos a las otras ciencias, la Educación Física siempre fue escrita por otras ciencias, lo que habíamos visto en el Proyecto de Identidad y Crisis [por el primer proyecto de investigación acreditado en el $\mathrm{PI}{ }^{156}$ era eso, que los que escribían sobre Educación Física eran los pedagogos, los fisiólogos, los médicos, los psicólogos, todos escribían sobre la Educación Física, no la Educación Física sobre sí misma porque no había tradición en investigación, en escritura, en nada. Toda la producción que había era de los demás, básicamente. Entonces, era 'Educación Física y Ciencias', todas las ciencias y la Educación Física. Después era 'Educación Física y Ciencia' porque la idea era que la producción de la Educación Física sea de la Educación Física; más allá de que el debate fuera si era científico o no" ${ }^{157}$ (Las cursivas son propias)
\end{abstract}

Aquí empezamos a comprender mejor las razones de la subordinación de la EF a otras disciplinas y su deslegitimación en la FaHCE, en tanto "la Educación Física siempre fue escrita por otras ciencias"; a la vez que encontramos intentos de distanciamiento con esa tradición por parte de graduados jóvenes y profesores. Es interesante también retomar las preposiciones resaltadas en la cita, como producción sobre y de la Educación Física. Por aquellos años, habían tenido mucha repercusión en este ámbito, producciones del pedagogo Eduardo Remedi en relación a la discusión sobre investigación en Educación Física y sobre Educación Física -análisis que, en rigor, ya había efectuado para el campo de las Ciencias de la Educación, de donde él provenía-. En un artículo inédito, denominado "El concepto de Educación Física", Remedi señalaba que esta diferencia radicaba en indagaciones propias de la disciplina, caracterizadas por la "reflexión sobre la propia práctica", o investigaciones de otras disciplinas que tomaban

perspectiva psicomotricista, que tuvo recepción en la Argentina a partir de la década de 1970 (Rocha Bidegain, 2012).

${ }^{154}$ Pierre Parlebas nació en Francia en 1934 y es Profesor de Educación Física y Sociología y ha sentado las bases de una ciencia de la acción motriz: la praxiología motriz. Su perspectiva ejerció una fuerte influencia en nuestro país entre las décadas de 1970 y 1980 (Saraví, 2012).

${ }^{155}$ André Lapierre (1923-2008) nació y murió en Francia, y fue un referente de la Psicomotricidad. Estudió en la École Normale Supérieur de Éducation Physique de París en 1947 y ejerció varios años como profesor en Liceos. Fundó y presidió entre 1968 y 1976 la Sociedad Francesa de Educación y Reeducación Psicomotriz. Su perspectiva dentro de la Psicomotricidad se denominó "Educación Vivenciada" y, hacia los años 1990, "Psicomotricidad Relacional" (Mayoral González, 2008).

${ }^{156}$ En breve desarrollaremos los inicios en la actividad de investigación de esta comunidad.

${ }^{157}$ Entrevista a María Eugenia Villa, el 3 de marzo de 2017 en Ensenada. 
por objeto a la EF y producían conceptos y teorías, que la EF adoptaba acríticamente. La realización de este Congreso de algún modo expresaba la intención de este grupo de constituir un campo de conocimiento, con producción propia.

En otros pasajes de las entrevistas a Villa y Achucarro, se refirieron a un debate que se dio en los años '90 sobre el carácter científico de la EF -debate presente no solamente en Argentina, sino en otras latitudes- ${ }^{158}$, que atravesó todas las políticas y estrategias por esos años, entre ellas, el Congreso:

"ese fue un debate fuertísimo del primer congreso. Porque era el debate que tenían los europeos también, sobre todo nos basábamos mucho en unas publicaciones que llegaban acá, que las traducía en ese momento del francés, Gabriela Madueño, que eran las mesas redondas de Le Bouche y Parlebas sobre si la Educación Física era científica o no. Y eso fue un debate fuertísimo en aquellas épocas, después nos dejó de preocupar si éramos o no ciencia, el día de hoy no es algo que nos preocupe. Sí se hace ciencia social, pero no....

E: pero no si sigue ciertos parámetros

EV: y antes si quería ser científico tenías que ir a medir cuánto ácido láctico producías en la carrera y todo para hacer ciencias. Hacían ciencia los que te medían, pesaban, calculaban cuánto podías correr y qué sé yo, eso era lo que más les preocupaba. Pero había otros factores, de hecho, que determinan eso. Sigue habiendo ese debate de 'naciste con talento deportivo o no naciste con talento deportivo', esa cosa del cuerpo, bueno, y ahora, la que se viene con las neurociencias es lo mismo, naciste inteligente o no." 159

"una de las viejas revistas que se llaman Stadium que tienen que ver con el ideal olímpico... me acuerdo de un español que se llamaba Ordoñez, que decía 'cuánta ciencia le hace falta a la educación física', era el título y lo teníamos como material de bibliografía de Teoría de la Educación Física, de lo que era la vieja Introducción a la Educación Física [por el plan 1984] o algo así como ¿¿le hace falta ciencia a la educación física?'. Nosotros creíamos en algún sentido, que la construcción de un saber científico nos iba a garantizar esta identidad, romper con la crisis, esta cosa de la búsqueda del objeto de estudio." 160

\footnotetext{
${ }^{158}$ Evidencias del alcance internacional de la discusión sobre el estatuto epistemológico de la EF son algunas producciones en el campo de la EF brasilero, como las de Valter Bracht en su libro editado en Córdoba en el año 1996 "Educación Física y aprendizaje social. Educación Física/Ciencia del Deporte: ¿Qué ciencia es esa?", o en su artículo publicado en el año 2000 en la Revista Brasilera de Ciencias del Deporte, titulado "Educación Física y Ciencia: Escenas de un casamiento (in)feliz". También había participado de este debate el francés Pierre Parlebas en otras tantas publicaciones, algunas de alcance local, como la presentada en Lecturas: Educación Física y Deportes, denominada "Problemas teóricos y crisis actual en la Educación Física" (1997).

${ }^{159}$ Entrevista a María Eugenia Villa, el 3 de marzo de 2017 en Ensenada.

${ }^{160}$ Entrevista al Prof. Santiago Achucarro el 13 de octubre de 2016 en Ensenada. Si bien Achucarro hace referencia a la Revista de divulgación española Stadium, la nota de opinión de Antonio Oña a la que hace referencia fue publicada en la Revista catalana Apunts, en el año 1986, denominada "Nos falta ciencia si queremos Educación Física". Ignoramos si previa o posteriormente fue publicada en Stadium, pero sí fue hallada en Apunts, y cotejada con los informantes para confirmar que se trataba de la misma nota. Allí afirmaba Oña: "En una sociedad como la nuestra cuyo paradigma de conocimiento es el método científico, es incoherente e improductivo ignorarlo por más tiempo". En otro pasaje de la breve nota y en la misma línea
} 
Por otro lado, vemos cómo el nombre del Congreso, no sólo fue materia de disputa entre los organizadores, sino que su resolución demuestra una voluntad por parte de los mismos de ligar a la EF con una visión particular de entender "la ciencia". Este entendimiento se vincula a prácticas legitimadas de producción científica en Humanidades, que no persiguen objetivos como medir, pesar, calcular, diagnosticar o predecir. Además, la cita precedente, nos brinda elementos para pensar los aportes que reportó a esta comunidad el hecho de "abrirse al mundo". Dar cuenta que las preocupaciones que ellos tenían formaban parte de un debate más amplio en Europa y en otras regiones de Latinoamérica, de alguna manera, los reposicionó: una cuestión es pensar en la relación de subordinación de la EF en la FaHCE por su vinculación con disciplinas tradicionales, y otra es advertir que la discusión epistemológica que estaban dando era propia de las discusiones centrales del campo disciplinar en un determinado momento histórico. Podríamos pensar al Congreso como parte del proceso de configuración de la EF como disciplina científica, en tanto que sus integrantes comenzaban a preocuparse por la producción propia, el establecimiento de relaciones y la demarcación de los límites con otros campos disciplinares y la construcción de espacios de discusión pública y colectiva sobre ese campo.

En un pasaje del acto de apertura del primer Congreso, el por entonces Decano De Diego se manifestaba en relación a la deslegitimación científica de la EF, estrechamente ligada a una tradición que calificaba de "regresiva y dogmática", en contraposición a una visión "humanista y social", a partir de la cual este grupo buscó prestigiar a la disciplina:

"La carrera de Educación Física es de las más jóvenes de nuestra Facultad y ha estado sujeta desde tiempo atrás a numerosas controversias. Toda una tradición regresiva y dogmática tiende a disociar las actividades del cuerpo y del pensamiento, así existe hasta una iconografía que asocia lo intelectual con la escualidez y la miopía, desde una biblioteca frondosa desprecia las actividades del cuerpo; inversamente aparece el hombre apto para las disciplinas del cuerpo, musculoso y fuerte, pero cuyo coeficiente intelectual deja que desear.

Nadie ya puede ignorar los riesgos de esta visión dogmática y maniquea que conforma una ideología que no podemos menos que condenar. La historia ha dado muestras de las distorsiones que llevan a la intolerancia y el autoritarismo cuando esta ideología se instala en los órganos de poder; es por ello que desde esta institución rescatamos desde siempre una dimensión humanista y social en la formación de nuestros estudiantes y esta dimensión da cotidianas muestras de llevarse a cabo". (FaHCE, 1993: 23-24) (Las cursivas son propias).

señalaba: "La Educación Física debe buscar sus ejes de referencia en la metodología científica; lo contrario constituye una lamentable falta, que permite, bajo una especie de mística, la admisión de conocimientos, lenguajes y prácticas que, con un ropaje pseudocientífico (sirva como ejemplo la llamada psicomotricidad), van floreciendo sin límites en un terreno abonado para ello." 
De algún modo, también, podemos considerar estas palabras del Decano ya no como indicativas de la disputa disciplinar interna a la que se refería Villa más arriba orientaciones más técnicas y orientaciones humanistas/sociales, que hemos abordado en profundidad en el capítulo 1-, sino a visiones más generales del campo científico que, expresadas en el contexto del primer Congreso, dan cuenta no sólo del posicionamiento de su gobierno, favorable a la deconstrucción de ese imaginario "dogmático" que escinde el cuerpo de la mente y que sustrae a la EF del "pensamiento", sino además de la trascendencia misma del evento en ese proceso.

En términos organizativos, el Congreso estuvo compuesto por un Comité de Honor, conformado básicamente por autoridades provinciales, de la Universidad Nacional de La Plata y de la FaHCE; un Comité Organizador, conformado por un Presidente (Ricardo Crisorio); Secretarios (Carlos Carballo, Carlos Parenti, Marcelo Giles, Marcos Pastorini); Prosecretaria (Laura Chiani); Tesorero (Jorge Fridman); Vocales (Osvaldo Ron, María Lucía Gayol, María Eugenia Villa, entre otros); y Coordinadores Técnico-Administrativo, de Extensión Cultural y de Asuntos Estudiantiles, todas autoridades de la FaHCE. Por otra parte, es interesante la conformación del Comité de Lectura, encabezado por el Secretario de Investigación y Posgrado de la Facultad, el filósofo Julio Moran, y la Comisión de Investigación y Posgrado: Amelia Aguado, María Luisa Freyre, Roberto Ringuelet, Mariana Versino, Andrea Rodríguez. ${ }^{161}$ Además, participaban del Comité de Lectura el Profesor Titular de la cátedra de Gimnástica IV Jorge Roig, el Profesor Titular de Seminario de Investigación en Educación Física, Jorge Saraví Riviere, y como consultores los Directores de los Departamentos Docentes de la FaHCE. Esta nutrida y plural comitiva fue designada fundamentalmente para la tarea de lectura y corrección de los trabajos presentados, aunque también, podemos pensarla como un apoyo institucional de respaldo al Congreso. En este sentido, De Diego señaló que algunos profesores "dimos nuestro nombre", "nos ponían en los consejos científicos del Congreso, de la revista", como una forma de colaboración y apoyo "en una primera etapa de despegue". Estas expresiones demuestran una situación de "tutelaje" en el primer Congreso, que explicitan la relación de subordinación de la EF respecto del resto de las disciplinas en la FaHCE.

\footnotetext{
${ }^{161}$ Esta Comisión de Investigación y Posgrado fue una de las que se conformaron en el marco del Consejo Académico por esos años, por tanto, todos los mencionados participaban de la misma en carácter de consejeros por el Claustro de Profesores, Graduados y Estudiantes, respectivamente.
} 
Las problemáticas centrales que abordó el mismo fueron tres: "Del cuerpo y movimiento en nuestra sociedad y cultura", "Pedagogía y Didáctica de la Educación Física actual", y "Epistemología de la Educación Física actual".

En el acto de apertura del primer Congreso, su Presidente, Crisorio, señalaba:

\begin{abstract}
"Nuestra disciplina, en particular, ha estado atravesada en todo lo que va del siglo, aunque con más énfasis en esta última mitad, por el anhelo de constituirse como ciencia, de delimitar su campo, su objeto propio, sus modos de proceder. En ese tiempo, y con ese afán, se han elaborado teorías y métodos, muchos de ellos valiosos, merecedores de nuestra atención y estudio. Sin embargo, al menos en nuestro país y hasta la información de la que dispongo, siempre parciales, incluso en el mundo, tales teorías y métodos no han transformado la realidad de la práctica de manera significativa $[\ldots]$

No está en mi ánimo, ni en el de mis palabras, desdeñar los desarrollos y experiencias ajenas, ni mucho menos el valor del conocimiento universal; la presencia aquí de invitados extranjeros corrobora esta negación a proclamar el encierro como método. Pero pretendo invitarnos a añadir a la escucha atenta y respetuosa, la articulación, ya afirmada imprescindible, con nuestra propia historia local, regional, nacional.
\end{abstract}

Mucha gente me ha manifestado que cree posible que este Congreso marque un antes y un después de él. Espero que no, espero que marque un hito, una ruptura en cierto sentido, pero no el olvido de la historia. Espero que no nos fascine el poder concretar un esfuerzo tan importante y que sepamos utilizar las herramientas que seguramente nos dejará en el análisis deconstructivo de nuestra historia y nuestra práctica. Espero también que nos anime a investigar, a pensar, a reflexionar sobre nuestros propios pensamientos, pero siempre con la práctica educativa, debería decir praxis educativa, que es lo nuestro, como último y definitivo criterio. Porque ella y sólo ella asegura criterios ni tan últimos ni tan definitivos. Ella y sólo ella requiere y propone la interminable búsqueda de un saber no preexistente pero que debe constituirse desde lo existente". (FaHCE, 1993: 20-22) (Las cursivas son propias).

En este extenso pasaje de sus palabras de apertura, Crisorio, por un lado, resumió aspectos de la identidad de la EF argentina, que en su expresión disciplinar en la FaHCE también se adoptaron como propias: lo que él denomina "el anhelo de constituirse como ciencia, de delimitar su campo" y que ubica sobre todo en la segunda mitad del siglo XX, dando cuenta de un vasto desarrollo teórico foráneo asumido localmente en forma desarticulada a la historia de nuestro país y de la región latinoamericana. Por otro lado, aunque en el mismo sentido, refirió específicamente a los alcances del Congreso e interpeló al auditorio a investigar, a construir saber propio, ubicando a la EF dentro de la educación, como "praxis educativa". Aunque, cabe decir, rescató un "saber existente" y desestimó la posibilidad de erigirse en el creador o fundador de algo y de elevar ese congreso a momento fundacional. Estos dos últimos aspectos son significativos ya que, de algún modo, reconoció la existencia de saberes en EF y específicamente en el plano 
local, que implicarían que no necesitaban de otros para saber sobre su disciplina, ni lo que tenían que hacer para ser una ciencia.

Sobre la experiencia previa para realizar un congreso de este tipo, Villa sostuvo que "no sabíamos lo que era un congreso", y, a diferencia de Crisorio, lo definió como "fundacional", en tanto que:

"[...] habíamos ido a un congreso que se llamaba "El niño y el deporte" que lo había hecho la Dirección de Deporte y eran congresos más ligados a la medicina, yo había hecho otro de algo...también "Entrenamiento deportivo" o algo así, pero eran ligados al deporte. Y sobre el saber de la Educación Física no había nada. Así que eso fue fundacional, vinieron como 1000 y pico de personas. Trajimos, en ese momento, yo estaba en el comité pero como vocal, me acuerdo, porque era muy pichona y trajimos a los popes de la Educación Física de ese momento, esos de los libros que todos pensábamos que estaban muertos, que todos estudiábamos, que no existían, europeos y los trajimos. Era el auge de la Psicomotricidad y trajimos a Le Boulch, que era el que todo el mundo leía y estudiaba. Era como si estuvieras estudiando Sociología y trajeras a Bourdieu...". (Las cursivas son propias).

Aquí se pone de manifiesto la estrategia de traer a los "próceres", a los "popes" de la EF según mencionó Villa, que en ese momento eran la voz "autorizada" en la disciplina, y que podrían compararse con un Bourdieu para los sociólogos. Por otro lado, rescatamos las diferencias entre las perspectivas de Crisorio y Villa en relación a la experiencia del Congreso, en función de las posiciones que asumían en aquel momento. La posición de Crisorio al frente del proceso, no sólo de la organización del Congreso sino liderando el proyecto disciplinar del que ese evento formaba parte, se vincula con su postura acerca de que éste último no constituía una fundación. Su proyecto disciplinar era mucho más ambicioso. En cambio, para Villa, que era "muy pichona", su experiencia fue que con el Congreso se originó algo. En ese sentido, rescatamos para el análisis la expresión "fundacional" que le atribuyó al evento. Y sobre este carácter vale preguntarse: ¿Qué es lo que se estaba fundando? ¿La práctica de los congresos? ¿Una perspectiva disciplinar novedosa ausente en otros congresos antecedentes? En ese sentido, ¿no podría pensarse a este hecho como parte de un proceso de fundación de la EF como disciplina académica en virtud que ya existía como carrera universitaria?

Los congresos se realizan hasta la actualidad con una periodicidad bianual y tuvieron desde el primero, como lo expresa Villa, una masividad nunca antes vista en la FaHCE. En palabras del por entonces decano De Diego "los congresos que hacían Crisorio y Giles traían 800 personas, eran cosas increíbles. Después fueron menguando, pero del $1^{\circ}$ al $3^{\circ}$ por decirte algo, eran multitudes que venían del país y de la provincia". Es interesante la identificación que construyó De Diego entre la realización de los 
congresos y dos actores relevantes de la "mesa chica" presentada en el capítulo anterior: Crisorio y Giles. Para De Diego los congresos parecen ser sinónimo del trabajo de esas dos figuras.

En el ámbito del Consejo Académico, luego de la edición del Congreso, durante el mes de septiembre de 1993, el vicedecano Luis Viguera, destacaba:

"la enorme satisfacción por la concreción del mismo, desde la concurrencia y participación de casi mil inscriptos, con la visita de profesores de Francia y México y especialistas en Ciencias de la Educación y otras disciplinas. La organización fue muy eficiente, un acontecimiento digno de resaltar. Hace pública la gratificación del decanato a docentes, graduados y muy especialmente a los estudiantes y al Director del Departamento. En el acto de cierre el Secretario General de la Universidad, Dr. Contreras, destacó estos aspectos y expresó que la Facultad de Humanidades está a la cabeza en este tipo de eventos dentro de la Universidad de La Plata" (FaHCE, 1993:1). ${ }^{162}$

El testimonio anterior brinda argumentos para sostener la trascendencia del evento en tanto tuvo carácter masivo y fue organizado de modo muy "eficiente", dos rasgos a destacar en un congreso que tenía su primera edición. Además, da cuenta del reposicionamiento que significó para la carrera a nivel institucional y de la UNLP, y que redundó también en un reposicionamiento de la propia FaHCE en la UNLP.

\section{El "hermano menor"163 ya tiene quien le escriba: la Revista Educación} Física y Ciencia.

\subsection{El germen de la Revista: El Congreso Educación Física y Ciencias}

En el año 1994, se organizó un equipo que comenzó a trabajar en lo que se constituyó como la primera revista académica en la disciplina a nivel nacional. Como antecedente se encontraba el Congreso recientemente efectuado en el año 1993, y aunque se constituyeron como dos actividades independientes, de algún modo, en palabras de uno de sus impulsores, Osvaldo Ron, "el congreso podía nutrir a la revista" 164 . El primer número fue presentado con motivo del segundo congreso, en 1995, y se constituyó en una herramienta de divulgación de la producción propia, en un campo

\footnotetext{
${ }^{162}$ Acta de Consejo Académico №128 del 16 de septiembre de 1993.

${ }^{163}$ Expresión acuñada por De Diego en discurso público con motivo del cincuentenario de la carrera de EF. FaHCE, mimeo, 2003.

${ }^{164}$ Las caracterizaciones relativas a la revista fueron posibles gracias a los testimonios de Osvaldo Ron y María Eugenia Villa. Las palabras y frases entre comilladas sobre el tema corresponden a los entrevistados.
} 
altamente "colonizado por perspectivas europeas y norteamericanas". En ese sentido, según el entrevistado, la revista "venía como algo incipiente y el congreso sumó a convencernos de que si nosotros poníamos en marcha la revista íbamos a tener insumos para publicar, esa era la relación que nosotros encontrábamos. Muy mecánica pero bueno, en un campo donde no se escribía".

Del mismo testimonio surge que:

"La revista es una idea que daba vueltas desde hacía mucho tiempo, nosotros teníamos el modelo de la revista Stadium como el modelo representativo de publicar en Educación Física en Argentina, es una revista de otras características, más profesionalista. Y aun así, nosotros veíamos que había mucha distancia entre nuestras posibilidades de producción y lo que esa revista representaba. Entonces, se había detectado como una necesidad la de generar algún tipo de publicación y, a la vez, había quienes teníamos un interés particular por encontrar lugares donde publicar las cosas que nosotros queríamos decir. Se formó un equipo de trabajo y en el '95 se presentó el primer número en el marco del segundo congreso".

Durante el período de nuestro estudio -1992 a 2004- se editaron 6 números entre el primero en 1995 y el último considerado en 2003 y, del análisis de su contenido, surge que quienes participaron fueron fundamentalmente docentes de EF de la FaHCE. ${ }^{165}$ Esta preeminencia inicial de autores locales puede comprenderse por las características de la comunidad en estudio: Carballo definió a la EF platense de aquel momento como una "cultura ágrafa", y Villa señaló también que "la gente no estaba acostumbrada a escribir", y amplió sobre la cuestión de la escritura:

"[...] fue una batalla porque era duro decirle a los profes, la revista venía como incitando a la gente que se sentara a escribir. No había posgrados, no había mucha investigación, entonces anda a decirle a los profes de atletismo "anda a escribirme sobre tu práctica" "¿qué te escribo? ¿Los 10 pasos metodológicos en la carrera de $100 \mathrm{mts}$ o en el pasaje de vallas?" era difícil pensar la enseñanza desde otro lado. $Y$ era gente valiosa que estaba trabajando hace mucho, que estudiaba mucho de lo suyo, pero no sabían escribir, no sabíamos escribir. De hecho, la maestría a nosotros nos enseñó a aprender a escribir y la investigación. Los primeros informes, además en esa época, no eran tan técnicos como ahora si no eran mucho contenido, muy académicos, eran páginas y páginas de información que... difícil, con una lógica técnica de informe investigación pero además queríamos aprovecharla para que sea material de divulgación y no había dónde, era muy dificultoso. Pensábamos bueno, que difícil que era, viendo ahora teniendo muchísimo más acceso a eso. Entonces invitar a los profes que escribieran, había como de todo en esos números, como vos decís".

${ }^{165}$ En breve realizaremos un análisis más en profundidad sobre el contenido y los autores de esos seis números. 
Aquí Villa refirió a las dificultades que encontraba la comunidad de EF para incluirse dentro de los criterios de legitimación académica de la FaHCE que abarcaban necesariamente escribir, investigar y publicar. Las dificultades se basaban en dos aspectos: por un lado, la escasa o nula tradición de escritura de la EF universitaria platense y, por otro, la carencia de espacios donde publicar.

Luego de estos primeros seis volúmenes, y ante la necesidad de someter a evaluación a la revista según las normas internacionales, fue preciso ir abandonando esa tendencia localista, e ir incluyendo artículos de autores extranjeros. Esta situación comenzó a darse entre los años 2004 y 2006, siendo en los últimos años mayoría de artículos de autores que no son de la FaHCE, y generalmente de fuera del país. Así relataba Villa los inicios de esta situación:

"[...] y cuando se empezó a querer, a necesitar jerarquizar la revista para poder indexarla en distintas normativas había, bueno, esas normativas indicaban que no era una revista de producción local, es decir, que había que tener artículos extranjeros. Tuvimos que salir a buscar a Wacquant, que nos escribiera... [...] fue el primero internacional que conseguimos, así como fuerte y novedoso fue ese."166

En la cita precedente, Villa señaló una estrategia diseñada por los coordinadores de aquel momento para poder "jerarquizar" e "indexar" la revista a las normativas internacionales vigentes. El hecho de recurrir a una figura destacada de la sociología francesa como Loïc J. D. Wacquant, haciendo uso de tácticas y contactos locales, permitió incluir un artículo que, sin salirse demasiado de las temáticas disciplinares, propició el inicio de una nueva etapa de la revista: el paso de ser un órgano de difusión del DEF a ser una publicación periódica, indexada internacionalmente, con autores de renombre y de preeminencia externa. Este proceso puede evidenciarse a partir del análisis de las seis revistas editadas en los ocho años transcurridos entre 1995 y 2003. En total, se produjeron 49 contribuciones, las cuales clasificamos según las siguientes categorías: artículos (36), entrevistas (3), comunicaciones (4), proyecto (1), divulgación (1), exposición oral transcripta (1), y trabajos (3) ${ }^{167}$. Resulta de interés mencionar algunas

\footnotetext{
${ }^{166}$ Villa hizo referencia a Loïc J. D. Wacquant, sociólogo francés contemporáneo, quien escribió junto a Pierre Bourdieu, trabajos como "Una invitación a la sociología reflexiva" (2005). La participación en la Revista Educación Física y Ciencia a la que alude fue en el 2006, Año 8, con el trabajo "Los tres cuerpos del boxeador profesional", disponible en: http://www.memoria.fahce.unlp.edu.ar/art revistas/pr.133/pr.133.pdf

${ }^{167} \mathrm{Si}$ bien algunas de estas categorías fueron nominadas de tal modo por la propia revista, ejemplo la entrevista, en el resto de los casos no hay una distribución y especificación de las contribuciones por secciones, sino un sumario donde están listados. Recién en el volumen 4 de 1998, incorporan una sección en el índice denominada "Espacios de divulgación", que contiene dos comunicaciones del DEF -proyecto del plan de estudios y la página web de la carrera, e incluyen allí una entrevista a un especialista realizada por Alfredo Furlan-. En el volumen 5 del año 2001 esta sección adopta el nombre "Espacio de difusión" en el que incluyen una separata de artículo de divulgación breve de 3 carillas, de un profesor local, denominado
} 
cuestiones relativas al tipo de trabajos, y cómo fue cambiando la forma de presentación de las contribuciones, la procedencia de los autores, la extensión, entre otros aspectos, como una estrategia de reconocimiento institucional de la revista a nivel local e internacional.

En relación a los artículos, llama la atención la disparidad en cuanto a su estructura y fundamentalmente en cuanto a su extensión. Los hay de 8 páginas y de $30-$ es por ello que, a los primeros, los denominamos trabajos, y a los segundos, artículos, en general apoyados en revisiones teóricas o investigaciones empíricas-. Es notable la preminencia de la presentación de artículos por sobre el resto de los formatos desde la primera edición en 1995 hasta la última considerada de 2002-2003. Asimismo, en los primeros años la tendencia era la presentación de contribuciones tanto individuales como colectivas e institucionales (sin especificación de autores), no habiendo en los dos últimos números (2001/2002-2003) contribuciones del último tipo mencionado.

Nos preguntamos, entre otras cuestiones: ¿Quiénes fueron los autores que publicaron en los primeros números de la revista? ¿Qué tipo de contribuciones realizaron a la misma? ¿Cuáles fueron los temas y cuestiones que se plantearon en estos primeros números? ¿Cuál fue la vinculación de la revista con otras políticas departamentales como el congreso o institucionales como la investigación?

En principio, de una mirada general de la producción del período, podemos destacar que la mayoría de los autores fueron locales, específicamente docentes del Profesorado en EF (34 de los 49 trabajos editados en esos seis números, lo que representa un $69,38 \%$ del total). ${ }^{168}$ Este dato nos permite sustentar que efectivamente la revista fue un órgano de difusión del trabajo en el DEF, un medio para mostrar lo que hacían y también de acreditar publicaciones. Es decir, la mayoría de los que publicaron

\footnotetext{
"Actividad física y prevención de enfermedades no transmisibles". En el último número considerado, el 6 del año 2002-2003, nuevamente aparece el sumario general, sin secciones específicas, en el que se encuentran sólo 9 artículos originales, provenientes de análisis teóricos y/o empíricos basados en investigaciones individuales o grupales, y ya no aparecen entrevistas o divulgaciones. La clasificación construida intenta aportar claridad respecto de las producciones realizadas. En este sentido, consignamos como categorías: artículos, entrevistas, comunicaciones, proyecto, divulgación, exposición oral transcripta y trabajos. Los artículos evidencian un trabajo más esforzado de revisión bibliográfica sobre un tema o basados en investigaciones empíricas; las comunicaciones son espacios de difusión de actividades del DEF o de otras instituciones referidas a aspectos legales de la disciplina, el curso de nivelación del Profesorado en la UNLP, la página web del mismo, entre otros; proyecto se refiere a iniciativas colectivas como el plan de estudios de 1998; divulgación a separatas de artículo del tipo notas de opinión; y trabajos a artículos muy breves de cinco o seis carillas que no remiten a investigaciones teóricas o empíricas, sino que son reflexiones que, en la mayoría de los casos, tienen un carácter de tipo prescriptivo, en tanto proponen aspectos a tener en cuenta en la práctica disciplinar.

168 Para una aproximación gráfica sobre estos trabajos, los autores, títulos, entre otros aspectos, ver Tabla 7, "Números editados de la Revista Educación Física \& Ciencia (Período 1995-2003)", en los anexos de esta tesis.
} 
fueron los integrantes del grupo descripto en el capítulo anterior o sus colaboradores más cercanos, pero en las seis ediciones están presentes uno o más de los primeros. La proporción de autores locales en relación a autores extranjeros fue determinante (43 de 49). En los primeros números, era prácticamente inexistente la presencia de autores extranjeros, aunque esta tendencia empieza a revertirse en los números siguientes, a mediados de los años 2000. Entre 1995 y 2003, hubo tan sólo 6 artículos de autores internacionales, siendo la primera contribución de este tipo en el tercer número de 1997. Los autores y lugares de procedencia fueron: Miguel Vicente Pedraz (España), Ingrid Marianne Baecker (Brasil), Alfredo Furlan y Martha Corenstein Zaslav (México), Adriana Marrero (Uruguay) y Pippo Russo (Italia).

Los tópicos más desarrollados tuvieron que ver con algunos de los denominados saberes de la EF, fundamentalmente el deporte y el juego. También están presentes publicaciones relativas a temas de la historia de la disciplina, como su carácter militarista o sexista, aspectos psicológicos o didácticos implicados en la enseñanza y aprendizaje de la EF en distintos niveles del sistema educativo, análisis referidos a las distintas concepciones de la EF y del cuerpo, y contribuciones orientadas a comprender la propia carrera en La Plata, relativas a la deserción estudiantil, el ingreso y la nueva propuesta curricular.

\section{5. "Nosotros tenemos que aprender de ellos": el comienzo de un camino en la investigación en Educación Física.}

Hasta la institucionalización del Programa de Incentivos a la investigación del Ministerio de Cultura y Educación de la Nación (en adelante, $\mathrm{Pl}$ ), la investigación en la FaHCE se sostenía por voluntades individuales y se encontraba dispersa y atomizada en disciplinas específicas. Las carreras más tradicionales como Historia, Filosofía y Letras desarrollaban investigación pero, según el testimonio de De Diego -decano por esos años-, de forma un tanto "vocacional" y "no siempre reconocida", aunque a nivel de la UNLP los ponía "a la cabeza de las ciencias blandas"169. Conforme su perspectiva, desde

\footnotetext{
${ }^{169}$ Es importante destacar que la UNLP está conformada actualmente por 17 unidades académicas. Dentro de ellas, son consideradas del área de "Sociales" por la Secretaría de Ciencia y Técnica: Bellas Artes, Trabajo Social, Periodismo y Comunicación Social, Ciencias Jurídicas y Sociales, Ciencias Económicas, Arquitectura y Urbanismo, Humanidades y Ciencias de la Educación y Psicología. Para 1992, cuando De Diego asumió como decano de la FaHCE, la UNLP estaba constituida por 13 unidades académicas. Del área "Sociales", si bien Periodismo y Comunicación Social, Trabajo Social y Psicología existían como carreras, se
} 
su gestión se propuso a través del PI "transformar a Humanidades en el duro de los blandos", y dicho programa "cambió el perfil de la Facultad" ya que implicó el requerimiento de "nuevas credenciales" para los docentes. Así lo señalaba en la entrevista:

"[...] ahí está claro cómo se va cambiando el perfil de la Facultad; es decir, en ese debate está clarísimo cómo cambia el perfil de la Facultad, en el cual los docentes, que antes eran buenos profesores o buenos profesionales, en el caso de Psicología o Sociología, de golpe descubrían que si querían participar además tenían que investigar, tenían que, bueno, requerían nuevas acreditaciones." (Las cursivas son propias).

En el testimonio anterior aparece la investigación de forma imperativa -"tenían que investigar"- como una tarea que empezaba a constituirse en fundamental dentro de la dedicación horaria de un docente universitario.

El PI fue una de las políticas estatales más vigorosas de la reforma universitaria encarada por esos años. Por un lado, porque implicó la introducción de nuevos mecanismos de distribución de presupuesto y de diferenciación salarial, y por el otro, porque incluyó a la evaluación en forma directa y sistemática en la cotidianeidad del trabajo de los docentes (Araujo, 2001). Respecto a la primera cuestión, cabe señalar que tradicionalmente el presupuesto de las universidades era distribuido en función de un criterio incremental -también denominado inercial o histórico- (Prati, 2003). Programas como el PI introdujeron una novedad en este sentido, en tanto que se inyectaban recursos financieros a las instituciones en base a "criterios objetivos". En un documento de la SPU, se define al PI dentro de los "Programas que asignan recursos mediante criterios de Equidad, Eficiencia y Calidad" (citado en Macario, 2007:51).

El Programa establece un pago en la forma de "incentivo" a los docentes, quienes deben cumplir una serie de condiciones: 1-estar categorizado, 2-participar en un proyecto de investigación acreditado por entidad reconocida, y 3-dictar un mínimo de horas de clase al año, en su mayoría en el grado. Tanto el proceso de categorización como el de aprobación de proyectos son procesos de evaluación de individuos y proyectos, según cada caso. Producto de la categorización, a los docentes se les asigna una categoría equivalente de investigación (CEI). Inicialmente eran cuatro y en letras: $A, B, C, D$. Las A y $\mathrm{B}$ correspondían a investigadores formados y habilitaban para dirigir proyectos. Con la modificación del Manual de Procedimientos del PI de 1997, las categorías pasan a ser 
cinco y en números: I, II, III, IV y V, y son las primeras tres las que pasan a habilitar para dirigir proyectos (Prati, 2003).

Si bien desde los inicios de la carrera de EF, su "fundador" Amavet promulgó la importancia de la investigación, la formulación y presentación efectiva de proyectos colectivos en los cuales participaban docentes de EF recién se materializó en los años '90 con el PI (Levoratti y Macario, 2013).

La inserción de esta comunidad en el PI fue dificultosa. En principio porque como mencionamos más arriba, el programa establecía una serie de condiciones para dirigir proyectos, como la de ser categoría A o B. A partir de algunas falencias en su funcionamiento, se modificaron algunos puntos del Manual de Procedimientos ${ }^{170}$, entre ellos que los docentes con categoría $C$ pudieran ser directores de proyectos, aunque ninguno de EF logró en esa primera instancia acceder a esa categoría. Es por ello que para participar de proyectos acreditados por el PI, los profesores de EF tuvieron que recurrir a la dirección de especialistas en Ciencias de la Educación, Filosofía o Psicología, dado que no había docentes de EF con las categorías requeridas para dirigir. Los primeros proyectos de incentivos de EF fueron radicados en el Departamento de Ciencias de la Educación de la FAHCE y dirigidos por la Dra. Ana Candreva. Al respecto, señalaba De Diego:

"Pero Ana Candreva de Ciencias de la Educación dirigía proyectos de ellos, Cristina Di Gregori de Filosofía dirigía proyectos de ellos. Entonces, algunos les dieron una mano y ellos reconocen que le dieron una mano, y fue necesaria esa mano. Pero lo cierto es que cuando no la necesitaron más, chau y armaron sus propios proyectos, y está muy bien. Así debe ser."

Según la perspectiva de Barletta, secretaria académica por esos años, la estrategia fue armar proyectos "colectivos" y multidisciplinarios que permitieran potenciar las capacidades de disciplinas que, como EF, tenían menor tradición en investigación:

"[...] En esa época hubo que armar proyectos de investigación colectivos para entrar en el Programa de Incentivos, pero para entrar en el Programa de Incentivos tenías que tener categorías. Y los de Educación Física no tenían categorías y les costaba, muchos no teníamos categorías pero a ellos les iba a costar mucho adquirirlas a través del proceso de evaluación porque no tenían trayectoria en investigación, porque no tenían posgrado, publicaciones. Entonces, armaron grupos con profesores de Educación, de Filosofía, ahí los ayudaron Ana Candreva, Cristina Di Gregori, Amalia Eguía, fueron personas que apoyaron mucho la constitución de equipos con Educación Física. Y eso, ellos lo consiguieron...".

\footnotetext{
${ }^{170}$ Existieron, hasta el año 2003, tres normativas vinculadas al PI: el Decreto de creación 2427/93 con sus anexos, el Manual de Procedimientos de 1997, y su modificatoria en el 2003.
} 
Ambas citas son indicativas de una estrategia de acercamiento a referentes de otras disciplinas que el grupo de EF desplegó para posicionarse institucionalmente, al mismo tiempo que la configuración de cierta dependencia inicial de las mismas, situación que Macario definió como de "interdisciplinariedad obligada" (2007: 135-136).

Carballo (2009) destaca que la investigación en este campo atravesó entre los años 1994 y 2008 por tres etapas: inicial, de transición y de expansión. En la primera, que ubica entre 1994 y 2000, los proyectos fueron dirigidos por docentes de otros Departamentos, siendo la mayoría de Ciencias de la Educación y con doble radicación (DCE y DEF), la mayor cantidad de proyectos ejecutados en un año fue de 4 y la cantidad de docentes-investigadores del DEF 16. La segunda etapa, entre los años 2001 y 2002 , se caracteriza por la emergencia de los primeros proyectos dirigidos por docentes del $\mathrm{DEF}$, y en donde se radican todas las investigaciones. La máxima cantidad de proyectos ejecutados en un año fue de 3,6 profesores del DEF estaban en condiciones de dirigir proyectos, y la cantidad de docentes-investigadores ascendió a 27. En la última etapa, entre el 2003 y 2005, también todos los proyectos eran dirigidos por docentes del DEF, aunque creció la cantidad de proyectos ejecutados (7) y la proporción de los docentesinvestigadores (41).

La actividad de investigación propiciada por el PI alentó, según la perspectiva de Achucarro, a replantearse cuestiones referidas a la identidad de la EF y a su relación con otras disciplinas:

"Lo interesante de Ricardo es que se da cuenta, y eso amerita esa cuestión, con el Programa de Incentivos debíamos empezar a pensar nuestra propia formación, participar de grupos de investigación y empezar a generar carreras de posgrado que nos permitan ir reforzando esta idea de hija menor que había acá. En algún sentido sigue existiendo esta cosa, este complejo de Edipo que tenemos nosotros con nuestros pares, que tiene que ver, no tenemos una construcción teórica muy fuerte, entonces recurrimos a pedir prestado elementos teóricos y trasponerlos rápidamente para asegurarnos una justificación teórica. Entonces, lo interesante es que estas nuevas formas de participación, no solo docente, sino en proyectos de investigación nos generaban como una mayor autonomía. Esto es lo que se pensaba en ese momento, y desprendernos de la maternidad de Ciencias de la Educación, desprendernos de la maternidad de Psicología, desprendernos de la paternidad de la Fisiología que había como, algunos decían invadido el campo; o habíamos ido a buscar esa paternidad no reconocida, esa confusión teórica nos dificultaba en el momento de enseñar."171

\footnotetext{
${ }^{171}$ Entrevista a Santiago Achucarro, Prof. de Educación Física por la FaHCE, el 13 de octubre de 2016 en Ensenada.
} 
Expresiones como "hija menor", "complejo de Edipo", "maternidad" y "paternidad", se encuentran cargadas de sentidos sobre la identidad y legitimidad de la EF, las relaciones de parentesco con otras disciplinas y la construcción de patrones de jerarquía y autoridad en las instituciones académicas. En estas afirmaciones -"en algún sentido sigue existiendo esta cosa, este complejo de Edipo"- ubicamos procesos de producción y reproducción de diferencias que constituyen la identidad de la EF en la FaHCE. Es decir, los miembros de esta comunidad definen y trasmiten su identidad a las nuevas generaciones, a través de complejos procesos de filiación y oposición con un pasado o una historia que consideran más o menos legítima. En este caso, podemos observar al mismo tiempo un reconocimiento y rechazo de ese pasado -“desprendernos de..."-, en una estrategia de subversión o herejía en términos de Bourdieu (2008) respecto de la ortodoxia del campo, representada por las Ciencias de la Educación, la Psicología y la Fisiología.

Achucarro destacó que iniciativas como el congreso, la revista o los propios proyectos de investigación fueron maneras de tramitar esa dependencia de otras disciplinas, constituyéndose en formas de ruptura con esas "maternidades" y "paternidades":

"[...] Esa cuestión de empezar a aparecer y la necesidad de mostrarnos generó nuevos ámbitos de trabajo en la investigación, en la construcción de teoría y en ese espaldarazo a romper con las maternidades y paternidades. De hecho, yo estudié Ciencias de la Educación cuando estaba en $3^{\circ}$ año de Educación Física porque no había posibilidad de investigación, entonces dije voy a buscar en otro departamento un poco más organizado y me acuerdo que decía bueno, la invasión de la Psicología sobre el campo de la educación con las psicologías educativas, evolutivas. Bueno, en algún sentido nosotros sentíamos que la invasión de las Ciencias de la Educación en que todas las didácticas eran gente, la enseñanza, es decir, todas las materias teóricas didácticas generales eran de Ciencias de la Educación, entonces sentíamos esa invasión de las Ciencias de la Educación en nosotros".

Es interesante también cómo en este pasaje definió esas relaciones de parentesco entre la EF y otras disciplinas en términos de "invasión". Una cadena de invasiones que se estructuraba desde la Psicología hacia las Ciencias de la Educación, y desde éstas hacia la Educación Física. Casi como si ésta última fuera un desprendimiento de aquellas.

En ese sentido, y volviendo al $\mathrm{PI}$, en estos pasajes se reconoce que este programa no sólo les permitió comenzar a participar de la investigación como actividad sistemática de un profesional universitario, sino que les posibilitó repensar su identidad y su lugar dentro del conjunto de disciplinas que teorizaron sobre la EF. 
El primer proyecto aprobado en el marco del PI en el año 1994 fue, para los distintos profesores de EF entrevistados, un proyecto muy significativo, de carácter masivo ya que reunió a decenas de docentes de Educación Física, Ciencias de la Educación y Psicología -a decir de Crisorio "todo el Departamento de Educación Física estaba ahí"-. Dicho proyecto se denominó "Educación Física: identidad y crisis" y fue dirigido "formalmente" por la Dra. en Educación Ana Candreva, aunque cumplían un papel de coordinación destacado su codirector Ricardo Crisorio y uno de sus integrantes, Marcelo Giles. Según Villa este proyecto fue "bastante revolucionario", y ante la pregunta sobre su importancia para la comunidad, señaló:

"Sí, sí fue fundador. Fue feroz, o sea, trabajamos muchísimo. Yo ahí trabajé junto con Ricardo, estábamos los dos, nos dividimos como en subgrupos y a nosotros nos tocó la tarea de revisión bibliográfica, lo que me hizo leer ese hombre, recopilar y fichar libros y todo. Fue un infierno. Pero bueno, era la primera vez que la Educación Física se sentaba a pensar en sí misma."

A partir del año 2001 EF logró radicar proyectos de dependencia exclusiva de su Departamento, dirigidos por un docente del mismo. Entre 1994 cuando se aprobó el primer proyecto y el año 2004, EF desarrolló 21 proyectos de investigación ya sea por iniciativa de sus docentes o porque participaron en ellos, de los cuales 16 fueron dirigidos o codirigidos por profesores de la carrera (Memoria Académica, FaHCE, 2017). ${ }^{172}$

\footnotetext{
${ }^{172}$ La fuente a partir de la cual se obtuvo información sobre los proyectos de investigación ejecutados durante el período, títulos, códigos, directores y codirectores, fue extraída de la sistematización efectuada por Carballo (2009) y contrastada y ampliada a través del repositorio institucional Memoria Académica de la FaHCE, colección Proyectos de investigación, de donde además se pudo extraer el nombre del resto de los integrantes y un resumen de cada uno de ellos. Para la búsqueda se utilizó el patrón "investigadores", colocando los apellidos de los docentes integrantes de la "mesa chica" descripta en el capítulo precedente. En el trabajo de Carballo, el autor se propuso retomar y analizar el quindenio que transcurre entre 1994 y 2008, contabilizando 30 proyectos de investigación en esos años. Para el período de nuestro interés (19922004) considera 19 proyectos, a los cuales nosotros le anexamos dos más radicados en el Departamento de Ciencias de la Educación y el de Psicología (Memoria Académica, última consulta: 3 de mayo de 2018). http://www.memoria.fahce.unlp.edu.ar/library?site=localhost\&a=p\&p=about\&c=proyecto\&l=es\&w=utf-8
} 


\section{6. "Nosotros somos los que estamos innovando": Propuesta de renovación curricular en EF a mediados de los años ' 90}

La carrera de Profesorado en EF de la FaHCE contó con seis planes de estudio previo a la modificación en el año 1998: el fundacional de 1953, el de 1960, 1970, 1978, 1982 y 1984 , todos con una extensión estipulada de cuatro años. ${ }^{173}$

El cambio curricular que se inició en los años 1990 es considerado por varios analistas del propio ámbito institucional, como el primero "significativo" respecto a la propuesta inicial de formación de 1953 (Galak y Simoy, 2015; Giles, Mamonde y Simoy, 2012; Villa, 2011). No sólo por el replanteo y reestructuración de materias y contenidos que significó, el cambio en la extensión de cuatro a cinco años, sino también, porque incorporó como novedad la carrera de licenciatura, con su respectiva propuesta de plan de estudios.

Retomamos para el análisis el proceso de reformulación del proyecto académico de EF entendiendo que fue una circunstancia de profundo debate entre actores que pugnaban por liderar una visión de la disciplina y de la formación de los estudiantes. Para ello, en un primer momento, se retoma el escenario institucional de la FaHCE en el que tuvo lugar la reformulación de la propuesta de formación en EF, y que devino en la aprobación de un nuevo plan de estudios en el año 1998. Se describe el clima político y los lineamientos institucionales para encarar las reformas curriculares; se retoman los debates que suscitó la única propuesta consensuada en la Comisión Curricular del DEF que se sometió a votación en el Consejo Académico, y se analiza el proceso que culminó con la aprobación del plan de estudios en 1998.

6. 1. Las reformas curriculares a mediados de los años 1990: nuevas normativas y políticas de financiamiento

La reforma de los planes de estudio fue uno de los pilares de la política de gobierno de la FaHCE de los años '90. Las pautas institucionales generadas para la elaboración de los planes de estudio partieron de un diagnóstico de los planes vigentes desde la "normalización", por lo general aprobados entre 1984 y 1986, entre los cuales

\footnotetext{
${ }^{173}$ Durante la dictadura, en 1982, hubo intentos de modificar la extensión de la carrera de cuatro a cinco años, así como la introducción de una Licenciatura, que duraron poco tiempo. Luego, en la "normalización universitaria" de 1983 y durante la gestión Parenti se "restaura" el plan de estudios a la extensión inmediatamente anterior (Planes de estudio del Profesorado en Educación Física 1982, 1984, FaHCE, UNLP).
} 
existían profundas diferencias y heterogeneidades. La sanción de las leyes educativas, Ley Federal de Educación y Ley de Educación Superior de 1993 y 1995, respectivamente, motivó a las universidades a replantearse sus propuestas de formación ya que, según se indica en los documentos de la FaHCE, dichas normas condicionarían "de modo directo los planes de estudio del Profesorado y sólo de modo indirecto los de la Licenciatura". ${ }^{174}$

Las reformas curriculares fueron en gran medida financiadas por el Fondo para el Mejoramiento de la Calidad Universitaria (FOMEC). El FOMEC fue un mecanismo de distribución de presupuesto novedoso para las universidades, a través de la presentación de proyectos concursables (previa aprobación del Ministerio de Educación). Este fondo se disputó entre los años 1995 y 2000 con una prórroga de ejecución hasta junio de 2003 y estuvo enmarcado en un programa más estructural: el Programa de Reforma de la Educación Superior (PRES) ${ }^{175}$. EI FOMEC ofrecía financiamiento para diversas áreas de las distintas instituciones universitarias que hacían a la formación de grado - reforma de planes de estudio y capacitación docente-y de posgrado -otorgamiento de becas para graduados locales en el exterior, y para externos en universidades locales-, infraestructura y equipamiento -bibliotecas, computadoras, insumos-, etc. ${ }^{176}$

En cuanto a su aprobación en el Consejo Superior de la UNLP, Atairo distingue dos grandes grupos con posicionamientos contrapuestos: los "principistas" y los "pragmáticos" (2007: 48). Dentro de los primeros, se encontraban aquellos que abogaban principios como la autonomía institucional y la libertad de investigación y enseñanza; y en los segundos, primaba un discurso más vinculado a intereses, sobre la base del cálculo racional de los beneficios que podía reportar la adhesión al programa.

Para los "principistas" una de las controversias fundamentales estuvo vinculada a que el FOMEC surgió a raíz de un convenio entre el PEN y el Banco Mundial. Este último aportó dos tercios de los recursos, y significó la adquisición de deuda externa para el país. El crédito mencionado dio lugar a la creación de la SPU, como organismo encargado de administrar los fondos, hacer la evaluación y seguimiento de los proyectos

\footnotetext{
174 Documento institucional de Obiols (1997) "La Reforma curricular en la Facultad de Humanidades y Ciencias de la Educación. Un diagnóstico y una propuesta”, FaHCE, La Plata.

${ }^{175}$ En 1995 se pone en marcha el PRES (Programa de Reforma de la Educación Superior) con dos componentes centrales: a) el mejoramiento de la eficiencia y calidad de la gestión vía el fortalecimiento institucional del sector universitario con la creación de la Comisión de Evaluación y Acreditación Universitaria (CONEAU), y de la gestión y planificación a través del fortalecimiento de la Secretaría de Políticas Universitarias (SPU); b) la promoción de reformas académicas y de gestión a través del Fondo para el Mejoramiento de la Calidad (FOMEC). Ver Atairo (2007).

${ }^{176}$ El 30 de agosto de 1995 se aprobó por Consejo Superior la participación de la UNLP en el FOMEC, y al día siguiente se hace lo propio en la FaHCE (Acta de Consejo Académico No 157 del 28/09/95).
} 
y controlar las contrapartidas de las universidades. Este programa resulta un indicio del papel que asumieron los organismos internacionales en las reformas educativas del período (Suasnábar, 1999). ${ }^{177}$

La inserción en la política nacional del PRES y dentro de éste del FOMEC, trajo aparejadas discusiones extensas y tensiones al interior de la FaHCE, que se tradujeron en el rechazo pleno del claustro estudiantil en el Consejo Académico (Atairo, 2007).

Finalmente, la adhesión de la FaHCE al FOMEC fue aprobada con seis votos a favor (4 votos de los profesores por la mayoría más 2 votos de graduados), y obtuvo cuatro votos en contra por los estudiantes y dos abstenciones por los profesores de la minoría.

La FaHCE presentó varios proyectos FOMEC en las tres convocatorias que se realizaron. En total fueron aprobados seis, uno de los cuales se trató de un proyecto interdepartamental. Dicho proyecto involucró a seis Departamentos Docentes (Ciencias de la Educación, Letras, Lenguas Modernas, Psicología, Educación Física y Sociología), abarcó sólo la formación de grado y consistió en diseñar e implementar reformas curriculares en las carreras de todos esos departamentos. Para ello, las autoridades de la Facultad resolvieron definir y financiar con esos fondos la participación de dos consultores institucionales para el asesoramiento y seguimiento de las reformas, que fueron José Antonio Castorina y Guillermo Obiols, y un consultor especialista por cada uno de los Departamentos, además del armado de comisiones departamentales con la participación de todos los claustros.

Obiols, como consultor institucional, construyó unas pautas a ser tenidas en cuenta para la elaboración de los planes de estudio, que fueron aprobadas a mediados de 1998 por el Consejo Académico. ${ }^{178}$ Dichas pautas fueron publicadas por la Facultad y están compuestas por un diagnóstico general de las carreras, y propusieron líneas generales surgidas de "las disposiciones legales vigentes" en aquel momento, "las posibilidades laborales" de los egresados y "el grado de desarrollo de las diversas disciplinas". De forma resumida, las definiciones establecidas se acordaron en torno a la extensión de las carreras (cinco años), los títulos expedidos (Licenciado y Profesor) y las cargas horarias mínimas para cada carrera (2600 horas reloj presenciales para las

\footnotetext{
177 Para profundizar sobre el papel de los organismos internacionales de crédito en las políticas educacionales de la región latinoamericana con especial referencia a Argentina, ver Oreja Cerruti y Vior, 2016.

178 Cabe señalar que, anteriormente a estas pautas, a fines de 1995, la Prof. María Dolores Béjar fue designada por las autoridades de la Facultad para la elaboración de un informe sobre los planes de estudio (Acta No 164 del 27/03/96). Dicho informe es citado en las pautas que luego elaboraría Obiols para 1998.
} 
Licenciaturas, y 2800 para los Profesorados). Asimismo, se habilitó a que todas las carreras de grado permitieran la continuidad en los estudios de posgrado y se instauró el régimen de cursadas cuatrimestral, con una duración de 6 horas semanales para cada espacio curricular, en planes de estudio que se compondrían por entre 29 y 33 espacios curriculares. Tanto Licenciaturas como Profesorados debían establecer un bloque común de entre 15 y 20 asignaturas a cursar en los primeros años, entre 4 y 8 asignaturas o seminarios optativos que supusieran "la profundización en algún aspecto de la disciplina o bien la conexión con otra disciplina" (1997: 42) dictados por carreras de la propia Facultad, de la UNLP o de otras universidades; y un bloque de espacios curriculares variable entre cada tipo de título, destinados al inicio a la investigación y la práctica profesional de cada disciplina. Se estableció que la Licenciatura culmine con un trabajo final de investigación y/o práctica profesional específica, denominado tesis; y que los Profesorados agregaran un bloque de formación pedagógica y la realización de prácticas docentes en diferentes niveles del sistema educativo de extensión anual.

\subsection{Las discusiones sobre el proyecto de la carrera de Licenciatura en Educación Física} en el año 1998

El 7 de octubre de 1998, en sesión ordinaria del Consejo Académico (CA) de la FaHCE, se debatió la última reforma curricular de EF. Se encontraban presentes los doce consejeros que, según el Estatuto de la UNLP de 1996 vigente en aquel momento, componían el Consejo, distribuidos de la siguiente manera: seis consejeros por el Claustro de Profesores, cuatro por la mayoría y dos por la minoría, los dos representantes por graduados, y cuatro estudiantes. Se trató de los consejeros Ana María Barletta, Norma Delucca, Carlos Parenti y José Luis De Diego por la mayoría en Profesores (Agrupación Independiente), y María Luisa Freyre y María Julia Bertomeu por la minoría (Agrupación Encuentro Académico). Por Graduados se encontraban Guillermo Banzato y Evelyn Vargas (FAG), y por estudiantes Leticia Muñiz Terra, Cecilia Abajo, Juan Misuraca y Ceferino Sabatini, pertenecientes a la agrupación FM. ${ }^{179}$ También se encontraba presente el director del DEF para los períodos 1998-2001 y 2001-2004, Marcelo Giles. El decano era Guillermo Obiols, quien presentó el plan señalando que desde mediados del año anterior, 1997, el DEF se encontraba diseñando esta nueva

\footnotetext{
179 Acta N²04 del Consejo Académico de la FaHCE del 07 de octubre de 1998. En las elecciones estudiantiles de fines del año 1997, la Franja Morada resultó triunfante en el Centro de Estudiantes y obtuvo la totalidad de los representantes de su claustro en el Consejo (4).
} 
propuesta de formación, en el momento en que él mismo se desempeñó como consultor institucional de las reformas curriculares.

Durante la sesión mencionada existieron controversias respecto de la aprobación del plan propuesto, generadas a partir del desacuerdo con la propuesta que expresaron las consejeras profesoras por la minoría, María Luisa Freyre ${ }^{180}$ y María Julia Bertomeu ${ }^{181}$. La principal resistencia se relacionó con la creación de la carrera de licenciatura en EF, y podríamos resumir las objeciones en los siguientes términos, que ampliaremos luego retomando la discusión:

-el desacuerdo a la propuesta de licenciatura con orientaciones en otros campos disciplinares (en Educación, Ciencias Sociales, Filosofía -en la que tuvieron mayores resistencias-, Arte y Comunicación y Ciencias Biológicas), y la orientación de un tutor (quién debía ser el tutor, qué requisitos debía reunir, etcétera).

-la falta de articulación con los departamentos docentes respectivos u otras facultades.

-el cuestionamiento a la interdisciplinariedad y a la falta de antecedentes sobre este aspecto en el Departamento de EF, y la posible puerta de entrada o habilitación de la licenciatura a posgrados.

-la falta de formación de los profesores para el dictado de las mencionadas orientaciones.

A partir del testimonio de Carballo pudimos reconstruir la composición de la comisión curricular que actuó en la reformulación del plan de estudios del profesorado en EF y la creación de la licenciatura. Dicha comisión estaba compuesta por cuatro de los integrantes de la "mesa chica" descripta en el capítulo anterior: Ricardo Crisorio, Marcelo Giles, Osvaldo Ron y él mismo. La incursión de Carballo se discontinuó "un año y pico antes de que terminara la redacción del plan". A diferencia de este testimonio, según Giles, él no participó ya que quien lo hizo activamente fue Crisorio, porque él "tenía que dirigir el Departamento como secretario y otras cosas", aunque se atribuyó "todo el laburo político y académico" y la escritura de la versión final del plan.

\footnotetext{
${ }^{180}$ Freyre perteneció al Departamento de Letras y fue Profesora en la asignatura Lingüística desde el retorno democrático (Memoria Académica, FaHCE, consulta: 07 de marzo de 2018). Según consta en el registro de libros de Actas del Consejo Académico de la FaHCE en nuestro período de estudio (1992-2004), se desempeñó como Consejera Académica por el Claustro de Profesores, entre los años 1992-1995, y entre abril de 1998 y julio de 1999. Falleció en el año 2007 (Fuente: Diario El Día, http://funebres.eldia.com/edis/20070903/funebres2.htm).

${ }^{181}$ Bertomeu es Profesora y Doctora en Filosofía por la UNLP, donde se desempeña actualmente como Profesora Titular de Ética. Es investigadora principal del CONICET, con lugar de trabajo en el Centro de Investigaciones Filosóficas (CIF) de la FaHCE (Fuente: Página del CIF: http://cifnet.org.ar/portfolio/maria-juliabertomeu/). A partir del registro de libros de Actas del Consejo Académico de la FaHCE, advertimos que se desempeñó como Consejera Académica por el Claustro de Profesores durante un breve período entre abril de 1998 y junio de 1999 .
} 
En un pasaje de la entrevista, Carballo señaló el derrotero que siguió el plan y ofreció algunas pistas para comprender las posiciones contrarias a su aprobación por parte de las consejeras profesoras por la minoría:

"[...] el plan se presentó y tuvo que enfrentar, en la Facultad algunas resistencias políticas de algún sector, en ese momento del Consejo Académico; todavía era antes de la reforma del estatuto. Básicamente gente más ligada a un pensamiento más, podríamos decir, tradicional o conservador, que no veía con buenos ojos que Educación Física tuviera una licenciatura, o sea, no le daba a Educación Física el estatus de...hablemos de disciplina, tentativamente, de una disciplina en pie de igualdad con el resto de las de Humanidades. Eso fue el escollo principal en el Consejo Académico, escollo que no tuvo mayores dificultades en el Consejo Superior. $[\ldots] "$

En la cita precedente no sólo se anticipa la controversia presente en la discusión de la reforma curricular respecto al estatus de la Educación Física como "una disciplina en pie de igualdad con el resto de las de Humanidades", sino que además es indicativa de la trascendencia del propio proceso de revisión curricular como hecho político y académico en la construcción de un "campo" disciplinar legitimado. Hasta aquí hemos visto el desarrollo de los congresos, la revista, la investigación, como estrategias e inversiones de los agentes para la construcción de legitimidad interna y externa de la EF, pero que evidentemente no bastaron para su reconocimiento, sino que hubo que discutir "cara a cara" con profesores de otras disciplinas que pedían "argumentos epistemológicos". En la entrevista con Giles identificó a este proceso curricular como una instancia para "dar el debate" a las otras disciplinas:

"[...] armamos un debate muy fuerte, académico, o sea, por un lado, el crecimiento académico de la carrera que hace los deberes, por otro lado, el crecimiento político en el sentido de dar el debate a la Filosofía, a la Historia, a las Letras, para eso hubo que ponerse a estudiar, no todos se pusieron a estudiar, fundamentalmente Ricardo y yo, fundamentalmente Ricardo más que yo, porque ahí yo arranco con una cosa más de gestión por lo tanto el estudio me queda un poco complicado, después me pongo al día, pero...[...]"

En el mismo sentido Barletta señaló que el gran cambio de este grupo, el crecimiento intelectual viene con esta reforma:

"para ellos era la revolución porque era dar un salto cualitativo muy importante [...] Y yo creo que ese fue un punto muy alto del desarrollo intelectual de ellos porque, bueno, viste lo que pasa con las disciplinas más consolidadas, ellas no tienen que ir a demostrar nada, pero ellos tenían que demostrar ahí y entonces eso lo impulsó mucho, a un desarrollo. [...] Ellos hicieron un proceso de mucho crecimiento porque 
se tenían que legitimar y entonces ellos estudiaron, armaron proyectos, ellos buscaron la legitimación". 182

En el acta de la sesión mencionada quedó reflejado el debate sobre el proyecto de reformulación del plan de estudios de EF, específicamente en cuanto a la creación de la licenciatura. Si bien no podemos conocer las estrategias o arreglos informales previos a la instancia del CA, relevar y analizar las posiciones allí plasmadas nos permitirá dar cuenta de los principales argumentos de los distintos actores en la disputa por la aprobación o no de una propuesta de formación académica. En este sentido, la consejera Freyre tuvo un rol saliente en cuanto a la fundamentación de una posición disidente a la propuesta del DEF. Como quedó expresado en el siguiente pasaje de la sesión:

“[...] no tenemos ninguna objeción respecto del Profesorado. En lo personal, sí tengo algunos problemas para entender la factibilidad que pueden tener las licenciaturas.

[...] para mí no resulta claro si el interés estaría puesto en la profundización de los estudios de Educación Física con algún aditamento de nociones procedentes de otros campos curriculares -lo cual, pido disculpas, pero me suena peligrosamente a cultura general-, o si lo que interesa es una profundización en otros campos del saber, como Filosofía, Comunicación, Arte, Ciencias Biológicas, etcétera. [...] No resulta claro, por ejemplo, cómo sería la organización de esas licenciaturas, cómo sería la organización de las materias de Educación Física, de las de los otros departamentos, de dónde provendría el tutor, porque el alumno tiene que inscribirse presentando un plan dirigido por un tutor y qué injerencia relativa pueden tener el Departamento de Educación Física o el que fuera en la aceptación del plan. [...] No veo claro qué es lo que se proponen lograr esas licenciaturas con orientación, insisto, no digo que esté mal sólo que para mí no está claro. Un problema es ver cuál sería el peso relativo y ese peso relativo estaría dado por qué propósitos tiene una licenciatura con orientación. [...] Creo que uno de los problemas de esto es, tal vez, una concepción que no es la mía, sobre qué son los estudios interdisciplinarios y qué es una licenciatura. A mi modo de ver, una licenciatura es una profundización en un área y no un diálogo, entiendo que lo del diálogo está concebido como metáfora, a lo mejor yo soy muy lineal y como no me dedico a la literatura quisiera que se me aclarara la metáfora, porque no resulta claro." (FaHCE, 1998: 8-9). (Las cursivas son propias).

Aquí la objeción planteada está centrada en la propuesta de una carrera de licenciatura con orientaciones. $Y$, cabe decir, no está dirigida solamente al plan de EF, ya que carreras como Ciencias de la Educación también estaban en ese momento proponiendo licenciaturas con orientaciones. En este caso puntual, el cuestionamiento deviene en si esas orientaciones significarían una "profundización" de los estudios de EF con "aditamentos" de otras disciplinas, o una "profundización" en otros campos del saber. En el primer caso, señala el peligro de que esa licenciatura persiga el propósito de

${ }^{182}$ Entrevista a Ana María Barletta el 20 de octubre de 2017 en La Plata. 
formación en "cultura general" o un mero "diálogo" entre disciplinas y, en el segundo caso, plantea cómo podrían organizarse las asignaturas y la figura de un tutor, desde la concepción de que una licenciatura implicaría efectivamente la profundización en un área que anticipa, como veremos luego, cuestionamientos respecto a su factibilidad en el marco de las condiciones del DEF.

Ante dichos cuestionamientos y previo a cederle la palabra al director del DEF, el Decano recordó a los presentes que en la última sesión del CA se habían aprobado las pautas generales para la elaboración de los planes de estudio, y dentro de ellas, en el punto 7 , se estableció que las carreras incluirian un "bloque de orientación" de materias electivas que implicarían, "o bien la profundización en algún aspecto de la disciplina, o bien la conexión con otra disciplina". En el mismo sentido, en su rol anterior como consultor institucional de las reformas, señaló haber aconsejado al DEF a incluir ambas opciones, y a propender al "diálogo" con otras disciplinas de la facultad.

En cuanto a los propósitos de la licenciatura con orientaciones y su factibilidad, el por entonces Director del DEF, Giles, señalaba:

"Las orientaciones de la Licenciatura tienen el objetivo de profundizar, en algún campo disciplinar, los estudios en Educación Física en función de mejorar la formación de nuestros graduados, en relación a las comunicaciones continuas que tenemos en esos campos. [...] En cuanto a la pregunta puntual de la consejera en relación a la implementación, no tenemos ninguna duda de que podemos funcionar, de la misma manera que hemos funcionado en otros eventos que hemos organizado en la Facultad. Presuponemos que la implementación de los tutores va a ser, sin ninguna duda, con profesores de Educación Física que estén en el Departamento y también suponemos que pueden ser otros profesores de la Universidad u otros profesores de la Facultad los que tutoreen a los licenciandos. [...] La idea es que los alumnos puedan implementar un plan de seis espacios curriculares, con un tutor y que puedan consultar al Departamento para que se les sugiera cuáles podrían ser esas asignaturas.

También la idea es que no solamente realicen cursadas en otras unidades académicas o en otros departamentos, sino que el Departamento pueda ofrecer, a través de esta comunicación que decimos, algunos seminarios dictados especialmente para esas orientaciones. Por supuesto, cuando hablamos de orientación en Educación, va a ser con la gente de Ciencias de la Educación con la que vamos a conversar, cuando hablamos de Filosofía, con la gente de Filosofía, y así en todos los casos. [...] Es importante que quede claro que no van a recibir el título de Licenciados en Educación Física con una orientación determinada, sino que dentro de esa orientación van a hacer su licenciatura en Educación Física y el título seguirá siendo licenciado en Educación Física. La idea es que puedan profundizar en un campo del conocimiento con el cual habitualmente nuestra disciplina tiene contacto profesional y académico". (FaHCE, 1998: 12). 
Para defender la propuesta, allí Giles apela a la "comunicación" de la EF con esos otros campos disciplinares planteados como orientaciones. Es decir, a una historia de la disciplina en vinculación directa con la Educación, las Ciencias Sociales, las Ciencias Biológicas, la Filosofía y la Comunicación y las Artes. Articulación entre disciplinas que además se instrumentaría mediante conversaciones ex post con los distintos departamentos docentes de la FaHCE. Por último, señaló un argumento que sostendrían luego otros profesores que avalaron el proyecto, vinculado a que la denominación del título no sufriría modificaciones por esas orientaciones, sino que continuaría siendo el de licenciado en Educación Física.

En relación a la concepción de interdisciplinariedad que según la consejera implicaban las orientaciones, manifestó Freyre:

\begin{abstract}
"El campo de conocimiento tal como yo lo entiendo -no pretendo tener la respuesta absoluta- es que no se trata de una cuestión de más o menos conocimiento de Filosofía, de Comunicación, de Arte o de lo que sea, sino todo un tipo de trabajo orientado desde el comienzo, con una fundamentación epistemológica determinada y con el aprendizaje de una metodología de trabajo.

Así como me merece el mayor de los respetos la metodología de trabajo de la Educación Física, creo que merecen el mismo respeto la organización disciplinar y la fundamentación metodológica que tienen los estudios filosóficos o de comunicación y todo ese tipo de cosas.

Me parece que ésta es una concepción interdisciplinaria que aunque yo no la comparta, eso no es lo importante, el hecho es que es apresurada. Preguntaría, por ejemplo, cuál es la historia de esa concepción de interdisciplinariedad, qué antecedentes tiene, dónde se dicta, etcétera. Porque yo sigo sin respuesta, respecto de cómo se va a diseñar en un campo en el que puedo juzgar, el único que puedo juzgar, que es comunicación. [...] Necesito que me digan cuál es la historia de esos estudios interdisciplinarios; quiero una fundamentación epistemológica concreta y también quiero que me digan qué antecedentes hay en el mundo, porque puede ser meramente mi ignorancia, lo reconozco, pero no los conozco.

Repito, necesito una fundamentación epistemológica más sólida o que, por lo menos, me digan: esto tiene tales antecedentes en el mundo y no lo estamos inventando porque sí. A partir de allí, discutiré. Sinceramente no sé qué antecedentes hay y hasta ahora no se ha justificado, es como si de pronto dijeran: bueno, los hacemos más cultos y no me parece que la Universidad esté para eso." (FaHCE, 1998: 12-13). (Las cursivas son propias)
\end{abstract}

Las expresiones anteriores incluyen cuestionamientos de orden epistemológico y político, que es preciso comprender en el escenario de la discusión. Es decir, los argumentos de Freyre no sólo se dirigían a los de EF que proponían el plan sino a la gestión de la Facultad que lo apoyaba, dado que este proyecto venía previamente con el aval del decanato. En ese marco, la consejera esgrimió argumentos epistemológicos y 
académicos, aunque estaba señalando como "apresurados" a los académicos de EF y a quienes formaban parte de la gestión de la institución. En relación a esos argumentos, se explayó sobre lo que significa un campo de conocimiento, su organización y forma de trabajo y las particularidades y límites con respecto a otros campos del saber. Planteó que el tipo de articulación entre disciplinas que se proponía el plan era "apresurada", apoyándose en el "respeto" que merecen las disciplinas y sus metodologías de trabajo. Esas concepciones condujeron a Freyre a solicitar "antecedentes" y una "fundamentación epistemológica" que justificara el trabajo interdisciplinario de la Educación Física con otras disciplinas. En la misma línea, se cuestionó que la inclusión de las orientaciones y su forma de instrumentación se explicaran por el mero hecho de que los estudiantes adquirieran "más o menos conocimiento" o que la universidad se planteara como un espacio para "hacerlos más cultos". Aquí se pusieron en evidencia argumentos inferiorizantes sobre la formación en EF, en tanto no se creía necesario o suficiente que la interdisciplinariedad se justificara por el contacto de los estudiantes de esta carrera con otras disciplinas, con particular referencia a la Comunicación y la Filosofía.

De Diego, por la mayoría del claustro de profesores, defendió la formulación general del plan de estudios, y se refirió puntualmente a la cuestión de las orientaciones:

"[...] Debo decir que tengo alguna experiencia en cuanto a planes de estudio, después de participar durante seis años en la Comisión de Enseñanza del Consejo Superior y creo que éste es un plan de estudios muy bien formulado. Eso es lo primero que quería decir. En segundo lugar, en relación con esta controversia, yo recuerdo que en el plan de estudios de la licenciatura en Letras, dice que pueden cursarse estudios con orientación literaria, en lingüística o en... Esas tres orientaciones son disciplinarias no interdisciplinarias, es decir, son profundizaciones en algún campo al interior de la disciplina, lo que no quiere decir que pueda haber seminarios que la conecte con otras. [...] Entiendo lo que dice la Profesora Freyre en algunas orientaciones, como Arte y Comunicación, donde cuesta mucho encontrar en el grado de Educación Física, alguna base previa que justifique una orientación en esa dirección. De todas maneras, yo no veo para nada mal que un licenciado en Educación Física hiciera algún tipo de seminario en Arte, estoy de acuerdo con el Decano en el sentido de que ese tipo de contactos siempre son muy fructíferos y siempre abren las perspectivas ideológicas y aun las disciplinarias.

Quizás podría decirse, tratando de interpretar a la Profesora Freyre, que eventualmente esto podría aprobarse así y que el Departamento, a futuro, tratara de dar una argumentación mayor para justificar esa orientación porque, efectivamente, a priori no aparece como demasiado justificada en el plan porque no tiene una relación muy clara con los estudios de grado". (FaHCE, 1998: 13, 14, 15).

La intervención de De Diego muestra el apoyo a la propuesta de cambio curricular que el DEF había conseguido de parte de miembros de la gestión y de algunos 
consejeros. Es posible suponer que tanto los miembros del DEF como quienes formaban parte de la gestión de la Facultad tuvieran una intención de que la sesión del CA culminara con la aprobación del plan, al tomar en cuenta intervenciones como la de De Diego: "eventualmente esto podría aprobarse así". Si recuperamos además la intervención de Obiols, en la que recordó que había un acuerdo previo respecto de que los nuevos planes tendrían orientaciones y la de Giles en la cual justificó las características de la propuesta, resulta plausible la hipótesis de que los consejeros por la mayoría y la gestión en general salieron a defender "en bloque" la propuesta, ante los cuestionamientos de las consejeras por la minoría. Entendemos que el caso de EF representó el "mascarón de proa" de una discusión política mucho más profunda, que pone en evidencia la dinámica política en las instituciones académicas, las negociaciones y arreglos de poder, que en esta contienda se traducen en el interés por aprobar los planes de estudio, excediendo la cuestión del estatus de la EF. Específicamente, en el pasaje citado puede reconocerse un posicionamiento en favor de que los estudiantes de EF tomen contacto con otras disciplinas en su proceso de formación, en tanto ese acercamiento representaría una "apertura" ideológica y disciplinar. Además de hallarse valoraciones positivas hacia la propuesta en su conjunto, también puede encontrarse un primer intento por agilizar su aprobación que, como veremos, intentó ser resistido por las profesoras de la minoría.

Inmediatamente a la intervención de De Diego, la consejera Freyre insistió más claramente en la articulación entre la EF y la Filosofía, así como señaló precipitada su aprobación:

"Tampoco veo muy clara la relación con la Filosofía, lo que pasa que no quiero hablar de Filosofía porque no es mi especialidad. Por otro lado, me parece que un plan de estudios es una cosa muy seria como para aprobarlo a futuro, además, no hay tanta prisa como para eso.

[...] A mí me gustaría saber cuál es la historia de los proyectos compartidos en esta Facultad, en esta Universidad, en el país, en el mundo o donde sea; qué formación de posgrado tendrían los profesores y de dónde los sacamos, porque también hay problemas de organización. Si a un señor que dicta la materia equis le llega un montón de gente a su curso habitual y con una formación distinta, eso crea una serie de conflictos de organización, incluso, se requerirán más ayudantes y un montón de cosas que supongo que habrá que tenerlas en cuenta". (FaHCE, 1998: 15).

Frente a cierta premura por aprobar el plan que podía leerse en las palabras de De Diego, Freyre se estaba oponiendo a su aprobación "a futuro". En este punto, es relevante considerar que tal oposición podía estar desbordando la discusión epistemológica sobre la EF, afectando la concreción de una política curricular 
institucional. Podríamos preguntarnos, en esta línea, si el plan de EF se estaba constituyendo en una "excusa" para discutir la modalidad de construcción y aprobación de los planes de estudio. ${ }^{183}$

Nuevamente, Freyre solicitó antecedentes sobre proyectos de articulación disciplinar, tanto sea en el ámbito del DEF como a nivel nacional y mundial, que justificaran la licenciatura con orientaciones en otras disciplinas. Por otro lado, introdujo cuestiones que luego aparecerán como argumentos para el diseño de materias o la apertura de comisiones exclusivas para $\mathrm{EF}^{184}$, como la incompatibilidad entre la formación de un profesor de Filosofía, Letras o Historia que dicta materias para esas carreras y la formación recibida por los estudiantes de EF y, fundamentalmente, el aumento matricular de la carrera a partir del retorno democrático.

Sobre estas cuestiones, Barletta señaló:

"Cuando tratamos este tema en la Comisión de Enseñanza, justamente, veíamos que en el plan de estudio de la licenciatura en Educación Física estaban estas orientaciones y lo que quedó claro desde el principio es que el título iba a ser de licenciado en Educación Física y no con orientación, es decir, esa orientación no va a figurar en el título.

[...] No lo entendimos de la manera que lo está planteando la Profesora Freyre, es decir, asociando un poco la licenciatura a estudios más específicos de posgrado, sino que lo pensamos como lo planteó el decano inicialmente, para que Educación Física pudiera contemplar en el plan una vinculación con un conjunto importante de asignaturas que se dan en esta Facultad y que también tienen que ver con la identidad de Educación Física dentro de la Facultad de Humanidades.

[...] Nunca pensamos que Artes y Comunicación lo iba a dar un Profesor de Educación Física o Filosofía, sino que era un plan que iba a estar vinculado con los departamentos respectivos y con los profesores especialistas de esas asignaturas. No se nos ocurrió que se desprendiera de aquí que estas orientaciones iban a estar dictadas exclusivamente por los profesores de Educación Física.

Cuando tomamos el tema de la licenciatura, lo pensamos como una apertura del Departamento de Educación Física a otros estudios de grado y también en una apertura de ese Departamento hacia el conjunto de la Facultad y no tan exclusivamente, como lo tenía hasta ahora, en Educación". (FaHCE, 1998: 15-16).

\footnotetext{
${ }^{183}$ Como no es el foco de la tesis el análisis de la política curricular institucional de los ' 90 en la FaHCE, no nos detendremos en esta cuestión, aunque es importante tener en cuenta que el problema de estas consejeras no era el estatus epistemológico de la EF sino la política institucional a la que oponían cuestionamientos.

${ }^{184}$ Se trata de asignaturas gestionadas por otros Departamentos Docentes de la FaHCE y que, por lo general, son dictadas por docentes que no son egresados en EF. Podemos mencionar por caso Introducción a la Filosofía (1er. Año), Sociología (2do. Año), Pedagogía e Historia de la Educación General (3er. Año), que fueron progresivamente, y al calor del aumento matricular, constituyéndose en espacios específicos para EF desde fines de los años ' 80 en adelante.
} 
Aquí Barletta sostuvo que las orientaciones fueron pensadas como formas de "vinculación" con otras disciplinas que, por otra parte, caracterizan la identidad de EF en la FaHCE. Es decir, en otras instituciones, como vimos en el capítulo 1, la articulación se efectuó más estrechamente con la Biología, la Anatomía o la Fisiología y, en el caso de la UNLP, existió una historia de afinidad con disciplinas como Ciencias de la Educación, Filosofía o Historia, que excedió el hecho de compartir el mismo espacio institucional. No obstante, en los términos de la consejera, esa vinculación se efectivizaría y ampliaría por la vía de las orientaciones, en tanto representaría una "apertura" del DEF hacia el conjunto de las disciplinas que componen la FaHCE, y no solamente hacia las Ciencias de la Educación, con quienes mayoritariamente compartían espacios de formación e investigación.

Los argumentos a favor y en contra planteados hasta aquí, son indicativos de una controversia no exclusivamente epistemológica sino además política que, en buena parte, radicaba en que la comunidad de EF buscaba más formación en las disciplinas de la Facultad para lograr legitimidad y aceptación académica y la consejera Freyre señalaba el límite de esa estrategia: no son ni filósofos, ni literatos ni comunicadores, son licenciados en EF y la relación con esas disciplinas se restringe, desde su perspectiva, a la mera convivencia institucional. Allí, los consejeros a favor de la propuesta entendían como positiva la vinculación de la EF con otras disciplinas de la facultad, en tanto instancia de enriquecimiento de la formación de grado, así como en una "apertura", como señaló Barletta, del DEF hacia el conjunto de la institución.

El decano Obiols manifestó preocupación por el planteo de Freyre, al indicar que EF no hacía más que cumplir una pauta que fue diseñada para el conjunto de los planes de estudio de la Facultad, y que "entendía que había un consenso sobre esa pauta que, vale la pena aclararlo, no trata de cambiar en nada los títulos" que "van a seguir siendo absolutamente disciplinares sin que digan nada respecto de ninguna orientación".

Sobre el pedido de "antecedentes" que hizo Freyre, el decano brindó como ejemplo la carrera de Filosofía de la UBA, en donde los estudiantes podían diseñar una orientación propia con la responsabilidad de un tutor, en la que podían cursar materias de otros departamentos de la misma facultad o de otras facultades de la UBA. Sostuvo que la propuesta de EF de la FaHCE era "razonable", en tanto brindaría la posibilidad de que los estudiantes realizaran una "aproximación a otra disciplina", defendiendo el carácter flexible de la formación de grado, la optatividad y la libertad de elección de los mismos.

En ese momento, la consejera Bertomeu expresó que, sobre los ejemplos, sin ir 
más lejos, podían referirse a la propia carrera de Filosofía de la FaHCE, en donde la licenciatura preveía la posibilidad de que los estudiantes realizaran cualquier materia de la misma facultad e incluso, de otras universidades. Aunque hizo la salvedad con EF:

\begin{abstract}
"Pero creo que acá hay una diferencia fundamental de la que nos estamos olvidando y es la siguiente: el cuestionamiento de la Profesora Freyre -que yo comparto y que también lo comparten un número importante de profesores de la lista de minoríatiene que ver con la diferencia fundamental entre lo que hace Filosofía acá y en la Universidad de Buenos Aires y lo que pretende hacer Educación Física, porque nosotros no vamos a dar el título de Licenciado en Filosofía con orientación en Educación Física o Licenciado en Filosofía con orientación en Historia, etcétera. [...] Lo que la Profesora Freyre cuestiona y yo apoyo, es la interdisciplina sin un apoyo de estudios, de proyectos, de formación interdisciplinaria de base. Si a nosotros nos mostraran que el Departamento de Educación Física tiene proyectos de investigación en marcha sobre Educación Física y Filosofía, Educación Física y Arte y demás; que tiene profesores con doctorados, maestrías o especializaciones hechas en esas áreas, entonces, nosotros pensaríamos que es factible. Nosotros estamos cuestionando la factibilidad actual de ese proyecto, porque si no nos parece que se van a estar formando al mismo tiempo los profesores y los estudiantes. [...]

Entonces creo que estamos hablando de cosas distintas y que el ejemplo de la carrera de Filosofía de la Universidad de Buenos Aires no sirve, porque nosotros no hablamos de un Licenciado en Filosofía con orientación en Educación Física." (FaHCE, 1998: 20-21) (Las cursivas son propias)
\end{abstract}

Bertomeu reforzó los argumentos contrarios en cuanto a la licenciatura con orientaciones, comparando EF con Filosofía -"nosotros no vamos a dar el título de Licenciado en Filosofía con orientación en Educación Física"-; y cuestionó la factibilidad de la EF para trabajar desde una perspectiva interdisciplinaria. No obstante, pretendió mantener a esta comunidad en un lugar subordinado al pedirle antecedentes que sabía de antemano los docentes pertenecientes al DEF no tenían: proyectos de investigación, profesores con posgrado, etc. Estos argumentos refuerzan la idea de ubicar este debate como una disputa política en un momento de toma de decisión de una política institucional fuerte, como son las reformas curriculares. En ese sentido, podríamos pensar que EF constituía un punto débil en esa política, del cual estas consejeras se aprovecharon como opositoras al proyecto curricular de la gestión. No obstante, lo significativo para nuestro análisis, es que en esa discusión sostuvieron una serie de preconceptos y desvalorizaciones vinculadas a la EF, que son indicativas del posicionamiento que tenía la disciplina en la institución y su relación con otras disciplinas.

Allí el decano insistió en que no se iba a dar un título con orientación, y según está escrito en las actas "hablan varios consejeros a la vez". La consejera Freyre continuó en la misma línea que Bertomeu cuando señaló: 
“...es como si yo dijera que quiero una Licenciatura en Letras con orientación en física atómica. Dentro de la Licenciatura en Letras hago una orientación en distintas disciplinas y, por ejemplo, dentro de la orientación en Literatura unos se dedicarán a argentina y otros a española o teoría literaria, pero no con cosas tan totalmente divorciadas y externas". (FaHCE, 1998: 21-22) (Las cursivas son propias)

En las expresiones anteriores se evidencia la voluntad de complejizar y "trabar" la discusión y, en el mejor de los casos, dilatar la aprobación de los planes. Aun así, las ideas que se ponen en juego sobre el estatus de la EF al momento del debate, señalan la construcción de una distancia, una relación asimétrica y jerárquica entre la EF y las otras disciplinas o, al menos, hasta aquí, de la Filosofía, las Letras o la Comunicación. Lo que se desprende del argumento de Bertomeu, es que esas disciplinas y la EF no tienen nada que ver, son "cosas totalmente divorciadas y externas" y, por tanto, no deben ni tienen por qué articularse.

El ex director del DEF, devenido consejero académico, Carlos Parenti, introdujo una serie de argumentos que cambiaron la retórica construida hasta el momento por los profesores a favor de la propuesta. En lugar de hacer un esfuerzo por explicar las orientaciones, su sentido, las relaciones con otros departamentos, partió de reconocer la falta de tradición académica de la EF y la justificación de la propuesta en virtud de constituir una "innovación":

"Reitero algo que ya fue expresado: el título de licenciado no tiene orientación sino que es una modalidad de profundización.

Hace dos o tres reuniones atrás habíamos entrado en un juego de palabras y se citó el caso en el que se piden trabajadores con experiencia, entonces no se pueden presentar aquellos que no la tienen. Lo digo por la referencia a que aquí se estarían formando los profesores y los alumnos, quizás esto sea por la tradición que no tiene Educación Física y que sí tienen Lingüística, Letras, Historia, Filosofía y Ciencias de la Educación y entonces, en el universo de las universidades latinoamericanas, europeas o argentinas uno puede encontrar personas que capaciten.

Aquí -esto puede ser novedoso o presuntuoso- nosotros somos los que estamos innovando. Esto tiene fundamentos en España, en Alemania, en Francia también hay doctores. Por ejemplo, el doctor...que vino acá, es profesor en Educación Física, doctor en Matemática, doctor en Sociología y su especificidad, su formación fue en Educación Física, después empezó a formarse porque veía que su campo disciplinar estaba siempre restringido por su historia y por el común, en campos biológicos. El imaginario social cree que la Educación Física es ejercitarse, nosotros reivindicamos esta posición y ampliamos mucho más, por eso cuando hablamos de una especialización en Educación es porque estamos íntimamente ligados.

Si puede ser que Educación tenga una orientación en Filosofía, por qué no Educación Física, si es un saber disciplinar como Educación ¿Cómo puede un médico hablar de ética si parecería que un médico sólo actúa sobre un cuerpo? Pero el doctor Mainetti habla de ética.

Me parece que estamos restringiendo, no con mala intención sino con esta idea 
pragmática de ver esta posible realización." (FaHCE, 1998: 22)

En la intervención precedente de Parenti es notorio el cambio en los términos de la discusión y su voluntad explícita de desactivar los argumentos contrarios de Freyre y Bertomeu, al reconocer las restricciones del campo disciplinar de la EF y la posibilidad que la Facultad se abra a una propuesta innovadora como la planteada.

Luego, una estudiante hizo un comentario con respecto a la materia Educación Física y sus ejes, y la profesora Freyre planteó poder enviar las objeciones por escrito "dado que algunas han sido tratadas y otras no bien porque la conversación se desvió". El decano indicó que no habría problemas ya que al elevar la propuesta al Consejo Superior de la UNLP se acompañarían las actas de esta sesión junto con los agregados.

Finalmente, el plan del profesorado se aprobó por unanimidad (12 votos a favor), y el de licenciatura con 10 votos a favor y 2 en contra, de las consejeras Freyre y Bertomeu.

Para cerrar, retomamos un pasaje de la entrevista a Carballo en relación al férreo posicionamiento contrario a la propuesta de formación en EF de las consejeras Freyre y Bertomeu:

\footnotetext{
"En la facultad representaron [...] lo más recalcitrante y conservador de la academia, 'para Educación Física un lugar subalterno para estos otros también, no van a comparar Filosofía, Letras e Historia con Sociología, Geografía y Ciencias de la Educación'. Ese lugar, un lugar muy de privilegio...tenían esas costumbres muy profesorales, muy de reverencia."
}

La reconstrucción de la discusión de la propuesta curricular y los testimonios de algunos de sus autores, como Carballo, permiten identificar que lo que estaba en disputa por esos años era una concepción sobre los estudios universitarios y el estatuto de una disciplina académica, que se debatían entre visiones identificadas como "elitistas" y "conservadoras", representadas en la voz de las consejeras profesoras por la minoría, y visiones más abiertas, aunque seguramente movidas por diferentes intereses, a que la EF estuviera en una posición más equitativa respecto a las disciplinas tradicionales en la FaHCE, en cuanto a la disposición de recursos y de acceso a las actividades propias del quehacer académico.

\section{Conclusiones}

En este capítulo reconstruimos y analizamos un conjunto de políticas y estrategias académicas desarrolladas por el grupo de profesores de EF descripto en el capítulo 
anterior. El análisis efectuado permitió identificar y caracterizar una etapa prolífica en cuanto al diseño y puesta en marcha de una serie de iniciativas de fuerte incidencia para la comunidad en estudio como fueron el congreso Educación Física y Ciencia, la Revista Educación Física y Ciencia, las primeras investigaciones formales en el marco del Programa de Incentivos a los docentes-investigadores, y la reforma curricular de los años '90, que dio lugar a una nueva propuesta formativa y a la inclusión de una carrera de licenciatura en la especialidad.

En ese sentido, pudimos establecer que durante el período seleccionado para este estudio (1992-2004), tuvo lugar una etapa de crecimiento y de reconocimiento al trabajo sostenido de un grupo que, mediante un proceso de construcción de equipos, de armado de estrategias políticas y de fortalecimiento de la formación disciplinar redundaron, entre otros aspectos, y desde la perspectiva de los actores, en un proceso de "crecimiento intelectual", "fundación", "legitimación" de la EF en la FaHCE.

Luego, caracterizamos el escenario de política nacional y universitario de los años '90 constituido tanto por las políticas estatales del gobierno de Menem, como también por la historia de la relación entre Estado Nacional y las Universidades, como parte de las condiciones en que la EF se fue "consolidando" en la FaHCE, haciendo un aprovechamiento de esas políticas desde tácticas y saberes locales. Durante esa etapa tuvo lugar un proceso de redefinición estatal, en el que las universidades públicas fueron objeto de una intervención inédita, mediante novedosos programas y políticas de evaluación y financiamiento, entre ellos el FOMEC y el PI. Ese escenario político fue calificado por otros actores institucionales como "adverso" y "conflictivo" y, al mismo tiempo, según la lectura particular de actores de EF, fue un contexto de "oportunidad" que les permitió crecer y que fue capitalizado por esa comunidad.

En ese escenario se desplegaron algunas de las políticas que fueron objeto de estudio en este capítulo: el PI y el FOMEC (que incluyó a las reformas curriculares) como dos iniciativas traccionadas verticalmente desde el MCE. El congreso y la revista no fueron determinados por el Estado y, en todo caso, fueron políticas de crecimiento y consolidación académica gestadas desde la "base del sistema" (Clark, 1983). Por esos años, y según los testimonios recogidos, tuvo lugar un proceso de carácter "fundante", "fundador", o "fundacional", que se identifica por una serie de hitos formales -traducidos en instituciones o documentos- e informales -instancias de debate, formación, conformación de grupos- que inauguraron una nueva etapa de la EF en la institución. Podemos concluir que tanto el Congreso como la Revista son "hitos fundantes" propios 
de un incipiente campo de conocimiento, que intentó autonomizarse de otras disciplinas que lo habían constituido, como la Fisiología, la Anatomía, la Psicología o las Ciencias de la Educación.

Al mismo tiempo, si bien el PI fue una política general para las universidades, en el caso de EF representó la posibilidad de organizar e institucionalizar la actividad de investigación. En esta instancia, fue definitoria la vinculación del DEF con los "próceres" tanto de la propia disciplina como de otras disciplinas conexas, para poder crecer y sostener en el tiempo esas políticas académicas. El hecho de apelar a investigadores internacionales y nacionales y referentes locales se constituyó en una táctica fundamental para el crecimiento, y que fue implementada ad hoc. Es decir, en la mayoría de los casos sin haberse tejido previamente redes de contacto.

Por otro lado, en el caso de las cuatro políticas estudiadas en este capítulo, pudo analizarse la relación de la EF de la FaHCE con otras disciplinas académicas. A partir del testimonio de actores clave, pudimos comprender relaciones de parentesco, cercanía y oposición construidas en la historia de la EF como disciplina con otras disciplinas, que pretendieron ponerse en entredicho durante estos años.

Un primer hito institucional muy significativo, que le dio visibilidad y trascendencia a la comunidad de EF de la FaHCE, fue el Congreso Educación Física y Ciencias, con la participación de figuras destacadas tanto del país como del extranjero. Esta instancia fue definida como una posibilidad para la producción académica propia, de la EF y sus propios saberes y prácticas, y dejar de ser pensada y teorizada sólo desde otras disciplinas. Asimismo, el Congreso propició un debate que tenía alcance internacional sobre el estatuto científico de la EF y, para el caso de la FaHCE, cómo esta comunidad pretendió ligar la producción académica a criterios alejados de las prácticas instituidas en las Ciencias Naturales y de la Salud, hasta ese momento dominantes en la bibliografía y los eventos sobre EF. Es decir, asociar las prácticas de la producción científica en EF con las prácticas legitimadas en Humanidades, no vinculadas con la medición, el peso, el cálculo o el diagnóstico. Por otra parte, el Congreso significó una "apertura al mundo" en tanto propició la participación de debates globales y de discusiones centrales sobre su campo disciplinar en un determinado momento histórico. En suma, el Congreso significó la posibilidad de la producción propia y la discusión sobre los criterios de esa producción, la relación con otras disciplinas y demarcación de los límites y fronteras, y la construcción de espacios de discusión pública y colectiva. Algunos docentes nóveles en aquel momento calificaron la experiencia del Congreso como "fundacional", en tanto fue el 
primer congreso que no se encontró mayormente vinculado a la medicina o al deporte, sino a los saberes propios de la EF y, además, por su poder de convocatoria y la apelación a figuras de reconocida trayectoria en el campo de la educación y de la EF nacional e internacional. Vimos cómo para aquellos impulsores del congreso, como Crisorio, este carácter de "fundacional" fue más resistido, en tanto lo creían como parte de un proyecto disciplinar más ambicioso.

En el cuarto apartado desarrollamos lo que fue la primera revista académica de la EF a nivel nacional, la Revista Educación Física y Ciencia, como una herramienta de divulgación de la producción propia.

Durante el período de nuestro estudio -1992/2004- se editaron seis números, el primero en 1995 y el último considerado en 2003. Del análisis de sus secciones, autores y contenidos surgió que quienes participaron fueron fundamentalmente docentes de EF de la FaHCE. Esto se explicó por dos aspectos complementarios: por un lado, la escasa tradición de escritura de la comunidad de EF platense y la escasez de espacios donde publicar. Del análisis de sus autores y contenidos, concluimos que se constituyó en un órgano de difusión del DEF, en tanto significó mostrar lo que hacían y acreditar publicaciones.

Luego, indagamos en profundidad el proceso de instalación del Programa de Incentivos a la investigación del MCE en la FaHCE y su adopción por parte de la comunidad de EF. Allí advertimos que dicho proceso fue dificultoso para toda la institución en general, aunque particularmente para carreras con poca o nula tradición en investigación, como era el caso de EF. Dimos cuenta cómo hasta la institucionalización del PI en el año 1994, la EF no desarrollaba prácticamente investigación, y dicho programa fue definido como la "oportunidad" para desarrollarse como un campo de conocimiento autónomo, en articulación con la docencia. Algunas de las tácticas y estrategias locales que la EF desarrolló para aprovechar el PI fue recurrir a la dirección de proyectos por parte de especialistas de otras disciplinas, dado que no había docentes de EF con las categorías que el Programa establecía para dirigir. Según las perspectivas relevadas, el PI les permitió a quienes participaron, replantearse cuestiones relativas a la identidad de la EF en la FaHCE y su relación con otras disciplinas. Identidad ubicada en un lugar de subordinación: "hija menor", "hermano menor", "prima pobre", "músculo y sonrisa", entre otras. Asimismo, en cuanto a la relación con disciplinas clásicas de la institución, pudo identificarse cierta situación de "minoridad" o "dependencia" que requirió de instancias de "tutelaje" para ser orientada, conducida, apoyada "en ese primer 
momento de despegue", que evidencian la construcción de patrones de jerarquía y autoridad en las instituciones académicas y complejos procesos de producción y reproducción de diferencias que se transmiten a las nuevas generaciones.

Por último, analizamos el proceso de discusión y aprobación de la propuesta de formación de grado de EF de 1998, aún vigente. Para ello, retomamos los lineamientos de política curricular del MCE y de la UNLP, en el marco de nuevas normativas (LFE y LES) y políticas de financiamiento específicas como el FOMEC, destinadas a las transformaciones en el grado y posgrado. Con los fondos de este Programa se financiaron consultores institucionales y especialistas por disciplina para encarar las reformas curriculares a nivel de la FaHCE. En octubre de 1998, con motivo de la discusión en el CA de la única propuesta consensuada en el DEF, se manifestaron fuertes resistencias por parte de las consejeras profesoras por la minoría. Dichas resistencias fueron analizadas como parte de una disputa no sólo epistemológica sino política, en tanto estas consejeras se oponían a la política curricular y de gestión de la FaHCE, en la cual la EF representó el eslabón más débil para ese enfrentamiento.

La resistencia más enérgica estuvo vinculada a la creación de la licenciatura con orientaciones en otras disciplinas. Para los representantes de EF esto representaba la posibilidad de mayor formación en otras disciplinas de la Facultad para lograr legitimidad y aceptación académica, mientras que para la oposición la interdisciplinariedad no debía limitarse al "contacto" con otras disciplinas y la relación entre estas y la EF parecía restringirse a la mera convivencia institucional. Asimismo, solicitaban insistentemente antecedentes y argumentos epistemológicos para sostener esa propuesta y cuestionaban la celeridad en la pretensión de su aprobación. Allí, el ex director del DEF y consejero académico, Carlos Parenti, logró cambiar el eje de la discusión y en lugar de quedarse en el pedido de antecedentes partió de reconocer la falta de tradición académica de la EF y la defensa de la propuesta en virtud de constituir una "innovación". Finalmente, el plan del Profesorado se aprobó por unanimidad con 12 votos a favor, y el de la Licenciatura con 10 a favor y 2 en contra, de las profesoras por la minoría.

En síntesis, podemos concluir que todas estas políticas universitarias y académicas constituyeron un aporte en la legitimación del campo de conocimiento de la $E F$, en tanto se plantearon disputar con relativo éxito en varios frentes: el disciplinar, el intelectual y el institucional. En el primer caso, porque evidenciaron la constitución de un grupo de trabajo sólido con una perspectiva de la EF distintiva de la de otras universidades e instituciones superiores, e incluso de la propia perspectiva presente en la 
FaHCE anterior a su participación en la gestión del DEF. En cuanto al frente intelectual, porque supieron establecer y sostener una serie de instancias de socialización y validación de dicha perspectiva -aunque con matices-, en numerosos proyectos de investigación y órganos de difusión, como los congresos y la revista. Y en relación a lo institucional, y en virtud tanto de las concepciones de actores de EF como de las de actores de otras disciplinas, estas políticas lograron poner en entredicho visiones históricas sobre la EF en general y en la FaHCE en particular, que redundaron además en una participación más activa de sus actores en el gobierno de la institución y en la creación y ocupación de espacios propios que lograron un grado considerable de institucionalización. Asimismo, la nueva propuesta curricular de grado con la incorporación de la Licenciatura, significó una "apertura" de la EF al conjunto de la FaHCE, en la medida en que demandó formación por parte de otras disciplinas que enriqueció la brindada hasta ese momento por el Profesorado. 


\section{Conclusiones finales}

En esta investigación nos propusimos analizar y comprender el proceso de legitimación disciplinar de la EF en la UNLP entre los años 1992 y 2004, a partir del estudio de las políticas y estrategias desplegadas por académicos/as de la disciplina homónima y sus perspectivas sobre ese proceso y las de académicos/as de otras disciplinas que comparten el espacio social de la FaHCE. El período que abarcó esta investigación, se fundó en el interés por indagar una etapa dinámica tanto a nivel de las gestiones de la carrera de EF, como a los cambios en las relaciones entre el Estado y la Universidad, en el marco de políticas universitarias que modificaron las lógicas y mecanismos de funcionamiento de las instituciones académicas (Araujo, 2001; Chiroleu, Suasnábar y Rovelli, 2012; Krotsch, Camou y Prati, 2007; Marquina, Mazzola y Soprano, 2009; Puiggrós y Krotsch, 1994).

En este apartado sintetizaremos los principales hallazgos que se derivan de nuestro trabajo y sugeriremos algunas líneas de indagación posibles que se abren a partir de esta investigación.

Iniciamos esta tesis con interrogantes generales, orientados a cierta desvalorización o deslegitimación histórica de la disciplina en la institución, imagen que nuestro propio recorrido institucional así como el trabajo de campo nos devolvía. Estas preguntas organizaron el acercamiento empírico inicial a la problemática, tales como: ¿Por qué los/as estudiantes de EF son vistos como "menos intelectuales", "menos comprometidos/as" que el resto de los/as estudiantes de la Facultad -o al menos, de aquellos/as de las carreras "más tradicionales"? ¿Cómo fue el proceso de aquellos/as que, siendo vistos/as como "los profesores de ejercicio", "músculo y sonrisa" o "la prima pobre del campo", lograron tener una política sostenida de congresos, revista, proyectos y espacios de investigación? ¿Cómo fue la convivencia de la EF con disciplinas tradicionales como la Historia, la Filosofía o las Letras?

Ya iniciado el trabajo de campo, nos interrogamos: ¿Cómo se definen a sí mismos/as los/as universitarios/as de EF? ¿Cómo son definidos por docentes, graduados/as y estudiantes/as de otras carreras y disciplinas de la FaHCE? Para luego preguntarnos, más específicamente: ¿Cuáles fueron las estrategias que desplegaron los/as universitarios/as de EF para ser legitimados institucionalmente? ¿En qué medida esas estrategias se relacionaron con los criterios de legitimidad institucionales? ¿Cómo son percibidas esas estrategias de legitimación por los/as universitarios/as de otras 
disciplinas? ¿Cuáles fueron los acuerdos, tensiones, controversias y conflictos ligados al proceso de legitimación disciplinar de los/as universitarios de EF de la UNLP suscitados entre los años 1992-2004? Dichas preguntas se constituyeron en los gérmenes de esta pesquisa que supuso desentrañar ese proceso de deslegitimación-legitimación.

Cabe destacar que esta tesis no se propuso determinar si la EF de la FaHCE finalmente logró cristalizar dicha legitimación o establecer grados de alcance de la misma en función de parámetros preestablecidos. Buscó reconocer y analizar el proceso de construcción del reconocimiento académico de la disciplina a través de identificar y describir políticas, estrategias y prácticas que, desde las perspectivas de los actores participantes, intervinieron en ese proceso.

En el capítulo 1, reconstruimos la trayectoria social y académica de la disciplina EF en Argentina, desde su creación como asignatura escolar, hasta su fundación como carrera universitaria en Tucumán y La Plata. Reconocimos, en línea con las investigaciones antecedentes sobre la $\mathrm{EF}$, las principales perspectivas que se desprendieron de las primeras instituciones de formación superior en la disciplina: la militarista (correspondiente a la Escuela de Gimnasia y Esgrima del Ejército) y la cívicofisiológica (presente en el Instituto Nacional de EF, fundado por Romero Brest). Identificamos que, para esta última perspectiva, las principales fuentes de legitimidad de la EF se recostaron en su fundamentación en la Fisiología, la Biología y la Anatomía, y en su contribución al control y disciplinamiento social por la vía de los cuerpos en el ámbito escolar.

A su vez, dimos cuenta que el contexto socio-político del segundo peronismo favoreció la sanción de normativas, recursos materiales y creación de estructuras institucionales para la EF, entre las que se destacaron la creación de las carreras universitarias de La Plata y Tucumán, en 1953, aunque con orientaciones diferentes. Identificamos las diferencias entre ambas propuestas de formación, en cuanto a su perfil, actores protagonistas, ubicación institucional, perspectivas teóricas y concepción disciplinar.

En este sentido, la carrera de EF de la FaHCE se distinguió de otras propuestas de formación presentes en ese momento, en la medida en que invirtió los parámetros de su legitimidad, vinculando a la EF con disciplinas como las Ciencias de la Educación, la Filosofía, la Historia, entre otras, a partir de dos procesos complementarios: su inserción institucional en la FaHCE y el trabajo y pensamiento de su "fundador", Alejandro Joaquín Amavet. No obstante, encontramos en esta nueva propuesta, algunas contradicciones y 
persistencias respecto a la matriz fundacional de la disciplina que expresaron tensiones y negociaciones entre los actores fundantes de la carrera. Algunas de esas contradicciones tuvieron que ver con la inclusión de espacios curriculares vinculados a la Medicina, la Biología y la Fisiología, bajo una concepción de cuerpo "integral", "normal" y "natural", y en cuanto a los requisitos de admisión a la carrera, ligados a criterios de "aptitud física" y destreza deportiva, que recién lograrían ponerse en entredicho hacia los años '80 con el retorno democrático. En este sentido, recurrimos para el análisis a un período de más larga duración, que se extendió, como dijimos, desde la creación de la carrera en Humanidades en 1953 hasta los primeros años de la denominada "normalización universitaria" (Buchbinder, 2005; Garatte, 2008). Precisamente, un hallazgo original de esta tesis es que esas fugas realizadas a tiempos de más larga duración permitieron advertir que ciertos problemas como el reconocimiento social y la legitimación disciplinar fueron fundacionales en la carrera, y se reactualizaron con otros contenidos en el período de nuestro estudio. Para comprender este resultado, debimos profundizar en el análisis de la trayectoria de quien fue definido por el grupo estudiado como el "fundador" de la carrera, Alejandro Amavet, aunque hayan participado de ese proceso un conjunto más amplio de actores. La reconstrucción de su itinerario profesional, académico e intelectual, no sólo permitió delinear esa matriz de formación característica de la EF de la UNLP y conectarla con debates más generales, sino además, identificar la configuración de "filias y fobias" en torno a su figura en épocas más cercanas a nuestro período de estudio, en significaciones que van desde la entronización hasta el distanciamiento. En este sentido, la perspectiva institucional de Remedi $(2004,2006,2013)$ nos auxilió en diversos momentos de la investigación, para dar cuenta de cómo las instituciones condicionan las acciones de los sujetos, a la vez que son construidas por ellos, en un proceso complejo de elaboración más o menos consciente de "mitos fundadores" y "fábulas" que constituyen la "novela institucional", y "que permiten a los actores dar sentido a lo que preservan y justificar lo que destruyen" (Didou Aupetit, 2008: 17). A su vez, este análisis permitió la apertura a nuevas preguntas que no estuvieron presentes en el desarrollo de la investigación, referidas a incluir la perspectiva estudiantil, tales como: ¿Cuáles son las miradas, percepciones y significaciones de los/as estudiantes sobre este proceso de deslegitimación-legitimación? ¿Lo reconocen? ¿Cómo lo valorizan? ¿Lo resisten? ¿De qué modos? ¿Reconocen figuras de liderazgo en la carrera? ¿Esas figuras guardan alguna correspondencia con las que construyen los/as académicos/as consolidados/as? ¿Qué percepciones acerca del pasado de la carrera sostienen? 
En el capítulo 2, emprendimos un análisis de la configuración social y política de un grupo de académicos/as de EF que cumplieron funciones como autoridad y/o gobierno de la carrera, sus redes de relaciones, trayectorias académicas y formas de sociabilidad que nos permitieron comprender la ocupación de posiciones a nivel del DEF y de la FaHCE, y la construcción de perspectivas y orientaciones político-académicas en un período de mediano plazo comprendido entre 1984 y 2004.

Esa reconstrucción nos permitió identificar la construcción de liderazgos y perfiles de autoridad, que se fueron legando desde la fundación de la carrera en 1953 hasta el período de nuestro estudio en los años '90. El primer liderazgo reconocido fue el de su "fundador" Amavet, que fue legado a una generación intermedia, encabezada por Carlos Parenti, luego del alejamiento y fallecimiento del primero en 1974, aunque rápidamente interrumpido previo a la última dictadura militar. A su regreso, a partir de 1984, descripto en el capítulo, Parenti inició un proceso de refundación de la carrera que incluyó, entre otros aspectos, la reformulación de la formación de grado, la reposición de la perspectiva de Amavet y una estrategia de reconversión de la planta docente. Asimismo, fueron paulatinamente incorporados una generación de estudiantes avanzados y graduados jóvenes, que fueron delineando una perspectiva disciplinar crítica sobre la intervención autoritaria de los '70, así como construyendo una diferenciación respecto de la perspectiva fundante de Amavet, de corte humanista.

Identificamos las diferentes redes de relaciones de estos actores con un agrupamiento político novedoso en la FaHCE, el Frente Amplio de Graduados (FAG), surgido en 1988, y describimos sus trayectorias académicas y político-institucionales. Dimos cuenta cómo la participación de auxiliares docentes y jóvenes graduados de EF en ese espacio fue clave para el acceso a posiciones legislativas y ejecutivas en el gobierno de la institución.

A partir de ese análisis, caracterizamos las distintas gestiones al frente del DEF, desde 1984 y hasta 2004. Las dos primeras definidas por varios de los actores con los que dialogamos como "más políticas" y "pedagógicas", y las dos últimas como "más académicas" o de "crecimiento académico". Asimismo, reconstruimos lo que para actores institucionales de otras disciplinas constituyó un momento de "refundación" o "transformación épica" de la carrera, iniciada en 1984 y profundizada a partir de la gestión de Ricardo Crisorio en 1992. Esa "gesta heroica" se constituyó por dos momentos: uno, el de distanciarse con orientaciones formativas técnicas y fortalecerse como formadores de 
formadores, y otro, lograr reconocimiento académico y científico a partir de disputar con las reglas de la academia.

Por último, identificamos a los y las participantes de la "gesta épica", quienes se propusieron imprimir un perfil alternativo a la carrera, distinto a la tradición eminentemente profesionalista. Allí advertimos que fue un grupo reducido que tuvo un protagonismo central en la definición de políticas y estrategias académicas en EF. En este sentido, es de destacar que fue un grupo de profesores y profesoras -aunque con diferentes niveles de autoridad e influencia- quienes apostaron por una modernización académica de la EF en la FaHCE y fueron por el objetivo del crecimiento, no habiendo encontrado evidencias empíricas de resistencias a este objetivo dentro de la propia comunidad. En todo caso, las resistencias a algunas de las políticas académicas (como el plan de estudio de la Licenciatura), como repasaremos en breve, provinieron fundamentalmente de representantes de otros campos disciplinares.

Otras investigaciones sobre la historia y el gobierno de las universidades, señalan la porosidad de las instituciones académicas a la política nacional en distintos períodos históricos, destacando la fuerte incidencia del radicalismo y su expresión partidaria, la UCR, durante la década del '80, que se cristalizó en un modelo de conducción de las universidades basado en la política de partidos (Garatte, 2008). A partir de los hallazgos de nuestro estudio resulta posible matizar tal afirmación, ya que el agrupamiento políticoacadémico FAG, gestado a finales de los años '80, disputó la construcción hegemónica del radicalismo en el gobierno de la FaHCE y del DEF, y no estaba directamente vinculado a estructuras partidarias. Este resultado es coincidente con los enfoques de antropólogos/as, historiadores/as y pedagogos/as retomados en el marco teórico, referidos a cómo las formas específicas de sociabilidad y los usos y experiencias políticas en el ámbito universitario gravitan en los procesos políticos y académicos locales (Caldo y Fernández, 2012; Carrera, 2014; Frederic y Soprano, 2009; Garatte, 2008, 2012; Garatte y García Clúa, 2013; Guber, 2001a; Soprano, 2011). Estas investigaciones nos alertaron acerca de la dificultad de definir normativamente las expresiones, identidades y prácticas políticas en estos espacios, es decir, establecer a priori cómo deberían ser, para dar lugar al análisis de cómo son o, más precisamente, están siendo. Además, revelaron la importancia de dar cuenta de los procesamientos y formas diversas que asumen las prácticas políticas, más allá de las instancias formales de política institucional, y las relaciones y significados que los actores le asignan en sus prácticas cotidianas. Algunas de ellas en particular (Caldo y Fernández, 2012; Garatte, 2008, 2012; 
Garatte y García Clúa, 2013; Soprano, 2011), nos permitieron comprender el peso de los lazos interpersonales y de las experiencias y relaciones políticas en el moldeamiento de las carreras académicas de los actores estudiados. Esas relaciones y prácticas de poder si bien son constitutivas de todo entramado social, en el ámbito académico aún permanecen vedadas, dado el carácter aparentemente aséptico y neutral de este tipo de instituciones, basadas en criterios meritocráticos. Asimismo, estos enfoques nos permitieron describir el contenido de esas prácticas y expresiones, sus vinculaciones con la política formal y las militancias diversas. Estas prácticas fueron abordadas en todos los capítulos, aunque en particular en el capítulo 2, y se manifestaron como indicios de la construcción y consolidación de una ciudadanía universitaria en este grupo y de la constitución y uso de capitales políticos como recursos visibles en el proceso de legitimación de la EF en la FaHCE (disciplinar e institucional). También, en línea con el trabajo de Soprano (2011), encontramos ciertas continuidades entre la política universitaria y la política partidaria (aun con las particularidades señaladas para el caso de la FaHCE en el período estudiado). Estas correspondencias dan cuenta de que los académicos no son actores desinteresados, sólo movidos por la búsqueda del conocimiento o, como vimos, la trascendencia en términos de una reputación, de un "nombre propio", sino que, por el contrario, son sujetos interesados, que interactúan en un espacio institucional como el universitario que no escapa a los usos y lógicas políticas de otros espacios institucionalizados. Para ello, apelan a mecanismos formales e informales para garantizar, reproducir y ampliar la posición y el espacio de poder que dominan. Es decir que, volviendo al enfoque de Remedi (2004, 2006, 2013), si hubiéramos hecho una lectura "prescriptiva" de la institución, siguiendo los procedimientos y reglas formales que condicionan las acciones de los sujetos, no hubiéramos podido captar la importancia y complejidad de las tramas políticas e interpersonales, de los lazos y capitales políticos sedimentados, y de las prácticas y mecanismos informales de ingreso, permanencia, ascenso y desplazamiento a esas posiciones y espacios que operan en el mundo académico.

No obstante, la porosidad de las universidades a la dinámica política nacional, sí estuvo dada en nuestro caso, por la orientación de las discusiones y las interpretaciones y apropiaciones de la política social, económica y universitaria del gobierno de Menem en la década de los '90. El clima institucional de la época se encontraba fuertemente atravesado por distintas tensiones que el gobierno mismo se había encargado de instalar, tales como: gratuidad-arancelamiento, masividad-calidad de la formación, libre 
disponibilidad del presupuesto-presupuesto por objetivos, entre otros aspectos, analizados en el capítulo 3.

En línea con las perspectivas teóricas organizacionales y de la sociología de la cultura, también pudimos identificar liderazgos tanto organizativos como intelectuales, aunque advertimos que, en este caso, los liderazgos fueron virando de un perfil político a un perfil académico, y si bien los perfiles que se consolidaron combinan cualidades de ambos tipos, se advierte un énfasis en incrementar las credenciales para constituir liderazgos académicos. De modo que, en este aspecto, se verifica más un continuum que una opción. Estos hallazgos nos invitan a realizarnos nuevas preguntas, tales como: En el marco del grupo analizado ¿Qué estrategias de reproducción de esos liderazgos y de reclutamiento de nuevos miembros tuvieron? ¿Qué procesos de ampliación y diversificación del grupo se dieron? ¿Qué dinámicas de conflicto, tensiones, alianzas tuvieron lugar a partir de la reconfiguración del grupo? ¿Cuáles fueron, en tiempos más recientes, los nuevos legados, filiaciones y oposiciones que las nuevas generaciones construyeron?

Los interrogantes anteriores nos advierten acerca de la necesidad de incluir, en el estudio del proceso de conformación y legitimación de grupos y disciplinas académicas, el procesamiento y producción de políticas y estrategias, y la construcción de perfiles de liderazgo universitarios, las perspectivas y experiencias que los individuos y grupos que participaron en ellas desarrollaron por fuera de la Universidad. Más aún, nos debemos una reconstrucción profunda de sus trayectorias académicas y profesionales que incluya otras dimensiones que no fueron abordadas en este trabajo, tales como, la inclusión de la perspectiva de género. Como vimos en el capítulo 2, el grupo de EF que se consolidó en el período estudiado es predominantemente masculino, aunque la matrícula de las carreras arrojen paridad de género en su composición (Dirección de Enseñanza, FaHCE, 2017). Resulta de sumo interés, por tanto, que en el estudio del procesamiento de las políticas que llevan a cabo individuos y grupos que son, como hemos visto, en su mayoría hombres, conocer cómo se distribuyen y se han distribuido históricamente los espacios y posiciones de poder entre hombres y mujeres en la comunidad de EF de la FaHCE, qué persistencias y rupturas pueden rastrearse en la historia y trayectoria de otros grupos académicos disciplinares, y las alternancias y matices que puede arrojar el análisis histórico y micro-social.

Otra cuestión analizada en este capítulo y que emergió del trabajo de campo, fue la sensación de "outsiders" institucionales de estos académicos, en gran medida por su 
deslegitimación, y a partir de la cual efectuaron diversas acciones para integrarse a la institución. La reconstrucción de los significados de esta condición evidenció la presencia de visiones o concepciones inferiorizantes de la EF, y de relaciones de jerarquía, autoridad y parentesco, que reforzaban la posición de "outsiders" -los "transpiradores", "la fuerza bruta", "músculo y sonrisa"-. Asimismo, describimos el contenido de esa condición, evidenciado en la vestimenta -ropa deportiva-, los objetos utilizados -"andábamos con pelotas, bolsos, bicicletas, y no con libros"-, los modos de relacionamiento -más "cercanos" dados tanto por el uso del cuerpo como por la empatía característica de los/as profesores de la especialidad que se irradia a los/as estudiantes-, el tipo de conocimiento con el que trabajan -más "práctico", menos "teórico"-, discordante con el paisaje institucional de la FaHCE. De este modo, esta tesis reconstruyó el proceso por el cual, en una coyuntura de cambio de orientación de las instituciones universitarias hacia un modelo definido como "managinario" -que articula management e imaginario- como ideal sostenido en el mérito individual y en la productividad medida en términos cuantificables (Remedi, 2006: 77), estos "outsiders" académicos desplegaron esfuerzos por crecer, legitimarse y devenir en "insiders" (Didou Aupetit, 2008: 20).

Un concepto considerado en el marco teórico de la tesis fue el de "prácticas académicas" (Carrera, 2014; Rocha Pinto, 2000, 2009). Entendidas como relaciones sociales entre los sujetos en un espacio determinado, la academia, que construyen afiliaciones, oposiciones, identidades, y mediante las cuales se aprenden y enseñan cuestiones del quehacer disciplinar y académico, que exceden el espacio clásico del aula. Prácticas que son propias, distintivas de los/as académicos/as: publicar, organizar o participar de congresos, investigar, cursar un posgrado, organizar una revista, conformar grupos, evaluar pares, diseñar una carrera de posgrado, entre muchas otras. Esta investigación permitió relevar cómo se expresan las prácticas académicas en un ámbito específico y describir el contenido de las mismas, que en este caso tuvieron como propósito incrementar su legitimación disciplinar, al decir de algunos de nuestros informantes, "haciendo los deberes", o siendo "los mejores alumnos". Desde la perspectiva de los/as académicos/as de la propia disciplina, "teníamos que aprender de ellos" en alusión a que aprendieron de aquellos/as académicos/as consolidados/as en la FaHCE.

Del análisis de estas prácticas académicas, emergen interrogaciones tales como: ¿Qué otras prácticas, además de las estudiadas, son propias de esta comunidad, tanto en el ámbito universitario como no universitario? ¿Cuáles y cómo son las relaciones entre 
esos ámbitos de desempeño profesional de la EF? ¿Qué prácticas, instancias y ámbitos de sociabilidad académica se dan en el colectivo estudiantil de esta comunidad? ¿Estas prácticas de sociabilidad integran el proyecto curricular formal de la carrera o se enseñan en espacios menos formalizados como la participación circunstancial en proyectos de investigación? ¿Cómo se interrelacionan estas prácticas con las desarrolladas por el colectivo de graduados/as y profesores/as de la comunidad?

En el capítulo 3, reconstruimos y analizamos un conjunto de políticas y estrategias académicas desarrolladas por el grupo de profesores de EF descripto en el capítulo anterior. De dicho análisis se identificó una etapa prolífica en cuanto al diseño de iniciativas de fuerte incidencia para esta comunidad, como fueron el congreso Educación Física y Ciencia, la Revista Educación Física y Ciencia, las primeras investigaciones formales en el marco del Programa de Incentivos a los docentes-investigadores, y la reforma curricular de los años '90, que dio lugar a una nueva propuesta formativa y a la inclusión de una carrera de licenciatura en la especialidad. Esa etapa fue definida, según la perspectiva de distintos actores, como de "crecimiento intelectual", "fundación" y "legitimación" sostenida sobre la construcción de un proyecto académico ambicioso, el armado de equipos de trabajo y de estrategias políticas, la reformulación de la formación disciplinar, entre otros aspectos salientes.

Al inicio de este capítulo nos preguntábamos en qué medida esas políticas universitarias y académicas operaron como modos de legitimación en la construcción de un campo de conocimiento, así como su funcionamiento como plataforma de acceso a la legitimidad institucional, y los acuerdos, desacuerdos, tensiones y conflictos asociados a ese proceso. En ese sentido, identificamos varios frentes de disputa, que fueron sorteados con relativo éxito por este grupo y sus adherentes: el disciplinar, el intelectual y el institucional. En el primer caso, se evidenció la constitución de un grupo de trabajo sólido con una perspectiva de la EF distintiva de la de otras universidades e instituciones superiores, e incluso de la propia perspectiva presente en la FaHCE anterior a su participación en la gestión del DEF. En cuanto al frente intelectual, supieron establecer y sostener una serie de instancias de socialización y validación de dicha perspectiva aunque con matices-, en numerosos proyectos de investigación, órganos de difusión y políticas de circulación, como los congresos y la revista. $Y$ en relación a lo institucional, y en virtud tanto de las concepciones de actores de EF como de las de actores de otras disciplinas, estas políticas lograron poner en entredicho visiones históricas sobre la EF en general y en la FaHCE en particular, que redundaron además en una participación más 
activa de sus actores en el gobierno de la institución y en la creación y ocupación de espacios propios que lograron un grado considerable de institucionalización. De este análisis se desprenden algunos interrogantes que no estuvieron presentes al inicio de la pesquisa y que es preciso profundizar en algún momento: ¿Cómo se tradujo esa perspectiva "crítica" de la disciplina en el diseño y puesta en marcha de carreras de posgrado diseñadas entre comienzos y mediados de los años 2000 ? ¿Cuáles fueron los diálogos y articulaciones, si es que se dieron, entre esta perspectiva y las orientaciones presentes en otras carreras de la especialidad del país y del extranjero? En otras palabras, ¿Qué repercusiones tuvo esta perspectiva en otros ámbitos institucionales especializados, localizados en diferentes latitudes? ¿De qué modos se vinculó este grupo estudiado con grupos de otras carreras de la especialidad en el país y en el extranjero?

Asimismo, la nueva propuesta de formación de grado de los/as estudiantes aprobada en 1998, supuso no sólo la creación de la carrera de Licenciatura, sino orientaciones en distintas disciplinas para su finalización y la inclusión de materias electivas, que habilitaban la posibilidad de articular con otras carreras de la Facultad. Esta articulación, si bien fue fuertemente resistida por las consejeras profesoras por la minoría en la instancia de debate en el Consejo Académico, fue valorada por docentes de otras disciplinas como una "apertura" de la EF al conjunto de la institución y en el enriquecimiento de su propuesta formativa. Las resistencias señaladas fueron enmarcadas en un debate no sólo por el estatus epistemológico de la EF sino como parte de una disputa política, en tanto estas consejeras se oponían a la política curricular y de gestión de la FaHCE, en la cual la EF representó el eslabón más débil para ese enfrentamiento. Aun así, el plan del Profesorado se aprobó por unanimidad con 12 votos a favor, y el de la Licenciatura con 10 a favor y 2 en contra, de las profesoras por la minoría.

Al respecto, la discusión por la reforma curricular evidenció que el proceso de legitimación analizado no estuvo exento de conflictos, tensiones y disputas con académicos/as de la misma disciplina y de otras disciplinas de la institución, particularmente nos referimos a las resistencias enérgicas a la creación de la Licenciatura. A partir de la literatura de referencia, entendemos que no es casual que el conflicto se haya desencadenado en ese escenario, dado que en ese plano este grupo disputó más enfáticamente una orientación formativa que se distanciaba del perfil profesionalista del Profesorado y que posibilitaba la formación de grado en investigación y la apertura a los posgrados. Asimismo, este análisis permitió mostrar cómo los 
procesos de reforma curricular son analizadores potentes de la vida de las instituciones, ya que allí se visualizan y reactualizan disputas de orden político, disciplinar y epistemológico (De Alba, 1998; Remedi, 2013).

De este modo, la reconstrucción de políticas efectuada en este último capítulo, permitió confirmar que, si bien el contexto nacional se caracterizó por la aplicación de lineamientos neoliberales traducidos en la apertura y desregulación económica, que desencadenó en una fuerte recesión y en altos niveles de desocupación y pobreza, para el caso en estudio (tanto a nivel del DEF como de la FaHCE en general) fue muy productivo en términos de sociabilidad académica. En este sentido, en la introducción de esta tesis, destacábamos cómo los años '90 aparecían aun opacos en el análisis de casos específicos y abundaban documentos oficiales y una percepción negativa relativamente generalizada en el ámbito universitario. Sin embargo, tanto por el rol activo del Estado en políticas para el sector, como por iniciativas propias de los órganos colegiados y de los/as docentes que cumplían funciones en la gestión, es que sostenemos que, al menos para el caso en estudio (EF), fue una etapa muy provechosa. En esta línea, una de las dimensiones que abordó la investigación se refiere justamente al cambio en la política estatal con respecto a las universidades durante esos años. Una política definida como de "fuerte intervención" por parte del Estado con iniciativas "verticalmente proyectadas" desde los organismos de gestión centralizados hacia las instituciones académicas. Es por estos años que se instala la lógica de financiamiento por programas, tales como el FOMEC y el PI -este último aún vigente-, analizados en esta tesis. La reconstrucción realizada permitió observar que, si bien parte de esas políticas se originaron a partir de fuerzas exógenas -Estado Nacional-, para nuestro caso, el proceso de construcción de reconocimiento académico de la EF ya se había iniciado previamente, con la realización del primer Congreso en 1993. Estos resultados son consistentes con los planteos de la literatura de referencia acerca de la dinámica política de las instituciones académicas. Por un lado, y en cuanto a la perspectiva de la sociología de la cultura, señalan el grado de autonomía relativa que tienen sus actores para introducir cambios y tomar decisiones en este ámbito de la acción humana. Desde la perspectiva pedagógico-institucional de Remedi, esas acciones se encuentran enmarcadas y condicionadas por una institución que contiene a los actores, a través de las historias, mitos, culturas y estilos institucionales, reglas, etc. de las cuales estos actores se apropiaron para legitimarse. Por otro lado, el enfoque organizacional nos brindó categorías para comprender que esos procesos de cambio asumen particularidades 
específicas para el caso de las universidades, en tanto son organizaciones complejas, "pesadas en la base", "de acoplamiento laxo", "débilmente cohesionadas", y en donde los cambios suelen tener mayor efectividad y perdurabilidad cuando son producto de acuerdos e intereses que confluyen en esa base, y no así cuando son direccionados e impuestos desde la cúpula del sistema. No obstante, para el caso de las políticas de los '90, aunque fueron públicamente resistidas por los actores de la base y generalmente, recordadas aun de manera negativa, vimos cómo fueron resignificadas y traducidas en oportunidad de crecimiento en el espacio local y en el grupo particular de EF.

En referencia específica a la política nacional del PI, se evidencia una apropiación por parte de esta comunidad (en el proceso de categorización de los investigadores y la conformación de grupos y presentación de proyectos de investigación) que les brinda mayor autonomía y forma parte de esa construcción de legitimación. El análisis de esta política en particular también nos permitió evidenciar que los actores efectuaron procesos de resignificación mediante una lectura del contexto, es decir, que los actores no sólo reciben las políticas, sino que también las producen, en tanto algunas de sus iniciativas no fueron emanadas del poder central ni desde la institución. Como ejemplos podemos citar nuevamente la realización del Congreso y la Revista, el primero calificado por informantes de otras disciplinas como "notable", en tanto "eran impresionantes, asistían alrededor de 800 personas", cambiando el paisaje institucional que se asemejaba a "una cancha de fútbol", en clara alusión a la multitud.

De este modo, evidenciamos que los actores académicos no son meros ejecutores de políticas, sino que son sujetos con capacidad de agencia, que interactúan en un escenario institucional en el que despliegan prácticas y estrategias que es al mismo tiempo performado y performativo de estas acciones. Aquí, rescatamos nuevamente la potencialidad del enfoque micro-social más allá de los estudios macro, ya que nos permitió leer la fase más productiva de los actores, la especificidad que asumen procesos como el descripto en esta tesis, las dinámicas institucionales, la conformación de las comunidades y cómo van acumulando un conjunto de experiencias, vinculadas a legados y herencias de más larga duración.

Por otro lado, si bien no fue un objetivo de la tesis abordar las discusiones epistemológicas de la disciplina, surgieron relaciones de dependencia, de "tutelaje" por parte de otras disciplinas con mayor tradición académica, que les sirvieron como andamiaje para dar sus primeros pasos en los proyectos de investigación. Al respecto, nos preguntamos: la consolidación de estas líneas de investigación a futuro ¿dio lugar a 
la creación de espacios de investigación específicamente referidos a las líneas consolidadas? ¿Qué procesos análogos u opuestos vivieron otras comunidades de la misma institución? Estas preguntas son evidencias de que el análisis micro-social resulta útil además para emprender este tipo de comparaciones.

En cuanto al recurso del nombre propio en la investigación, referido tanto a la opción teórico-metodológica del estudio de lo individual para la reconstrucción de una red de relaciones $\mathrm{y}$, fundamentalmente, en el ámbito académico, por su trascendencia en la configuración de figuras públicas, de referentes de peso, nos alienta a preguntarnos: ¿Cuáles fueron las prácticas formales e informales que los actores más jóvenes produjeron para su inserción académica en la comunidad y en la institución? ¿Qué estrategias desplegaron estos "yuppies institucionales" o "golden boys" en palabras de Remedi (2006: 79), para abrirse paso en nuevos ámbitos de legitimación disciplinar como por ejemplo el acceso a organismos de ciencia y técnica del Estado, tales como el Consejo Nacional de Investigaciones Científicas y Técnicas (CONICET)? ¿Qué tipo de relaciones establecieron en tiempos más actuales con esos referentes disciplinares y sus respectivas líneas de investigación?

Retomando nuevamente los aportes de los enfoques organizacionales y de la sociología de la cultura, específicamente el concepto de crecimiento institucional desarrollado por Clark (1998) y de disciplina académica de Becher (2001), podemos concluir para nuestro caso que, del relevamiento empírico realizado, EF atravesó un proceso de crecimiento reactivo importante a partir del retorno democrático -demanda de acceso a su carrera que se tradujo en un aumento matricular destacado y sostenido-, combinado con cierto crecimiento sustantivo, sustentado tanto en las políticas generadas desde el Estado Nacional (PI, FOMEC), como por las políticas y estrategias académicas desarrolladas desde la gestión de la carrera y sus allegados particularmente analizadas en el capítulo 3 (Congreso, Revista, reforma curricular, entre otros). Esta idea puede vincularse con la de disciplina académica de Becher, en tanto que el autor sostiene que para su existencia no es suficiente contar con una estructura administrativa independiente (en nuestro caso, DEF), lo que podría equipararse con la idea de crecimiento reactivo, sino que además deben adicionarse aspectos como la credibilidad académica y el prestigio. Todos estos aspectos traducidos en el establecimiento de una comunidad de pertenencia, redes de comunicación, tradiciones, un estilo de investigación, un armazón conceptual, entre otros que, con distintos grados de desarrollo, pudimos encontrar en el caso estudiado. 
Llegados hasta aquí, creemos que este trabajo habilita nuevas líneas de investigación en la medida en que pueden desarrollarse estudios que profundicen hacia adelante sobre el proceso de institucionalización académica y científica de la EF en la UNLP y la apropiación del legado de la generación de académicos estudiados en académicos jóvenes o recientes, así como la construcción de redes de cooperación y producción con otros países, tal como se continuará en la tesis de doctorado. Asimismo, pueden efectuarse pesquisas con perspectiva comparada entre el desarrollo de la EF en la UNLP y en otras universidades del país, e incluso de la región o el mundo. Por último, y de modo más general, esta investigación también creemos que aporta a la vez que abre la posibilidad de continuar indagando sobre procesos de institucionalización y legitimación académica y científica en disciplinas de orientación profesionalista, anclados en culturas institucionales y políticas específicas, con la pretensión de contribuir a la construcción de marcos analíticos sobre estos procesos, a escala nacional y regional. 
Aisenstein, A. (1995). Curriculum presente, ciencia ausente. El modelo didáctico en la Educación Física: entre la escuela y la formación docente. Buenos Aires, Argentina: Miño y Dávila.

Aisenstein, A. (2006). "Cuerpo, Escuela y Pedagogía. Argentina, siglos XIX y XX". En Aisenstein A. y Scharagrodsky, P. Tras las huellas de la Educación Física escolar argentina. Cuerpo, género y pedagogía: 1880-1950 (pp. 19-48). Buenos Aires, Argentina: Prometeo.

Aisenstein A. y Scharagrodsky, P. (2006). Tras las huellas de la Educación Física escolar argentina. Cuerpo, género y pedagogía: 1880-1950. Buenos Aires, Argentina: Prometeo.

Alfonso, M. (2016). El exilio como viaje de formación y conocimiento. El caso de Azucena Rodríguez Ousset en México (1976-1983). Anuario de la Sociedad Argentina de Historia de la Educación, volumen 17, número 2, 198-220.

Alfonso, M. (2017). Un ejercicio de memoria: Diálogo con Eduardo Remedi Allione (19492016). Educación, Formación e Investigación. Vol. 3, №5, 307-323.

Amavet, A. (1957). Apuntes para una introducción al estudio de la Educación Física. Buenos Aires, Argentina: Compañía Impresora Argentina, S.A.

Amavet, A. (1967). Cuaderno de Educación Física Renovada №1. En Ron, O. y Levoratti, A. (coord.) (2015). Diálogos con Alejandro J. Amavet: A propósito de la Educación Física Renovada (pp. 75-83). Facultad de Humanidades y Ciencias de la Educación, UNLP. Ensenada, Argentina.

Amavet, A. (1968). Cuaderno de Educación Física Renovada №2. En Ron, O. y Levoratti, A. (coord.) (2015). Diálogos con Alejandro J. Amavet: A propósito de la Educación Física Renovada (pp. 87-102). Facultad de Humanidades y Ciencias de la Educación, UNLP. Ensenada, Argentina.

Amavet, A. (1969). Cuaderno de Educación Física Renovada №3. En Ron, O. y Levoratti, A. (coord.) (2015). Diálogos con Alejandro J. Amavet: A propósito de la Educación Física Renovada (pp. 105-121). Facultad de Humanidades y Ciencias de la Educación, UNLP. Ensenada, Argentina.

Amavet, A. (1972). El cambio en la actitud del pensamiento educativo. Inédito.

Araujo, S. (2001). Los universitarios en la lupa: evaluación de la calidad, incentivos a la actividad investigadora y sus efectos en la profesión académica. Pensamiento Universitario, № 9, 23-37.

Atairo, D. (2007). Estado, Universidad y actores: el FOMEC en la UNLP (Tesis de Maestría). FLACSO, Buenos Aires, Argentina.

Barletta, A. M. (2010). Universidad y política en registro personal. Revista de la Universidad Nacional de La Plata, № 35, La Plata: Editorial de la Universidad Nacional de La Plata.

Barletta, A. M. (2011). La Revista Archivos de Ciencias de la Educación. Apuntes para una o varias historias institucionales. Archivos de Ciencias de la Educación, 5. Departamento de Ciencias de la Educación. Facultad de Humanidades y Ciencias de la Educación. Universidad Nacional de La Plata, 17-36. 
Becher, T. (2001). Tribus y territorios académicos. La indagación intelectual y las culturas de las disciplinas. Barcelona: Gedisa.

Becker, H. (2009). "Outsiders". En Outsiders. Hacia una sociología de la desviación (pp. 21-37). Buenos Aires, Argentina: Siglo XXI.

Birgin, A. (1999). El trabajo de enseñar. Buenos Aires, Argentina: Editorial Troquel.

Bisso, A. (2009). Ricardo Levene y los estudios históricos en La Plata: El distanciado historiador profesional frente a las cercanías temporales y espaciales. Ciertos cruces no siempre predecibles. Trabajo presentado en: El centenario de los estudios históricos en La Plata, Ciclo de conferencias. Departamento de Historia. Universidad Nacional de La Plata, Facultad de Humanidades y Ciencias de la Educación, La Plata, Argentina.

Bourdieu, P. (1990). "Algunas propiedades de los campos". En Sociología y cultura, México: Grijalbo.

Bourdieu, P. (2000). "El campo científico". En Los usos sociales de la ciencia, Buenos Aires, Argentina: Nueva Visión.

Bourdieu, P. (2008). Homo academicus. Buenos Aires, Argentina: Siglo XXI.

Bourdieu, P. (2011). La ilusión biográfica. Acta Sociológica, núm. 56, 121-128.

Bracht, V. (1996). Educación Física y aprendizaje social. Córdoba, Argentina: Editorial Vélez Sarsfield.

Bracht, V. (2000). Educação física e ciência: cenas de um casamento (in)feliz. Rev. Bras. Cienc. Esporte, v. 22, n. I, 53-63.

Brunner, J. J. (1994). "Presentación: Estado y educación superior en América Latina". En Neave, G. y van Vught, F. (eds.) Prometeo encadenado. Estado y educación superior en Europa (pp. 11-42). Barcelona: Gedisa.

Buchbinder, P. (2005). Historia de las Universidades Argentinas. Buenos Aires, Argentina: Editorial Sudamericana.

Caldo, P. y Fernández, S. (2012). La vida como pretexto. Una aproximación a la relación entre biografía e historia a partir del caso de Olga Cossettini, Santa Fe, 18981987. Revista Estudios del ISHiR. Año 2, Número 4, 175-187.

Calvo Etcheverry, P. (1998). Pienso... luego existo: reflexiones en torno a la Educación Física y el contenido y transformación histórica de sus Espacios Institucionales. Revista Educación Física y Ciencia, nº 4, 7-13.

Camou, A. (2002). "Reformas estatales de "segunda generación" y reformas universitarias en la Argentina actual ( $O$ de por qué es bastante más fácil privatizar una compañía telefónica que reformar una universidad)". En Krotsch, P. y Prati, M. (org.) La universidad cautiva: Legados, marcas y horizontes (pp. 131-151). La Plata, Argentina: Ed. Al Margen.

Carballo, C. (2009). "La investigación en Educación Física". En Crisorio, R. y Giles, M. (dir.) Educación Física. Estudios críticos de Educación Física (pp. 285-301). La Plata, Argentina: Ed. Al Margen.

Carballo, C. (2010). "Algunas tensiones en el campo de la Educación Física en Argentina". En Cachorro, G. y Salazar, C. (coord.). Educación Física Argenmex: temas y posiciones (pp. 33-54). Facultad de Humanidades y Ciencias de la 
Educación, Universidad Nacional de La Plata. La Plata, Argentina. Recuperado el 15 de junio de 2017, de:

http://www.memoria.fahce.unlp.edu.ar/libros/pm.14/pm.14.pdf

Carballo, C. (2014). "El nacimiento de un oxímoron: la Educación Física como tecnología crítica". En Educación física escolar, académica y profesional (pp. 123-132). Universidad Nacional de La Plata. Facultad de Humanidades y Ciencias de la Educación. La Plata, Argentina. (Colección Colectiva y Monográfica: 1). Recuperado el 20 de octubre de 2017, de: http://www.memoria.fahce.unlp.edu.ar/libros/pm.392/pm.392.pdf

Carballo, C. (2015). "Educación Física". En Diccionario Crítico de la EF Académica. Rastreo y análisis de los debates y tensiones del campo académico de la educación física en Argentina. Buenos Aires, Argentina: Prometeo.

Carballo, C. y Fernandez Vaz, A. (2003). "Educación Física y metodología de la investigación". En Crisorio, R. y Bracht, V. (coord.) La educación Física en Argentina y Brasil. Identidad, desafíos y perspectivas (pp. 107-118). La Plata, Argentina: Ed. Al Margen.

Carli, S. (2013). El viaje de conocimiento en las humanidades y las ciencias sociales. Un estudio de caso sobre profesores universitarios en la Argentina durante la segunda mitad del siglo XX. Historia de la Educación. Anuario, Vol 14, No2, 1-38. Recuperado el 10 de marzo de 2018, de: http://ppct.caicyt.gov.ar/index.php/anuario/article/view/3941/pdf

Carrera, M. C. (2014). Aprender a ser sociólogo. Prácticas de lenguaje, militancia y formas de sociabilidad en el proceso de formación de sociólogos y sociólogas en la FAHCE-UNLP (Tesis de Maestría). Universidad Nacional de La Plata. Facultad de Humanidades y Ciencias de la Educación, Ensenada, Argentina.

Cerruti, M. B. y Vior, S. E. (2016). La educación y los Organismos Internacionales de crédito. Préstamos y recomendaciones para América Latina (2000-2015). Journal of Supranational Policies of Education, $\mathrm{n}^{\circ} 4,18-37$.

Chiroleu, A., Suasnábar, C. y Rovelli, L. (2012). Política universitaria en la Argentina: revisando viejos legados en busca de nuevos horizontes. Buenos Aires, Argentina: Universidad Nacional de General Sarmiento.

Clark, B. (1983). El sistema de educación superior. Una visión comparativa de la organización académica. México: Universidad Autónoma Metropolitana.

Clark, B. (1998). Crecimiento sustantivo y organización innovadora: nuevas categorías para la investigación en educación superior. Perfiles Educativos, $N^{\circ} 81$. DF, México.

Clark, B. (2011). Cambio sustentable en la universidad. Buenos Aires, Argentina: Universidad de Palermo.

Coria, A. (2004). "Sujetos, institución y procesos político-académicos en el caso de la institucionalización de la Pedagogía en la UNC, Argentina (1955-1975). Trama de una perspectiva teórico-metodológica relacional". En Remedi Allione, E. (coord.) Instituciones educativas. Sujetos, historia e identidades (pp. 193-245). México: Plaza y Valdés editores.

Coria, A. (2015). Tejer un destino. La formación de pedagogos en la Universidad Nacional de Córdoba, Argentina, 1955-1976. Buenos Aires, Argentina: Miño y Dávila. 
Crisorio, R. (2007). Educación Física y biopolítica. Revista TEMAS \& MATIZES, Cascavel, Paraná, Brasil, Año VI, $\mathrm{n}^{\circ} 11$, Universidade Estadual do Oeste do Paraná, 67-78.

Crisorio, R. (2009). "Educación Física". En Crisorio, R. y Giles, M. (Dirs.) Educación Física. Estudios críticos en Educación Física (pp.45-58). La Plata: Ed. Al Margen.

Crisorio, R. (2015). "Educación Corporal". En Crisorio, R., Rocha Bidegain, L. y Lescano A. (coord.) Ideas para pensar la educación del cuerpo (pp. 8-13). La Plata, Argentina: EDULP.

Crisorio, R. y Bracht, V. (Coord.) (2003). La Educación Física en Argentina y en Brasil. Identidad, desafíos y perspectivas. La Plata, Argentina: Ed. Al Margen.

Crisorio, R. y Giles, M. (Dir.) (2009). Educación Física. Estudios críticos de Educación Física, La Plata, Argentina: Ed. Al Margen.

De Alba, A. (1998). Currículum. Crisis, mito y perspectivas. Buenos Aires, Argentina: Miño y Dávila.

Didou Apetit, S. (2008). "Prólogo". En Remedi Allione, E., Detrás del murmullo. Vida político-académica en la Universidad Autónoma de Zacatecas 1959-1977 (pp. 1520). Tesis de Doctorado. México: Casa Juan Pablos, Universidad Autónoma de Zacatecas.

Di Paolo, A. (1993). Historia de la creación del Profesorado Universitario en Educación Física. Semblanza de vida y obra del Profesor Alejandro Amavet. La Plata, Argentina: Ed. De la Campana.

Feiguin, M. A., Cobiella, M. del P. y Aisenstein, A. (2015). Un nuevo dispositivo para la formación de profesores en Educación Física: marco normativo y primeras normas institucionales. Trabajo presentado en las VIII Jornadas Nacionales y $1^{\circ}$ Congreso Internacional sobre la Formación del Profesorado. Facultad de Humanidades, Universidad Nacional de Mar del Plata, Argentina.

Finocchio, S. (Coord.) (2001). Facultad de Humanidades y Ciencias de la Educación. Documentos y notas para su historia. La Plata, Argentina: Ed. Al Margen-UNLP.

Franco, M. S. (2011). "Los discursos sobre la Educación Física en los inicios de la escuela argentina". En Rozengardt, R. y Acosta, F. (comp.) Historia de la Educación Física y sus instituciones: continuidades y rupturas (pp. 119-141). Buenos Aires, Argentina: Miño y Dávila.

Frederic, S. y Soprano, G. (2009). Política y variaciones de escalas en el análisis de la Argentina. Buenos Aires, Argentina: Prometeo.

Galak, E. (2012a). Del sintagma al oxímoron. La construcción del currículum y del oficio de Educación Física en la Argentina de fin de siècle XIX. Educación Física y deporte (Colombia), vol. 31, $\mathrm{n}^{\circ}$ 1, 777-787.

Galak, E. (2012b). Del dicho al hecho (y viceversa). El largo trecho de la construcción del campo de la formación profesional de la Educación Física en Argentina. Legalidades, legitimidades, discursos y prácticas en la institucionalización de su oficio entre finales del siglo XIX y el primer tercio del XX (Tesis de Doctorado). Universidad Nacional de La Plata. Facultad de Humanidades y Ciencias de la Educación, La Plata, Argentina. 
Galak, E. (2013a). "Herbert Spencer y la pedagogía integralista. Influencias en los inicios de la Educación Física argentina". En Varea, V. y Galak, E. (eds.) Cuerpo y Educación Física. Perspectivas latinoamericanas para pensar la educación de los cuerpos (pp.45-66). Buenos Aires, Argentina: Biblos.

Galak, E. (2013b). "Paradojas de la epistemología de la Educación Física argentina: verdad, identidad y doxa en la formación superior". En Gomes, I., Quintão, F., Velozo, E. (org.) Epistemologia, ensino e crítica. Desafioscontemporâneos para a Educação Física (pp. 193-220). Nova Petrópolis: Nova Harmonia.

Galak, E. (2014). Educación del cuerpo y política: concepciones de raza, higienismo y eugenesia en la Educación Física Argentina. Revista Movimento, Artigos Originais, Porto Alegre, v. 20, n. 4, 1543-1562.

Galak, E. y Simoy, S. (2015). "El oficio de ser "profe". Prácticas, saberes y discursos de la formación superior en educación física en Argentina". En Crisorio, R., Rocha Bidegain, L. y Lescano, A. (coord.) Ideas para pensar la educación del cuerpo (pp. 125-137). La Plata, Argentina: EDULP.

Garatte, L. (2008). Grupos académicos y cambios curriculares durante la normalización universitaria en Argentina (Tesis de Maestría). FLACSO, Buenos Aires, Argentina.

Garatte, L. (2012). Políticas, grupos académicos y proyectos curriculares de Ciencias de la Educación en la Universidad Nacional de La Plata (1966-1986) (Tesis de Doctorado). Universidad de San Andrés, Buenos Aires, Argentina.

Garatte, L. y García Clúa, M. N. (2013). Circulación de saberes entre la Universidad y el Estado. Un análisis sobre trayectorias de pedagogos peronistas y católicos en Argentina, entre 1955 y 1983. Estudios del ISHiR. Año 3, Número 6, 150-170.

García de Fanelli, A. M. (Editora) (2009). Profesión académica en Argentina: carrera e incentivos a los docentes en las universidades nacionales. Buenos Aires, Argentina: CEDES.

Giles, M. (2012). Educación Corporal: cuerpo, movimiento y sujeto. Una mirada sobre el Plan 2000 (UNLP), las prácticas y sus imposibles cambios. Educación Física y Deporte, 31, (1), 885-890.

Giles, M., Mamonde, M. y Simoy, M. S. (2012). El cuerpo transmitido y construido en la formación de grado en Educación Física en la Argentina. En: Actas del I Encuentro Latinoamericano de Investigadores sobre Cuerpos y Corporalidades en las Culturas. Facultad de Humanidades y Artes, UNR, Rosario, Argentina.

Gómez, P. (2006). "La Educación Física en la legislación argentina. El itinerario normativo de una asignatura escolar (1880-1955)". En Aisenstein A. y Scharagrodsky, P. Tras las huellas de la Educación Física escolar argentina. Cuerpo, género y pedagogía: 1880-1950 (pp. 247-292). Buenos Aires, Argentina: Prometeo.

González De Álvarez, M. L. (Comp.) (2012). La Educación Física en Latinoamérica. Orígenes y trayectorias de la formación de profesores. Tucumán, Argentina: EDUNT.

González De Álvarez, M. L. (2014). Instituto de Educación Física de la UNT. Primeros tiempos de la formación de profesores en la universidad (1953/1959). Trabajo presentado en el I/ Congreso sobre la Historia de la UNT. Facultad de Educación Física, UNT. Tucumán, Argentina. 
Guber, R. (2001a). Etnografía: método, enfoque y reflexividad. Buenos Aires, Argentina: Grupo Editorial Norma.

Guber, R. (2001b). ¿Por qué Malvinas? De la causa nacional a la guerra absurda. Buenos Aires, Argentina: Fondo de Cultura Económica.

Hernando, G. (2015). Trayectorias de formación de un grupo de pedagogos en la Universidad Nacional de La Plata entre 1957 y 1983: Utopías, imaginarios revolucionarios y exilios (Tesis de Maestría). Facultad de Filosofía y Letras, UBA.

Izaguirre, I. (2011). La Universidad y el Estado terrorista. La Misión Ivanissevich. Conflicto social, Año 4, nº 5, 287-303.

Kirk, D. (1990). Educación física y curriculum. Introducción crítica. Valencia, España: Univesitat de Valencia.

Kopelovich, P. (2013). Entrevista a Carlos Parenti. La visión del Profesorado en Educación Física de la Universidad Nacional de La Plata: pasado, presente y futuro. Educación Física y Ciencia, v. 15, № 2.

Krotsch, P. (2001). Educación Superior y Reformas Comparadas. Cuadernos Universitarios $N^{\circ} 6$. Buenos Aires, Argentina: Universidad Nacional de Quilmes.

Krotsch, P. (Comp.) (2003). Las miradas de la Universidad. III Encuentro Nacional La Universidad como Objeto de Investigación'. La Plata, Argentina: Ed. Al Margen.

Krotsch, P. y Suasnábar, C. (2002). Los estudios sobre la Educación Superior: Una reflexión en torno en torno a la existencia y posibilidades de construcción de un campo. Pensamiento Universitario, $N^{\circ} 10,35-54$.

Krotsch, P., Camou, A. y Prati, M. (Comp.) (2007). Evaluando la evaluación: políticas universitarias, instituciones y actores en Argentina y América Latina. Buenos Aires, Argentina: Prometeo.

Landesmann, M. (Coord.) (2006). Instituciones educativas. Instituyendo disciplinas e identidades. Casa Juan Pablos, Centro Cultural, Coyoacán, México, D.F.

Larrosa, J. (2000). Pedagogía profana. Estudios sobre lenguaje, subjetividad, formación. Buenos Aires, Argentina: Novedades Educativas.

Levoratti, A. y Macario, P. (2013). La lógica perversa y las exigencias académicas. Una aproximación a las perspectivas de los Profesores en Educación Física de la Universidad Nacional de La Plata (UNLP) sobre el Programa de Incentivos a los Docentes-Investigadores. Rev. Bras. Ciênc. Esporte, Florianópolis, v. 35, n. 2, 341-357.

Macario, P. (2007). Universidad, investigación: El Programa de Incentivos a los Docentesinvestigadores (Tesis de grado). Universidad Nacional de La Plata. Facultad de Humanidades y Ciencias de la Educación, La Plata, Argentina.

Mamonde, M. (2008). ¿Qué quiere Perón de la Educación Física? Trabajo presentado en el Primer Congreso de Estudios sobre el peronismo. Mar del Plata, Buenos Aires, Argentina.

Marquina, M. (2013). ¿Hay una profesión académica Argentina? Avances y reflexiones sobre un objeto en construcción. Pensamiento Universitario, Año 15, No. 15, 3558. 
Marquina, M., Mazzola, C. y Soprano, G. (Comp.) (2009). Políticas, instituciones y protagonistas de la Universidad Argentina. Buenos Aires, Argentina: Prometeo.

Maxwell, J. (1996). "Un modelo para el diseño de investigación cualitativo" y “¿Qué Hará Para Conducir La Investigación? En Qualitative Research Design. An interactive Approach. Traducción: María Luisa Graffigna. SAGE Publications.

Mayoral González, A. (2008). André Lapierre: De la Reeducación Física a la Psicomotricidad Relacional. RICYDE. Revista Internacional de Ciencias del Deporte, vol. IV, núm. 12.

Milstein, D. y Mendes, H. (1999). La escuela en el cuerpo. Estudios sobre el Orden Escolar y la Construcción Social del Alumno en Escuelas Primarias. Madrid: Miño y Dávila.

Montenegro, E. B. J. (2016). Políticas de acceso a la Universidad Nacional de La Plata. Un análisis de las estrategias de ingreso desde la sanción de la Ley de Educación Superior (1995-2015) (Tesis de Maestría). Universidad Nacional de La Plata. Facultad de Humanidades y Ciencias de la Educación, Ensenada, Argentina.

Morgade, G. (Comp.) (1997). Mujeres en la educación. Género y docencia en la Argentina 1870-1930. IICE (UBA). Buenos Aires, Argentina: Miño y Dávila.

Neiburg, F. y Plotkin, M. (Comps.) (2004). Intelectuales y expertos. La constitución del conocimiento social en la Argentina. Buenos Aires, Argentina: Paidós.

Nosiglia C. y Rebello G. (2005). La concertación Educativa. Una aproximación al estilo de definición e implementación de la "Transformación Educativa" en la Argentina de los `90. Revista del IICE, n²3, 3-12.

Oña, A. (1986). Nos falta ciencia si queremos E.F. Revista Apunts. №3.

Orbuch, I. (2016). Peronismo y Educación Física. Políticas públicas entre 1946 y 1955. Buenos Aires, Argentina: Miño y Dávila.

Oszlak, O. (1997). La formación del Estado argentino. Orden, progreso y organización nacional. Buenos Aires, Argentina: Editorial Planeta.

Parenti, C. (2006). Los orígenes del Primer Profesorado Universitario en Educación Física (PUEF, UNLP) en la Argentina. El cruce de la formación docente y la biografía del Profesor Alejandro Joaquín Amavet. Trabajo presentado en las II Jornadas Académicas "Los nuevos desafíos de la Educación Física y el Deporte", UNLu. I.N.E.F Gral. Manuel Belgrano. Luján, Argentina.

Parlebas, P. (1997). Problemas teóricos y crisis actual en la Educación Física. Lecturas: Educación Física y Deportes, Año 2, № 7.

Paso, M. (2012). Políticas, elites intelectuales y discursos en la construcción de la universidad excluyente: el caso de la Facultad de Humanidades y Ciencias de la Educación de la Universidad Nacional de La Plata: 1976 - 1983 (Tesis de Maestría). FLACSO, Buenos Aires, Argentina.

Paso, M. y Garatte, L. (2011). Pedagogía y teoría pedagógica de la educación física: hacia una articulación entre campos en la formación de profesores. Trabajo presentado en el VIII Encuentro de Cátedras de Pedagogía de Universidades Nacionales Argentinas, Universidad Nacional de La Plata, La Plata, Argentina.

Paviglianiti, N. (1995). La Ley Federal de Educación como elemento de regulación de la realidad socioeducacional en la Argentina: Sus orientaciones hacia la 
privatización, provincialización y retiro del Gobierno Nacional del financiamiento del sistema de educación pública. Serie Pedagógica (2), 123-146.

Peterson, M. W. (2007). "The study of colleges and universities as organizations". En Gumport, P. (Ed.), Sociology of higher education. Contributions and their contexts (pp. 147-186). Baltimore: The John Hopkins University Press.

Pich, S. y Rodríguez, N.B. (2014). Los cuerpos de Foucault: Una genealogía de los estudios foucaultianos en el campo académico de la Educación Física en Brasil y en la Argentina. Revista Brasileira de Educação Física e Esporte, 28 (3), 453-467.

Pineau, P., Dussel, I. y Caruso, M. (2001). La escuela como máquina de educar. Buenos Aires, Argentina: Paidós.

Prati, M. (2003). El impacto del Programa de Incentivos a partir de las percepciones de los académicos (Tesis de grado). Universidad Nacional de La Plata. Facultad de Humanidades y Ciencias de la Educación, La Plata, Argentina.

Prati, M. (2011). De cómo hacer política universitaria en la Argentina: enseñanzas a partir de la implementación del Programa de Incentivos (Tesis de doctorado inédita). FLACSO, Buenos Aires, Argentina.

Pucci, R. (2013). Pasado y presente de la Universidad de Tucumán. Argentina: Lumiere Ediciones.

Puiggrós, A. (1990). Sujetos, disciplina y curriculum en los orígenes de sistema educativo argentino (1885-1916). Buenos Aires, Argentina: Galerna.

Puiggrós, A. (1995). Volver a educar. Buenos Aires, Argentina: Ariel.

Puiggrós, A. (2002). Que pasó en la Educación Argentina. Breve historia desde la Conquista hasta el Presente. Buenos Aires, Argentina: Galerna.

Puiggrós, A. y Krotsch, P. (Comp.) (1994). Universidad y Evaluación. Estado del debate. Buenos Aires, Argentina: Aique Grupo Editor.

Reitano, E. (2009). Enrique Barba y el orbe colonial rioplatense. Balances y proyecciones. Anuario del Instituto de Historia Argentina, 9, 215-227.

Remedi Allione, E. (2004). "La institución: un entrecruzamiento de textos". En Remedi Allione, E. (coord.) Instituciones educativas. Sujetos, historia e identidades (pp. 25-55). México: Plaza y Valdés editores.

Remedi Allione, E. (2006). "Calidad y sufrimiento en la búsqueda desbocada de la excelencia". En Landesmann, M. (coord.) Instituciones educativas. Instituyendo disciplinas e identidades (pp. 61-88). Casa Juan Pablos, Centro Cultural, Coyoacán, México, D.F.

Remedi Allione, E. (2013). "Conferencia central". En Paso, M., Elías, M. E. y Hernando, G. (comp.) Debates en Pedagogía. Teoría, formación e intervención. Tomo I (pp. 39-69). La Plata, Argentina: EDULP.

Revel, J. (2005). Un momento historiográfico. Trece ensayos de historia social. Buenos Aires, Argentina: Manantial.

Rocha Bidegain, A. L. (2012). El aprendizaje motor: Una investigación desde las prácticas (Tesis de Maestría). Universidad Nacional de La Plata. Facultad de Humanidades y Ciencias de la Educación, Ensenada, Argentina. 
Rocha Pinto, P. G. (2000). Saber ver: recursos visuais e formaçao médica. Phycis. Revista Saúde Coletiva. Rio de Janeiro.

Rocha Pinto, P. G. (2009). Açao afirmativa, identidades e práticas acadêmicas: uma etnografía das cotas para negros na UERJ. Recuperado el 20 de marzo de 2016, de: http://w3.ufsm.br/afirme/ARTIGOS/ensinosuperior/es03.pdf

Rockwell, E. (2009). La experiencia etnográfica: historia y cultura en los procesos educativos. Buenos Aires, Argentina: Paidós.

Rodríguez, L. (2014). La universidad durante el tercer gobierno peronista (1973-1976). Conflicto Social, vol. 7, $114-145$.

Rodríguez, L. (2015). La Universidad Nacional de La Plata entre 1973 y 1983. PolHis, Año 7 - número 14, 258-279.

Romero Brest, E. (1917). El ISEF. Antecedentes, organización, resultados. Buenos Aires, Argentina: Cabaut y cía. Editores.

Ron, O. (2003). "El campo de la Educación Física: constitución, saber, rasgos". En Crisorio, R. y Bracht, V. (coord.), La Educación Física en Argentina y en Brasil. Identidad, desafíos y perspectivas (pp. 59-73). La Plata, Argentina: Ed. Al Margen.

Ron, O. y Levoratti, A. (coord.) (2015). Diálogos con Alejandro J. Amavet: A propósito de la Educación Física Renovada. Facultad de Humanidades y Ciencias de la Educación, UNLP. Ensenada, Argentina. Recuperado el 12 de septiembre de 2017, de:

http://www.memoria.fahce.unlp.edu.ar/libros/pm.435/pm.435.pdf

Saraví, J. (2012). La Praxiología Motriz: presente, pasado y futuro. Entrevista a Pierre Parlebas. Revista Movimento, v. 18, n. 01, 11-35.

Saraví Riviere, J. (2012). Historia de la Educación Física Argentina. Buenos Aires, Argentina: Libros del Zorzal.

Scharagrodsky, P. (2006). "El padre de la Educación Física Argentina: fabricando una política corporal generizada (1901-1938)". En Aisenstein A. y Scharagrodsky, P. Tras las huellas de la Educación Física escolar argentina. Cuerpo, género y pedagogía: 1880-1950 (pp. 159-197). Buenos Aires, Argentina: Prometeo.

Scharagrodsky, P. (2011). "La constitución de la educación física escolar en la Argentina: tensiones, conflictos y disputas con la matriz militar en las primeras décadas del siglo XX". En La invención del Homo Gymnasticus. Fragmentos históricos sobre la educación de los cuerpos en movimiento en Occidente (pp. 441-477). Buenos Aires, Argentina: Editorial Prometeo.

Sheldon, W. (1972) Las variedades del temperamento. Buenos Aires, Argentina: Paidós.

Silber, J., García Clúa N. y Fava, M. (2011). "La antesala de la dictadura. Quiebres con el pasado y continuidades con el régimen militar en el Departamento de Ciencias de la Educación". En Silber, J. y Paso, M. (comps.), Universidad y formación docente. Políticas, tendencias y prácticas en la Carrera de Ciencias de la Educación y en otros profesorados (1960-1990) (pp. 47-74). La Plata, Argentina: EDULP.

Soprano, G. (2011). "Clientelismo y facciones. Del estudio de la política en el peronismo al conocimiento de las formas de sociabilidad universitaria. Potencialidades y limitaciones de conceptos clásicos". En Pérez, G. J., Aelo, O. y Salerno, G. Todo 
aquel fulgor: la política argentina después del neoliberalismo (pp. 309-326). Buenos Aires, Argentina: Nueva Trilce.

Stake, R. (1995). Investigación con estudios de caso. Madrid: Ediciones Morata.

Suasnábar, C. (1999). "Las "agendas" de la globalización para la educación superior en América Latina. Una revisión crítica de las propuestas de los organismos internacionales y otros actores académicos". En Tiramonti, G., Suasnábar, C. y Seoane, V. Políticas de modernización universitaria y cambio institucional (pp. 3146). Universidad Nacional de La Plata, Facultad de Humanidades y Ciencias de la Educación. La Plata, Argentina. (Serie Estudios e Investigaciones: № 38).

Suasnábar, C. y Rovelli, L. (2011). Políticas universitarias en Argentina: entre los legados modernizadores y la búsqueda de una nueva agenda. Revista Innovación Educativa, vol. 11 núm. 57, 21-30.

Talamonti Calzetta, P. (2008). La lucha contra la Ley de Educación Superior en la UNLP 1994-1996. Trabajo presentado en las $V$ Jornadas de Sociología de la UNLP. Departamento de Sociología. Facultad de Humanidades y Ciencias de la Educación. Universidad Nacional de La Plata. La Plata, Argentina.

Tedesco, J. C., Braslavsky, C. y Carciofi, R. (1983). El proyecto educativo autoritario. Argentina 1976 - 1982. Buenos Aires, Argentina: FLACSO.

Tiramonti, G. (2001). Modernización educativa de los '90 ¿El fin de la ilusión emancipadora? Buenos Aires, Argentina: FLACSO - Temas Grupo Editorial.

Trotta, L. (2016). Estudiantes y política de acreditación: una mirada desde lo local: el caso de la Facultad de Ciencias Médicas de la UNLP 2001- 2010 (Tesis de Maestría). FLACSO, Buenos Aires, Argentina.

Vallina, J. y Rodríguez, N. (2015). Debates curriculares actuales. La educación física en cuestión. Trabajo presentado en el $11^{\circ}$ Congreso Argentino de Educación Física y Ciencias. Departamento de Educación Física. Facultad de Humanidades y Ciencias de la Educación. Universidad Nacional de La Plata. Ensenada, Argentina.

Vignoli, M. y Cardozo, D. (2013). La Sociedad Sarmiento, el Instituto de Estudios Históricos y los orígenes de la profesionalización de la historia en Tucumán en los años 1930. Prohistoria, Año XVI, núm. 19, 97-117.

Villa, A. (2003). Lógicas y discursos en la formación docente. El caso del Profesorado universitario en Educación Física (Tesis de Maestría). Universidad Academia de Humanismo Cristiano, Santiago, Chile.

Villa, A. (2007). La conformación de la profesionalidad de la Educación Física desde la formación de profesores universitarios. Revista Brasileira de História da Educacao. SBHE. CNPq, Autores Associados. V. 7, n. 2 [14], 117-144.

Villa, A. (2011). Currículum, Educación Física y formación del profesorado. El caso del Profesorado de Educación Física de la Universidad Nacional de La Plata, Argentina. Ágora para la EF y el Deporte, № 13 (3), 321-340.

Visciglia, B. S. (2016). La manifiesta presencia del discurso amavetiano en la educación del cuerpo (Tesis de Maestría). Universidad Nacional de La Plata. Facultad de Humanidades y Ciencias de la Educación, Ensenada, Argentina.

Yin, R. (1989). Case Study Research. Design and Methods. London: SAGE. 


\section{ANEXOS}

\section{Fuentes consultadas}

Ley de Educación Superior $N^{\circ}$ 24.521. Sancionada el 20 de julio de 1995. Promulgada el 7 de agosto de 1995 (Decreto 268/95). Publicada el 10 de agosto de 1995, Boletín Oficial $n^{\circ} 28204$.

Universidad Nacional de La Plata (UNLP) (1953). Acta Fundacional de la Carrera de Educación Física. La Plata.

Universidad Nacional de La Plata. Estatuto Universitario 1996. Disponible en: http://www.unlp.edu.ar/uploads/docs/estatuto universitario con diseno.pdf, último acceso 15/12/16.

Facultad de Humanidades y Ciencias de la Educación, FaHCE-UNLP (1995). Memoria de Gestión (1992-1995). La Plata.

Facultad de Humanidades y Ciencias de la Educación, FaHCE-UNLP (1993). Evaluación Ingreso 1993 a la FaHCE de la UNLP y Proyecto Ingreso 1994. Presentado al Honorable Consejo Académico el día 4 de noviembre de 1993. La Plata, Mimeo.

Facultad de Humanidades y Ciencias de la Educación, FaHCE-UNLP (2017). Dirección de Enseñanza. La Plata.

Departamento de Educación Física, Facultad de Humanidades y Ciencias de la Educación, Universidad Nacional de La Plata. Planes de estudios de la Carrera de Profesorado en Educación Física 1953, 1964, 1970, 1974, 1982, 1984 y del Profesorado y Licenciatura en Educación Física 2000.

Departamento de Educación Física, Facultad de Humanidades y Ciencias de la Educación, Universidad Nacional de La Plata. Diagnóstico Plan de estudios de la Carrera de Profesorado y Licenciatura en Educación Física. 2000. Ensenada, 09 de diciembre de 2015.2 Recuperado de: http://www.fahce.unlp.edu.ar/academica/areas/educacion-fisica/noticias/comisioncurricular-del-def-diagnostico-plan-de-estudios-2000-reunion-ampliada, el 10-0217.

Departamento de Educación Física, Facultad de Humanidades y Ciencias de la Educación, Universidad Nacional de La Plata. Programas de la cátedra Introducción a la Educación Física de 1984, 1985 y 1986 (mimeo).

Departamento de Educación Física, Facultad de Humanidades y Ciencias de la Educación, Universidad Nacional de La Plata. Actas del $1^{\circ}$ Congreso Argentino de Educación Física y Ciencias.

Departamento de Educación Física, Facultad de Humanidades y Ciencias de la Educación, Universidad Nacional de La Plata. Actas del $2^{\circ}$ Congreso Argentino de Educación Física y Ciencias.

Departamento de Educación Física, Facultad de Humanidades y Ciencias de la Educación, Universidad Nacional de La Plata. Revista Educación Física \& Ciencia. Volúmenes I, II, III, IV, V, VI de los años 1995, 1996, 1997, 1998, 2001, 2002/2003. 
Departamento de Educación Física, Facultad de Humanidades y Ciencias de la Educación, Universidad Nacional de La Plata. Propuesta curricular del Ciclo extraordinario de Licenciatura en Educación Física. La Plata. http://www.fahce.unlp.edu.ar/academica/areas/educacion-fisica/carreras/cicloextraordinario-de-licenciatura-en-educacion-fisica, último acceso el 10/02/2017.

De Diego, José Luis (2003) Discurso pronunciado con motivo de celebrarse los 50 años del Departamento de Educación Física. Facultad de Humanidades y Ciencias de la Educación. Universidad Nacional de La Plata. 2003 (mimeo).

Obiols, Guillermo (1997) La Reforma curricular en la Facultad de Humanidades y Ciencias de la Educación. Un diagnóstico y una propuesta. Facultad de Humanidades y Ciencias de la Educación. Universidad Nacional de La Plata.

Archivo de Resoluciones de la Facultad de Humanidades y Ciencias de la Educación. Mesa de Entradas. Libros correspondientes al período Febrero 1992 - Diciembre de 2004.

Archivo del Consejo Académico de la Facultad de Humanidades y Ciencias de la Educación. Actas del período Febrero 1992- Diciembre de 2004.

Archivo de Legajos de Profesores de la Facultad de Humanidades y Ciencias de la Educación. Departamento de Personal.

Curriculum Vitae de docentes entrevistados.

Sitios web:

Portal de la Universidad Nacional de La Plata. Disponible en: https://unlp.edu.ar/

Portal de la Facultad de Humanidades y Ciencias de la Educación, FaHCE. Disponible en: http://www.fahce.unlp.edu.ar/

Memoria Académica. Repositorio institucional de la FaHCE. Disponible en: http://www.memoria.fahce.unlp.edu.ar/ 


\section{Fuentes producidas}

Tabla 2

Los profesores que participaron en políticas académicas de EF entre los años 1992 y 2004.

\begin{tabular}{|l|l|l|l|l|l|}
\hline $\begin{array}{l}\text { Cohorte } \\
\text { de estudio }\end{array}$ & $\begin{array}{l}\text { Año de } \\
\text { graduación }\end{array}$ & Nombre & $\begin{array}{l}\text { Año } \\
\text { nacimiento }\end{array}$ & $\begin{array}{l}\text { Año de ingreso a } \\
\text { la FaHCE }\end{array}$ & $\begin{array}{l}\text { Viajó a Chile a } \\
\text { realizar } \\
\text { posgrado }\end{array}$ \\
\hline 1968 & 1973 & Carlos Parenti & 1948 & $\begin{array}{l}1973 \\
1984^{185}\end{array}$ & NO \\
\hline 1976 & 1979 & $\begin{array}{l}\text { Ricardo } \\
\text { Crisorio }\end{array}$ & 1952 & 1984 & SI \\
\hline 1981 & 1984 & Carlos Carballo & 1963 & 1985 & SI \\
\hline 1981 & 1984 & Marcelo Giles & 1962 & 1985 & SI \\
\hline 1984 & 1988 & Osvaldo Ron & 1963 & 1988 & SI \\
\hline
\end{tabular}

Fuente: Elaboración propia a partir de legajos de la Oficina de Personal y del Archivo de Resoluciones de la FaHCE $^{186}$

\footnotetext{
${ }^{185}$ Carlos Parenti posee dos fechas de ingreso a la docencia en la Facultad, dado que ingresó durante el tercer gobierno peronista (Res. 58/73, Res. 59/73) y fue "invitado a renunciar" el 01 de agosto de 1974 (Res. de renuncia $\mathrm{N}^{\circ}$ 625/74). Su cese se da en el marco de una creciente conflictividad social, días después de la muerte del entonces presidente Juan Domingo Perón y de una escalada de violencia institucional que en la universidad se desatará fuertemente con la "Misión Ivanissevich", en alusión al Ministro de Educación que asume el 14 de agosto de 1974, en reemplazo de Jorge Taiana, y se mantiene un año en el cargo (Buchbinder, 2005; Rodríguez, 2015). Su segundo ingreso se produce a comienzos del año 1984, ya con el retorno democrático como Director "normalizador" del DEF y Profesor Titular (Res. 39/84, 151/84, 257/84, $547 / 84)$.

${ }^{186}$ Resoluciones de ingreso a la FaHCE de los docentes en orden de aparición: Res. 58/73, Res. 59/73, Res. 641/84, Res. 494/85, Res. 494/85, Res. 362/88, Res. 830/88.
} 
Tabla 3

Funciones que desempeñaron en docencia entre los años 1992 y 2004, situación actual, dedicación, categoría de investigación ${ }^{187}$.

\begin{tabular}{|c|c|c|c|c|c|c|c|c|}
\hline 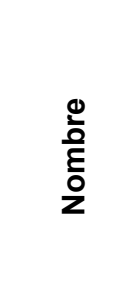 & 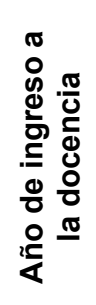 & 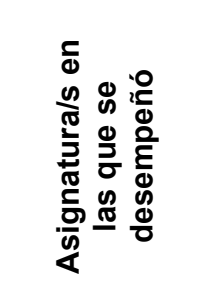 & 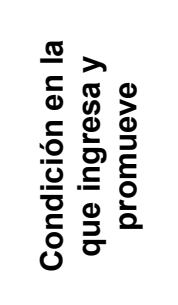 & 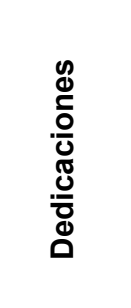 & 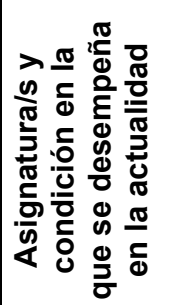 & 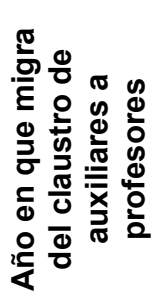 & 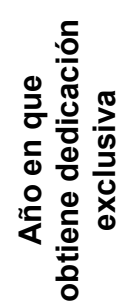 & 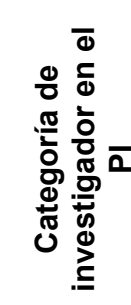 \\
\hline $\begin{array}{l}\text { Carlos } \\
\text { Parenti }\end{array}$ & $\begin{array}{l}1973, \\
1984\end{array}$ & $\begin{array}{l}\text { Seminario de } \\
\text { Investigación } \\
\text { en EF (4to. } \\
\text { Año), Teoría } \\
\text { especial de la } \\
\text { gimnástica } \\
\text { (3er. Año), } \\
\text { Didáctica } \\
\text { Especial y } \\
\text { Prácticas de } \\
\text { la enseñanza } \\
\text { en EF (4to. } \\
\text { Año), Teoría } \\
\text { de la EF III } \\
\text { (3er. Año). }{ }^{188}\end{array}$ & $\begin{array}{l}\text { Profesor } \\
\text { Titular }\end{array}$ & $\begin{array}{l}\text { Simple } \\
(1973), \\
\text { Semi- } \\
\text { exclusiv } \\
\text { a } \\
\text { (1984), } \\
\text { Exclusiv } \\
\text { a } \\
\text { (2005). }\end{array}$ & $\begin{array}{l}\text { Profesor } \\
\text { Titular en } \\
\text { Teoría de la } \\
\text { Educación } \\
\text { Física III } \\
\text { (dedicación } \\
\text { exclusiva, } \\
\text { jubilado a } \\
\text { mayo de } \\
2016 \text { ) }\end{array}$ & $\begin{array}{l}1973 / 198 \\
4\end{array}$ & 2005 & III \\
\hline $\begin{array}{l}\text { Ricardo } \\
\text { Crisorio }\end{array}$ & 1984 & $\begin{array}{l}\text { Gimnástica I } \\
\text { (1er. Año), } \\
\text { Curso de } \\
\text { Nivelación, } \\
\text { Didáctica } \\
\text { especial y } \\
\text { práctica de la } \\
\text { enseñanza en } \\
\text { EF (4to. año), } \\
\text { Curso de } \\
\text { Ingreso, } \\
\text { Educación } \\
\text { Física V (5to. } \\
\text { Año). }{ }^{189}\end{array}$ & $\begin{array}{l}\text { Ayudante } \\
\text { diplomado } \\
\text { interino ad- } \\
\text { honorem, } \\
\text { Profesor } \\
\text { Adjunto } \\
\text { interino, } \\
\text { Profesor } \\
\text { Adjunto } \\
\text { Ordinario, } \\
\text { Profesor } \\
\text { Titular } \\
\text { Ordinario. }\end{array}$ & $\begin{array}{l}\text { Simple } \\
\text { (1985), } \\
\text { Semi- } \\
\text { Exclusiv } \\
\text { a } \\
\text { (1988), } \\
\text { Exclusiv } \\
\text { a } \\
\text { (1994). }\end{array}$ & $\begin{array}{l}\text { Profesor } \\
\text { Titular en } \\
\text { Educación } \\
\text { Física V } \\
\text { (dedicación } \\
\text { exclusiva) }\end{array}$ & 1985 & 1994 & II \\
\hline
\end{tabular}

${ }^{187}$ Los datos de situación actual, dedicación y categoría de investigación corresponden a julio de 2017.

188 Res. 58/73, Res. 59/73, Res. 625/74, Res. 151/84, Res. 257/84, Res. 547/84 (a través de esta resolución del 15/10/84, Parenti obtiene por primera vez semi-dedicación en un cargo docente interino en la asignatura "Didáctica Especial y Práctica de la Enseñanza en EF" aunque por un período breve, dado que reemplazaba al Prof. Rossotti), Res. 21/85 (con esta resolución del 07/03/85, Parenti obtiene semi-dedicación en igual asignatura, ya no como suplente aunque todavía interino, y sin fecha de finalización, desde el 01/03/85), Res. 159/86 (con fecha 14/03/86 Parenti es limitado en su cargo interino en la materia mencionada, al ser designada en forma ordinaria la Prof. Gayol), Res. 160/86 (con fecha 19/03/86, Parenti obtiene su primer cargo ordinario en la asignatura "Teoría Especial de la Gimnástica" a partir del 15/03/86, con dedicación semi-exclusiva), Res. 550/89 (se limita la designación semi-exclusiva anteriormente citada a partir del 30/06/89 por ser designado a partir del 01 de julio de ese año, Director del DEF con dedicación semi-exclusiva), Res. 550/93 (con fecha 06/08/93, Parenti accede por concurso al cargo de Profesor Titular Ordinario de "Teoría Especial de la Gimnástica" por un período de 7 años), Res. 595/93 (con fecha 24/08/93, se le asigna dedicación semi-exclusiva en el cargo anterior sin fecha de finalización), Res. 726/01 (Prórroga del cargo ordinario anteriormente citado, dedicación simple), Res. 643/05 (con fecha 05/09/05 se le asigna dedicación exclusiva en su cargo de Profesor Titular Ordinario en la asignatura "Teoría de la Educación Física III" -ex Teoría Especial de la Gimnástica en la que se venía desempeñando- a partir del 01/09 del mismo año y sin fecha de finalización), Res. 16/09 (del 13/02/09 en la que accede nuevamente al cargo de Profesor Titular Ordinario en "Teoría de la Educación Física III" y se le mantiene su dedicación exclusiva), Res. 539/16 (renuncia para jubilación con fecha 20/04/16, a partir del 01/04/16)

${ }^{189}$ Crisorio ingresó a la docencia en la FaHCE como Ayudante Diplomado Ad-Honorem en Gimnástica I (Res. 641/84, de reconocimiento de los servicios prestados entre el 01/04/84 y el 31/12/84 en dicho cargo), Res. 15/86 (Con esta resolución 


\begin{tabular}{|c|c|c|c|c|c|c|c|c|}
\hline $\begin{array}{l}\text { 0) } \\
\text { ํㅡㄹ } \\
\text { Z }\end{array}$ & 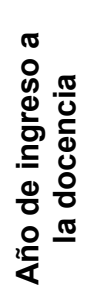 & 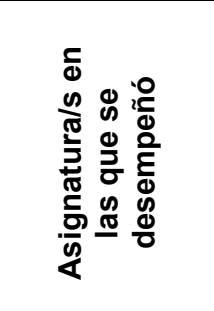 & 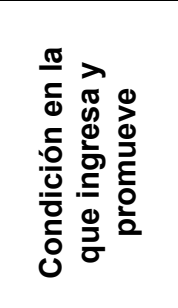 & 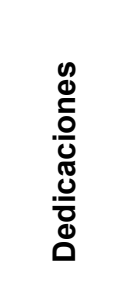 & 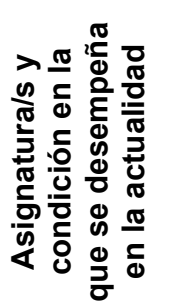 & 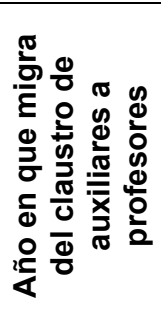 & 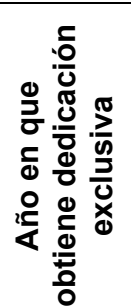 & 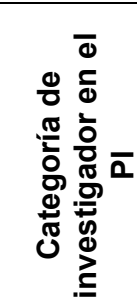 \\
\hline $\begin{array}{l}\text { Carlos } \\
\text { Carballo }\end{array}$ & 1985 & $\begin{array}{l}\text { Introducción a } \\
\text { la EF (1er. } \\
\text { Año), Curso } \\
\text { de Nivelación, } \\
\text { Teoría de la } \\
\text { EF I (1er. } \\
\text { año) y Teoría } \\
\text { de la EF II } \\
\text { (2do. año). }{ }^{190}\end{array}$ & $\begin{array}{l}\text { Ayudante } \\
\text { diplomado } \\
\text { ad- } \\
\text { honorem, } \\
\text { Ayudante } \\
\text { diplomado } \\
\text { interino, } \\
\text { Jefe de } \\
\text { trabajos } \\
\text { prácticos } \\
\text { interino, } \\
\text { Profesor } \\
\text { Adjunto } \\
\text { interino, } \\
\text { Profesor } \\
\text { Adjunto } \\
\text { Ordinario, } \\
\text { Profesor } \\
\text { Titular } \\
\text { interino, } \\
\text { Profesor } \\
\text { Titular } \\
\text { Ordinario. }\end{array}$ & $\begin{array}{l}\text { Simple } \\
\text { (1986), } \\
\text { Semi- } \\
\text { Exclusiv } \\
\text { a } \\
\text { (1992), } \\
\text { Exclusiv } \\
\text { a } \\
\text { (1998). }\end{array}$ & $\begin{array}{l}\text { Profesor } \\
\text { titular en } \\
\text { Teoría de la } \\
\text { EF II } \\
\text { (dedicación } \\
\text { exclusiva) }\end{array}$ & 1989 & $1998^{191}$ & II \\
\hline
\end{tabular}

del 02/01/1986 se le prorroga el cargo interino con dedicación simple hasta el 31/03/1986, luego vendrían una serie de resoluciones varias en las que se le prorroga -junto a otros docentes- igual cargo. El "cambio de claustro" de auxiliares a profesores fue anterior a esta fecha y, aunque no contamos con la resolución por la que accede al cargo de Profesor Adjunto en Gimnástica I por primera vez, en una certificación laboral emitida por la Facultad presente en su legajo, su ingreso como Profesor Adjunto data del 01/04/1985), Res. 145/88, Res. 206/88 (con fecha 01/04/1988, accede por primera vez a una dedicación semi-exclusiva en el cargo mencionado anteriormente), Res. 236/88, Res. 181/89, Res. 23/90, Res. 213/90, Res. 769/90 (con fecha 26/12/1990, accede por concurso al cargo de Profesor Titular en la asignatura mencionada a partir del 01/03/1991 y por el término de 7 años según lo establecido en el Artículo №21 del Estatuto de la UNLP vigente en aquel momento), Res. 55/91, Res. 108/91, Res. 453/91, Res. 31/92, Res. 40/92, Res. 143/94 (Renuncia a su cargo de Profesor Adjunto Ordinario en Didáctica Especial y Práctica de la Enseñanza en EF), Res. 726/01, Prov. 210 (Providencia con fecha 28/11/2002, en la que el Decano dispone su "pase" de funciones como Profesor Titular Ordinario en Educación Física I a Educación Física V, a partir del 01/02/2003, asignatura en la que se desempeña hasta la fecha), Res. 620/04 (Con fecha 27/08/2004, concursa y gana el cargo mencionado anteriormente), Res. 988/04 (con fecha exacta ilegible de diciembre de 2004, toma posesión de ese cargo, a partir del 30/11/04 y por 7 años). Cabe destacar que a través de la Resolución 919/94, accede por primera vez a una dedicación exclusiva en el marco del Programa de Incentivos, por medio de un proyecto de extensión de dedicaciones de la UNLP denominado GRANT (Macario, 2007).

${ }^{190}$ Carballo ingresó a la docencia en la FaHCE como Ayudante Diplomado Ad-Honorem en Introducción a la Educación Física (Res. 494/85, de reconocimiento de los servicios prestados entre el 01/04/85 y el 31/07/85 en dicho cargo), Res. 543/86 (es designado Ayudante diplomado interino en Introducción a la Educación Física a partir del 01/08/86), Res. 151/87 (es designado Jefe de Trabajos Prácticos Interino en igual asignatura a partir del 15/04/87, cargo en el que se desempeña mediante distintas resoluciones de prórroga hasta el 31/12/89), Res. 361/89 (accede por primera vez a un cargo de Profesor Adjunto interino en igual asignatura a partir del $1^{\circ}$ de mayo de 1989), Res. 392/89 (Renuncia al cargo de JTP por haber sido designado Profesor Adjunto), Res. 23/02 (Profesor Adjunto dedicación Simple en Curso de Nivelación 1990), Res. 697/02 (con fecha 07/10/2002, se lo designa como Profesor Titular Interino con dedicación exclusiva en Teoría de la Educación Física II con extensión de funciones en Teoría de la Educación Física I, a partir del 01/09/2002), Res. 925/03 (Io ponen en funciones en su cargo obtenido por concurso -Res. 773/03- como Profesor Titular Ordinario en Teoría de la Educación Física II, a partir del 01/12/2003 y por el término de 7 años, manteniéndole su dedicación exclusiva).

${ }^{191}$ Información extraída de su CV, en donde indica haber obtenido dedicación exclusiva en su cargo de Profesor Adjunto de la asignatura Introducción a la EF desde mayo del año 1998 a julio del 2000 y luego, de agosto del 2000 a septiembre de 2002, en Teoría de la EF I, y de enero de 2001 a septiembre de 2002 en Teoría de la EF II, siempre como Profesor Adjunto. Formalmente, como dijimos, contamos con el acto resolutivo Res. 697/02 por el que se le otorga dedicación exclusiva en su cargo de Profesor Titular interino en Teoría de la EF II con extensión de funciones en Teoría de la Educación Física I, a partir del 01/09/2002. Luego, en octubre de 2003, concursa como Profesor Titular Ordinario en Teoría de la Educación Física II, manteniéndole la dedicación exclusiva desde el 01/12/2003, cargo que conserva hasta la fecha. 


\begin{tabular}{|c|c|c|c|c|c|c|c|c|}
\hline $\begin{array}{l}\text { 0 } \\
\text { 름 } \\
\text { Z }\end{array}$ & 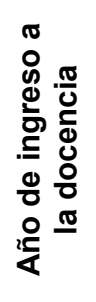 & 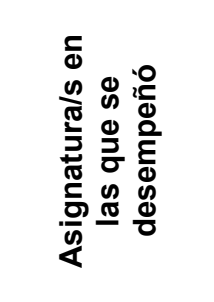 & 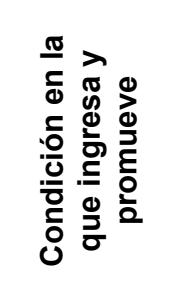 & 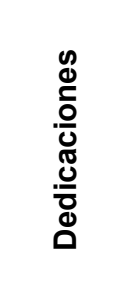 & 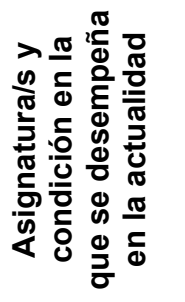 & 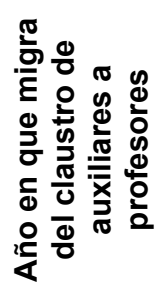 & 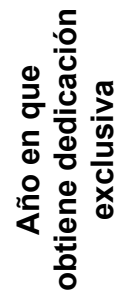 & 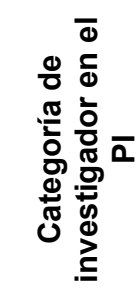 \\
\hline $\begin{array}{l}\text { Marcelo } \\
\text { Giles }\end{array}$ & 1985 & $\begin{array}{l}\text { Gimnástica I } \\
\text { (1er. año), } \\
\text { Gimnástica II } \\
\text { (2do. año), } \\
\text { Curso de } \\
\text { Nivelación, } \\
\text { Curso de } \\
\text { Ingreso, } \\
\text { Educación } \\
\text { Física II (2do. } \\
\text { año), } \\
\text { Educación } \\
\text { Física I (1er. } \\
\text { año). }\end{array}$ & 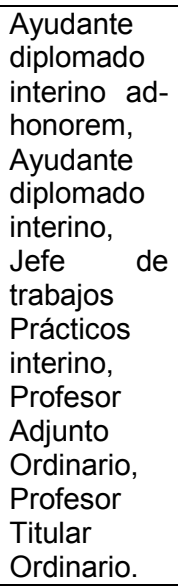 & $\begin{array}{l}\text { Simple } \\
\text { (1986), } \\
\text { Semi- } \\
\text { Exclusiv } \\
\text { a } \\
\text { (1993), } \\
\text { Exclusiv } \\
\text { a } \\
\text { (1998). }\end{array}$ & $\begin{array}{l}\text { Profesor } \\
\text { Titular en } \\
\text { Educación } \\
\text { Física I } \\
\text { (dedicación } \\
\text { exclusiva) }\end{array}$ & 1990 & $1998^{193}$ & II \\
\hline
\end{tabular}

\footnotetext{
192 Giles ingresó a la docencia en la FaHCE como Ayudante Diplomado Ad-Honorem en Gimnástica I (Res. 494/85 de reconocimiento de los servicios prestados entre el 01/04/85 y el 31/07/85 en dicho cargo), Res. 498/86 (se prorroga su cargo de Ayudante diplomado interino en igual cátedra del 01/08/1986 al 31/12/86), luego le son otorgadas otras prórrogas dado que no se sustanciaban los respectivos concursos, Res. 490/87 por la que accede a un cargo de JTP en Gimnástica II por el período 01/07/1987-31-12-1987, este último cargo lo desempeñó en las dos cátedras mencionadas y también le sería prorrogado por varias resoluciones, hasta que accede de forma ordinaria, por Res. 731/90 con fecha 26/12/1990, a un cargo de Profesor Adjunto en Gimnástica I por un período de 7 años a partir del 01/02/1991. También accede a mismo cargo de forma interina en Gimnástica II por Res. 326/91 a partir del 01/06/1991, por ascenso del Profesor que ocupaba ese cargo a Profesor Titular. Se desempeñó también en numerosas oportunidades en el Curso de Nivelación en cargos de JTP y Profesor, tal como lo indican las Res. 23/90, Res. 31/92 y Res. 58/93. Por Res. 593/93 con fecha 26/08/93 obtiene por primera vez dedicación semi-exclusiva en su cargo de Profesor Adjunto Ordinario en Gimnástica I. Por Res. 699/94 del día 26/09/1994, se lo designa de forma interina como Profesor Adjunto en Gimnástica II a partir del 01/03/1994. Si bien la Res. 365/96 da cuenta de un pedido favorable de licencia con goce de sueldo para estudios, evidencia que también le fue extendida su dedicación simple como Profesor Adjunto en Gimnástica II a semi-exclusiva por medio del Proyecto de extensión de dedicaciones vinculado al Programa de Incentivos (GRANT). Es decir que Giles, tenía, para agosto de 1996, dos cargos de Profesor Adjunto con dedicación semi-exclusiva en Gimnástica I y II, y un cargo de Profesor Adjunto con dedicación simple con funciones como secretario del Departamento de EF. No contamos con resoluciones que den cuenta de su trayectoria entre los años 1996 y 2008, momento en el cual le prorrogan un cargo de Profesor Adjunto Ordinario en Educación Física II (ex Gimnástica II), por un período de 7 años entre julio de 2008 y julio de 2015 (Res. 785/08). Actualmente se desempeña como Profesor Titular en Educación Física I (Página web, FaHCE, última consulta: 30/10/2017).

193 Información brindada por el mismo docente en la entrevista del 17 de diciembre de 2015 en La Plata, aunque no contamos con el acto resolutivo formal.
} 


\begin{tabular}{|c|c|c|c|c|c|c|c|c|}
\hline $\begin{array}{l}\text { 0. } \\
\text { है } \\
\text { ¿ }\end{array}$ & 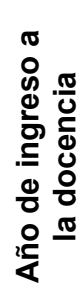 & 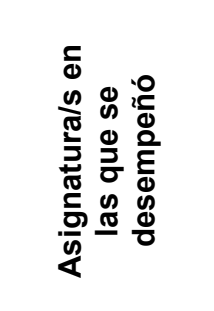 & 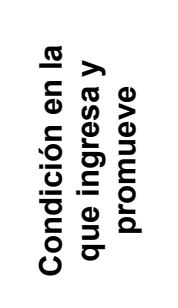 & 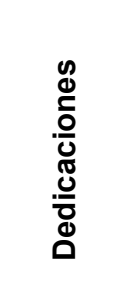 & 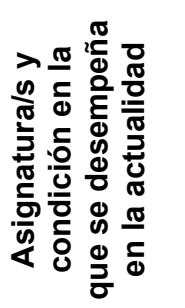 & 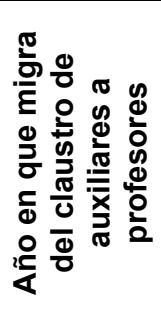 & 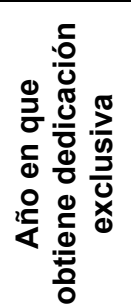 & 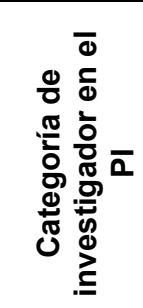 \\
\hline $\begin{array}{l}\text { Osvaldo } \\
\text { Ron }\end{array}$ & 1988 & $\begin{array}{l}\text { Gimnástica I } \\
\text { (1er. año), } \\
\text { Gimnástica II } \\
\text { (2do. año), } \\
\text { Gimnástica III } \\
\text { (3er. año), } \\
\text { Curso } \\
\text { Introductorio, } \\
\text { Educación } \\
\text { Física I (1er. } \\
\text { año), } \\
\text { Educación } \\
\text { Física II (2do. } \\
\text { año). }{ }^{194}\end{array}$ & $\begin{array}{l}\text { Ayudante } \\
\text { alumno ad- } \\
\text { honorem, } \\
\text { Ayudante } \\
\text { diplomado } \\
\text { ad- } \\
\text { honorem, } \\
\text { Ayudante } \\
\text { diplomado } \\
\text { interino, } \\
\text { Jefe de } \\
\text { trabajos } \\
\text { Prácticos } \\
\text { interino, } \\
\text { Jefe de } \\
\text { Trabajos } \\
\text { Prácticos } \\
\text { Ordinario, } \\
\text { Profesor } \\
\text { Adjunto } \\
\text { interino, } \\
\text { Profesor } \\
\text { Adjunto } \\
\text { Ordinario, } \\
\text { Profesor } \\
\text { Titular } \\
\text { Ordinario. }\end{array}$ & $\begin{array}{l}\text { Simple } \\
\text { (1988), } \\
\text { Semi- } \\
\text { Exclusiv } \\
\text { a } \\
\text { (1994), } \\
\text { Exclusiv } \\
\text { a } \\
\text { (1998). }\end{array}$ & $\begin{array}{l}\text { Profesor } \\
\text { Titular en } \\
\text { Educación } \\
\text { Física II } \\
\text { (dedicación } \\
\text { exclusiva) }\end{array}$ & 2000 & 1998 & III \\
\hline
\end{tabular}

Fuente: Elaboración propia a partir de los Legajos de Profesores de la Oficina de Personal, el Archivo de Resoluciones, página web de la FaHCE y CV y entrevistas a los Profesores.

194 Ron ingresó a la docencia en la FaHCE como Ayudante Alumno Ad-Honorem en la cátedra Gimnástica I, Eje Recreación (Res. 362/88) a partir del 01/05/1988 y hasta el 31/12/1988. Por medio de la Res. 830 de igual año, accede al cargo de Ayudante Diplomado interino para el período 01/10/1988-31/12/1988, en reemplazo del Prof. Marcos Pastorini en uso de licencia. Por Res. 957 del 29/12/1988, se lo designa como Ayudante Diplomado interino en igual cátedra, desde el 01/01/1989 al 31/12/1989, prorrogado por Res. 1001/89 hasta el 31/12/1990, y luego por Res. 771/90 hasta el 31/03/1992. Comparte la actividad docente con otro cargo de Ayudante Diplomado Ad-Honorem en Gimnástica III a partir del 01/06/1988 y el 31/12/1988 (Res. 482/88). Este cargo se le prorroga hasta el 31/12/1989 por Res. 894/89. Luego, por selección docente, accede nuevamente en igual cargo y condición a esta materia, Eje Rugby, entre el 01/10/1990 y el 31/03/1991 (Res. 633/90). Por Res. 349/91 con fecha 08/07/1991 accede a un cargo de JTP en Gimnástica I a partir del 01/06/1991, dejando sin efecto las prórrogas anteriores al cargo de Ayudante. Por Res. 404/92, se lo designa como JTP interino en la cátedra Gimnástica II, a partir del 01/06/1992 y hasta el 31/03/1993, cargo que se le prorroga en numerosas oportunidades y que concursa el 18/06/98, tomando posesión del mismo a partir del 01/07/1998 y por el término de tres años, según el Art. 39 de Estatuto Universitario de 1996 (Res. 191/98). Se desempeñó en varias oportunidades en el Curso Introductorio en cargos de Profesor y Coordinador, como lo indican las Res. 51/98, Res. 61/99 y Res. 135/01. Si bien la Res. 385/97 da cuenta de un pedido favorable de licencia con goce de sueldo para estudios, evidencia que también le fue extendida su dedicación simple como JTP en Gimnástica II a semi-exclusiva por medio del Proyecto de extensión de dedicaciones vinculado al PI (GRANT). Es decir que Ron, tenía, para julio de 1997, tres cargos de JTP, dos con dedicación semi-exclusiva en Gimnástica I, II y Proyecto del PI, y uno simple con funciones en el DEF. Por Res. 727/98 accede a una dedicación exclusiva en su cargo de JTP en Gimnástica I y con funciones en el DEF. Mediante Res. 373/00, cambia de claustro de auxiliares a profesores, siendo designado Profesor Adjunto interino con dedicación exclusiva en igual cátedra, a partir del 01/06/2000. La Res. 512/01 con fecha 07/09/2001, lo pone en posesión del cargo de Profesor Adjunto Ordinario en Gimnástica II, a partir del 10/07/2001 y por el término de 7 años (Res. del concurso 669/00). Prov. 357 (Providencia con fecha 22/12/2004, en la que la Decana dispone su "pase" de funciones como Profesor Adjunto Ordinario en Gimnástica I a Educación Física II, a partir del 01/12/2004, asignatura en la que se desempeña hasta la fecha). Luego, por Res. 18/05, toma posesión de un cargo de Profesor Adjunto Ordinario en Educación Física I a partir del 21/12/2004 y por un período de 7 años (Res. de Concurso 815/04). El 13 de octubre de 2005, por Res. 774/05, ponen en funciones su cargo de Profesor Titular Ordinario con dedicación exclusiva en Educación Física II, asignatura en la que se mantiene hasta la fecha. 
Tabla 4

Funciones desempeñadas en el Departamento de $\mathrm{EF}^{195}$

\begin{tabular}{|l|l|l|l|}
\hline \multicolumn{1}{|c|}{$\begin{array}{c}\text { Año de } \\
\text { graduación }\end{array}$} & \multicolumn{1}{|c|}{ Nombre } & Funciones desempeñadas & \multicolumn{1}{c|}{ Período } \\
\hline 1973 & Carlos Parenti & $\begin{array}{l}\text { Director } \\
\text { Presidente de la Comisión } \\
\text { Curricular }\end{array}$ & $1984-1990$ \\
\hline 1979 & Ricardo Crisorio & $\begin{array}{l}\text { Director } \\
\text { Presidente de la Comisión } \\
\text { Curricular }\end{array}$ & $1992-1995 / 1995-1998$ \\
\hline 1984 & Marcelo Giles & $\begin{array}{l}\text { Secretario } \\
\text { Director } \\
\text { Presidente de la Comisión } \\
\text { Curricular }\end{array}$ & $1998-2001 / 2001-2004$ \\
\hline 1988 & Osvaldo Ron & $\begin{array}{l}\text { Secretario } \\
\text { Director } \\
\text { Presidente de la Comisión } \\
\text { Curricular }\end{array}$ & 2004-2010 \\
\hline 1984 & Carlos Carballo & $\begin{array}{l}\text { Director } \\
\text { Presidente de la Comisión } \\
\text { Curricular }\end{array}$ & 2010-2015 \\
\hline
\end{tabular}

Fuente: Elaboración propia a partir de los Legajos de Profesores de la Oficina de Personal y del Archivo de Resoluciones de la FaHCE ${ }^{196}$

${ }^{195}$ En función de darle continuidad a las fechas de los actores aludidos, las funciones desempeñadas en el DEF abarcan desde el año 1984 al 2015.

${ }^{196}$ Por orden de aparición: Res. 39/84, Res. 523/90, Res. 306/92, Res. 789/92, Res. 196/96, Res. 18/97, Res. 727/98, Res. 319/2004, Res. 381/2010. 
Tabla 5

Funciones desempeñadas en la Facultad de Humanidades (FaHCE) ${ }^{197}$

\begin{tabular}{|l|l|l|l|}
\hline \multicolumn{1}{|c|}{$\begin{array}{c}\text { Año de } \\
\text { graduación }\end{array}$} & \multicolumn{1}{|c|}{ Nombre } & Funciones desempeñadas & \multicolumn{1}{c|}{ Período } \\
\hline 1973 & Carlos Parenti & $\begin{array}{l}\text { Consejero Académico por el } \\
\text { Claustro de Profesores }\end{array}$ & $1998-2001$ \\
\hline 1979 & Ricardo Crisorio & $\begin{array}{l}\text { Vicedecano } \\
\text { Director de la Maestría en } \\
\text { Educación Corporal } \\
\text { Profesor de Posgrado }\end{array}$ & $\begin{array}{l}\text { 2001-2004, 2004-2007 } \\
\text { 200ntinúa }\end{array}$ \\
\hline 1984 & Carlos Carballo & $\begin{array}{l}\text { Consejero Académico por el } \\
\text { Claustro de Profesores } \\
\text { Secretario de Extensión }\end{array}$ & $1995-1998$ \\
\hline 1984 & Marcelo Giles & $\begin{array}{l}\text { Consejero Académico por el } \\
\text { Claustro de Profesores } \\
\text { Director de la Maestría en } \\
\text { Deporte }\end{array}$ & 2004 \\
\hline 1988 & Osvaldo Ron & $\begin{array}{l}\text { Consejero académico por el } \\
\text { Claustro de Graduados }\end{array}$ & 1994-1996 \\
\hline
\end{tabular}

Fuente: Elaboración propia a partir de los Legajos de Profesores de la Oficina de Personal, de la Página web de la FaHCE, del Archivo de Resoluciones y de las Actas de Consejo Académico de la FaHCE.

\footnotetext{
${ }^{197}$ Aquí, como en el caso de la tabla anterior, los años no siguen el período recortado para el estudio, sino la linealidad del tiempo en el espacio ocupado por los actores aludidos, que se posponen o exceden a dicho período.
} 
Tabla 6

Políticas académicas en EF para el período 1992-2004

\begin{tabular}{|c|c|c|c|c|}
\hline $\begin{array}{l}\text { Congreso } \\
\text { Argentino de } \\
\text { Educación } \\
\text { Física } \\
\text { Ciencia, } \quad 5 \\
\text { (cinco) } \\
\text { ediciones } \\
\text { (1993/1995/ } \\
\text { 1997/1999/ } \\
\text { 2001) }\end{array}$ & $\begin{array}{l}\text { Proyectos de } \\
\text { investigación } \\
\text { del período (21 } \\
\text { proyectos } \\
\text { acreditados en } \\
\text { el Programa de } \\
\text { Incentivos, } \\
\text { siendo } \\
\text { primero del año } \\
\text { 1994, y el último } \\
\text { extendido entre } \\
\text { los años } 2003 \text { y } \\
2005 \text { ) }\end{array}$ & \begin{tabular}{|ll} 
Revista & \\
Educación & \\
Física & y \\
Ciencia, & 6 \\
(seis) & \\
volúmenes & \\
editados en & el \\
período & \\
$(1995 / 1996 /$ & \\
1997/1998/ & \\
$2001 / 2002-$ & \\
$2003)$ &
\end{tabular} & \begin{tabular}{|l} 
Reforma \\
curricular del \\
año 1998, que \\
culminó con el \\
Plan de \\
Estudios 2000, \\
incorporando la \\
Licenciatura en \\
EF.
\end{tabular} & $\begin{array}{l}\text { Creación de } \\
\text { dos carreras } \\
\text { de posgrado } \\
\text { (Maestrías): } \\
\text { Maestría en } \\
\text { Educación } \\
\text { Corporal } \\
\text { (2001) } \\
\text { Maestría en } \\
\text { Deporte } \\
\text { (2004) }\end{array}$ \\
\hline 1993 & 1994 & 1995 & 1998 & $2001-$ \\
\hline
\end{tabular}

Fuente: Elaboración propia a partir de las Actas de Consejo Académico del período 1992-2004, Actas del Congreso Educación Física \& Ciencia, Números de la Revista Educación Física \& Ciencia y proyectos de investigación relevados en publicaciones y repositorio institucional Memoria Académica.

Tabla 7

Números editados de la Revista Educación Física \& Ciencia (Período 1995-2003)

Año 1, Número 0, Septiembre de 1995

\begin{tabular}{|c|c|c|c|c|c|c|c|c|}
\hline & $\begin{array}{c}\text { Nombre de } \\
\text { la } \\
\text { contribución }\end{array}$ & $\begin{array}{c}\text { Tipo de } \\
\text { contribución }\end{array}$ & Páginas & $\begin{array}{c}\text { Nombre } \\
\text { del/ de los } \\
\text { Autor/es }\end{array}$ & $\begin{array}{c}\text { Autor/es } \\
\text { local/es } \\
\text { (EF-FAHCE) }\end{array}$ & $\begin{array}{c}\text { Autor/es } \\
\text { local/es de } \\
\text { otras } \\
\text { disciplinas }\end{array}$ & $\begin{array}{c}\text { Autor/es } \\
\text { nacional/es }\end{array}$ & $\begin{array}{c}\text { Autor/es } \\
\text { extranjero/s }\end{array}$ \\
\hline 1. & $\begin{array}{l}\text { La formación } \\
\text { de las ideas } \\
\text { infantiles } \\
\text { sobre las } \\
\text { reglas del } \\
\text { fútbol: } \\
\text { algunos } \\
\text { problemas } \\
\text { cognitivos. }\end{array}$ & Artículo & 21 & $\begin{array}{l}\text { José Antonio } \\
\text { Castorina }\end{array}$ & & $\mathrm{x}$ & $x$ & \\
\hline 2. & $\begin{array}{l}\text { Entrevista al } \\
\text { Prof. Ricardo } \\
\text { Crisorio }\end{array}$ & Entrevista & 9 & $\begin{array}{l}\text { Pablo } \\
\text { Scharagrodsky }\end{array}$ & $x$ & & & \\
\hline
\end{tabular}




\begin{tabular}{|c|c|c|c|c|c|c|c|c|}
\hline & $\begin{array}{c}\text { Nombre de } \\
\text { la } \\
\text { contribución }\end{array}$ & $\begin{array}{c}\text { Tipo de } \\
\text { contribución }\end{array}$ & Páginas & $\begin{array}{c}\text { Nombre } \\
\text { del/ de los } \\
\text { Autor/es }\end{array}$ & $\begin{array}{c}\text { Autor/es } \\
\text { local/es } \\
\text { (EF-FAHCE) }\end{array}$ & $\begin{array}{c}\text { Autor/es } \\
\text { local/es de } \\
\text { otras } \\
\text { disciplinas }\end{array}$ & $\begin{array}{c}\text { Autor/es } \\
\text { nacional/es }\end{array}$ & $\begin{array}{c}\text { Autor/es } \\
\text { extranjero/s }\end{array}$ \\
\hline 3. & $\begin{array}{l}\text { El desarrollo } \\
\text { de la } \\
\text { capacidad de } \\
\text { la } \\
\text { anticipación } \\
\text { en el voleibol }\end{array}$ & Artículo & 13 & $\begin{array}{l}\text { José Antonio } \\
\text { Fotia }\end{array}$ & $x$ & & & \\
\hline 4. & $\begin{array}{l}\text { Educación } \\
\text { física } \\
\text { militarizada } \\
\text { en Argentina }\end{array}$ & Artículo & 8 & $\begin{array}{l}\text { Mario V. } \\
\text { Mamonde }\end{array}$ & $x$ & & & \\
\hline 5. & $\begin{array}{l}\text { Investigación } \\
\text { y Juego: } \\
\text { Reflexiones } \\
\text { desde una } \\
\text { Práctica. }\end{array}$ & Artículo & 10 & Victor Pavía & & & $x$ & \\
\hline 6. & $\begin{array}{l}\text { Experiencia } \\
\text { de Rugby } \\
\text { escolar. } \\
\text { Localización: } \\
\text { Escuela } \\
\text { Privada } \\
\text { Ranelagh. } \\
\end{array}$ & Artículo & 11 & Osvaldo Ron & $x$ & & & \\
\hline 7. & $\begin{array}{l}\text { Hacia una } \\
\text { Educación } \\
\text { Física no } \\
\text { sexista }\end{array}$ & Artículo & 12 & $\begin{array}{l}\text { Jorge Ricardo } \\
\text { Saraví }\end{array}$ & $x$ & & & \\
\hline
\end{tabular}

Año 2, №1, Octubre de 1996

\begin{tabular}{|c|c|c|c|c|c|c|c|c|}
\hline & $\begin{array}{c}\text { Nombre de la } \\
\text { contribución }\end{array}$ & $\begin{array}{c}\text { Tipo de } \\
\text { contribución }\end{array}$ & Páginas & $\begin{array}{c}\text { Nombre } \\
\text { del/ de los } \\
\text { Autor/es }\end{array}$ & $\begin{array}{c}\text { Autor/es } \\
\text { local/es } \\
\text { (EF- } \\
\text { FAHCE) }\end{array}$ & $\begin{array}{c}\text { Autor/es } \\
\text { local/es } \\
\text { de otras } \\
\text { disciplinas }\end{array}$ & $\begin{array}{c}\text { Autor/es } \\
\text { nacional/es }\end{array}$ & $\begin{array}{c}\text { Autor/es } \\
\text { extranjero/s }\end{array}$ \\
\hline 1. & $\begin{array}{l}\text { Las corrientes } \\
\text { evolutivas, sus } \\
\text { consecuencias } \\
\text { para la clase de } \\
\text { Educación Física }\end{array}$ & Artículo & 16 & $\begin{array}{l}\text { Carlos } \\
\text { Parenti }\end{array}$ & $x$ & & & \\
\hline 2. & $\begin{array}{l}\text { De } \\
\text { Frente...March }\end{array}$ & Artículo & 8 & $\begin{array}{l}\text { Abel Patricio } \\
\text { Calvo } \\
\text { Etcheverry }\end{array}$ & $x$ & & & \\
\hline 3. & $\begin{array}{l}\text { El nivel medio y } \\
\text { la Educación } \\
\text { Física: apuntes } \\
\text { para la reflexión } \\
\text { de un modelo } \\
\text { didáctico. }\end{array}$ & Artículo & 9 & $\begin{array}{l}\text { Mónica } \\
\text { Dorato y } \\
\text { Alicia Villa }\end{array}$ & $x$ & $x$ & & \\
\hline 4. & $\begin{array}{l}\text { El AIKIDO en la } \\
\text { UNLP }\end{array}$ & Entrevista & 5 & $\begin{array}{l}\text { Enzo Di } \\
\text { Girolamo, } \\
\text { Ricardo } \\
\text { Torres } \\
\text { Medrano y } \\
\text { Alejandro } \\
\text { Núñez }\end{array}$ & $x^{198}$ & $x$ & $x$ & \\
\hline
\end{tabular}

${ }^{198}$ El autor local no se contabiliza dentro de los artículos de autores del DEF, ya que no ejercía la docencia en la FaHCE. 


\begin{tabular}{|c|c|c|c|c|c|c|c|c|}
\hline & $\begin{array}{l}\text { Nombre de la } \\
\text { contribución }\end{array}$ & $\begin{array}{c}\text { Tipo de } \\
\text { contribución }\end{array}$ & Páginas & $\begin{array}{c}\text { Nombre } \\
\text { del/ de los } \\
\text { Autor/es }\end{array}$ & $\begin{array}{c}\text { Autor/es } \\
\text { local/es } \\
\text { (EF- } \\
\text { FAHCE) }\end{array}$ & $\begin{array}{l}\text { Autor/es } \\
\text { local/es } \\
\text { de otras } \\
\text { disciplinas }\end{array}$ & $\begin{array}{c}\text { Autor/es } \\
\text { nacional/es }\end{array}$ & $\begin{array}{c}\text { Autor/es } \\
\text { extranjero/s }\end{array}$ \\
\hline 5. & $\begin{array}{l}\text { Consideraciones } \\
\text { sobre Educación } \\
\text { Física para la } \\
\text { Formación } \\
\text { Docente }\end{array}$ & Artículo & 10 & $\begin{array}{l}\text { Fernando } \\
\text { González }\end{array}$ & & & $x$ & \\
\hline 6. & $\begin{array}{l}\text { La deserción en } \\
\text { el Profesorado } \\
\text { Universitario en } \\
\text { Educación Física }\end{array}$ & Artículo & 15 & $\begin{array}{l}\text { Pablo Zuazo } \\
\text { y Christian } \\
\text { Brini }\end{array}$ & $x$ & & & \\
\hline 7. & $\begin{array}{l}\text { La } \\
\text { responsabilidad } \\
\text { civil en la clase } \\
\text { de Educación } \\
\text { Física }\end{array}$ & $\begin{array}{l}\text { Comunicación } \\
\text { (Mesa } \\
\text { redonda) }\end{array}$ & 11 & $\begin{array}{l}\text { Especialistas } \\
\text { varios }\end{array}$ & $x$ & & $x$ & \\
\hline
\end{tabular}

Año 3, №2, Septiembre de 1997

\begin{tabular}{|c|c|c|c|c|c|c|c|c|}
\hline & $\begin{array}{l}\text { Nombre de la } \\
\text { contribución }\end{array}$ & $\begin{array}{c}\text { Tipo de } \\
\text { contribución }\end{array}$ & Páginas & $\begin{array}{c}\text { Nombre } \\
\text { del/ de } \\
\text { los } \\
\text { Autor/es }\end{array}$ & $\begin{array}{c}\text { Autor/es } \\
\text { local/es } \\
\text { (EF-FAHCE) }\end{array}$ & $\begin{array}{c}\text { Autor/es } \\
\text { local/es de } \\
\text { otras } \\
\text { disciplinas }\end{array}$ & $\begin{array}{c}\text { Autor/es } \\
\text { nacional/es }\end{array}$ & $\begin{array}{c}\text { Autor/es } \\
\text { extranjero/s }\end{array}$ \\
\hline 1. & $\begin{array}{l}\text { Curso de } \\
\text { nivelación, } \\
\text { 1997, } \\
\text { Profesorado en } \\
\text { Educación } \\
\text { Física, } \\
\text { Universidad } \\
\text { Nacional de La } \\
\text { Plata }\end{array}$ & Comunicación & 14 & $\begin{array}{l}\text { Sin } \\
\text { especificar. } \\
\text { Informe de } \\
\text { ingreso }\end{array}$ & $x$ & & & \\
\hline 2. & $\begin{array}{l}\text { Detección del } \\
\text { niño y de la } \\
\text { niña } \\
\text { talentosos: la } \\
\text { orientación } \\
\text { deportiva. } \\
\text { Ejemplo en } \\
\text { Vóleibol. }\end{array}$ & Artículo & 23 & $\begin{array}{l}\text { José } \\
\text { Antonio } \\
\text { Fotia }\end{array}$ & $x$ & & & \\
\hline 3. & $\begin{array}{l}\text { La evaluación } \\
\text { en Educación } \\
\text { Física y en el } \\
\text { nivel medio de } \\
\text { la enseñanza: } \\
\text { ¿cuáles son sus } \\
\text { funciones? ¿Se } \\
\text { cumple con } \\
\text { ellas? }\end{array}$ & Artículo & 8 & $\begin{array}{l}\text { María } \\
\text { Lucía Gayol }\end{array}$ & $x$ & & & \\
\hline 4. & $\begin{array}{l}\text { Poder y cuerpo: } \\
\text { EL } \\
\text { (incontestable) } \\
\text { mito de la } \\
\text { relación entre } \\
\text { Ejercicio Físico } \\
\text { y Salud }\end{array}$ & Artículo & 18 & $\begin{array}{l}\text { Miguel } \\
\text { Vicente } \\
\text { Pedraz }\end{array}$ & & & & $\begin{array}{l}\text { Instituto } \\
\text { Nacional de } \\
\text { EF de León, } \\
\text { España }\end{array}$ \\
\hline
\end{tabular}




\begin{tabular}{|c|c|c|c|c|c|c|c|c|}
\hline & $\begin{array}{l}\text { Nombre de la } \\
\text { contribución }\end{array}$ & $\begin{array}{c}\text { Tipo de } \\
\text { contribución }\end{array}$ & Páginas & $\begin{array}{c}\text { Nombre } \\
\text { del/ de } \\
\text { los } \\
\text { Autor/es }\end{array}$ & $\begin{array}{c}\text { Autor/es } \\
\text { local/es } \\
\text { (EF-FAHCE) }\end{array}$ & $\begin{array}{l}\text { Autor/es } \\
\text { local/es de } \\
\text { otras } \\
\text { disciplinas }\end{array}$ & $\begin{array}{c}\text { Autor/es } \\
\text { nacional/es }\end{array}$ & $\begin{array}{c}\text { Autor/es } \\
\text { extranjero/s }\end{array}$ \\
\hline 5. & $\begin{array}{l}\text { Las } \\
\text { concepciones } \\
\text { de la Educación } \\
\text { Física }\end{array}$ & Artículo & 12 & $\begin{array}{l}\text { María } \\
\text { Eugenia } \\
\text { Villa }\end{array}$ & $x$ & & & \\
\hline 6. & $\begin{array}{l}\text { Relacionando } \\
\text { interés, acción, } \\
\text { producción de } \\
\text { conocimiento, } \\
\text { concepciones } \\
\text { de cuerpo y } \\
\text { concepciones } \\
\text { de } \\
\text { movimiento: } \\
\text { ¿Es posible una } \\
\text { ciencia del } \\
\text { movimiento } \\
\text { humano? }\end{array}$ & Artículo & 15 & $\begin{array}{l}\text { Ingrid } \\
\text { Marianne } \\
\text { Baecker }\end{array}$ & & & & $\begin{array}{l}\text { Universidad } \\
\text { Federal de } \\
\text { Santa Maria - } \\
\text { RS-Brasil }\end{array}$ \\
\hline
\end{tabular}

Año 4, Octubre de 1998

\begin{tabular}{|c|c|c|c|c|c|c|c|c|}
\hline & $\begin{array}{l}\text { Nombre de la } \\
\text { contribución }\end{array}$ & $\begin{array}{c}\text { Tipo de } \\
\text { contribución }\end{array}$ & Páginas & $\begin{array}{c}\text { Nombre del/ } \\
\text { de los } \\
\text { Autor/es }\end{array}$ & $\begin{array}{l}\text { Autor/es } \\
\text { local/es } \\
\text { (EF- } \\
\text { FAHCE) }\end{array}$ & $\begin{array}{l}\text { Autor/es } \\
\text { local/es } \\
\text { de otras } \\
\text { disciplinas }\end{array}$ & $\begin{array}{c}\text { Autor/es } \\
\text { nacional/es }\end{array}$ & $\begin{array}{c}\text { Autor/es } \\
\text { extranjero/s }\end{array}$ \\
\hline 1. & $\begin{array}{l}\text { Pienso...luego } \\
\text { existo: } \\
\text { Reflexiones en } \\
\text { torno a la } \\
\text { Educación Física } \\
\text { y el contenido y } \\
\text { transformación } \\
\text { histórica de sus } \\
\text { espacios } \\
\text { institucionales. }\end{array}$ & Artículo & 11 & $\begin{array}{l}\text { Abel Patricio } \\
\text { Calvo } \\
\text { Etcheverry }\end{array}$ & $x$ & & & \\
\hline 2. & $\begin{array}{l}\text { Comunicación: } \\
\text { Círculo docente } \\
\text { de Educación } \\
\text { Física }\end{array}$ & Comunicación & 4 & $\begin{array}{l}\text { Círculo } \\
\text { Docente de } \\
\text { Educación } \\
\text { Física } \\
\text { (C.I.D.E.F) }\end{array}$ & & & $x$ & \\
\hline 3. & $\begin{array}{l}\text { Constructivismo, } \\
\text { cuerpo y } \\
\text { lenguaje }\end{array}$ & Artículo & 11 & $\begin{array}{l}\text { Ricardo Luis } \\
\text { Crisorio }\end{array}$ & $x$ & & & \\
\hline 4. & $\begin{array}{l}\text { Comunicación: } \\
\text { El P.U.E.F en } \\
\text { Internet }\end{array}$ & Comunicación & 3 & $\begin{array}{l}\text { Sin especificar. } \\
\text { Comunicación } \\
\text { institucional. }\end{array}$ & $x$ & & & \\
\hline 5. & $\begin{array}{l}\text { Sobre el juego y } \\
\text { el jugar: } \\
\text { Entrevista a } \\
\text { Víctor Pavía }\end{array}$ & Entrevista & 15 & Alfredo Furlan & & & & $\begin{array}{l}\text { Universidad } \\
\text { Autónoma de } \\
\text { México }\end{array}$ \\
\hline 6. & $\begin{array}{l}\text { Un nuevo marco } \\
\text { para repensar la } \\
\text { Educación Física }\end{array}$ & Artículo & 10 & Jorge Fridman & $x$ & & & \\
\hline 7. & $\begin{array}{l}\text { Los juegos } \\
\text { deportivos en la } \\
\text { Educación } \\
\text { General Básica }\end{array}$ & Trabajo & 6 & $\begin{array}{l}\text { Carlos Alberto } \\
\text { Manazza }\end{array}$ & $x$ & & & \\
\hline
\end{tabular}




\begin{tabular}{|c|c|c|c|c|c|c|c|c|}
\hline & $\begin{array}{l}\text { Nombre de la } \\
\text { contribución }\end{array}$ & $\begin{array}{c}\text { Tipo de } \\
\text { contribución }\end{array}$ & Páginas & $\begin{array}{c}\text { Nombre del/ } \\
\text { de los } \\
\text { Autor/es }\end{array}$ & $\begin{array}{c}\text { Autor/es } \\
\text { local/es } \\
\text { (EF- } \\
\text { FAHCE) }\end{array}$ & $\begin{array}{l}\text { Autor/es } \\
\text { local/es } \\
\text { de otras } \\
\text { disciplinas }\end{array}$ & $\begin{array}{c}\text { Autor/es } \\
\text { nacional/es }\end{array}$ & $\begin{array}{c}\text { Autor/es } \\
\text { extranjero/s }\end{array}$ \\
\hline 8. & $\begin{array}{l}\text { Vía Regia Vs. Vía } \\
\text { democrática del } \\
\text { aprendizaje }\end{array}$ & Trabajo & 7 & Rafael Pertus & $x$ & & & \\
\hline 9. & $\begin{array}{l}\text { Construcción y } \\
\text { constitución de } \\
\text { la } \\
\text { representación- } \\
\text { cuerpo }\end{array}$ & Artículo & 12 & Graciela Petriz & & $x$ & & \\
\hline 10. & $\begin{array}{l}\text { Proyecto del } \\
\text { Plan de Estudios } \\
\text { del } \\
\text { Departamento } \\
\text { de EF } 1998\end{array}$ & Proyecto & 16 & $\begin{array}{l}\text { Sin especificar. } \\
\text { Proyecto } \\
\text { institucional. }\end{array}$ & $x$ & & & \\
\hline 11. & $\begin{array}{l}\text { Algunas } \\
\text { reflexiones } \\
\text { sobre el cuerpo } \\
\text { durante el } \\
\text { franquismo }\end{array}$ & Artículo & 19 & $\begin{array}{l}\text { Pablo Ariel } \\
\text { Scharagrodsky }\end{array}$ & $x$ & & & \\
\hline
\end{tabular}

Año 5, agosto de 2001

\begin{tabular}{|c|c|c|c|c|c|c|c|c|}
\hline & $\begin{array}{l}\text { Nombre de la } \\
\text { contribución }\end{array}$ & $\begin{array}{c}\text { Tipo de } \\
\text { contribución }\end{array}$ & Páginas & $\begin{array}{c}\text { Nombre del/ } \\
\text { de los } \\
\text { Autor/es }\end{array}$ & $\begin{array}{l}\text { Autor/es } \\
\text { local/es } \\
\text { (EF- } \\
\text { FAHCE) }\end{array}$ & $\begin{array}{l}\text { Autor/es } \\
\text { local/es } \\
\text { de otras } \\
\text { disciplinas }\end{array}$ & $\begin{array}{c}\text { Autor/es } \\
\text { nacional/es }\end{array}$ & $\begin{array}{c}\text { Autor/es } \\
\text { extranjero/s }\end{array}$ \\
\hline 1. & $\begin{array}{l}\text { "La } \\
\text { introducción } \\
\text { en las arenas } \\
\text { de la } \\
\text { investigación": } \\
\text { Reconstrucción } \\
\text { de una } \\
\text { experiencia en } \\
\text { un universo } \\
\text { problemático. }\end{array}$ & Artículo & 30 & $\begin{array}{l}\text { Gabriel } \\
\text { Armando } \\
\text { Cachorro }\end{array}$ & $x$ & & & \\
\hline 2. & $\begin{array}{l}\text { La enseñanza } \\
\text { del Basquetbol. }\end{array}$ & Artículo & 29 & $\begin{array}{l}\text { Ricardo Luis } \\
\text { Crisorio }\end{array}$ & $x$ & & & \\
\hline 3. & $\begin{array}{l}\text { De aquí y de } \\
\text { allá. }\end{array}$ & Trabajo & 5 & $\begin{array}{l}\text { Mónica } \\
\text { Dorato y Alicia } \\
\text { Villa }\end{array}$ & $x$ & $x$ & & \\
\hline 4. & $\begin{array}{l}\text { El ingreso a } \\
\text { Educación } \\
\text { Física: de la } \\
\text { especulación al } \\
\text { dato } \\
\text { investigado. }\end{array}$ & Artículo & 13 & $\begin{array}{l}\text { Jorge Fridman, } \\
\text { Lilia Rossi } \\
\text { Cassé y } \\
\text { Susana Sautel }\end{array}$ & $x$ & $x$ & & \\
\hline 5. & $\begin{array}{l}\text { Una nueva } \\
\text { aproximación } \\
\text { al } \\
\text { conocimiento } \\
\text { científico. }\end{array}$ & Artículo & 9 & $\begin{array}{l}\text { Ricardo } \\
\text { Gómez }\end{array}$ & & $x$ & & $\begin{array}{l}\text { Universidad } \\
\text { de Los } \\
\text { Ángeles } \\
\text { (EEUU) }\end{array}$ \\
\hline
\end{tabular}




\begin{tabular}{|c|c|c|c|c|c|c|c|c|}
\hline & $\begin{array}{l}\text { Nombre de la } \\
\text { contribución }\end{array}$ & $\begin{array}{c}\text { Tipo de } \\
\text { contribución }\end{array}$ & Páginas & $\begin{array}{c}\text { Nombre del/ } \\
\text { de los } \\
\text { Autor/es }\end{array}$ & $\begin{array}{c}\text { Autor/es } \\
\text { local/es } \\
\text { (EF- } \\
\text { FAHCE) }\end{array}$ & $\begin{array}{l}\text { Autor/es } \\
\text { local/es } \\
\text { de otras } \\
\text { disciplinas }\end{array}$ & $\begin{array}{c}\text { Autor/es } \\
\text { nacional/es }\end{array}$ & $\begin{array}{c}\text { Autor/es } \\
\text { extranjero/s }\end{array}$ \\
\hline 6. & $\begin{array}{l}\text { La habilidad } \\
\text { motriz en el } \\
\text { Nivel Inicial de } \\
\text { la Escuela Toba } \\
\text { "Nueva } \\
\text { Esperanza" y su } \\
\text { vinculación el } \\
\text { marco social. }\end{array}$ & Artículo & 12 & $\begin{array}{l}\text { Fernando } \\
\text { Komar }^{199}\end{array}$ & $x$ & & & \\
\hline 7. & $\begin{array}{l}\text { De la } \\
\text { testosterona a } \\
\text { la virilidad. } \\
\text { Visibilizando } \\
\text { una política } \\
\text { escolar } \\
\text { generizada. }\end{array}$ & Artículo & 12 & $\begin{array}{l}\text { Pablo Ariel } \\
\text { Scharagrodsky }\end{array}$ & $x$ & & & \\
\hline 8. & $\begin{array}{l}\text { Actividad física } \\
\text { y prevención } \\
\text { de } \\
\text { enfermedades } \\
\text { no } \\
\text { transmisibles. } \\
\text { Separata del } \\
\text { artículo de } \\
\text { divulgación. }\end{array}$ & Divulgación & 3 & $\begin{array}{l}\text { Gabriel } \\
\text { Tarducci }\end{array}$ & $\mathrm{x}$ & & & \\
\hline 9. & $\begin{array}{l}\text { Un repaso de la } \\
\text { etnografía } \\
\text { educativa en } \\
\text { México hoy. }\end{array}$ & Exposición & 14 & $\begin{array}{l}\text { Martha } \\
\text { Corenstein } \\
\text { Zaslav }\end{array}$ & & & & $\begin{array}{l}\text { Universidad } \\
\text { Nacional } \\
\text { Autónoma de } \\
\text { México }\end{array}$ \\
\hline
\end{tabular}

${ }^{199}$ No se contabiliza dentro de los artículos de autores del DEF, ya que si bien es egresado de EF de la FaHCE, en ese momento no ejercía la docencia en la misma. 


\begin{tabular}{|c|c|c|c|c|c|c|c|c|}
\hline & $\begin{array}{l}\text { Nombre de la } \\
\text { contribución }\end{array}$ & $\begin{array}{c}\text { Tipo de } \\
\text { contribución }\end{array}$ & Páginas & $\begin{array}{l}\text { Nombre } \\
\text { del/ de los } \\
\text { Autor/es }\end{array}$ & $\begin{array}{c}\text { Autor/es } \\
\text { local/es } \\
\text { (EF- } \\
\text { FAHCE) }\end{array}$ & $\begin{array}{l}\text { Autor/es } \\
\text { local/es } \\
\text { de otras } \\
\text { disciplinas }\end{array}$ & $\begin{array}{c}\text { Autor/es } \\
\text { nacional/es }\end{array}$ & $\begin{array}{c}\text { Autor/es } \\
\text { extranjero/s }\end{array}$ \\
\hline 1. & $\begin{array}{l}\text { Educación Física } \\
\text { y Servicios } \\
\text { Penitenciarios: } \\
\text { críticas } \\
\text { epistémicas a } \\
\text { propuestas } \\
\text { vigentes de } \\
\text { intervención. }\end{array}$ & Artículo & 9 & $\begin{array}{l}\text { Santiago } \\
\text { Achucarro }\end{array}$ & $x$ & & & \\
\hline 2. & $\begin{array}{l}\text { Las prácticas de } \\
\text { la Educación } \\
\text { Física: ni tan } \\
\text { autoritarias ni } \\
\text { tan } \\
\text { participativas. }\end{array}$ & Artículo & 10 & $\begin{array}{l}\text { Carlos } \\
\text { Carballo }\end{array}$ & $x$ & & & \\
\hline 3. & $\begin{array}{l}\text { El aprendizaje } \\
\text { motor: un } \\
\text { problema } \\
\text { epigenético. }\end{array}$ & Artículo & 13 & $\begin{array}{l}\text { Ricardo } \\
\text { Crisorio, } \\
\text { Marcelo Giles, } \\
\text { Liliana Rocha } \\
\text { Bidegain y } \\
\text { Agustín } \\
\text { Lescano }\end{array}$ & $x$ & & & \\
\hline 4. & $\begin{array}{l}\text { ¿Qué es esa cosa } \\
\text { llamada juego? } \\
\text { El caso } \\
\text { particular de } \\
\text { acciones } \\
\text { sociales } \\
\text { consideradas } \\
\text { lúdicas en } \\
\text { jóvenes varones } \\
\text { de } 16 / 17 \text { años } \\
\text { en la localidad } \\
\text { de Berisso } \\
\text { (Argentina). }\end{array}$ & Artículo & 14 & Jorge Fridman & $x$ & & & \\
\hline 5. & $\begin{array}{l}\text { La gestión en } \\
\text { Educación Física } \\
\text { como problema }\end{array}$ & Artículo & 17 & Marcelo Giles & $x$ & & & \\
\hline 6. & $\begin{array}{l}\text { Acerca del } \\
\text { concepto de } \\
\text { deporte: } \\
\text { Alcances de } \\
\text { su(s) } \\
\text { significado(s). }\end{array}$ & Artículo & 16 & $\begin{array}{l}\text { Néstor } \\
\text { Hernández y } \\
\text { Carlos } \\
\text { Carballo }\end{array}$ & $x$ & & & \\
\hline 7. & $\begin{array}{l}\text { La Educación } \\
\text { Física en } \\
\text { Uruguay: } \\
\text { tensiones de un } \\
\text { campo } \\
\text { profesional } \\
\text { problematizado. }\end{array}$ & Artículo & 26 & $\begin{array}{l}\text { Adriana } \\
\text { Marrero }\end{array}$ & & & & $\begin{array}{l}\text { Universidad } \\
\text { de la } \\
\text { República, } \\
\text { Uruguay. }\end{array}$ \\
\hline 8. & $\begin{array}{l}\text { El análisis } \\
\text { sociológico del } \\
\text { deporte. }\end{array}$ & $\begin{array}{l}\text { Artículo } \\
\text { (traducido al } \\
\text { español) }\end{array}$ & 10 & Pippo Russo & & & & $\begin{array}{l}\text { Universidad } \\
\text { de Florencia, } \\
\text { Italia }\end{array}$ \\
\hline
\end{tabular}




\begin{tabular}{|l|l|c|c|c|c|c|c|}
\hline $\begin{array}{l}\text { Nombre de la } \\
\text { contribución }\end{array}$ & $\begin{array}{c}\text { Tipo de } \\
\text { contribución }\end{array}$ & Páginas & $\begin{array}{c}\text { Nombre } \\
\text { del/ de los } \\
\text { Autor/es }\end{array}$ & $\begin{array}{c}\text { Autor/es } \\
\text { local/es } \\
\text { (EF- } \\
\text { FAHCE) }\end{array}$ & $\begin{array}{c}\text { Autor/es } \\
\text { local/es } \\
\text { de otras } \\
\text { disciplinas }\end{array}$ & $\begin{array}{c}\text { Autor/es } \\
\text { nacional/es }\end{array}$ & $\begin{array}{c}\text { Autor/es } \\
\text { extranjero/s }\end{array}$ \\
\hline $\begin{array}{l}\text { En la Educación } \\
\begin{array}{l}\text { Física queda } \\
\text { mucho "género" } \\
\text { por cortar. }\end{array}\end{array}$ Artículo & 26 & $\begin{array}{l}\text { Pablo Ariel } \\
\text { Scharagrodsky }\end{array}$ & $\mathrm{X}$ & & & \\
\hline
\end{tabular}




\section{Entrevistas realizadas}

- A Ricardo Crisorio:

-Entrevista $\mathrm{N}^{\circ} 1$, el 26 de octubre de 2015 en Ensenada.

-Entrevista N², el 13 de septiembre de 2016 en Ensenada.

- A Marcelo Giles, el 17 de diciembre de 2015 en La Plata.

- A Carlos Carballo:

-Entrevista No1, el 13 de abril de 2016 en Ensenada.

-Entrevista No2, el 28 de septiembre de 2016 en Ensenada.

- A Osvaldo Ron, el 01 de septiembre de 2016 en Ensenada.

- A María Lucía Gayol, el 02 de septiembre de 2016 en La Plata.

- A Carlos Parenti:

-Entrevista $\mathrm{N}^{0} 1$, el 23 de septiembre de 2016 en Ensenada.

-Entrevista №2, el 23 de mayo de 2017, vía digital.

- A José Luis De Diego, el 27 de septiembre de 2016 en Ensenada.

- A Santiago Achucarro, el 13 de octubre de 2016 en Ensenada.

- A María Eugenia Villa, el 03 de marzo de 2017 en Ensenada.

- A Ana María Barletta, el 20 de octubre de 2017 en La Plata. 